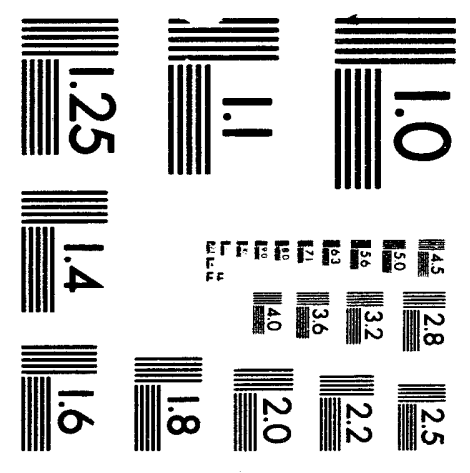



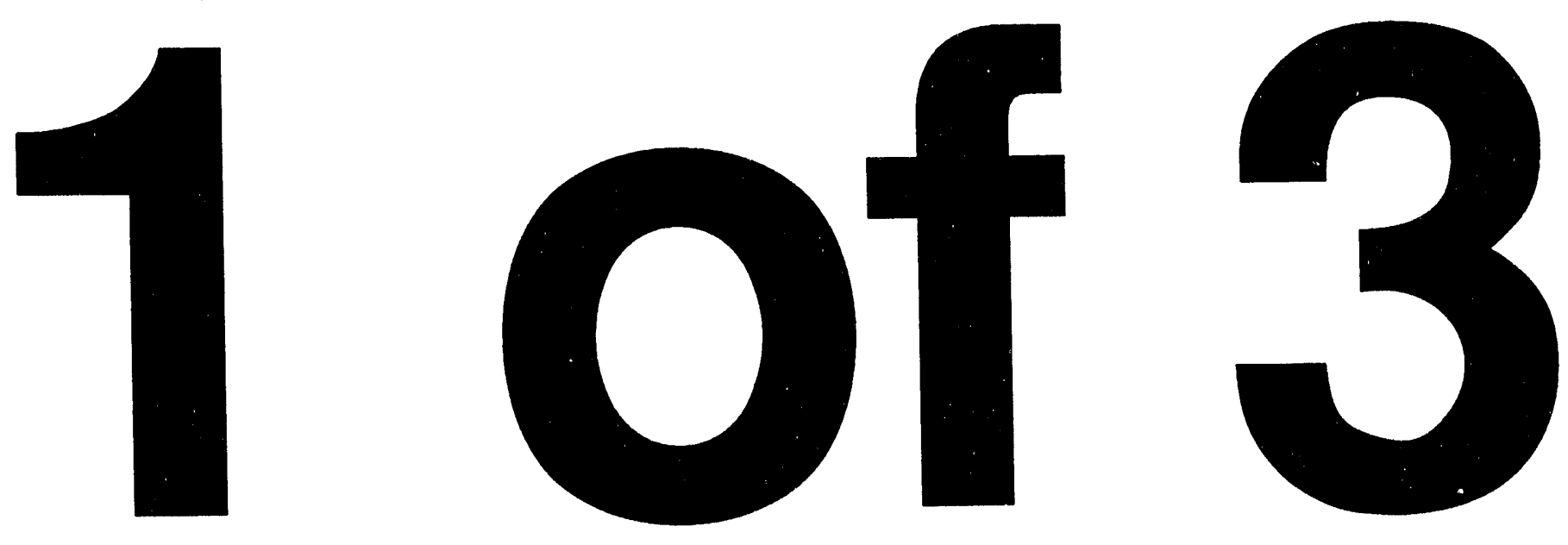


\title{
Characterization of the Sodium Void Reactivity Effect for Advanced Liquid Metal Reactor Fuels
}

\author{
S. F. Kessler
}

Date Published

December 1993

Prepared for the U.S. Department of Energy Office of Environmental Restoration and Waste Management

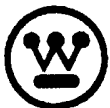

Thesle (or Diasertation) This document was prepared in partial fullilment of the requirements for a Master of Science de Nuclear Engineering from the University of Washington, Soattlo, Washington. 


\section{LEGAL DISCLAMER}

This report was prepared as an account of work sponsored by an agency of the United States Government. Neither the

United States Government nor any agency thereol, nor any of their employees, nor any of their contractors, subcontractors or their employees, makes any warranty, express or implied, or assumes any legal liability or responsibility for the accuracy, completeness, or any third party's use or the results of such use of any information, apparatus, product, or process disclosed, or represents that its use would not infringe privately owned rights. Relerence herein to any specific commercial product, process, or service by trade name, trademark, manufacturer, or otherwise, does not necessarily constitute or imply its endorsement, recommendation, or favoring by the United States Government or any agency thereof of its contractors or subcontractors. The views and opinions of authors expressed herein do not necessarily state or reflect those of the United States Government or any agency thereot.

This report has been reproduced from the best available copy.

Printed in the Unitod States of Amerion

DISCLM-2.CHP (1-01) 
WHC-MR-0451 Rev. 0

CHARACTERIZATION OF THE SODIUM VOID REACTIVITY EFFECT FOR

ADVANCED LIQUID METAL REACTOR FUELS

by

Stephen F. Kessler

A thesis submitted in partial fulfillment of the requirements for the degree of

Master of Science in Nuclear Engineering

University of Washington

1993

Approved by

(Chairperson of Supervisory Committee)

Program Authorized

to Offer Degree.

Date 


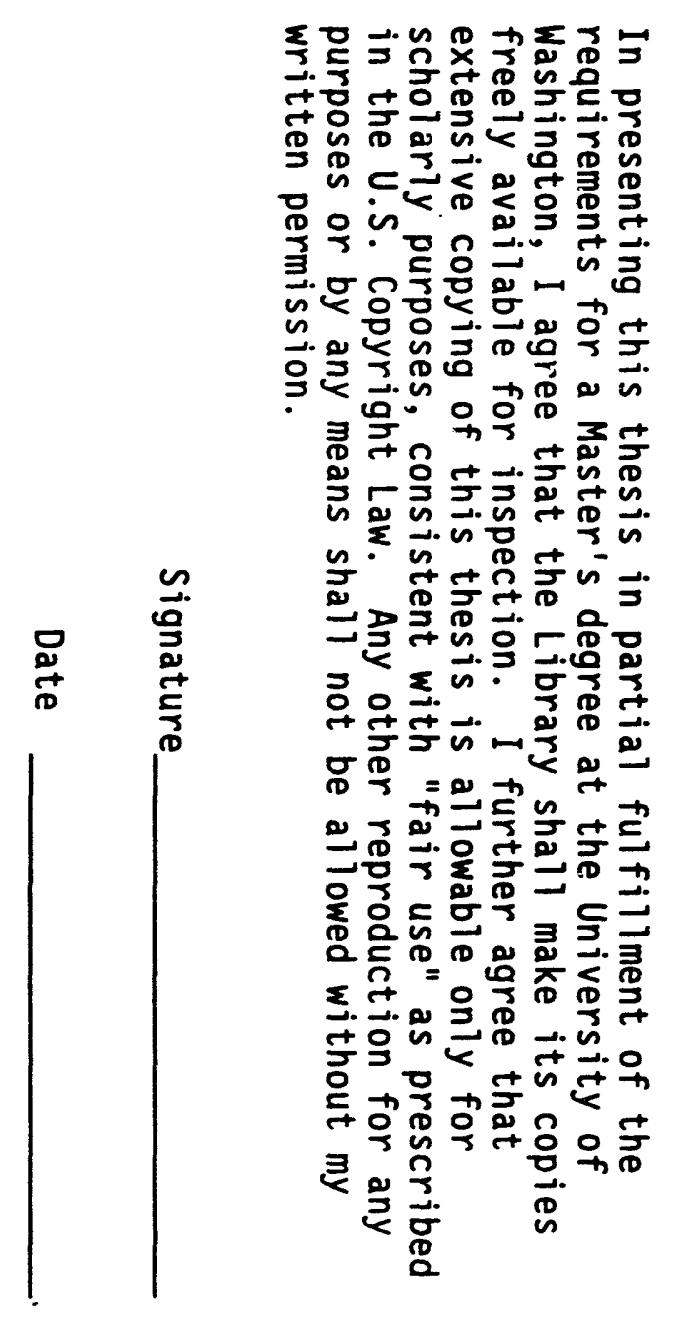


University of Washington

Abstract

CHARACTERIZATION OF THE SODIUM VOID REACTIVITY EFFECT FOR ADVANCED LIQUID METAL REACTOR FUELS

by Stephen F. Kessler

Chairperson of the Supervisory Committee: Professor Kermit L. Garlid Department of Chemical Engineering

The problems of a large positive sodium void reactivity effect in liquid metal reactors have received increased attention following the accident at Chernobyl, a light water reactor with a positive coolant void coefficient. While the probability of voiding sodium is small, a large positive sodium void reactivity effect is, in many minds, unacceptable. Analyses were performed on models of an advanced liquid metal reactors to determine the effects fuel type have on the sodium void reactivity effect. Three fuel types were considered; metal, oxide, and nitride. Calculations were performed using three-dimensional, multigroup diffusion theory. Two programs were developed to aid the analyses. One calculated the capture-to-fission ratio and the other calculated reaction rates of selected materials. A one-group equation was derived to determine a theoretical basis for the sodiuni void reactivity effect. An option was presented for a shortened core having a near-zero sodium-void worth. The effect on the sodium void reactivity effect of using actinides as fuel is also considered. 


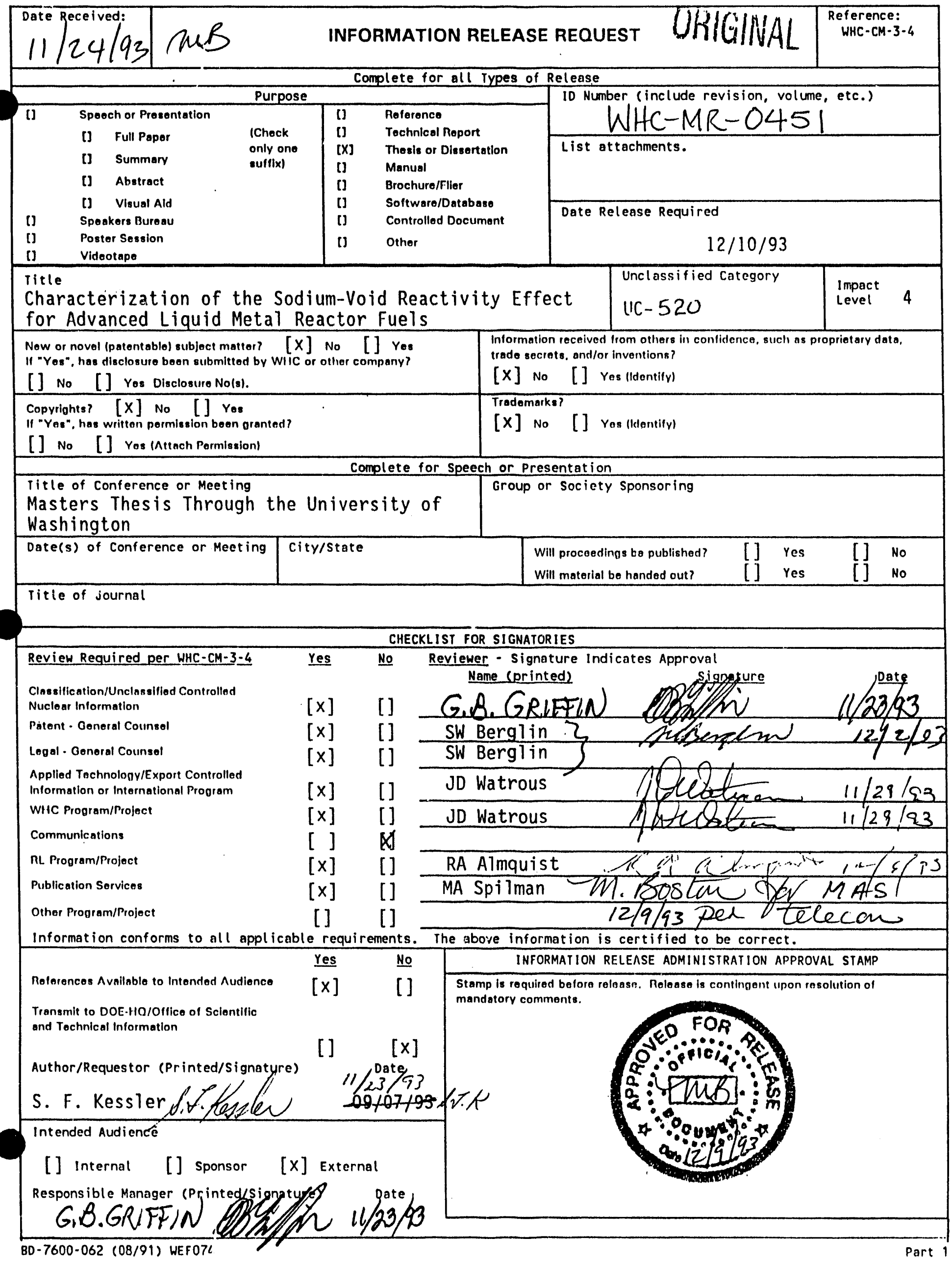


List of figures ................... . . iii

List of Tables ................... . . xij

List of Acronyms .............................

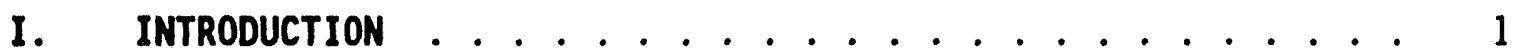

II. SUMMARY AND CONCLUSIONS ............... 5

III. OBJECTIVE ................................. 14

IV. METHODOLOGY ....................... 15

A. Core Models ................ 15

B. Factors Affecting Sodium Void ........... 19

C. Calculation of Reactor Parameters . . . . . . . . 19

D. Industry Computer Codes . . . . . . . . . . 22

E. New Computer Codes ............... 24

V. RESULTS . . . . . . . . . . . . . . 25

A. 2DB Results .................. 25

B. 3DB Results .................. 25

C. 3DB Neutron Balance Results ........... 30

D. Spectral Effects on the Capture-to-fission Ratio . . . 33

E. Slowing Down Power ............... 46

F. Reaction Rates .............. 60

G. Effects of Increased Capture in Nitrogen . . . . . . 71

H. Derivation of the Sodium Void Reactivity Worth . . . . 74

I. The Near Zero Sodium Void Worth Core . . . . . . . 86

J. The ALMR as an Actinide Burner ......... 86

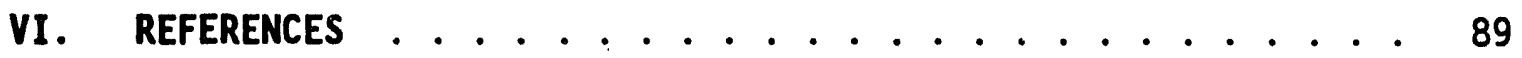

APPENDIX A: Ratio Program ................. 92 
APPENDIX B: Reaction Rate Program . . . . . . . . . . . . . 99

APPENDIX C: Reaction Rates .................. 121 


\section{List of Figures}

FIGURE 1: Advanced Liquid Metal Reactor Core Without Universal

Shutdown Assembly or Gas Expansion Modules . . . . . . . . . 3

FIGURE 2: Advanced Liquid Metal Reactor Core With Universal

Shutdown Assembly and Gas Expansion Modules . . . . . . . . . 4

FIGURE 3: Typical Fissile Material Capture-to-Fission Ratios . . . 8

FIGURE 4: Typical Nonfissile Material Capture-to-Fission Ratios . . 9

FIGURE 5: 1DX Radial Model .................. . 23

FIGURE 6: Fuel and Blanket Pin Dimensions . . . . . . . . . . . . 27

FIGURE 7: Oxide Core Inner Fuel ${ }^{239} \mathrm{Pu}$ Capture-to-Fission Ratio. . . 34

FIGURE 8: Nitride Core Inner Fuel ${ }^{239} \mathrm{Pu}$ Capture-to-Fission Ratio. $\quad 35$

FIGURE 9: Metal Core Inner Fuel ${ }^{239} \mathrm{Pu}$ Capture-to-Fission Ratio. . . 36

FIGURE 10: Oxide Core Inner Fuel ${ }^{238}$ U Capture-to-Fission Ratio. . . 37

FIGURE 11: Nitride Core Inner Fuel ${ }^{238} \mathrm{U}$ Capture-to-Fission Ratio. . 38

FIGURE 12: Metal Core Inner Fuel ${ }^{238} \mathrm{U}$ Capture-to-Fission Ratio. . . 39

FIGURE 13: Oxide Core 2-Cycle Radial Blanket ${ }^{239} \mathrm{Pu}$ Capture-to-

Fission Ratio. . . . . . . . . . . . . . . . . . 40

FIGURE 14: Nitride Core 2-Cycle Radial Blanket ${ }^{239} \mathrm{Pu}$ Capture-to-

Fission Ratio. ..................... . 41

FIGURE 15: Metal Core 2-Cycle Radial Blanket ${ }^{239} \mathrm{Pu}$ Capture-to-

Fission Ratio. .................... . 42

FIGURE 16: Oxide Core 2-Cycle Radial Blanket ${ }^{238} \mathrm{U}$ Capture-to-

Fission Ratio. ..................... . 43

FIGURE 17: Nitride Core 2-Cycle Radial Blanket ${ }^{238} \mathrm{U}$ Capture-to-

Fission Ratio. . . . . . . . . . . . . . . . . 44

FIGURE 18: Metal Core 2-Cycle Radial Blanket ${ }^{238} \mathrm{U}$ Capture-to-

Fission Ratio. . . . . . . . . . . . . . . . . 45

FIGURE 19: Oxide Core Inner Fuel Fissile Material Capture-to-

Fission Ratio. . . . . . . . . . . . . . . . . 47

FIGURE 20: Nitride Core Inner Fuel Fissile Material Capture-to-

Fission Ratio. ..................... . 48

FIGURE 21: Metal Core Inner Fuel Fissile Material Capture-to-

Fission Ratio. . . . . . . . . . . . . . . . . 
FIGURE 22: Oxide Core 2-Cycle Radial Blanket Fissile Material

Capture-to-fission Ratio. . . . . . . . . . . 50

FIGURE 23: Nitride Core 2-Cycle Radial Blanket Fissile Material

Capture-to-fission Ratio. . . . . . . . . . . . 51

FIGURE 24: Metal Core 2-Cycle Radial Blanket Fissile Material

Capture-to-fission Ratio. . . . . . . . . . . . . 52

FIGURE 25: Oxide Core Inner Fuel Nonfissile Material Capture-to-

Fission Ratio. ................. 53

FIGURE 26: Nitride Core Inner Fuel Nonfissile Material Capture-to-

Fission Ratio. . . . . . . . . . . . . 54

FIGURE 27: Metal Core Inner Fuel Nonfissile Material Capture-to-

Fission Ratio. . . . . . . . . . . . . 55

FIGURE 28: Oxide, Core 2-Cycle Radial Blanket Nonfissile Material

Capture-to-Fission Ratio. . . . . . . . . . . . 56

FIGURE 29: Nitride Core 2-Cycle Radial Blanket Nonfissile Material

Capture-to-Fission Ratio. . . . . . . . . . . 57

FIGURE 30: Metal Core 2-Cycle Radial Blanket Nonfissile Material

Capture-to-Fission Ratio. . . . . . . . . . 58

FIGURE 31: ${ }^{239} \mathrm{Pu}$ Absorption Reaction Rate Difference in an Inner

Fuel Assembly. ................ 65

FIGURE 32: ${ }^{249} \mathrm{Pu}$ Absorption Reaction Rate Difference in an Inner

Fuel Assembly. ................ 66

FIGURE 33: ${ }^{235} \mathrm{U}$ Absorption Reaction Rate Difference in an Inner

Fuel Assembly. ................ 67

FIGURE 34: ${ }^{238} \mathrm{U}$ Absorption Reaction Rate Difference in an Inner

Fuel Assembly. ................ 68

FIGURE 35: ${ }^{240} \mathrm{Pu}$ Absorption Reaction Rate Difference in an Inner

Fuel Assembly. . . . . . . . . . . . . . . 69

FIGURE 36: ${ }^{242} \mathrm{Pu}$ Absorption Reaction Rate Difference in an Inner

Fuel Assembly. . . . . . . . . . . . 70

FIGURE 37: Voided to Flooded Capture Reaction Rate Difference. . . 72

FIGURE 38: Two Region Reactor with a Core and Reflector.... . . 74

FIGURE 39: Sodium Void Reactivity Effect of a Minor Actinide

Burner. . . . . . . . . . . . . . 87 
FIGURE C-1: Fission Reaction Rate for ${ }^{239} \mathrm{Pu}$ in an Oxide Inner Fuel Assembly. . . . . . . . . . . . . . . . . . 122

FIGURE C-2: Fission Reaction Rate for ${ }^{239} \mathrm{Pu}$ in an 0xide 2 cycle

Radial Blanket. . . . . . . . . . . . . . . 123

FIGURE C-3: Fission Reaciion Rate for ${ }^{239} \mathrm{Pu}$ in a Nitride Inner

Fuel Assembly. . . . . . . . . . . . . . . . . 124

FIGURE C-4: Fission Reaction Rate for ${ }^{239} \mathrm{Pu}$ in a Nitride 2 Cycle

Radial Blanket. . . . . . . . . . . . . . . 125

FIGURE C-5: Fission Reaction Rate for ${ }^{239} \mathrm{Pu}$ in a Metal Inner Fuel

Assembly. . . . . . . . . . . . . . . . 126

FIGURE C-6: Fission Reaction Rate for ${ }^{239} \mathrm{Pu}$ in a Metal 2 Cycle

Radial Blanket. . . . . . . . . . . . . . . 127

FIGURE C-7: Absorption Reaction Rate for ${ }^{239} \mathrm{Pu}$ in an 0xide Inner

Fuel Assembly. . . . . . . . . . . . . . . . . 128

FIGURE C-8: Absorption Reaction Rate for ${ }^{239} \mathrm{Pu}$ in an 0xide 2 Cycle

Radial Blanket. . . . . . . . . . . . . . . . 129

FIGURE C-9: Absorption Reaction Rate for ${ }^{239} \mathrm{Pu}$ in a Nitride Inner

Fuel Assembly. ................ 130

FIGURE C-10: Absorption Reaction Rate for ${ }^{239} \mathrm{Pu}$ in a Nitride 2

Cycle Radial Blanket. ................. . 131

FIGURE C-11: Absorption Reaction Rate for ${ }^{239} \mathrm{Pu}$ in a Metal Inner

Fuel Assembly. . . . . . . . . . . . . . . . 132

FIGURE C-12: Absorption Reaction Rate for ${ }^{239} \mathrm{Pu}$ in a Metal 2 Cycle

Radial Blanket. .. . . . . . . . . . . . . . . 133

FIGURE C-13: Capture Reaction Rate for ${ }^{239} \mathrm{Pu}$ in an Oxide Inner

Fuel Assembly. .................... . 134

FIGURE C-14: Capture Reaction Rate for ${ }^{239} \mathrm{Pu}$ in an 0xide 2 cycle

Radial Blanket. . . . . . . . . . . . . . . . 135

FIGURE C-15: Capture Reaction Rate for ${ }^{239} \mathrm{Pu}$ in a Nitride Inner

Fuel Assembly. ... . . . . . . . . . . . . . 136

FIGURE C-16: Capture Reaction Rate for ${ }^{239} \mathrm{Pu}$ in a Nitride 2 Cycle

Radial Blanket. . . . . . . . . . . . . . . 137

FIGURE C-17: Capture Reaction Rate for ${ }^{239} \mathrm{Pu}$ in a Metal Inner Fuel Assembly. . . . . . . . . . . . . . . . . 138 
FIGURE C-18: Capture Reaction Rate for ${ }^{239} \mathrm{Pu}$ in a Metal 2 Cycle

Radial Blanket. . . . . . . . . . . . . . . 139

FIGURE C-19: Fission Reaction Rate for ${ }^{249} \mathrm{Pu}$ in an Oxide Inner

Fuel Assembly. . . . . . . . . . . . . . . . . 140

FIGURE C-20: Fission Reaction Rate for ${ }^{249} \mathrm{Pu}$ in an 0xide 2 cycle

Radial Blanket. . . . . . . . . . . . . . . 141

FIGURE C-21: Fission Reaction Rate for ${ }^{249} \mathrm{Pu}$ in a Nitride Inner

Fuel Assembly. . . . . . . . . . . . . . . . . 142

FIGURE C-22: Fission Reaction Rate for ${ }^{241} \mathrm{Pu}$ in a Nitride 2 Cycle

Radial Blanket. . . . . . . . . . . . . . . 143

FIGURE C-23: Fission Reaction Rate for ${ }^{241} \mathrm{Pu}$ in a Metal Inner Fuel

Assembly. . . . . . . . . . . . . . . . . . . 144

FIGURE C-24: Fission Reaction Rate for ${ }^{249} \mathrm{Pu}$ in a Metal 2 Cycle

Radial Blanket. . . . . . . . . . . . . . . 145

FIGURE C-25: Absorption Reaction Rate for ${ }^{241} \mathrm{Pu}$ in an Oxide Inner

Fuel Assembly. . . . . . . . . . . . . . . . . 146

FIGURE C-26: Absorption Reaction Rate for ${ }^{241} \mathrm{Pu}$ in an 0xide 2

Cycle Radial Blanket. . . . . . . . . . . . . . . 147

FIGURE C-27: Absorption Reaction Rate for ${ }^{249} \mathrm{Pu}$ in a Nitride Inner

Fuel Assembly. . . . . . . . . . . . . . . . . . 148

FIGURE C-28: Absorption Reaction Rate for ${ }^{249} \mathrm{Pu}$ in a Nitride 2

Cycle Radial Blanket. . . . . . . . . . . . . . . 149

FIGURE C-29: Absorption Reaction Rate for ${ }^{241} \mathrm{Pu}$ in a Metal Inner

Fuel Assembly. . . . . . . . . . . . . . . . . . 150

FIGURE C-30: Absorption Reaction Rate for ${ }^{249} \mathrm{Pu}$ in a Metal 2 Cycle

Radial Blanket. .. ................. 151

FIGURE C-31: Capture Reaction Rate for ${ }^{249} \mathrm{Pu}$ in an Oxide Inner

Fuel Assembly. . . . . . . . . . . . . . . . . . 152

FIGURE C-32: Capture Reaction Rate for ${ }^{249} \mathrm{Pu}$ in an Oxide 2 cycle

Radial Blanket. . . . . . . . . . . . . . . . 153

FIGURE C-33: Capture Reaction Rate for ${ }^{249} \mathrm{Pu}$ in a Nitride Inner

Fuel Assembly. . . . . . . . . . . . . . . . . . . . 154

FIGURE C-34: Capture Reaction Rate for ${ }^{241} \mathrm{Pu}$ in a Nitride 2 Cycle

Radial Blanket. . . . . . . . . . . . . . . . 155 
FIGURE C-35: Capture Reaction Rate for ${ }^{241} \mathrm{Pu}$ in a Metal Inner Fuel

Assembly. . . . . . . . . . . . . . . . . . 156

FIGURE C-36: Capture Reaction Rate for ${ }^{241} \mathrm{Pu}$ in a Metal 2 Cycle

Radial Blanket. . . . . . . . . . . . . . . . . 157

FIGURE C-37: Fission Reaction Rate for ${ }^{235} \mathrm{U}$ in an 0xide Inner Fuel

Assembly. . . . . . . . . . . . . . . . . . 158

FIGURE C-38: Fission Reaction Rate for ${ }^{235} \mathrm{U}$ in an 0xide 2 cycle

Radial Blanket. . . . . . . . . . . . . . . . 159

FIGURE C-39: Fission Reaction Rate for ${ }^{235} \mathrm{U}$ in a Nitride Inner

Fuel Assembly. . . . . . . . . . . . . . . . . . 160

FIGURE C-40: Fission Reaction Rate for ${ }^{235} \mathrm{U}$ in a Nitride 2 Cycle

Radial Blanket. . . . . . . . . . . . . . . . 161

FIGURE C-41: Fission Reaction Rate for ${ }^{235} \mathrm{U}$ in a Metal Inner Fuel

Assembly. . . . . . . . . . . . . . . . 162

FIGURE C-42: Fission Reaction Rate for ${ }^{235} \mathrm{U}$ in a Metal 2 Cycle

Radial Blanket. . . . . . . . . . . . . . . . . 163

FIGURE C-43: Absorption Reaction Rate for ${ }^{235} \mathrm{U}$ in an 0xide Inner

Fuel Assembly. . . . . . . . . . . . . . . . . . . 164

FIGURE C-44: Absorption Reaction Rate for ${ }^{235} \mathrm{U}$ in an 0xide 2 Cycle

Radial Blanket. . . . . . . . . . . . . . . . 165

FIGURE C-45: Absorption Reaction Rate for ${ }^{235} \mathrm{U}$ in a Nitride Inner

Fuel Assembly. .................. 166

FIGURE C-46: Absorption Reaction Rate for ${ }^{235} \mathrm{U}$ in a Nitride 2

Cycle Radial Blanket. . . . . . . . . . . . . . . 167

FIGURE C-47: Absorption Reaction Rate for ${ }^{235} \mathrm{U}$ in a Metal Inner

Fuel Assembly. . . . . . . . . . . . . . . . . . 168

FIGURE C-48: Absorption Reaction Rate for ${ }^{235} \mathrm{U}$ in a Metal 2 Cycle

Radial Blanket. . . . . . . . . . . . . . . . 169

FIGURE C-49: Capture Reaction Rate for ${ }^{235} \mathrm{U}$ in an 0xide Inner Fuel

Assembly. . . . . . . . . . . . . . . . . . 170

FIGURE C-50: Capture Reaction Rate for ${ }^{235} \mathrm{U}$ in an oxide 2 cycle

Radial Blanket. ................... 171

FIGURE C-51: Capture Reaction Rate for ${ }^{235} \mathrm{U}$ in a Nitride Inner

Fuel Assembly. . . . . . . . . . . . . . . 172 
FIGURE C-52: Capture Reaction Rate for ${ }^{235} \mathrm{U}$ in a Nitride 2 Cycie

Radial Blanket. . . . . . . . . . . . . . 173

FIGURE C-53: Capture Reaction Rate for ${ }^{235} \mathrm{U}$ in a Metal Inner Fuel

Assembly. . . . . . . . . . . . . . . . 174

FIGURE C-54: Capture Reaction Rate for ${ }^{235} \mathrm{U}$ in a Metal 2 Cycle

Radial Blanket. . . . . . . . . . . . . . 175

FIGURE C-55: Fission Reaction Rate for ${ }^{238} \mathrm{U}$ in an 0xide Inner Fuel

Assembly. . . . . . . . . . . . . 176

FIGURE C-56: Fission Reaction Rate for ${ }^{238} \mathrm{U}$ in an 0xide 2 Cycle

Radial Blanket. . . . . . . . . . . . . . 177

FIGURE C-57: Fission Reaction Rate for ${ }^{238} \mathrm{U}$ in a Nitride Inner

Fuel Assembly. . . . . . . . . . . . . . 178

FIGURE C-58: Fission Reaction Rate for ${ }^{238} \mathrm{U}$ in a Nitride 2 Cycle

Ridial Blanket. . . . . . . . . . . . . 179

FIGURE C-59: Fission Reaction Rate for ${ }^{238} \mathrm{U}$ in a Metal Inner Fuel

Assembly. . . . . . . . . . . . . . . 180

FIGURE C-60: Fission Reaction Rate for ${ }^{238} \mathrm{U}$ in a Metal 2 Cycle

Radial Blanket. ................ 181

FIGURE C-61: Absorption Reaction Rate for ${ }^{238} \mathrm{U}$ in an 0xide Inner

Fuel Assembly. . . . . . . . . . . . . . . . . 182

FIGURE C-62: Absorption Reaction Rate for ${ }^{238} \mathrm{U}$ in an 0xide 2 Cycle

Radial Blanket. . . . . . . . . . . . . . 183

FIGURE C-63: Absorption Reaction Rate for ${ }^{238} \mathrm{U}$ in a Nitride Inner

Fuel Assembly. . . . . . . . . . . . . . . . 184

FIGURE C-64: Absorption Reaction Rate for ${ }^{238} \mathrm{U}$ in a Nitride 2

Cycle Radial Blanket. . . . . . . . . . . . . . . 185

FIGURE C-65: Absorption Reaction Rate for ${ }^{238} \mathrm{U}$ in a Metal Inner

Fuel Assembly. . . . . . . . . . . . . . . . 186

FIGURE C-66: Absorption Reaction Rate for ${ }^{238} \mathrm{U}$ in a Metal 2 Cycle

Radial Blanket. . . . . . . . . . . . . . . . 187

FIGURE C-67: Capture Reaction Rate for ${ }^{238} \mathrm{U}$ in an 0xide Inner Fuel

Assembly. . . . . . . . . . . . . . . . 188

FIGURE C-68: Capture Reaction Rate for ${ }^{238} \mathrm{U}$ in an Oxide 2 Cycle

Radial Blanket. ............... 189 
FIGURE C-69: Capture Reaction Rate for ${ }^{238} \mathrm{U}$ in a Nitride Inner

Fuel Assembly.

FIGURE C-70: Capture Reaction Rate for ${ }^{238} U$ in a Nitride 2 Cycle

Radial Blanket. . . . . . . . . . . . . . . . . 191

FIGURE C-71: Capture Reaction Rate for ${ }^{238} U$ in a Metal Inner Fuel

Assembly. . . . . . . . . . . . . . . . . . . 192

FIGURE C-72: Capture Reaction Rate for ${ }^{238} \mathrm{U}$ in a Metal 2 Cycle

Radial Blanket. . . . . . . . . . . . . . . . . 193

FIGURE C-73: Fission Reaction Rate for ${ }^{240} \mathrm{Pu}$ in an Oxide Inner

Fuel Assembly. . . . . . . . . . . . . . . . . . . . 194

FIGURE C-74: Fission Reaction Rate for ${ }^{240} \mathrm{Pu}$ in an oxide 2 cycle

Radial Blanket. . . . . . . . . . . . . . . 195

FIGURE C-75: Fission Reaction Rate for ${ }^{240} \mathrm{Pu}$ in a Nitride Inner

Fuel Assembly. . . . . . . . . . . . . . . . . . 196

FIGURE C-76: Fission Reaction Rate for ${ }^{240} \mathrm{Pu}$ in a Nitride 2 Cycle

Radial Blanket. . . . . . . . . . . . . . . . . 197

FIGURE C-77: Fission Reaction Rate for ${ }^{240} \mathrm{Pu}$ in a Metal Inner Fuel

Assembly. . . . . . . . . . . . . . . . . . 198

FIGURE C-78: Fission Reaction Rate for ${ }^{240} \mathrm{Pu}$ in a Metal 2 Cycle

Radial Blanket. . . . . . . . . . . . . . . 199

FIGURE C-79: Absorption Reaction Rate for ${ }^{240} \mathrm{Pu}$ in an Oxide Inner

Fuel Assembly. . . . . . . . . . . . . . . . 200

FIGURE C-80: Absorption Reaction Rate for ${ }^{240} \mathrm{Pu}$ in an 0xide 2

Cycle Radial Blanket. .................. 201

FIGURE C-81: Absorption Reaction Rate for ${ }^{240} \mathrm{Pu}$ in a Nitride Inner

Fuel Assembly. . . . . . . . . . . . . . . . 202

FIGURE C-82: Absorption Reaction Rate for ${ }^{240} \mathrm{Pu}$ in a Nitride 2

Cycle Radial Blanket. . . . . . . . . . . . . . . 203

FIGURE C-83: Absorption Reaction Rate for ${ }^{240} \mathrm{Pu}$ in a Metal Inner

Fuel Assembly. . . . . . . . . . . . . . . . . . 204

FIGURE C-84: Absorption Reaction Rate for ${ }^{240} \mathrm{Pu}$ in a Metal 2 Cycle

Radial Blanket. .................... 205

FIGURE C-85: Capture Reaction Rate for ${ }^{240} \mathrm{Pu}$ in an 0xide Inner

Fuel Assembly. . . . . . . . . . . . . . . . 206 
FIGURE C-86: Capture Reaction Rate for ${ }^{240} \mathrm{Pu}$ in an 0xide 2 Cycle

Radial Blanket. . . . . . . . . . . . . . . . . 207

FIGURE C-87: Capture Reaction Rate for ${ }^{240} \mathrm{Pu}$ in a Nitride Inner

Fuel Assembly. . . . . . . . . . . . . . . . . 208

FIGURE C-88: Capture Reaction Rate for ${ }^{240} \mathrm{Pu}$ in a Nitride 2 Cycle

Radial Blanket. . . . . . . . . . . . . . . 209

FIGURE C-89: Capture Reaction Rate for ${ }^{240} \mathrm{Pu}$ in a Metal Inner Fuel

Assembly. . . . . . . . . . . . . . . . . 210

FIGURE C-90: Capture Reaction Rate for ${ }^{240} \mathrm{Pu}$ in a Metal 2 Cycle

Radial Blanket. . . . . . . . . . . . . . . . 211

FIGURE C-91: Fis:ion Reaction Rate for ${ }^{242} \mathrm{Pu}$ in an Oxide Inner

Fuel Assembly. . . . . . . . . . . . . . . . . 212

FIGURE C-92: Fission Reaction Rate for ${ }^{242} \mathrm{Pu}$ in an 0xide 2 Cycle

Radial Blanket. . . . . . . . . . . . . . . . 213

FIGURE C-93: Fission Reaction Rate for ${ }^{242} \mathrm{Pu}$ in a Nitride Inner

Fuel Assembly. . . . . . . . . . . . . . . . 214

FIGURE C-94: Fission Reaction Rate for ${ }^{242} \mathrm{Pu}$ in a Nitride 2 Cycle

Radial Blanket. .................... 215

FIGURE C-95: Fission Reaction Rate for ${ }^{242} \mathrm{Pu}$ in a Metal Inner Fuel

Assembly. . . . . . . . . . . . . . . . . 216

FIGURE C-96: Fission Reaction Rate for ${ }^{242} \mathrm{Pu}$ in a Metal 2 Cycle

Radial Blanket. . . . . . . . . . . . . . . 217

FIGURE C-97: Absorption Reaction Rate for ${ }^{242} \mathrm{Pu}$ in an 0xide Inner

Fuel Assembly. . . . . . . . . . . . . . . . 218

FIGURE C-98: Absorption Reaction Rate for ${ }^{242} \mathrm{n}_{u}$ in an 0xide 2

Cycle Radial Blanket. . . . . . . . . . . . . . . 219

FIGURE C-99: Absorption Reaction Rate for ${ }^{242} \mathrm{Pu}$ in a Nitride Inner

Fuel Assembly. . . . . . . . . . . . . . . . . 220

FIGURE C-100: Absorption Reaction Rate for ${ }^{242} \mathrm{Pu}$ in a Nitride 2

Cycle Radial Blanket. .................. 221

FIGURE C-101: Absorption Reaction Rate for ${ }^{242} \mathrm{Pu}$ in a Metal Inner

Fuel Assembly. . . . . . . . . . . . . . . . . 222

FIGURE C-102: Absorption Reaction Rate for ${ }^{242} \mathrm{Pu}$ in a Metal 2

Cycle Radial Blanket. . . . . . . . . . . . . . . 223 
FIGURE C-103: Capture Reaction Rate for ${ }^{242} \mathrm{Pu}$ in an Oxide Inner

Fuel Assembly. . . . . . . . . . . . . . . . . . 224

FIGURE C-104: Capture Reaction Rate for ${ }^{242} \mathrm{Pu}$ in an 0xide 2 Cycle

Radial Blanket. . . . . . . . . . . . . . . . 225

FIGURE C-105: Capture Reaction Rate for ${ }^{242} \mathrm{Pu}$ in a Nitride Inner

Fuel Assembly. . . . . . . . . . . . . . . . . 226

FIGURE C-106: Capture Reaction Rate for ${ }^{242} \mathrm{Pu}$ in a Nitride 2 Cycle

Radial Blanket. . . . . . . . . . . . . . . . 227

FIGURE C-107: Capture Reaction Rate for ${ }^{242} \mathrm{Pu}$ in a Metal Inner

Fuel Assembly. . . . . . . . . . . . . . . . 228

FIGURE C-108: Capture Reaction Rate for ${ }^{242} \mathrm{Pu}$ in a Metal 2 Cycle

Radial Blanket. .................. 229 


\section{List of Tables}

TABLE 1: 1-Group to 12-Group SVRE Comparison . . . . . . . . . . . 6

TABLE 2. Effects of Hardening Neutron Spectrum on the SVRE . . . . 12

TABLE 3. 2-D Analysis Sodium Void Reactivity Worths for the Reference Cores .. . . . . . . . . . . . . . . 26

TABLE 4. 3-D Analys is Sodium Void Reactivity Worth Comparison . . . 29

TABLE 5. Neutron Balance by Process Component . . . . . . . . . . . 31

TABLE 6. Sodium Void Neutron Balance Change . . . . . . . . . . 32

TABLE 7. Slowing Down Power for the Oxide Core. . . . . . . . . . . 61

TABLE 8. Slowing Down Power for the Nitride Core. . . . . . . . . . 62

TABLE 9. Slowing Down Power for the Metal Core. . . . . . . . . . 63

TABLE 10. Slowing Down Power Summary. . . . . . . . . . . . . 64 


\section{List of Acronyms}

$\begin{array}{ll}\text { ALMR } & \text { Advanced Liquid Metal Reactor } \\ \text { ANL } & \text { Argonne National Laboratory } \\ \text { DOE } & \text { U.S. Department of Energy } \\ \text { ENDF/B-V } & \text { Evaluated Nuclear Data File/B Version V } \\ \text { FFTF } & \text { Fast Flux Test Facility } \\ \text { GE } & \text { General Electric Corporation } \\ \text { GEM } & \text { Gas Expansion Module } \\ \text { LMR } & \text { liquid metal reactors } \\ \text { NUREG } & \text { identifier on NRC documents } \\ \text { PRISM } & \text { Power Reactor Inherently Safe Module } \\ \text { SDP } & \text { slowing down power } \\ \text { SVRE } & \text { Sodium void reactivity effect } \\ \text { ULOF } & \text { unprotected loss of flow } \\ \text { USA } & \text { Ultimate Shutdown Assembly }\end{array}$




\section{ACKNOWLEDGEMENT}

The author wishes to express his sincere appreciation for the assistance of Dr. Ron Omberg, Ken Dobbin, and Joe Nelson in setting up the core models used for all calculations and for providing helpful advice on interpreting the results. The author would also like to thank Dr. Kermit Garlid and Dr. Duane Lindstrom for their input and suggestions on the text of the thesis and for providing objective overviews. 


\section{INTRODUCTION}

Following the accidents at light water reactors at Three Mile Is 1 and and Chernobyl, reactor designers throughout the world have been working to develop inherently safe reactor designs. These efforts have included designs for breeder reactors using liquid sodium as the coolant. The excellent heat transfer characteristics of sodium make it attractive as a coolant, and, with a boiling point higher than the normal operating temperature of most reactor designs, it does not require high primary system pressure. Accident scenarios, however, may lead to sodium boiling in hotter portions of the core creating voids. In the United States, the Advanced Liquid Metal Reactor (ALMR) program is based on metal as the reference fuel because of its favorable neutronic feedback characteristics for passive safety. In particular, the Power Reactor Inherently Safe Module (PRISM) design combines favorable relationships between core performance and safety to provide a passively. safe metal fuel system with a large margin to sodium boiling. This large margin is required because this design has a large positive sodium void reactivity effect (SVRE).

A large coolant void worth was a major contributor to the severity of the accident at Chernobyl.

Most efforts to reduce the SVRE have concentrated on changing the physical characteristics of the reactor core while using a specific fuel type. Some studies ${ }^{1,2,3}$ have examined the effect of the fuel type on the SVRE. The fuel types analyzed were ternary metal fuel consisting of an alloy of uranium, plutonium, and zirconium, mixed oxide fuel, and mixed nitride fuel. These studies have shown that fuel type can significantly alter the SVRE. The purpose of this thesis is to determine the effect of fuel type on the sodium void and investigate the phenomena causing the problem. This investigation is limited to these three fuel types in a core conficuration similar to the reference core $e^{4,5}$ supplied by the lead United States ALMR designer. Alterations to this design are limited such that the rest of the plant design 
will not change. The goal is to determine which fuel type can be used to minimize the performance tradeoffs in a near-zero sodium void worth design. Using minor actinides from spent reactor fuel as a source of fuel to minimize waste, one of the promising uses of the ALMR, will also be considered but only with respect to its effect on the SVRE. 


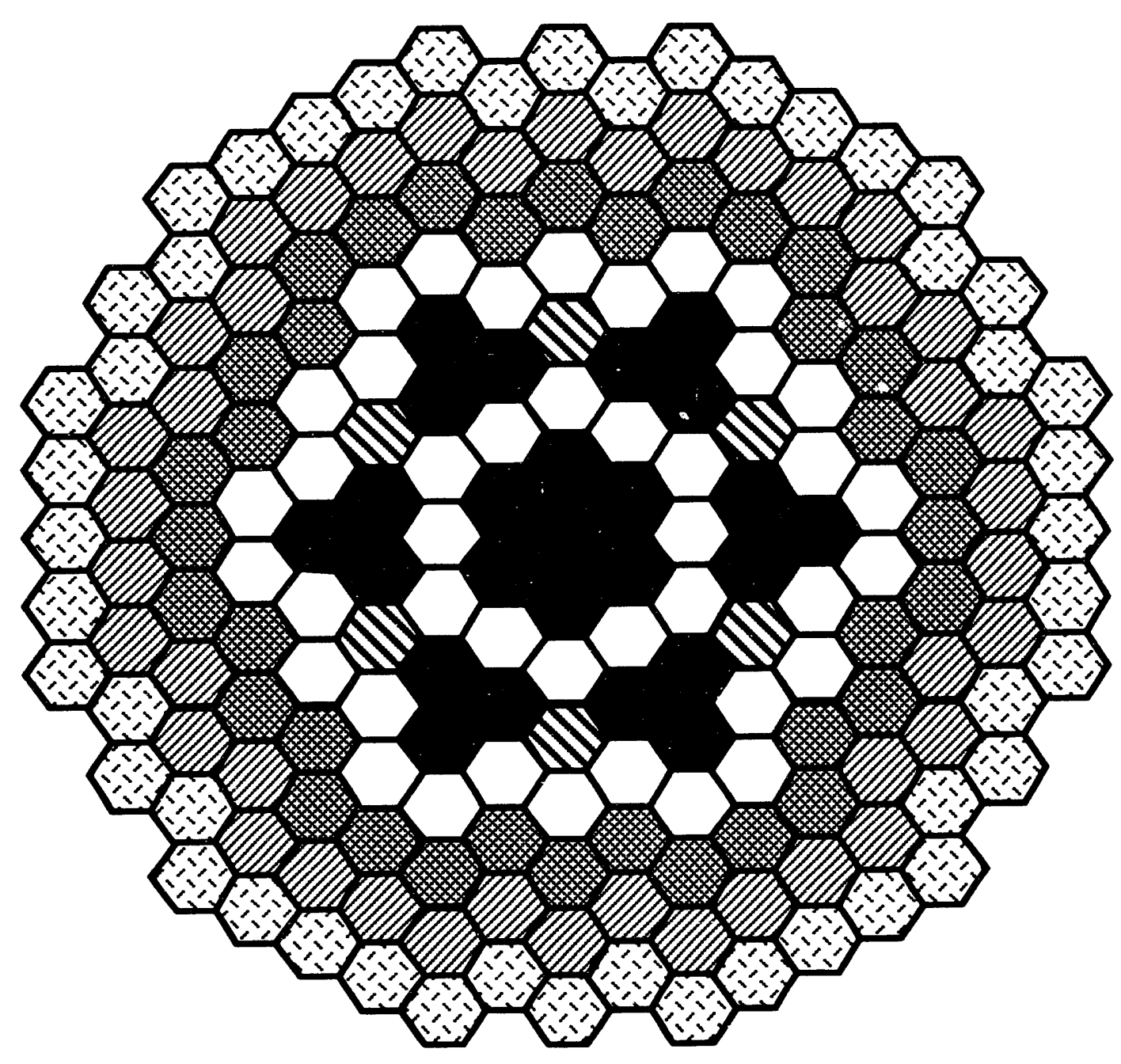

$\bigcirc$ Fuel 42

Internal Blanket 25

Radial Blanket 36

42

Radial Shield 48

10. Control/Shutdown 6

Total

199

FIGURE 1: Advanced Liquid Metal Reactor Core Without Universal Shutdown Assembly or Gas Expansion Modules 

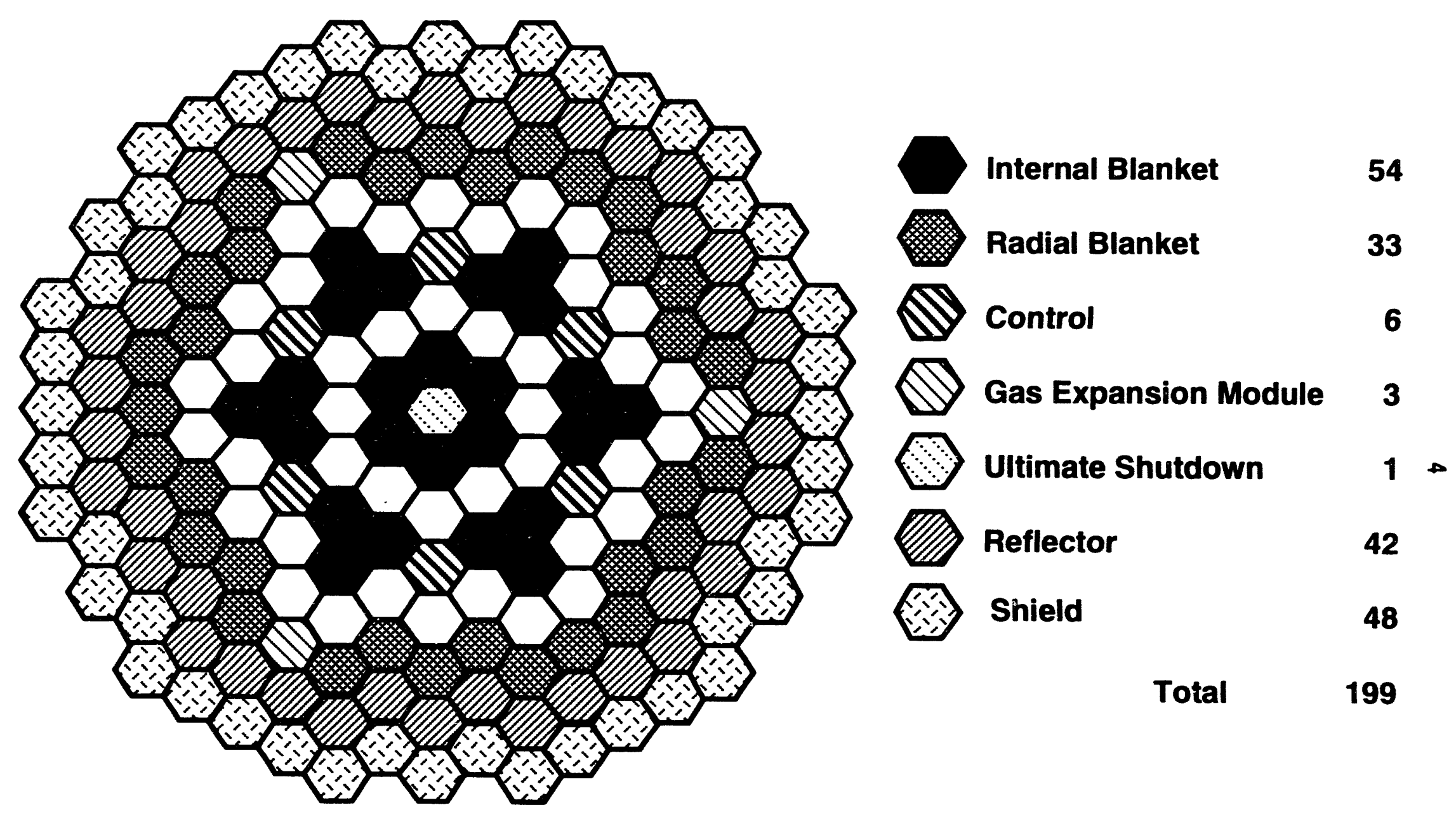

39105057.3

FIGURE 2: Advanced Liquid Metal Reactor Core With Universal Shutdown Assembly and Gas Expansion Modules 


\section{SUMMARY AND CONCLUSIQNS}

Designers of liquid metal reactors (LMR) have long been aware of the problems associated with a large positive SVRE. Since the probability of gross sodium voiding in LMRs was thought to be extremely low, severe compromises in LMR designs to reduce the SVRE were generally considered unwarranted ${ }^{6}$. After the accident at Chernobyl, the potential reactivity effects of light water reactor coolant voiding have received increased attention in both the light water and LMR communities, and reducing, if not minimizing the SVRE is receiving increased attention ${ }^{7}$. To achieve this goal, several innovative ALMR designs with low and negative SVRE have been proposed $8,9,10,11,12$ showing that the importance of reducing this effect is receiving international attention. The optimum method for reducing the SVRE will retain other desirabie reactor performance characteristics.

Diffusion theory was chosen for this study because it is an acceptable method for calculating the SVRE. Diffusion theory calculations of the SVRE were used in the design of the Fast Flux Test Facility (FFTF) at the U.S. Department of Energy (DOE) Hanford Site and were compared to results of fast test reactor engineering mockup critical assembly sodium void experiments with good agreement ${ }^{13}$. Calculations are typically performed using multigroup diffusion theory. This study used 12 neutron energy groups for the majority of the calculations. One set of one-group calculations was used for comparison to the 12-group calculations. The results are listed in Table 1. The one-group calculation overestimates the SVRE compared to the 12-group calculation for two reasons. First, in one-group, all spectral effects are accounted for by the code used to generate the cross sections. The code used for $K_{\text {eff }}$ calculations handles the spectral effects differently and calculates a different result. Second, leakage is conserved when the transport cross section is collapsed by assuming the buckling is constant over all neutron energies. In 
TABLE 1: 1-Group to 12-Group SVRE Comparison

\begin{tabular}{ccc}
\multicolumn{3}{c}{ Void Worth $(\Delta K / K)$} \\
Fuel Type & 1 -Group & 12 -Group \\
Oxide & 0.0064 & 0.0046 \\
Nitride & 0.0083 & 0.0070 \\
Metal & 0.0243 & 0.0178
\end{tabular}


reality, buckling is dependent on energy, and errors in the transport cross sections are produced by collapsing from many fine groups to few coarse groups. These errors are maximized when collapsing to nne-group. Many of the references to this paper emphasize the importance of using accurate cross sections to improve SVRE predictions. Other work recommends that multigroup calculations be used for fast reactor neutronics analysis because of the wide range of neutron energies over which most reactions occur $^{14}$. Therefore, a one-group SVRE calculation is useful as an educational tool where accuracy is not considered to be of highest importance but where relationships between core designs is desired.

In comparative studies of the three fuel types, metal fuel always has the most positive SVRE and oxide fuel always has the least positive. The SVRE for nitride fuel is slightiy more positive than that of oxide fuel but less positive than metal fuel.

To understand the effect of changes in fuel type, the SVRE may be split into three components; leakage, spectral, and capture. As sodium voids, leakage increases. Increasing leakage may have either a positive or negative effect on the SVRE depending on the location of the void in the core. The neutron spectrum hardens as the sodium voids. A harder spectruin results in reduced capture cross sections and a reduced capture rate. A harden spectrum al so results in reduced fission cross sections and a reduced fission rate. However, for some isotopes, the capture rate decreases more rapidly than the fission rate causing the SVRE to be positive.

Typical capture-to-fission ratios for an ALMR are shown in Figures 3 and 4 . In Figure 3 , note how the ratio for ${ }^{239} \mathrm{Pu}$ decreases more rapidly than that for ${ }^{235} \mathrm{U}$ or ${ }^{249} \mathrm{Pu}$ as the neutron energy increases. A core driven by ${ }^{239} \mathrm{Pu}$ should have a more positive SVRE than one driven by either ${ }^{235} \mathrm{U}$ or ${ }^{241} \mathrm{Pu}$. In Figure 4 , the decrease in the ratio for ${ }^{238} U$ is on a separate 


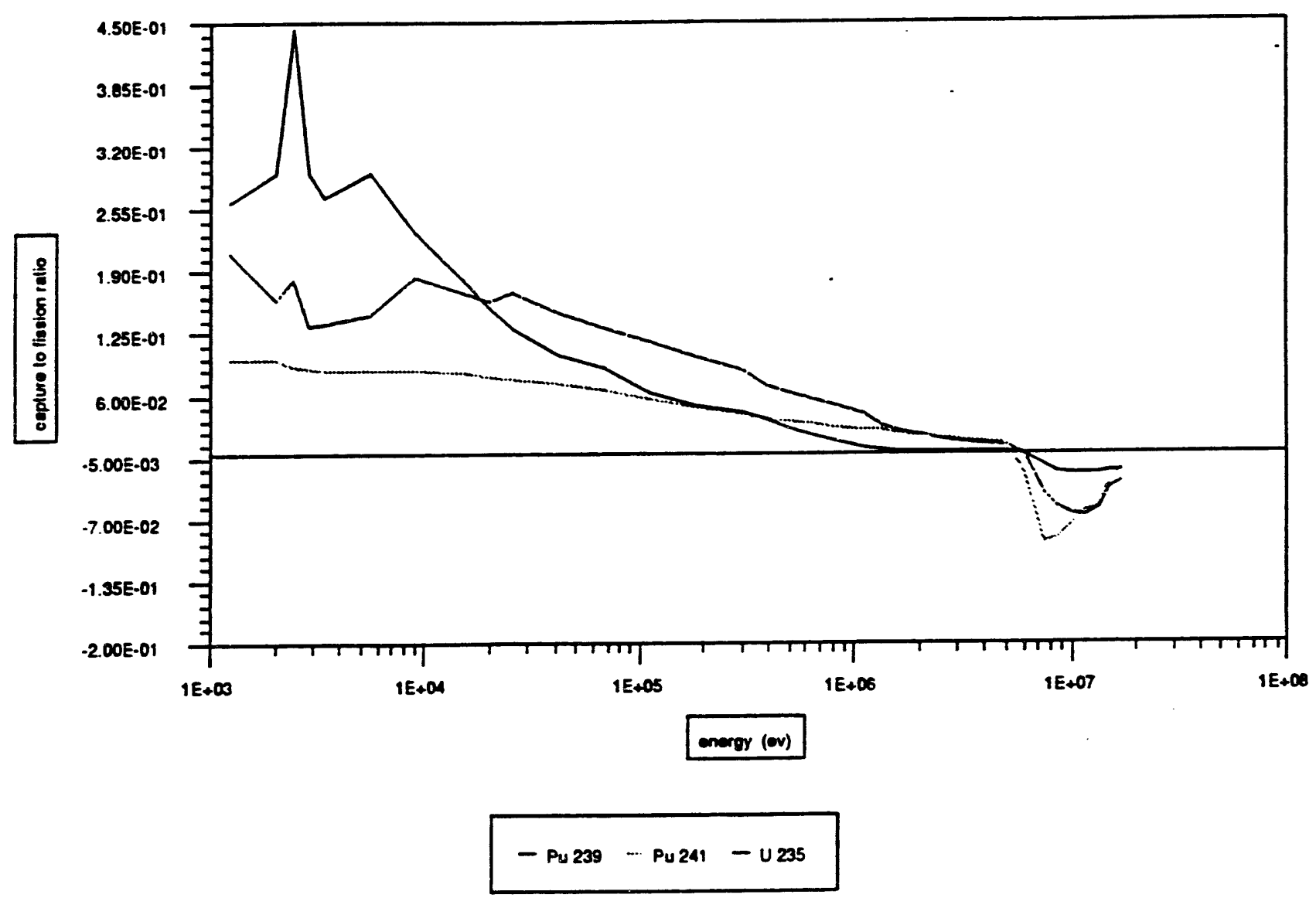

$\infty$

FIGURE 3: Typical Fissile Material Capture-to-Fission Ratios 


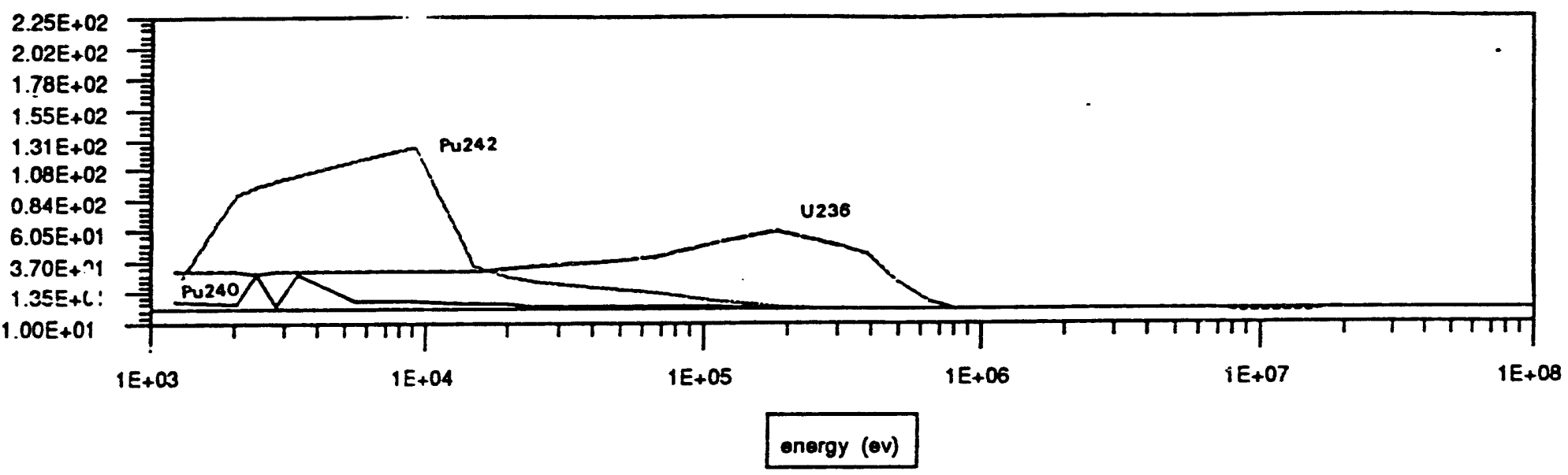

$\omega$

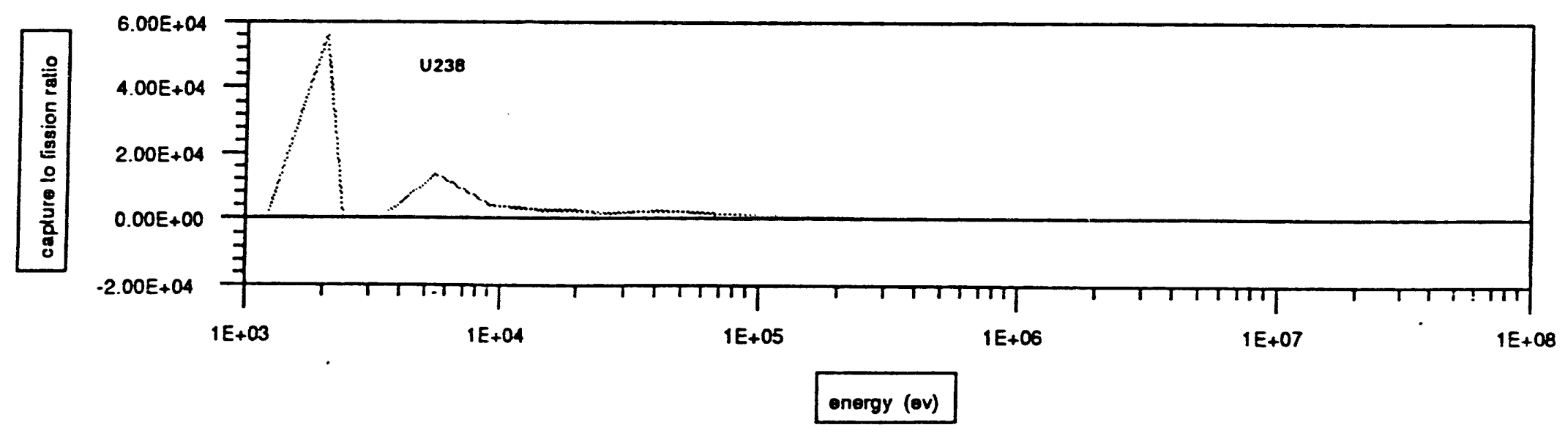

FIGURE 4: Typical Nonfissile Material Capture-to-Fission Ratios 
graph to show how it dominates all other nonfissile isotopes. A fuel design which changes the amount of ${ }^{238} \mathrm{U}$ in the core will affect the SVRE. Removal of ${ }^{238} \mathrm{U}$ from the core will cause the SVRE to be less positive. It should also be noted that the scale of Figure 4 is much larger than the scale of Figure 3 . The presence of large quantities of any of these nonfissile isotopes will cause the SVRE to be more positive.

A decreasing capture-to-fission ratio causes $K_{\text {eff }}$ to increase unless leakage increases enough to compensate as shown in Section $D$ of this paper. The effect of a decrease in capture-tofission ratio on the SVRE is most positive in the metal core where the sodium is the most important moderator in the core. In an oxide or nitride core, the oxygen and nitrogen are much better moderators than the sodium and they remain in the core during coolant voiding. Their presence serves to limit spectral hardening in these cores.

The following derivation may serve to help determine the relative importance of the components of the SVRE. By taking the natural $\log$ of Equation 1 and differentiating with respect to the number of sodium atoms, the SVRE may be defined as:

$$
\alpha_{v}=\frac{\partial \ln K_{e f f}}{\partial N_{N a}}=\frac{1}{K_{e f f}} \frac{\partial K_{e f f}}{\partial N_{N a}}
$$

Carrying out the differentiation of Equation 1 gives the following:

$$
\alpha_{v}=\frac{1}{v} \frac{\partial v}{\partial N_{N a}}+\frac{1}{\sum_{f}} \frac{\partial \Sigma_{f}}{\partial N_{N a}}-\left(\frac{P_{n 1}}{\Sigma_{a}}+\frac{\left(P_{n 1}-1\right)}{\Sigma_{t r}}\right) \frac{\partial \Sigma_{a}}{\partial N_{N a}}-\frac{\left(P_{n 1}-1\right)}{\sum_{t r}} \frac{\partial \Sigma_{b}}{\partial N_{N a}}
$$


Where:

$$
\begin{aligned}
v & =\text { number of neutrons per fission } \\
P_{n l} & =\text { the non-leakage probability } \\
\Sigma_{a} & =\text { macroscopic absorption cross section } \\
\Sigma_{t r} & =\text { macroscopic transport cross section } \\
\Sigma_{s} & =\text { macroscopic scatter cross section. }
\end{aligned}
$$

The consequences of sodium voiding may be seen in this formula and are shown in Table 2. Increasing the leakage decreases the nonleakage probability, $P_{n l}$, contributing to a decrease in the SVRE by the change in the absorption term and through the change in the scattering term. Hardening the spectrum increases the number of neutrons per fission, $v$, and reduces both the fission and absorption cross sections of most of the isotopes in the reactors. It has a minimal effect on the scattering cross section. Therefore, the change in $v$ is a positive contributor to the SVRE, the change in $\Sigma_{f}$ is a negative contributor, and the change in $\Sigma_{a}$ is a positive contributor. The effect of a reduction in capture will increase the positive contribution of the change in $\Sigma_{a}$ on the SVRE. These observations explain why the SVRE can be positive in an ALMR.

It is the effect of the change in moderation that explains the difference in magnitude of the SVRE between metal, oxide, and nitride fuels. In a metal fueled reactor, the scattering cross section of the sodium coolant is a much larger fraction of the total scatter cross section of all the core materials, resulting in a harder spectrum. This causes a large positive contribution to the SVRE. For an oxide or nitride fueled ALMR, the oxygen and nitrogen constitute the largest fraction of the total scatter cross section. Thus, when the sodium voids, the change in moderation is smaller, limiting the spectral hardening, resulting in a smaller positive contribution to the SVRE. The net result is that a metal fueled ALMR will always have the most positive SVRE 
TABLE 2. Effects of Hardening Neutron Spectrum on the SVRE

\begin{tabular}{|c|c|c|c|}
\hline Term & $\begin{array}{l}\text { Change due } \\
\text { to Spectral } \\
\text { Hardening }\end{array}$ & $\begin{array}{l}\text { Effect on } \\
\text { the SVRE }\end{array}$ & Reason \\
\hline$\alpha_{v}(v)$ & Positive & Positive & $\begin{array}{l}\text { The number of neutrons per } \\
\text { fission increases. }\end{array}$ \\
\hline$\alpha_{v}\left(\Sigma_{f}\right)$ & Negative & Negative & $\begin{array}{l}\text { The fission cross section } \\
\text { decreases. }\end{array}$ \\
\hline$\alpha_{v}\left(\Sigma_{a}\right)$ & Negative & Positive & $\begin{array}{l}\text { Parasitic absorption decreases } \\
\text { releasing more neutrons for } \\
\text { fission. }\end{array}$ \\
\hline$\alpha_{v}\left(\Sigma_{s}\right)$ & Negative & Negative & $\begin{array}{l}\text { Loss of scattering increases the } \\
\text { leakage. }\end{array}$ \\
\hline
\end{tabular}


when compared to an oxide or nitride fueled ALMR of similar design. Likewise, core design changes to reduce the SVRE will always be more severe and consequently less durable in a metal fueled ALMR. 


\section{OBJECTIVE}

Using the present United States ALMR design as a reference, and the reduction of the positive sodium void worth of the current core designs as an industry directive, this thesis study had three objectives. The first was to determine how the type of fuel affects the SVRE. The second was to investigate the physics of the problem by looking at the spectral effects of sodium voiding and macroscopic reaction rates of selected materials. The third objective was to present a near-zero sodium void worth design and consider the performance tradeoffs.

Another potential use of the ALMR would be to use minor actinides from spent thermal and fast reactor fuels as a fuel source. "Burning" these actinides not only produces energy but also could reduce the amount of high level waste requiring disposal. This was examined in this study only to show the effect minor actinides have on SVRE. 


\section{METHODOLOGY}

\section{A. Core Models}

Two reference core designs, both supplied by the General Electric Corporation (GE), the ALMR lead designer, were used to investigate how fuel types affected the SVRE. The first, shown in Figure 1, consisted of 42 fuel assemblies, 25 internal blanket assemblies, 6 control rods, 42 HTg radial reflectors, and 48 boron carbide radial shield assemblies. The HT9 alloy is a ferritic stainless steel which has low irradiation swelling characteristics making its use attractive for cores requiring a long fuel lifetime. This core was $128 \mathrm{~cm} \mathrm{high}$ and was used as the model for the initial sodium void calculations. The second, safety enhanced reference core design shown in Figure 2, had an ultimate shutdown assembly (USA) in place of the central blanket, three gas expansion modules (GEM) in place of three radial blankets, and inconel radial reflectors in place of the HTg reflectors. The core height was also increased to $134.6 \mathrm{~cm}$. The USA is a sodium channel through the core with boron-carbide balls in the region above the core. These balls would be released into the central core channel to shut the reactor down in the event of an accident. The GEMs are similar to the ones tested at the FFTF. During normal operation, they are sodium filled and act as reflectors. When flow is lost, the GEMs will become sodium voided as a compressed gas bubble in the top of the assembly expands. This void provides a leakage path for neutrons, adding negative reactivity during a loss-of-flow event. This safety enhanced model was used for developing a near-zero worth core by reducing core height. Effects on other reactor performance characteristics (i.e., breeding ratio and linear power, etc.) were also investigated. No attempts were made to optimize the core configuration during this study. 
Ternary metal fuel, consisting of an alloy of uranium, plutonium, and zirconium, and binary metal blankets, consisting of an alloy of depleted uranium and zirconium, have been chosen as the reference fuel/blanket system for the United States ALMR. The advantages of this system are its high heat transfer characteristics for accident mitigation and high density for good breeding. While it has not yet been proven to work on an industrial scale, the Pyroprocessing of metal fuel may also be an advantage over other fuel types. Pyroprocessing is a process used to recover actinide elements from spent reactor fuel and recycling them for use as new reactor fuel and is based on electrorefining of metals. The process was developed in this country by Argonne National Laboratory (ANL) $)^{15}$. This system also has disadvantages which must be considered in the ALMR design. Metal fuel releases virtually all of the fission gas from the fuel matiix and therefore requires a large plenum above the top of the fuel. This large plenum is also required to accommodate the axial expansion of the fuel. A large pellet-to-clad gap is required to allow for the fuel's radial expansion. Because the fuel and cladding may interact to form a eutectic at temperatures slightly higher than normal operating temperature, the fuel has a low linear power limit. Eutectic penetration of the cladding could lead to the release of fission products to the coolant, or, in the worst case, release of fuel into the coolant. Finally, metal fuel has a large positive SVRE.

Unlike water, sodium does not need to be pressurized to prevent boiling at the normal operating temperatures in a reactor. It may be that low linear power and large margin to boiling under most accident scenarios would el iminate the problem of sodium voiding. However, as reported in NUREG-1368 ${ }^{16}$, a bounding event consisting of an unprotected loss of flow (ULOF) with three pump coastdowns could result in sodium boiling within ihe first minute. A large SVRE would 
then cause a power excursion event resulting in both fuel and cladding damage.

Oxide fuel has been chosen as the backup fuel for the United States ALMR because its physics are well known. It releases less fission gas, so plenum size may be reduced and core size may be increased without increasing reactor height. Because of its low density, the breeding ratio is reduced so that the ability to increase core height to improve the breeding becomes an important factor. Oxide fuel does have a higher linear power capability than metal fuel, but its thermal conductivity is much lower. In order to be considered inherently safe, a reactor using oxide fuel requires passive safety devices such as GEMs which act quickly to automatically insert negative reactivity during a loss of flow without scram event. The negative reactivity serves to limit fuel and clad temperatures to acceptable values. These have been incorporated in the design of the backup oxide core along with axial blankets to improve breeding. Another important characteristic of oxide fuel is the SVRE which, while still positive, is much smaller than that of metal fuel.

Nitride fuel is being considered for ALMRs in many countries (e.g., Commonwealth of Independent States [formerly USSR], France, and Japan) as an advanced fuel type that combines the attributes of both metal and oxide. Use of nitride fuel in large sodium cooled reactors is not a new idea. Its thermal conductivity is comparable to that of metal fuel. Fuel density is also comparable to metal fuel giving nitride fuel a similar breeding ratio. Like oxide fuel, nitride fuel has a relatively small positive SVRE. According to Bauer ${ }^{17}$, at temperatures below $1400^{\circ} \mathrm{C}$, less than $10 \%$ of the fission gas is released from the fuel. This property, along with a high linear power capability, allows both a reduction in reactor height and core size as a potential method of reducing the 
18

SVRE. With its high linear power capability, nitride fuel would seem to be the ideal ALMR fuel. However, operating experience with nitride fuels is limited and the buildup of carbon-14 through the $(n, p)$ reaction with nitrogen-14 may be a drawback. Testing is continuing in France. Nitride fuel has been selected for use in the United States space reactor program. Testing of this fuel was performed at FFTF. 


\section{B. Factors Affecting Sodium Void}

Hummel and Okrent ${ }^{18}$ split the SVRE into three components; spectral, capture. and leakage. The change in core reactivity resulting from the change in both the elastic and inelastic scattering cross sections as sodium voids is defined as the spectral component. While the slowing down power (SDP) is a measure of the spectral effect, it does not show in detail the neutron balance and competition among other factors contributing to the SVRE. The effects of capture-to-fission ratio, fuel/clad bond, and heavy metal composition also contribute to the spectral effect of SVRE. Similarly, the change in core reactivity resulting from the change in macroscopic capture cross sections as sodium voids is defined as the capture component. Heavy metal composition of the fuel also contributes to the capture component of the SVRE. The change in core reactivity resulting from the change in the transport cross section as sodium voids is defined as the leakage component. Core size contributes to the leakage component of the SVRE. For both ALMR cores the spectral component is the most important. The leakage component becomes important when shortening the core to obtain a nearzero void worth. The capture component is small in all cases. Hummel and Okrent also point out that the spectral component is much smaller in a ${ }^{235} \mathrm{U}$ driven, core than in a ${ }^{239} \mathrm{Pu}$ driven core. Other analyses performed on the ALMR reference core design ${ }^{19}$ showed that this design has a negative sodium void when driven by ${ }^{235} \mathrm{U}$ fuel.

\section{Calculation of Reactor Parameters}

In order to compare the three fuel types, a methodical approach of limiting the number of core parameters varied per calculation was used. Core size and fuel composition were initially held constant while an individual core parameter, 
such as clad thickness, was altered and the sodium void worth calculated. A nitride fueled core containing a generic equilibrium blanket in all core blanket locations using the configuration of the first reference ALMR design was used as the starting point. This procedure continued until both metal and oxide cores of correct density, enrichment, pellet size, and pin dimensions were created. The final step in this process was to create realistic equilibrium cores based on data supplied by the lead designer for the reference metal core.

The ALMR was initially modeled in R-Z geometry and scoping studies performed in two-dimensional, multigroup diffusion theory ${ }^{20}$. Using the first reference core design, shown in Figure 1 , the assemblies were homogenized into concentric cylinders representing different material zones. This model was used only for the initial scoping studies of nitride and metal fuel which showed that use of nitride fuel had a potential for reducing the SVRE. The modeling of the control rods as a thin cylinder of material homogenized over the entire height of the core with the density of boron carbide being smeared over the rod height was considered to be too inaccurate for this analysis. To improve the accuracy and to be consistent with other analyses, three-dimensional, multigroup diffusion theory ${ }^{21}$ was used for all further analyses. The three-dimensional model was a triangular- $Z$ model in which each assembly is modeled as a hexagon consisting of six triangles in the $x$ and $y$ plane. Axially, the assemblies were divided into layers based on the region (i.e., below core, core, above core). The below core region was one layer, the core region was divided into eight layers, and the above core region was divided into three layers. The materials in each assembly were homogenized throughout the hexagonal assembly area. Because this model was not burned and used an assumed equilibrium blanket assembly, material 
densities were constant in the axial layers, except for the control rods. The control rods were modeled as HTg and sodium channels up to the layer containing the boron carbide. This model, and a similar one for the updated ALMR core, was used for the void comparisons and the proposed near-zero rod worth core. A spreadsheet was used to convert the material densilies from one fuel type to another and to correct the materia: densities as the pin parameters were modified. The model for the second reference core design was reduced to a $1 / 6$ core modei. Additionally, the GEM and USA were modeled as HT-9 and sodium channels in the core region.

Neutron cross sections were taken from the Evaluated Nuclear Data File/B Version $V$ (ENDF/B-V) cross section library ${ }^{22}$. Multigroup cross section sets were calculated using the shielding factor method ${ }^{14}$ in twelve energy groups with five downscattering terms. The one dimensional diffusion theory code $10 x^{23}$ was used to generate all cross section sets. For the initial studies using the first reference core, a new cross section set was prepared each time the material density was modified. The only exception to this method was for the equilibrium oxide core calculations. Both the equilibrium oxide core developed from the original equilibrium metal core and the equilibrium oxide core supplied by the lead designer used the same cross section set. Only one cross section set was prepared for each fuel type used in the second core model. Fifty-three energy group cross section sets with fifty-two downscattering terms were created for each equilibrium core. All cross section sets included separate sodium-flooded and sodium-voided cross sections.

Void worth was defined in two ways. For the first core, without GEMs or USA, the void worth was defined as the change in core reactivity due to the removal of coolant from the total core. The sodium bond in the pins of the nitride core 
remained in the model. For the metal core, it was assumed that the radial expansion of the pellets expelled the sodium out of the bond after a short period of operation. The void worth of the reference core with GEMs and USA was defined as the removal of the coolant only from the fuel and blanket assemblies. This change was made to be consistent with void worths reported in the literature.

A value of less than one dollar for the void worth of the fuel and blankets is attractive for reactor safety in that the reactor will not go prompt critical if the coolant voids. When the affects of the radial reflectors and shields on the void is included, the total core void worth will be near zero.

\section{Industry Computer Codes}

Industry computer codes were used for the majority of the analyses. Multipurpose, one-dimensional ${ }^{23}$ diffusion theory code MIDX was used to prepare resonance shielded cross sections in both 53 and 12 neutron energy groups, using a radial model consisting of concentric rings of material out to the core barrel. The thickness of the rings was determined by the area of the assemblies in each material zone, shown in Figure 5. To prepare the cross sections for the lower shield and upper plenum, plane geometry was used. Basic cross section data was from the ENDF/B-V library 22 . Cross sections were prepared for both sodium-flooded and sodium-voided cases and for each core parameter change.

Multigroup diffusion code $2 \mathrm{DB}^{20}$ was used for the initial scoping studies on both nitride and metal fuel. $R-Z$ geometry was used with the model consisting of concentric cylinders of material. In this model, the control rods were modeled as a 


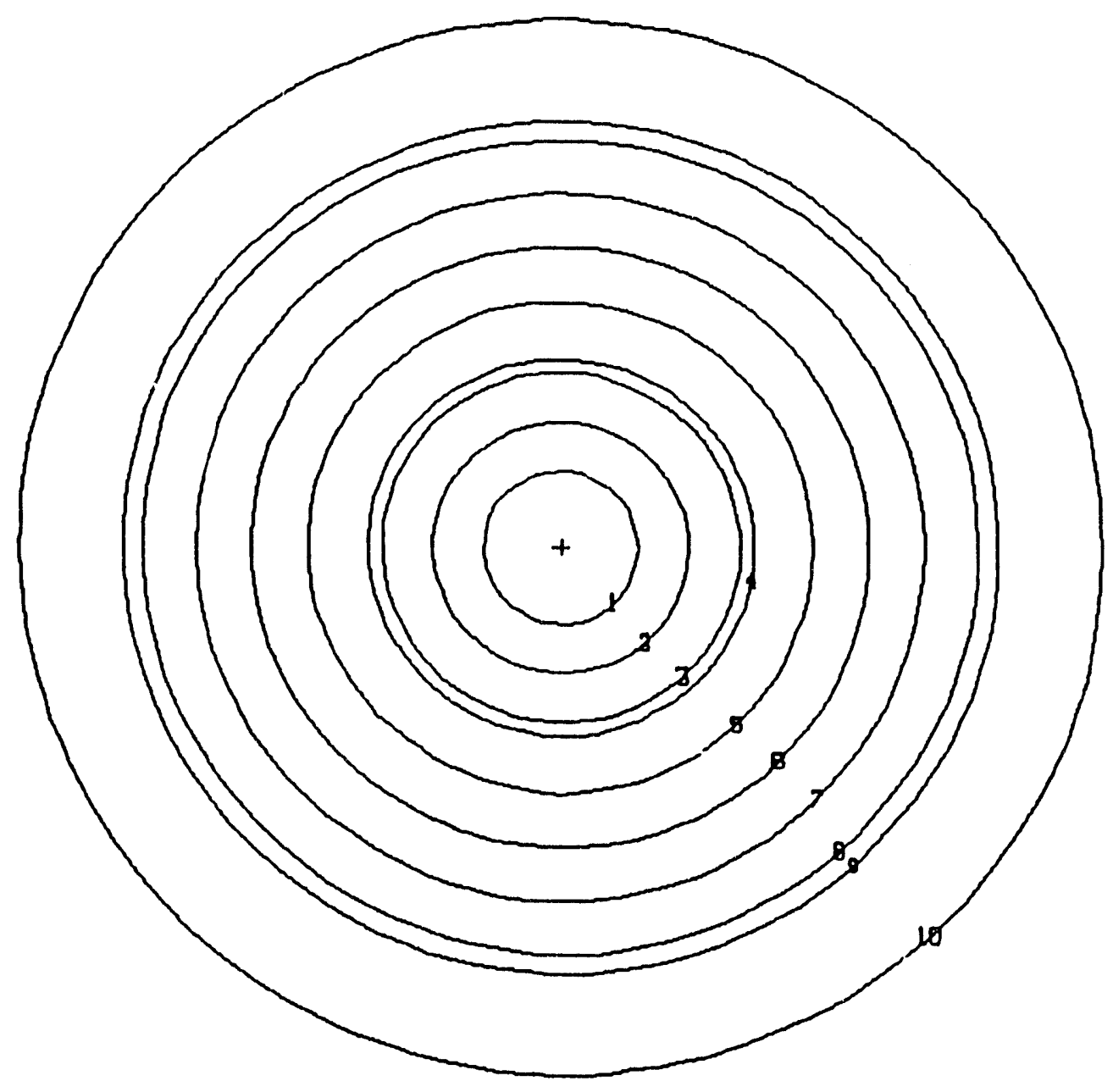

REGIONS

1. Inner $B$ lanket

2. Inner Fue I

3. Middle Blanket

4. Control Rod

5. Outer Fuel

6. Radial Reflector

7. Radial Reflector

8. Radial Shield

9. Surrounding Sodium

10. Core Barrel 
curtain of material. The concentration of material was determined by the amount of control rod insertion and homogenizing with the control rod channel.

Multigroup diffusion code $3 \mathrm{DB}^{21}$ was used for void calculations on all three fuel types. Triangular-Z geometry was used to match the hexagonal design of the ALMR core assemblies. Radially, each assembly, was broken down into six triangles. Axially, each assembly was broken down into twelve layers. The lowest layer was the lower shield, the next eight layers were the core region, and the top three layers were the upper shield, load pad, and plenum. This version also contains a burn module which was used to burn cores into equilibrium.

Perturbation theory code $3 \mathrm{DP}^{24}$ was used to calculate the beta effective for the nitride core. For simplicity, this beta was used for all reactivity calculations.

\section{E. New Computer Codes}

Two programs were written to support this study. RATIO is a program written to calculate the capture-to-fission ratio. This program uses any cross section file and calculates the capture-to-fission ratios of selected isotopes by neutron energy group. A listing of RATIO is provided in Appendix A.

The second program was titled RATE and was designed to take a modified 3DB input deck, the cross section file, and the output neutron flux from the 3DB calculation and calculate macroscopic reaction rates for selected isotopes. Fluxes are averaged over each zone of the model and the fission, absorption, scatter, and fission reaction rates printed out by neutron energy groups. A listing of this program is provided in Appendix B. 


\section{RESULTS}

\section{A. 2DB Results}

A nitride fuel was examined as a possible compromise solution to the sodium void problem of metal fuel and the low breeding ratio of oxide fuel. It has a thermal conductivity and density comparable to metal, a higher linear power capability, and releases very little fission gas. Table 3 lists the results of the scoping studies using $2 D B$ in $R-Z$ geometry. Both helium bonded and sodium bonded fuel and blanket pins were examined. The delayed neutron fraction, beta, was assumed to be the same for all three fuel types. Of interest is that the SVRE is approximately three dollars less than that for metal. Also, sodium bonded fuel has a slightly lower SVRE than helium bonded. The sodium bond also improves the thermal performance of the pin. The models for these cores were developed from data supplied by GE and used two different types of assemblies; one fresh fuel assembly and an estimated equilibrium blanket assembly. Number densities for the nitride cores were developed by substituting nitrogen for zirconium and correcting for density and isotopic fractions. Based on these results, it was decided to study nitride fuel further using sodium bonded pins. To be consistent with GE, all further studies were done in three dimensions, using 3DB, in triangular-z geometry.

\section{B. 3DB Results}

The three dimensional model used for this part of the study consisted of the original reference core configuration using nitride fuel with the pin internal parameters modified, as shown in Figure 6 , to take advantage of nitride fuel's swelling characteristics ${ }^{25}$. This nitride reference core used fresh fuel and an estimated equilibrium blanket assembly 
TABLE 3. 2-D Analysis Sodium Void Reactivity Worths for the Reference Cores

Fuel Type

Metal

He Bonded Nitride

$\mathrm{Na}$ bonded Nitride
Full Core Sodium Void Worth (\$)

\subsection{1}

2.03

1.76

The delayed neutron fraction used for all fuel types was 0.00374 . 
0208 Pellet 0.0

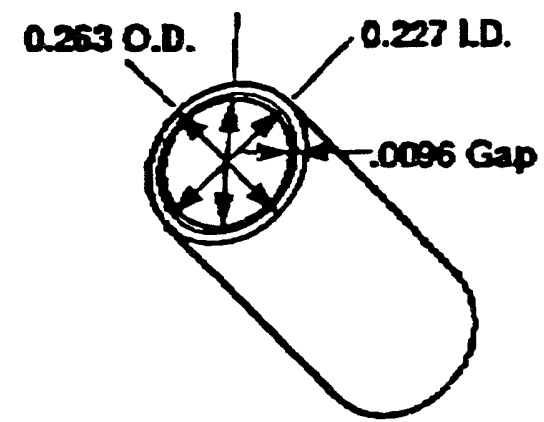

Oxide and Nitride Fuel Pin

0.193 Pellat OD.

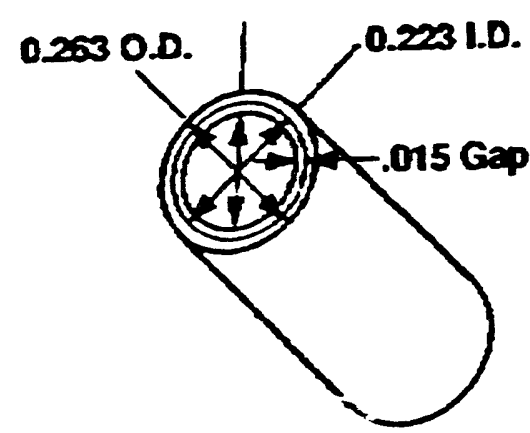

Metal Fuel Pin o.tas Pellet OD.

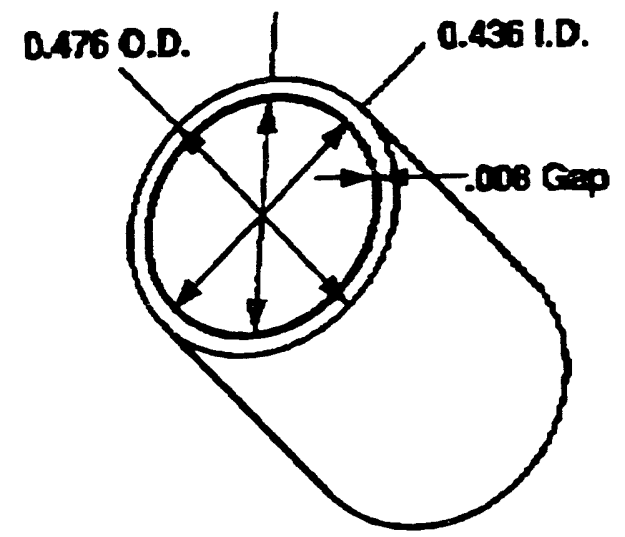

Oxide and Nitride Blanket Pin

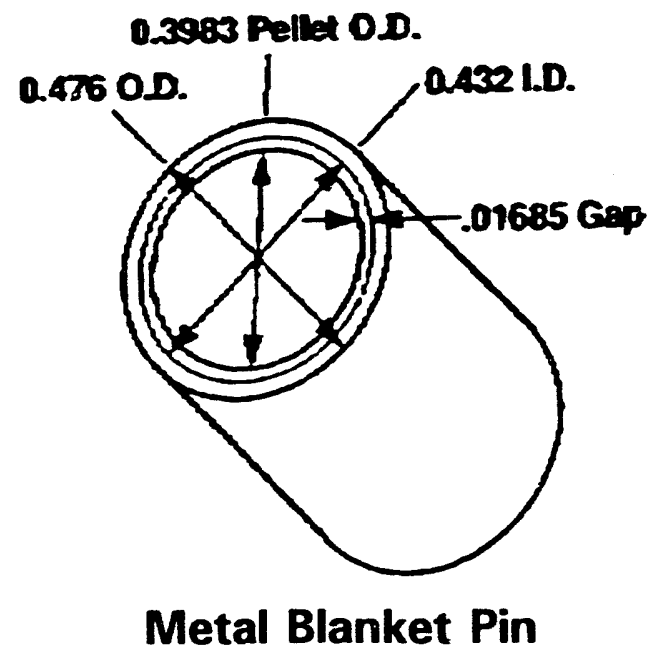

FIGURE 6: Fuel and Blanket Pin Dimensions. 
similar to the previous 20 work. A logical progression of changing an individual parameter and then performing a calculation to determine the effect on the void reactivity worth was used. The equilibrium nitride and oxide cores were developed from data supplied by GE and modified using the ORIGEN computer code ${ }^{26}$. Oxide fuel and blanket pins had the same dimensions as the nitride pins but contained no sodium bond. The results are listed in Table 4. New cross section sets for both sodium-flooded and sodium-voided cores were prepared for each calculation. Starting with the nitride core as a reference, a metal core was developed by substituting one zirconium atom for each nitrogen atom and calculating the sodium void reactivity worth. Two calculations were performed to determine the effect of changing the fuel and blanket densities to the densities used for the reference metal core. The third calculation was performed with both the fuel and blanket densities corrected. Fuel composition was then corrected to the $(\mathrm{Pu}, \mathrm{U}) \mathrm{Zr}$ alloy used in the reference metal core. The next step was to correct the fuel and blanket pin dimensions to the reference core dimensions. Next, the fuel enrichment was reduced to get the $k_{\text {eff }}$ for the flooded core as close as possible to unity. The final calculation was performed on an equilibrium reference metal core. A similar procedure was used for the oxide core. While some of these cores are unrealistic, it is instructive to note how various parameters effect SVRE. Changing the type of fuel has the largest effect followed by changing fuel enrichment and fuel/blanket pin density. Similar to the 20 analyses, the equilibrium nitride core has an SVRE approximately three dollars less than that of the equilibrium metal core. The equilibrium oxide core's void worth is more negative than that for the nitride. These cores are all similar in that they are plutonium driven. The major difference is in the fuel composition. Further study requires breaking down the SVRE effect into three components: leakage, capture, and spectral. 
TABLE 4. 3-D Analysis Sodium Void Reactivity Worth Comparison

Fue1

Nitride

Reference Core

Equilibrium Core

Metal

One Zirconium Substituted for One Nitrogen

$0.0138 \quad 3.67$

Blanket Density Increased to Metal Density

0.0136

0.0130

0.0127

Fuel and Blanket Density Increased to Metal Density

0.0124

0.0122

Clad Thickness, Gap Thickness, and Pellet Diameter Corrected to Metal Reference Core Dimensions

Enrichment reduced by $4 \%$

0.0134

0.0178

Metal Equilibrium Core

oxide

One Oxygen Substituted for each Nitrogen

0.0083

2.22

Two Oxygens substituted for each Nitrogen

0.0041

0.0050

0.0025

0.0022

0.0030

0.0047

Equilibrium Oxide Core

3.64

3.40

3.32

3.26

3.58

4.76

Blanket Density Decreased to Oxide Density

Fuel Density Decreased to Oxide Density

Fuel and Blanket Density Decreased to Oxide Density

Enrichment Increased by $2 \%$

Note: The delayed neutron fraction was set equal to 0.00374 for all cores. 


\section{3DB Neutron Balance Results}

By examining the data from the neutron balance tables in the 3DB output, one can gain further insight into the leakage and capture components of the sodium void. Table 5 contains a listing of these data for all three cores. The change in leakage between the sodium-flooded and-voided cores is similar for the three fuel types. Since the cores are the same size, this is to be expected. This also indicates that the change in leakage due to voiding the sodium is not a major contributor to the difference seen in the SVRE. However, the change in capture as sodium voids leads to a different conclusion. The magnitude of the change in capture for the metal core is approximately twice that of both the oxide and metal cores. Again, since these cores are very similar, the expectation would be that the change in capture shoulci also be similar to the nitride and oxide cores. These data show that the change in capture is a major contributor to the sodium void worth and this change is due to spectral hardening as the sodium voids.

The last data included in the balance table is the fission source. As seen with leakage, only minor differences are seen between the three cores.

A value for the SVRE may also be calculated from these data. As shown in Table 6 , these values are similar to the values calculated using the $K_{\text {eff }}$ difference method. 
TABLE 5. Neutron Balance by Process Component

\section{Neutron Change Due to Voiding Sodium}

\begin{tabular}{|c|c|c|c|c|c|c|c|c|c|c|c|c|}
\hline Process & & Oxide & & Nit & ide $(U, P$ & & & Metal & & & ride (UI & \\
\hline Component & $\mathrm{Pu}$ & $\mathbf{U}$ & 0 & $\mathrm{Pu}$ & U & $N$ & $\mathrm{Pu}$ & U & $\mathrm{Zr}$ & $\mathrm{Pu}$ & U & N \\
\hline Fission & -9.47 & 2.26 & 0 & -6.50 & 2.68 & 0 & -8.28 & 2.31 & 0 & 0 & -7.73 & 0 \\
\hline $\begin{array}{l}\text { Source, } \\
\text { Fuel }\end{array}$ & & & & & & & & & & & & \\
\hline $\begin{array}{l}\text { Fission } \\
\text { Source, } \\
\text { Blanket }\end{array}$ & 8,70 & 8.98 & 0 & -3.45 & 8.32 & 0 & -2.32 & 9.74 & 0 & 0.06 & 10.72 & $\begin{array}{l}0 \\
\omega\end{array}$ \\
\hline $\begin{array}{l}\text { Capture } \\
\text { Fuel }\end{array}$ & -10.79 & -7.05 & 0.09 & -9.18 & -7.83 & 1.02 & -11.16 & -13.38 & -0.42 & 0 & -9.11 & 0.13 \\
\hline $\begin{array}{l}\text { Capture } \\
\text { Blanket }\end{array}$ & -1.20 & -11.41 & 0.16 & -2.16 & -19.20 & 2.02 & -2.40 & -32.57 & -0.72 & -1.65 & -12.74 & 0.25 \\
\hline $\begin{array}{l}\text { Total HM } \\
\text { Matrix } \\
\text { Capture }\end{array}$ & & -30.20 & & & -35.33 & & & -60.65 & & & -23.12 & \\
\hline
\end{tabular}

* Per 1,000 Neutrons Generated for the Sodium-Flooded Case 
TABLE 6. Sodium Void Neutron Balance Change

\begin{tabular}{|c|c|c|c|c|c|c|}
\hline & \multicolumn{2}{|c|}{ Oxide } & \multicolumn{2}{|c|}{ Nitride } & \multicolumn{2}{|c|}{ Metal } \\
\hline & Flooded & Voided & Flooded & Voided & Flooded & Voided \\
\hline Leakage $\left(\mathrm{n} / \mathrm{cm}^{2}-\mathrm{sec}\right)$ & $5.594 E+17$ & $1.258 E+18$ & $4.935 \mathrm{E}+17$ & $1.023 E+18$ & $6.579 E+17$ & $1.383 E+18$ \\
\hline Capture $\left(\mathrm{n} / \mathrm{cm}^{2}-\mathrm{sec}\right)$ & $2.556 E+19$ & $2.476 E+19$ & $2.613 E+19$ & $2.536 E+19$ & $2.577 E+19$ & $2.439 E+19$ \\
\hline Fission Source $\left(\mathrm{n} / \mathrm{cm}^{2}-\mathrm{sec}\right)$ & $4.057 E+19$ & $4.062 E+19$ & $4.052 E+19$ & $4.057 E+19$ & $4.047 E+19$ & $4.051 E+19$ \\
\hline Delta Leakage $\left(\mathrm{n} / \mathrm{cm}^{2}-\mathrm{sec}\right)$ & \multicolumn{2}{|c|}{$6.626 E+17$} & \multicolumn{2}{|c|}{$5.295 E+17$} & \multicolumn{2}{|c|}{$7.251 E+17$} \\
\hline Delta Capture $\left(\mathrm{n} / \mathrm{cm}^{2}-\mathrm{sec}\right)$ & \multicolumn{2}{|c|}{$-8.000 E+17$} & \multicolumn{2}{|c|}{$-7.700 E+17$} & \multicolumn{2}{|c|}{$-1.380 E+18$} \\
\hline Delta Fission $\left(\mathrm{n} / \mathrm{cm}^{2}-\mathrm{sec}\right)$ & \multicolumn{2}{|c|}{$4.839 E+16$} & \multicolumn{2}{|c|}{$4.474 E+16$} & \multicolumn{2}{|c|}{$4.066 E+16$} \\
\hline $\operatorname{Net}\left(\mathrm{n} / \mathrm{cm}^{2}-\mathrm{sec}\right)$ & \multicolumn{2}{|c|}{$1.857 E+17$} & \multicolumn{2}{|c|}{$2.852 E+17$} & \multicolumn{2}{|c|}{$6.955 E+17$} \\
\hline$\Delta k$ Net & \multicolumn{2}{|c|}{ 4.579E-03 } & \multicolumn{2}{|c|}{$7.038 E-03$} & \multicolumn{2}{|c|}{$1.719 \mathrm{E}-02$} \\
\hline Rho (\$) & \multicolumn{2}{|c|}{1.224} & \multicolumn{2}{|c|}{1.882} & \multicolumn{2}{|c|}{4.595} \\
\hline
\end{tabular}




\section{Spectral Effects on the Capture-to-Fission Ratio}

The effect of a spectral shift on the capture-to-fission ratio may be illustrated by considering the value of $K_{\infty}$.

$$
K_{\text {off }}=\frac{v \Sigma_{f}}{\Sigma_{a}} \times P_{n l}
$$

where:

$$
v=\text { number of neutrons per fission }
$$

$\Sigma_{f}=$ macroscopic fission cross section

$\Sigma_{a}=$ macroscopic absorption cross section

$P_{n i}=$ non-leakage probability.

Recall that $\Sigma_{a}=\Sigma_{f}+\Sigma_{c}$. As sodium is voided, if $\Sigma_{c}$ decreases faster than $\Sigma_{f}, \Sigma_{a}$ decreases faster than $\Sigma_{f}$, then $K_{\text {eff }}$ increases. Conversely, if $\Sigma_{f}$ decreases faster than $\Sigma_{c}, K_{\text {eff }}$ decreases. Figures 7 to 9 show the capture-to-fission ratio of ${ }^{239} \mathrm{Pu}$ in the fuel assemblies for each fuel type. Note that the capture-to-fission ratio decrease as the spectrum hardens. Similarly, Figures 10 to 12 show the results for the ${ }^{238} \mathrm{U}$ in the ALMR fuel. The conclusion is that, for all three fuel types, $K_{\text {eff }}$ should increase as sodium voids. Figures 13 through 18 show the same comparison between ${ }^{239} \mathrm{Pu}$ and ${ }^{238} \mathrm{U}$ for the blankets and lead to the same conclusion. 


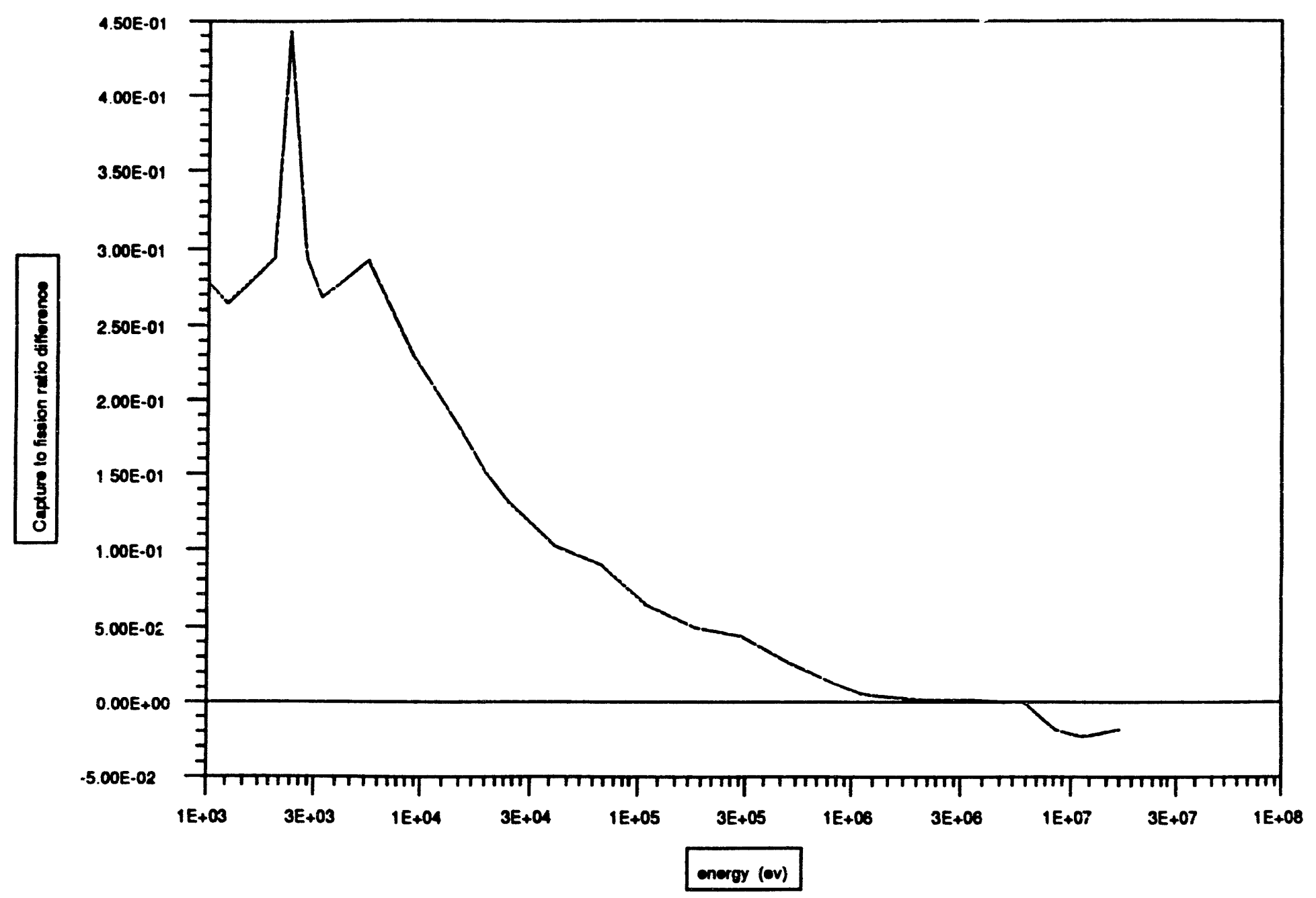

FIGURE 7: 0xide Core Inner Fuel ${ }^{239} \mathrm{Pu}$ Capture-to-Fission Ratio. 


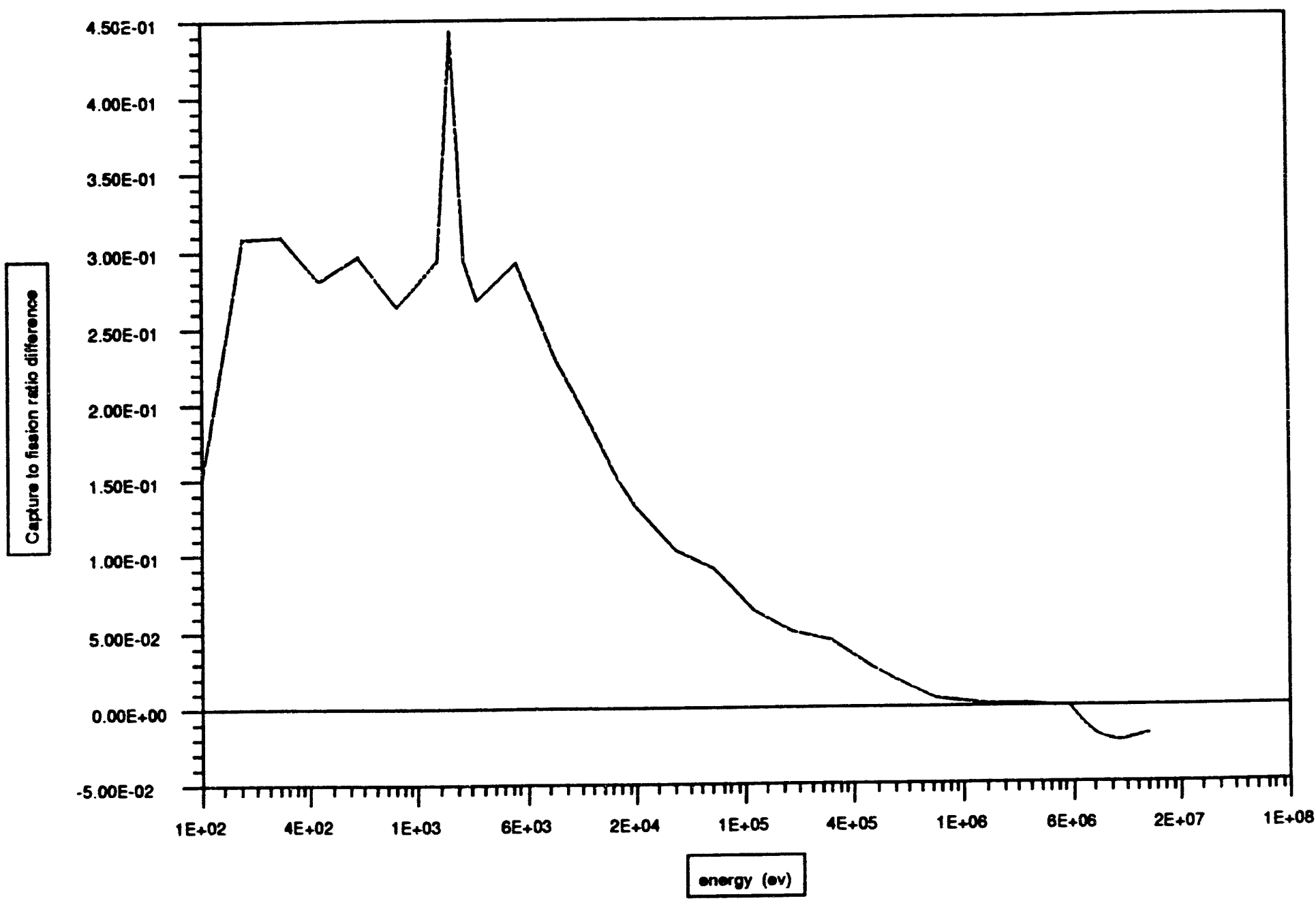

FIGURE 8: Nitride Core Inner Fuel ${ }^{239} \mathrm{Pu}$ Capture-to-Fission Ratio. 


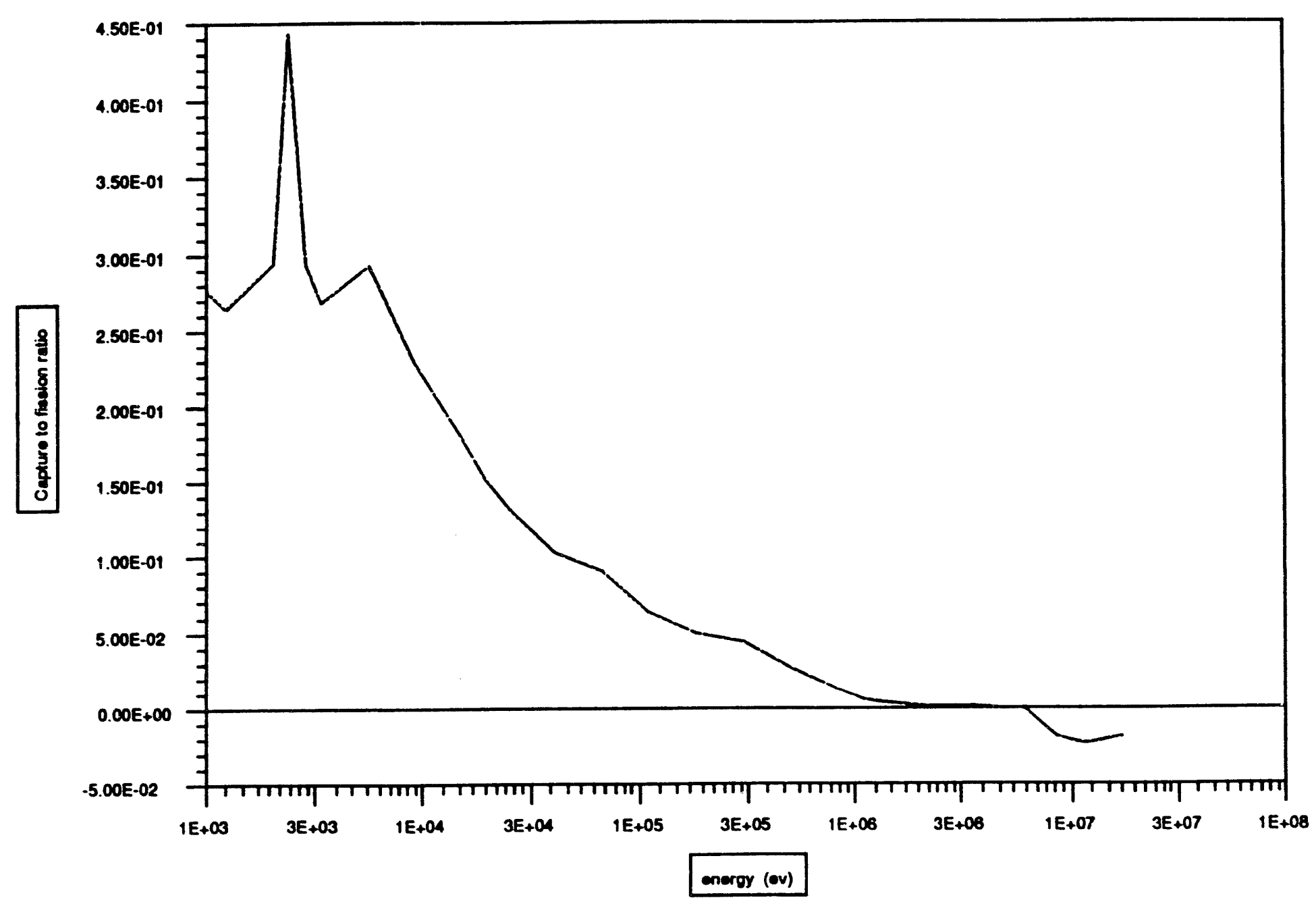

FIGURE 9: Metal Core Inner Fuel ${ }^{239} \mathrm{Pu}$ Capture-to-Fission Ratio. 


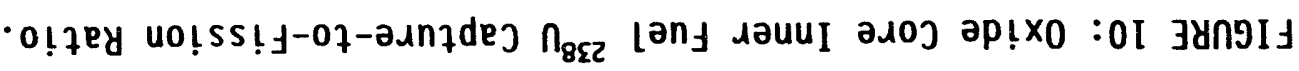

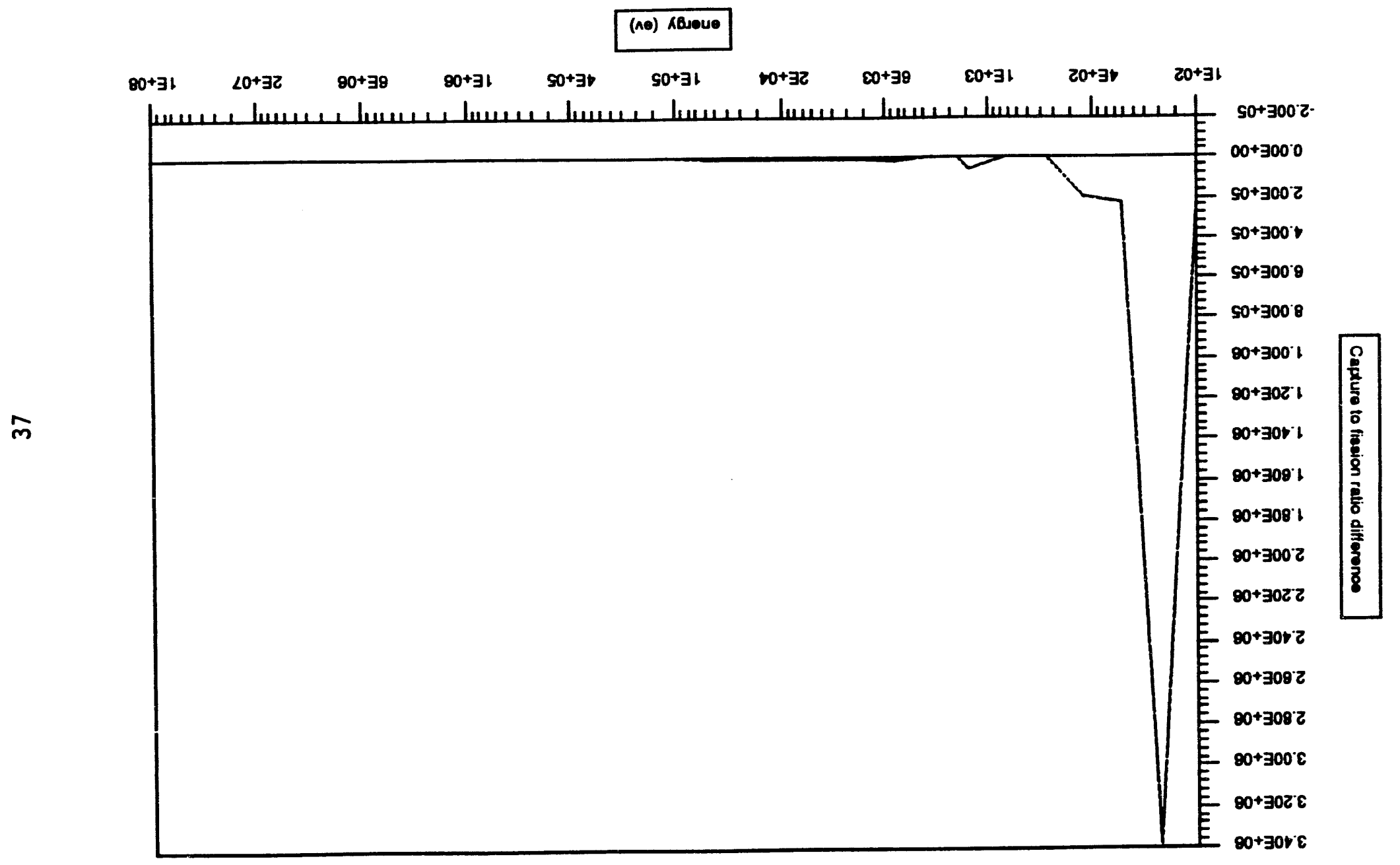




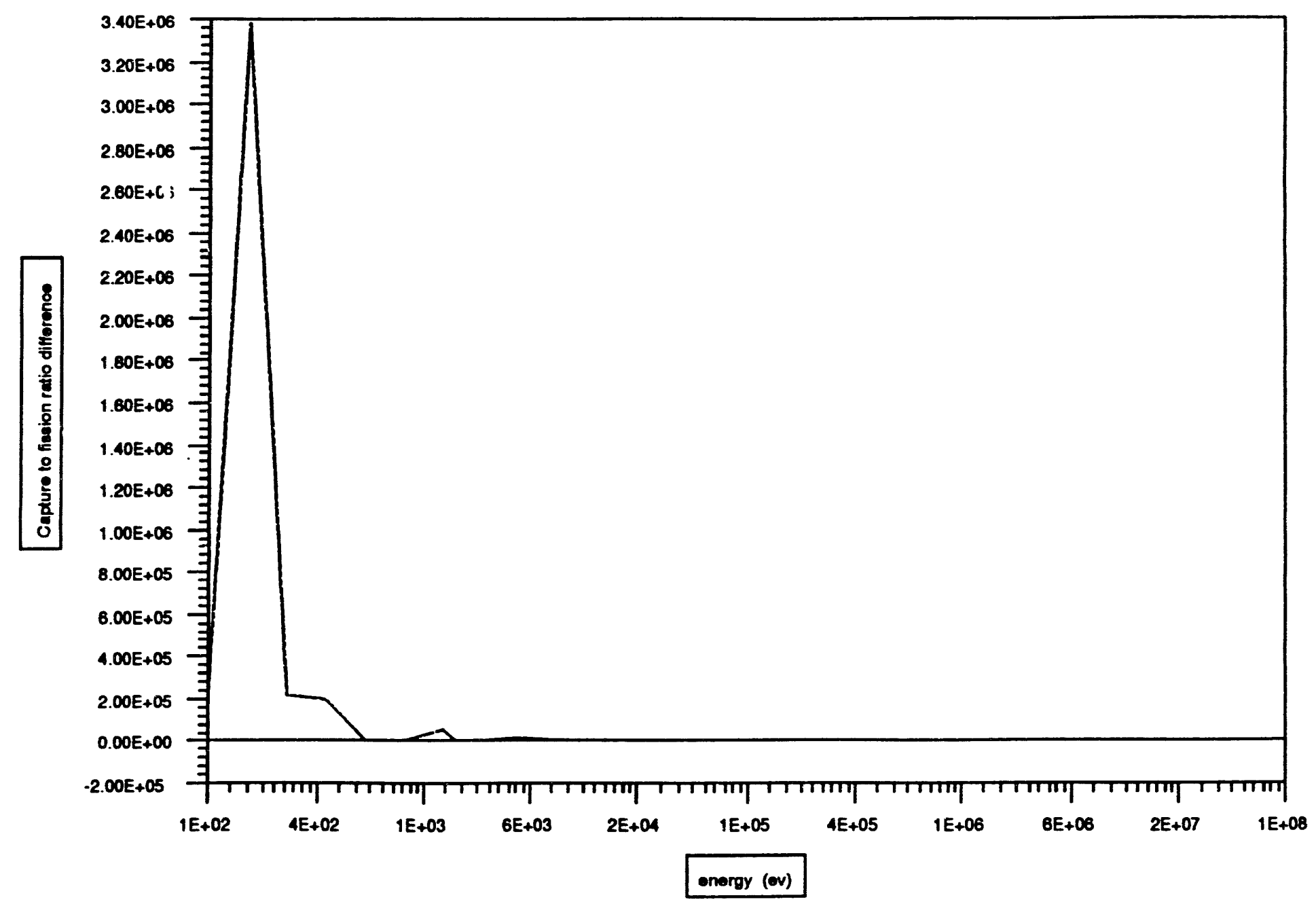

FIGURE 11: Nitride Core Inner Fuel ${ }^{238} \mathrm{U}$ Capture-to-Fission Ratio. 


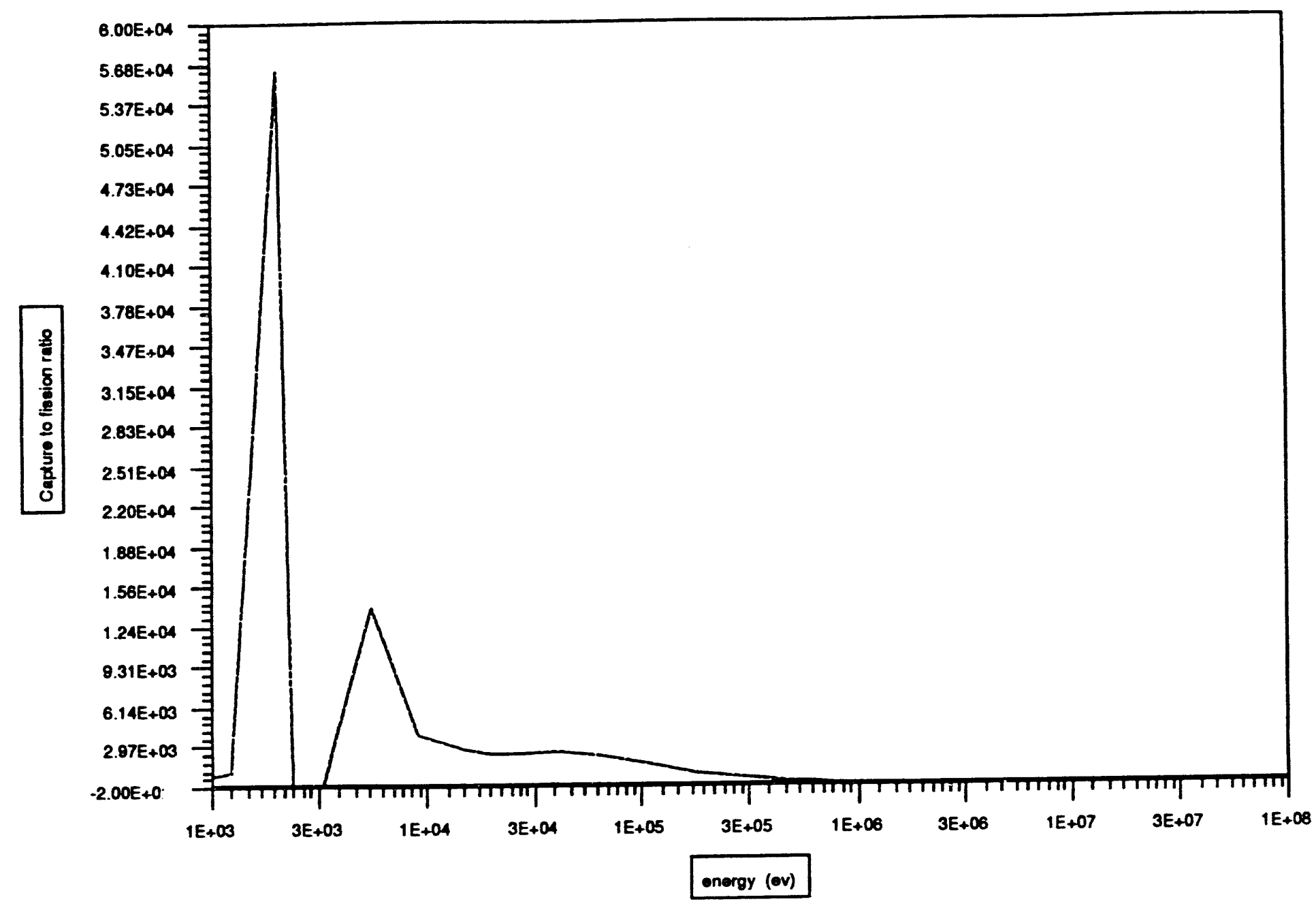

FIGURE 12: Metal Core Inner Fuel ${ }^{238} \mathrm{U}$ Capture-to-Fission Ratio. 


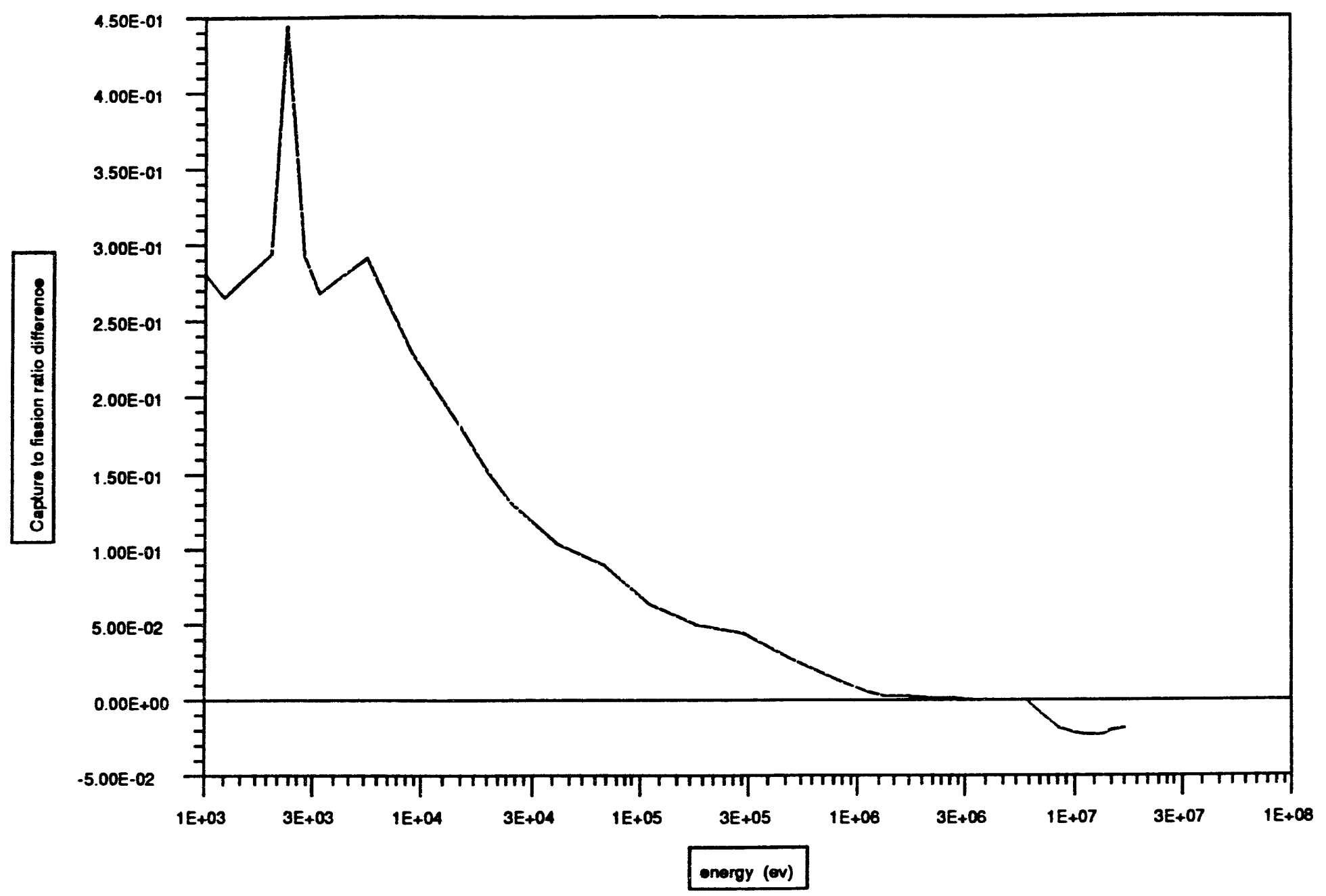

官

FIGURE 13: Oxide Core 2-Cycle Radial Blanket ${ }^{239} \mathrm{Pu}$ Capture-to-Fission Ratio. 


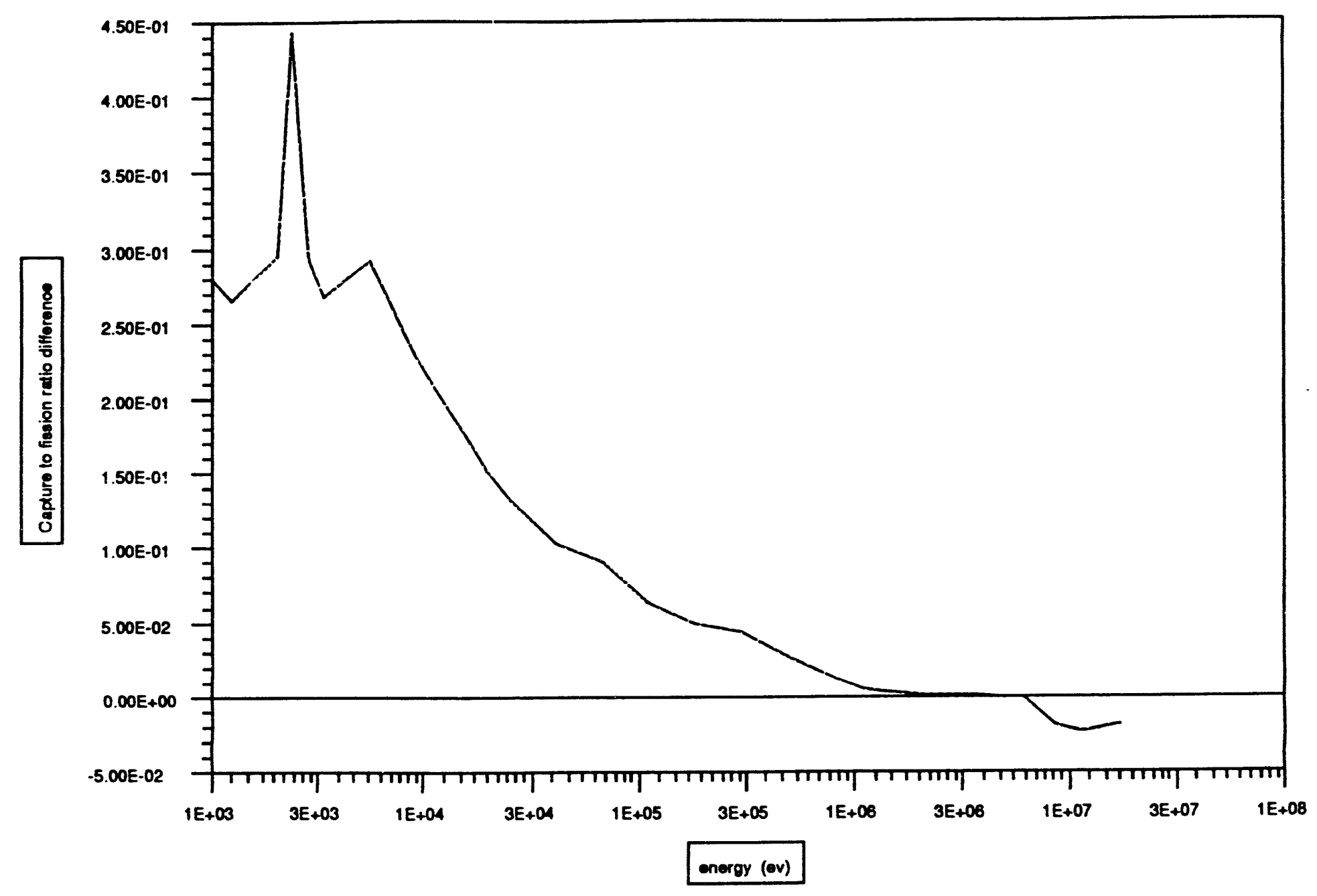

FIGURE 14: Nitride Core 2-Cycle Radial Blanket ${ }^{239} \mathrm{Pu}$ Capture-to-Fission Ratio. 


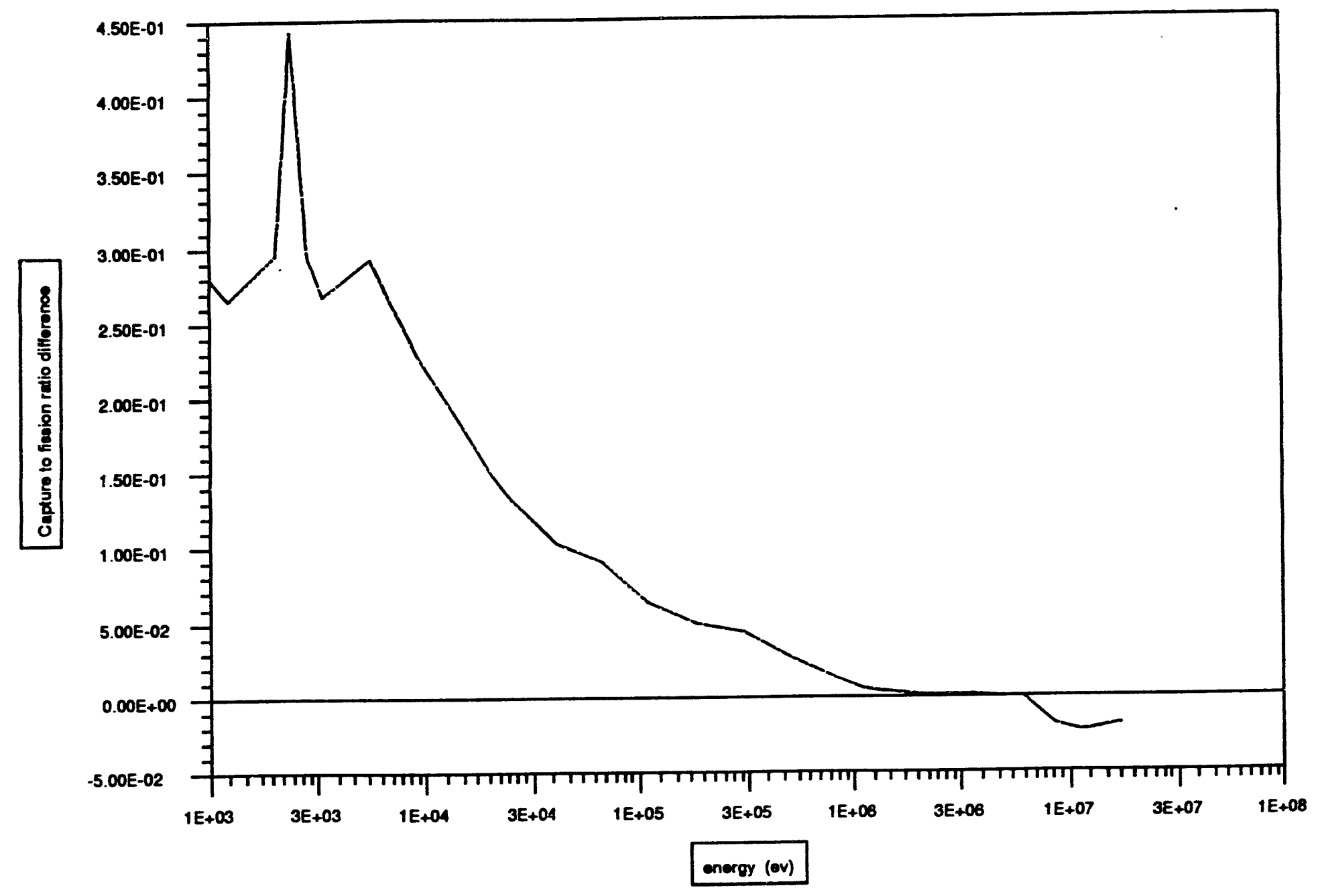

N

FIGURE 15: Metal Core 2-Cycle Radial Blanket ${ }^{239}$ Pu Capture-to-Fission Ratio. 


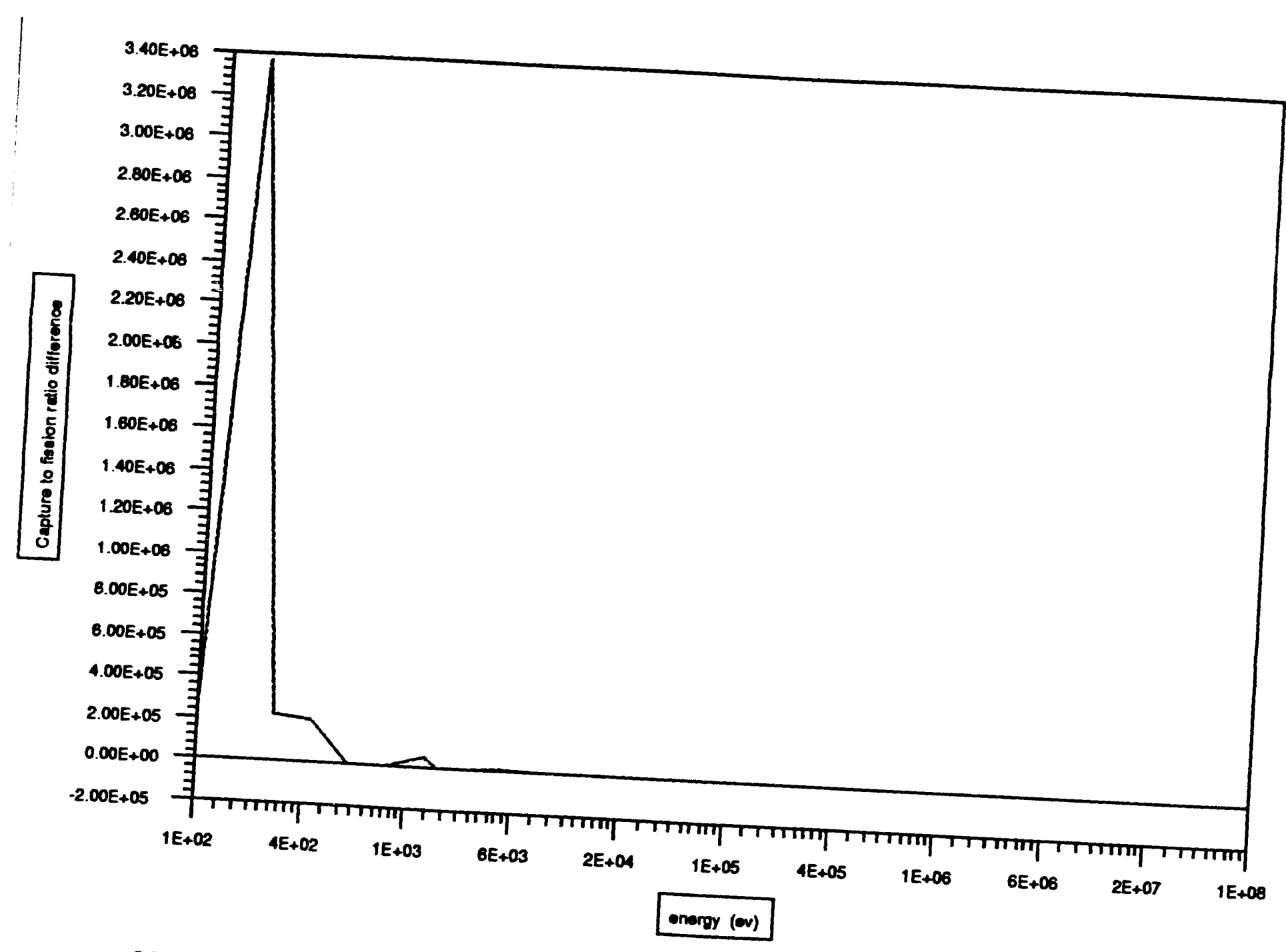

FIGURE 16: Oxide Core 2-Cycle Radial Blanket ${ }^{238} \mathrm{U}$ Capture-to-Fission Ratio. 


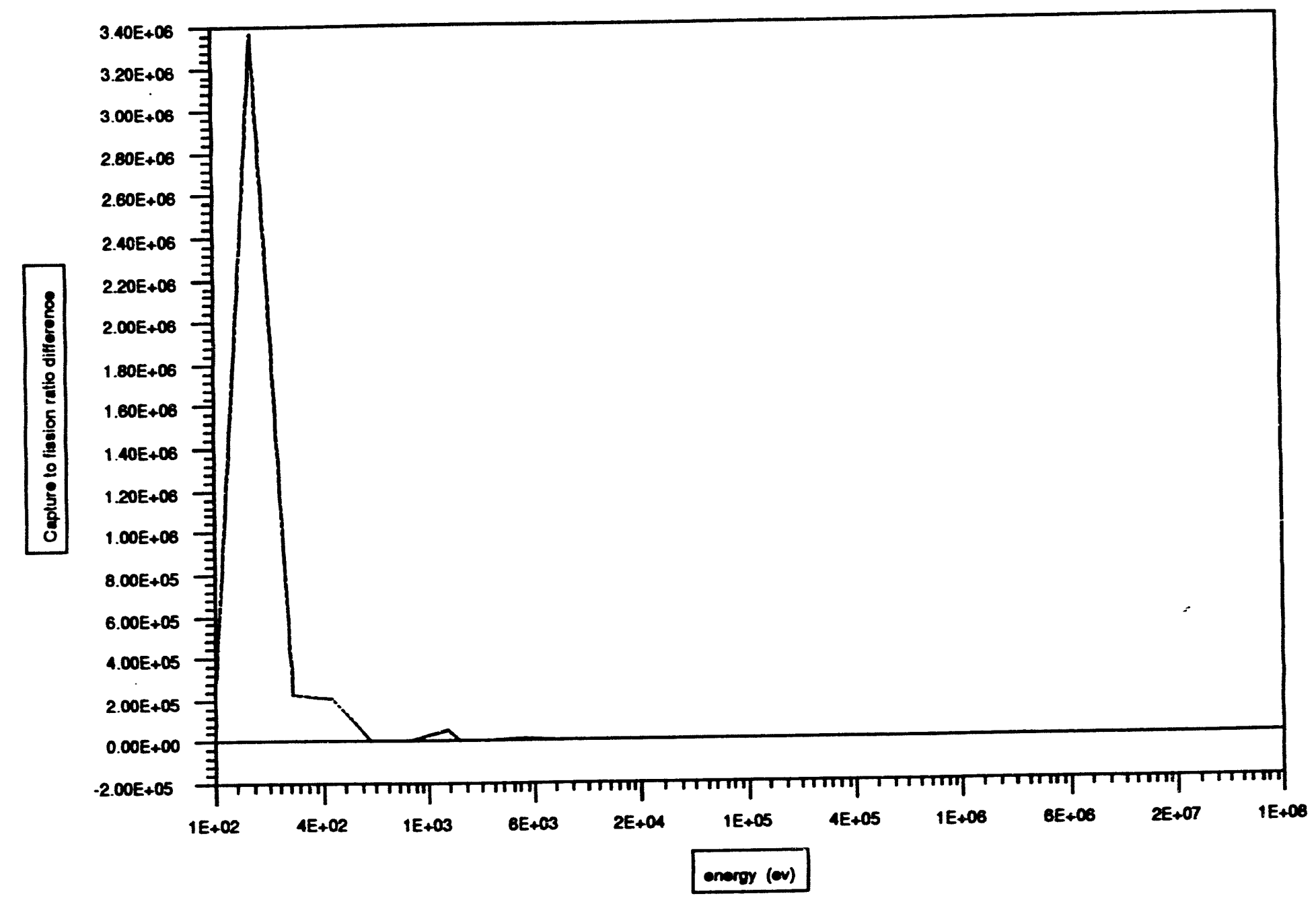

FIGURE 17: Nitride Core 2-Cycle Radial Blanket ${ }^{238} \mathrm{U}$ Capture-to-Fission Ratio. 


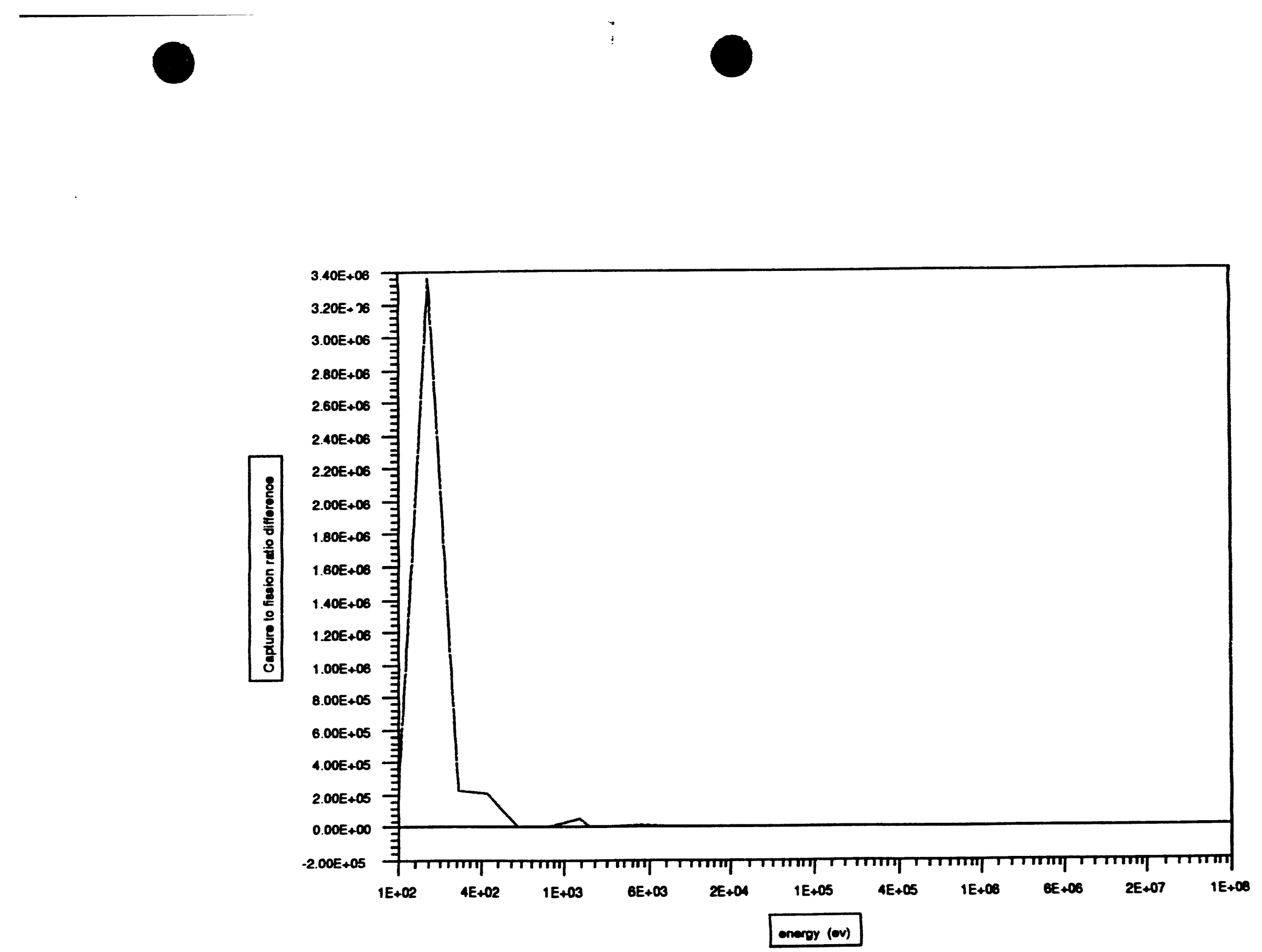

FIGURE 18: Metal Core 2-Cycle Radial Blanket ${ }^{238} \mathrm{U}$ Capture-to-Fission Ratio. 
The next step in this investigation is to compare the captureto-fission ratios of all the fissile and nonfissile heavy metal to the difference in flux between the sodium-flooded and -voided cases (i.e., the spectral shift caused by sodium voiding). Figures 19 through 24 show the capture-to-fission ratios of the fissile material for all three fuel types and the flooded-to-void flux difference. In all cases, the capture-to-fission ratios are decreasing as the flux difference peaks with the ${ }^{239} \mathrm{pu}$ decreasing most rapidly. Similarly, Figures 25 through 30 show the data for the nonfissile material. In these cases, the decrease in the ${ }^{238} \mathrm{U}$ capture-to-fission ratio overwhelms the decreases in the other isotopes. Differences in the ratio between the three fuel types are small. However, the flux difference varies between the three fuel types. While the flux difference for nitride fuel is similar to that of oxide fuel, the metal fuel has a much higher peak flux difference. Thus, $K_{\text {eff }}$ for the metal fuel increases more than either nitride or oxide giving it the most positive SVRE. Also of interest is that the ${ }^{235} \mathrm{U}$ capture-to-fission ratio decreases at the slowest rate. This explains why a ${ }^{235} \mathrm{U}$ driven core does not have the similar positive SVRE problem of a ${ }^{239} \mathrm{Pu}$ driven core ${ }^{19}$.

\section{E. Slowing Down Power}

During normal operation of fast reactors, the moderation of neutrons is not considered to be important. However, when discussing the effects of spectral hardening on the sodium void, it is imporiant to investigate the relative slowing down power (SDP) of the three fuel types. The SDP is defined as $\xi \Sigma_{s}$ where $\xi$ is approximately equal to $\frac{2}{A+\frac{2}{3}}, A$ is the atomic number, and $\Sigma_{3}$ is the macroscopic scattering cross section. 


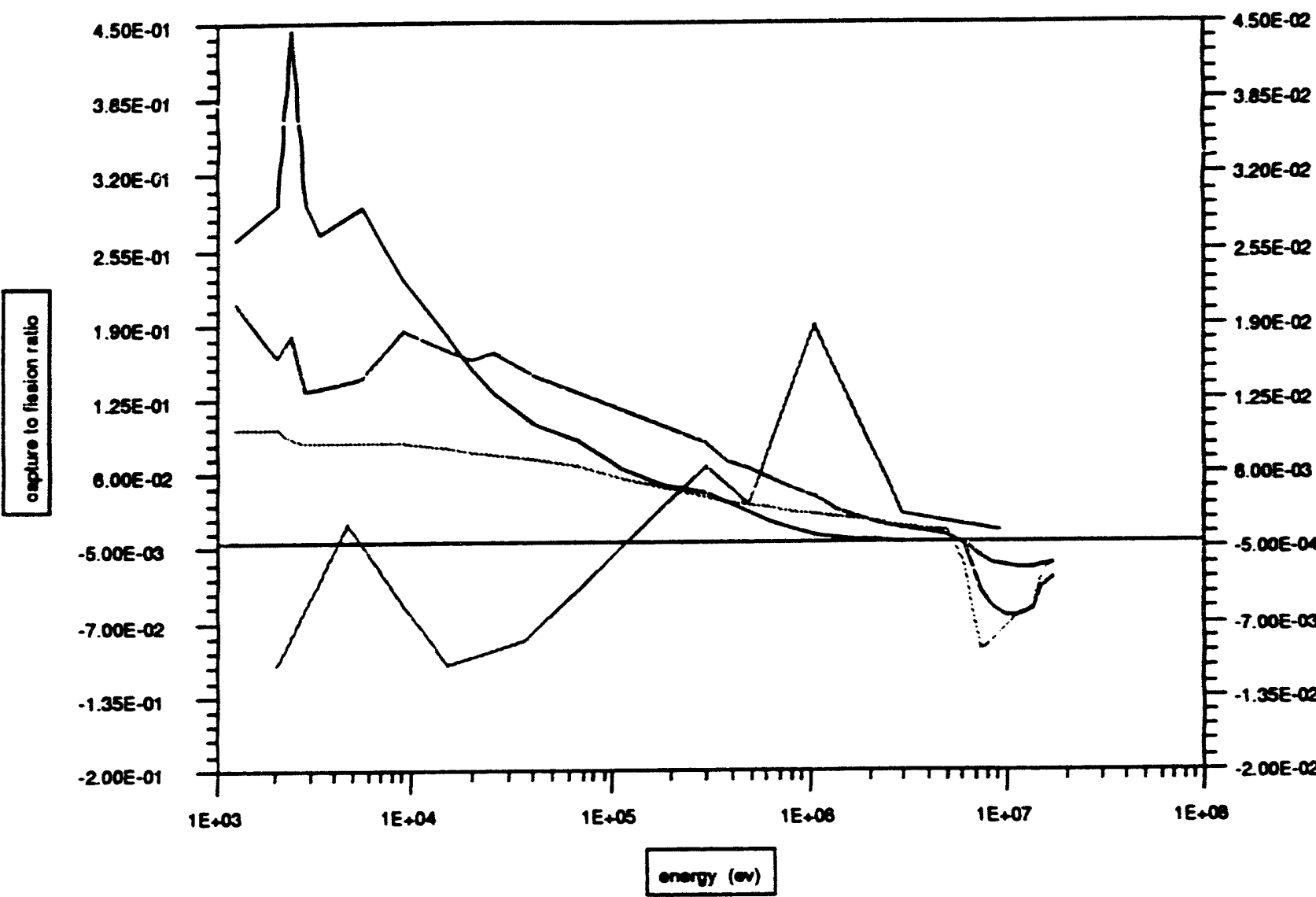

FIGURE 19: Oxide Core Inner Fuel Fissile Material Capture-to-Fission Ratio. 


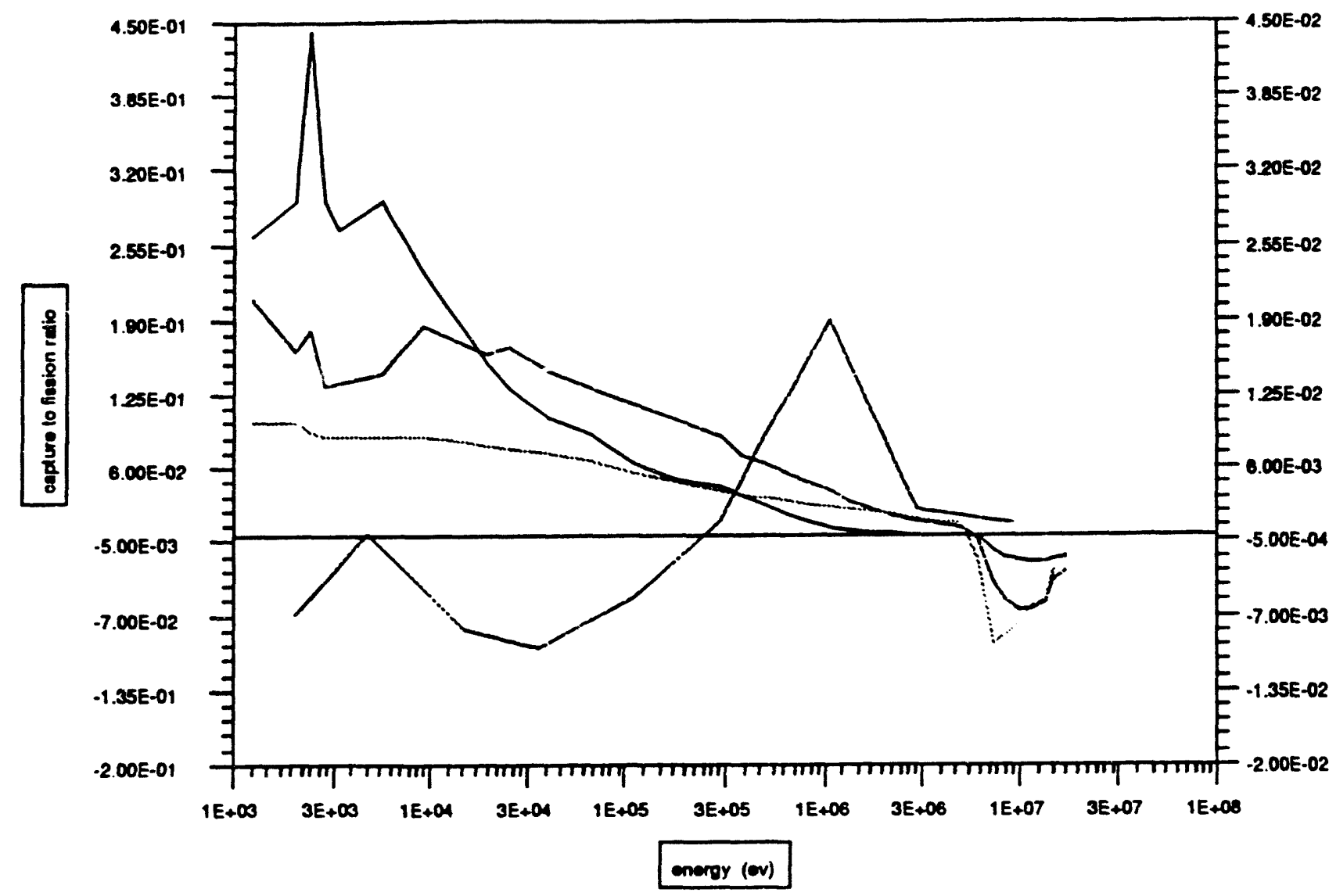

FIGURE 20: Nitride Core Inner Fuel Fissile Material Capture-to-Fission Ratio. 


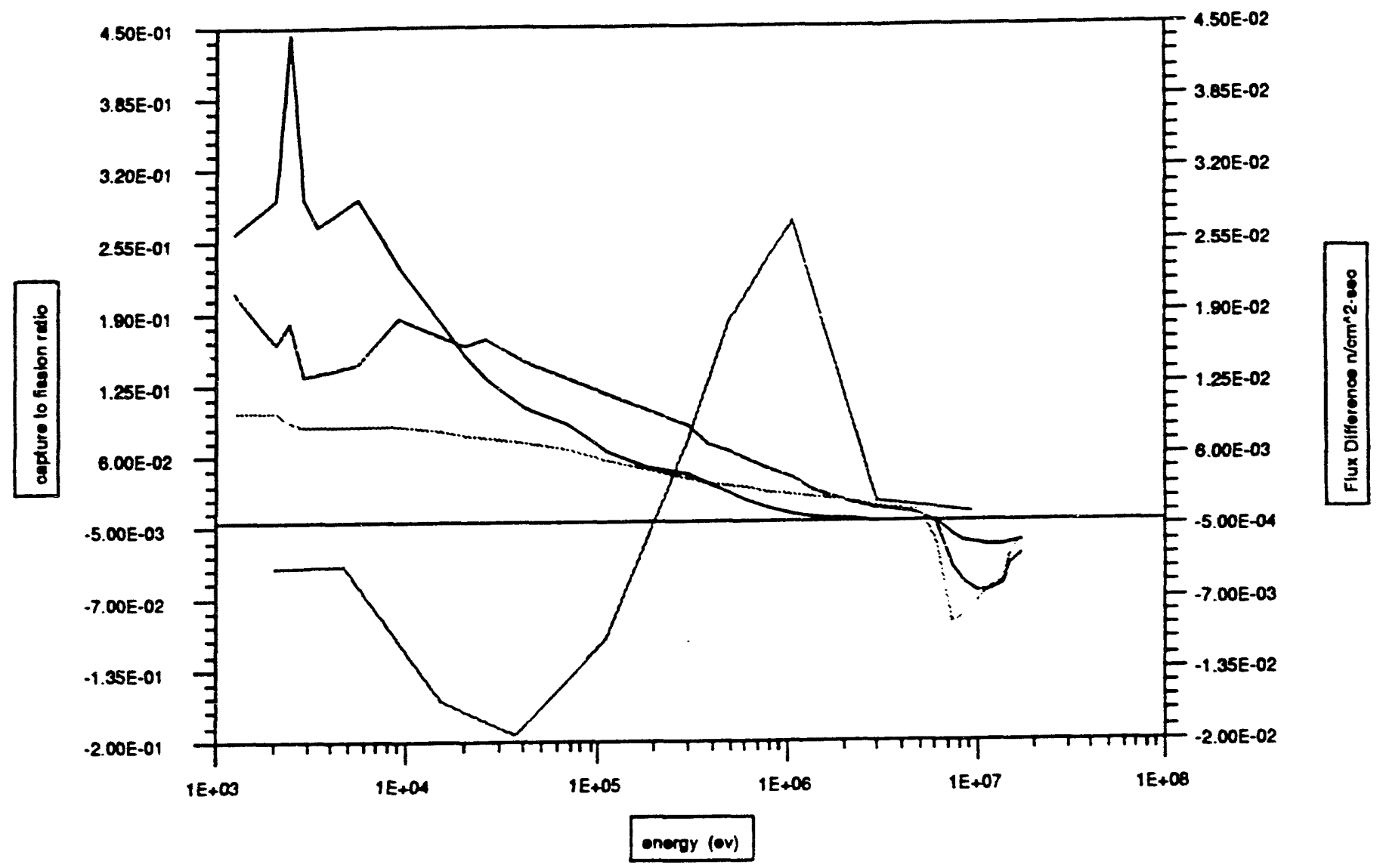

FIGURE 21: Metal Core Inner Fuel Fissile Material Capture-to-Fission Ratio. 


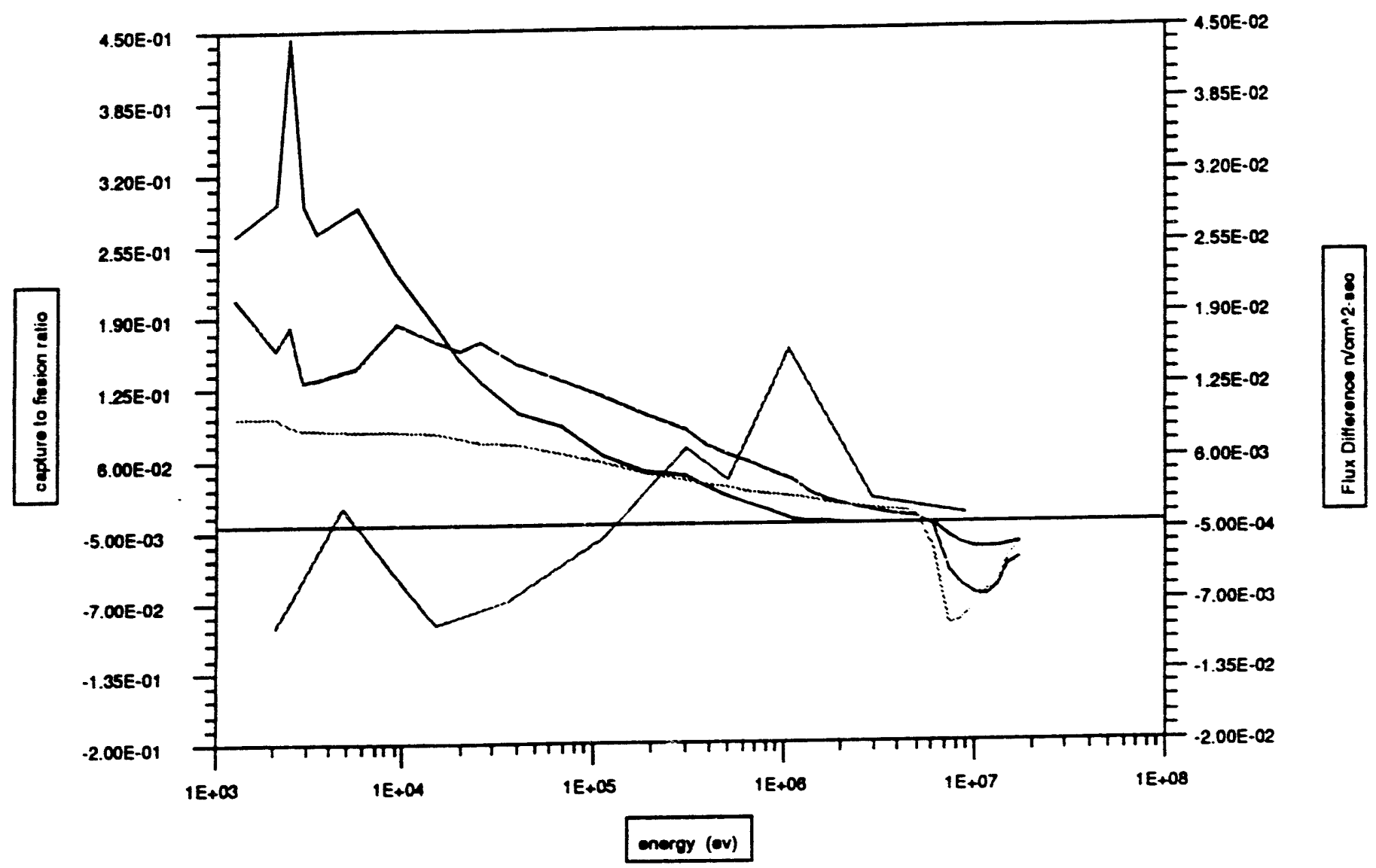

FIGURE 22: Oxide Core 2-Cycle Radial Blanket Fissile Material Capture-to-Fission Ratio. 


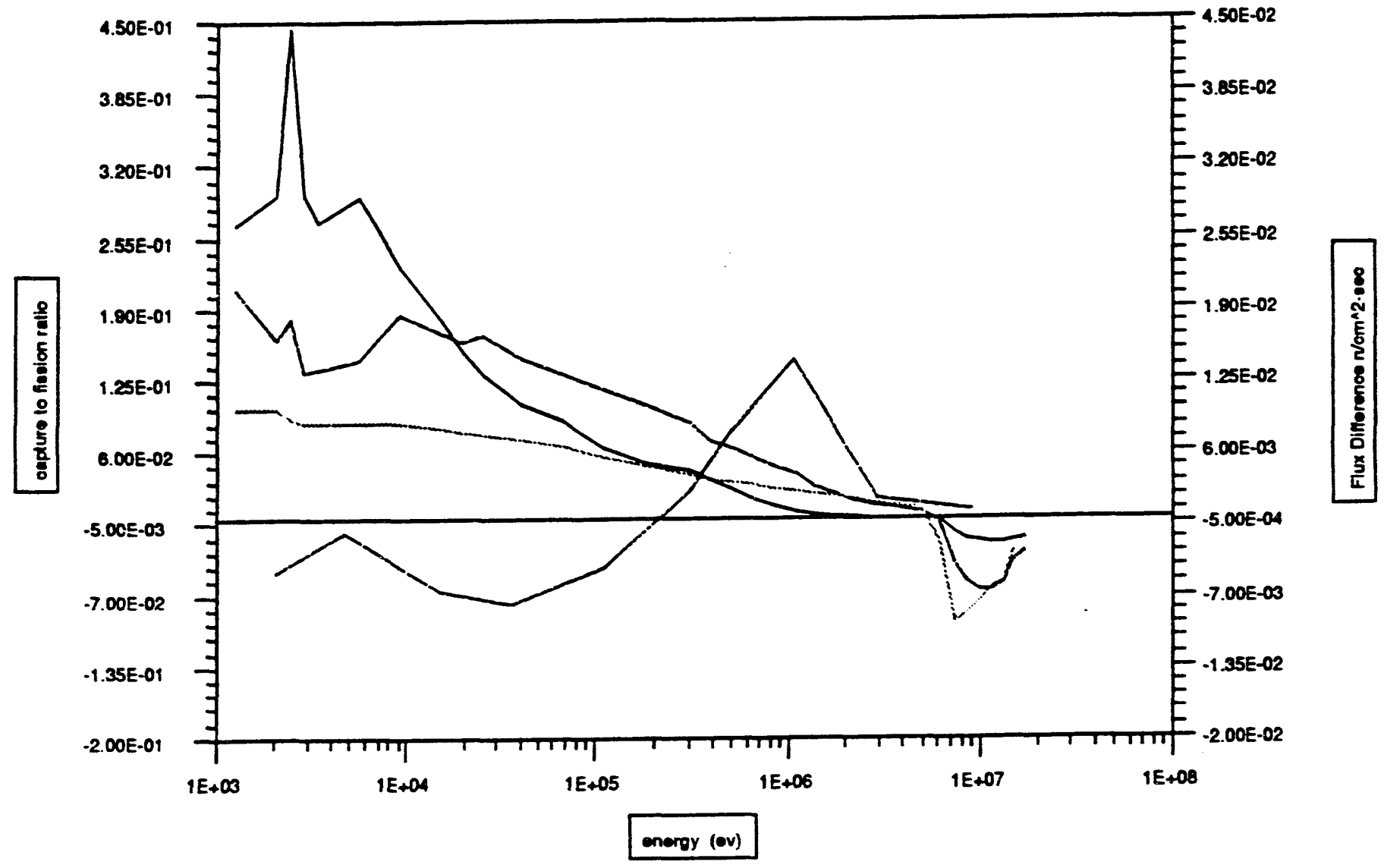




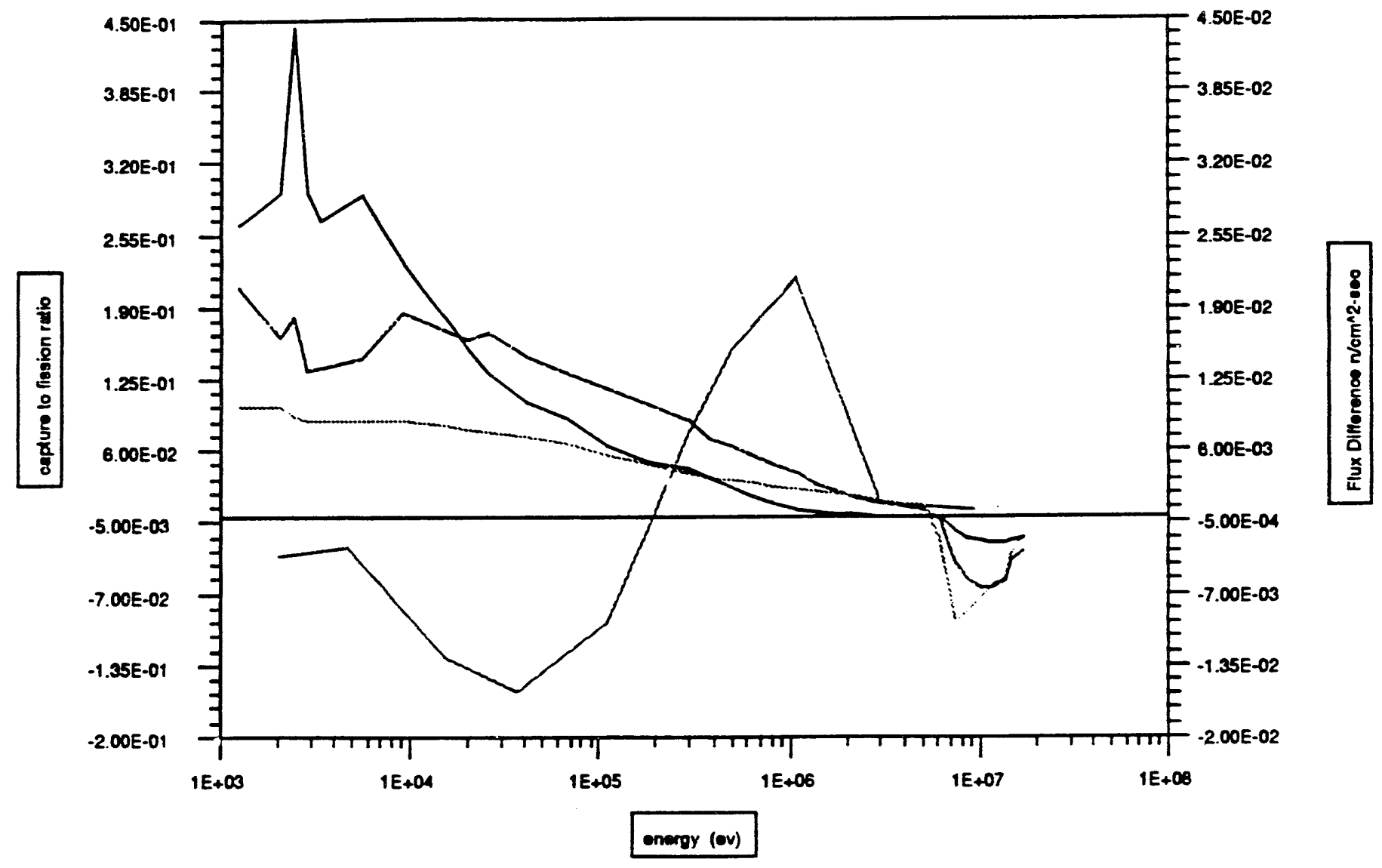

FIGURE 24: Metal Core 2-Cycle Radial Blanket Fissile Material Capture-to-Fission Ratio. 


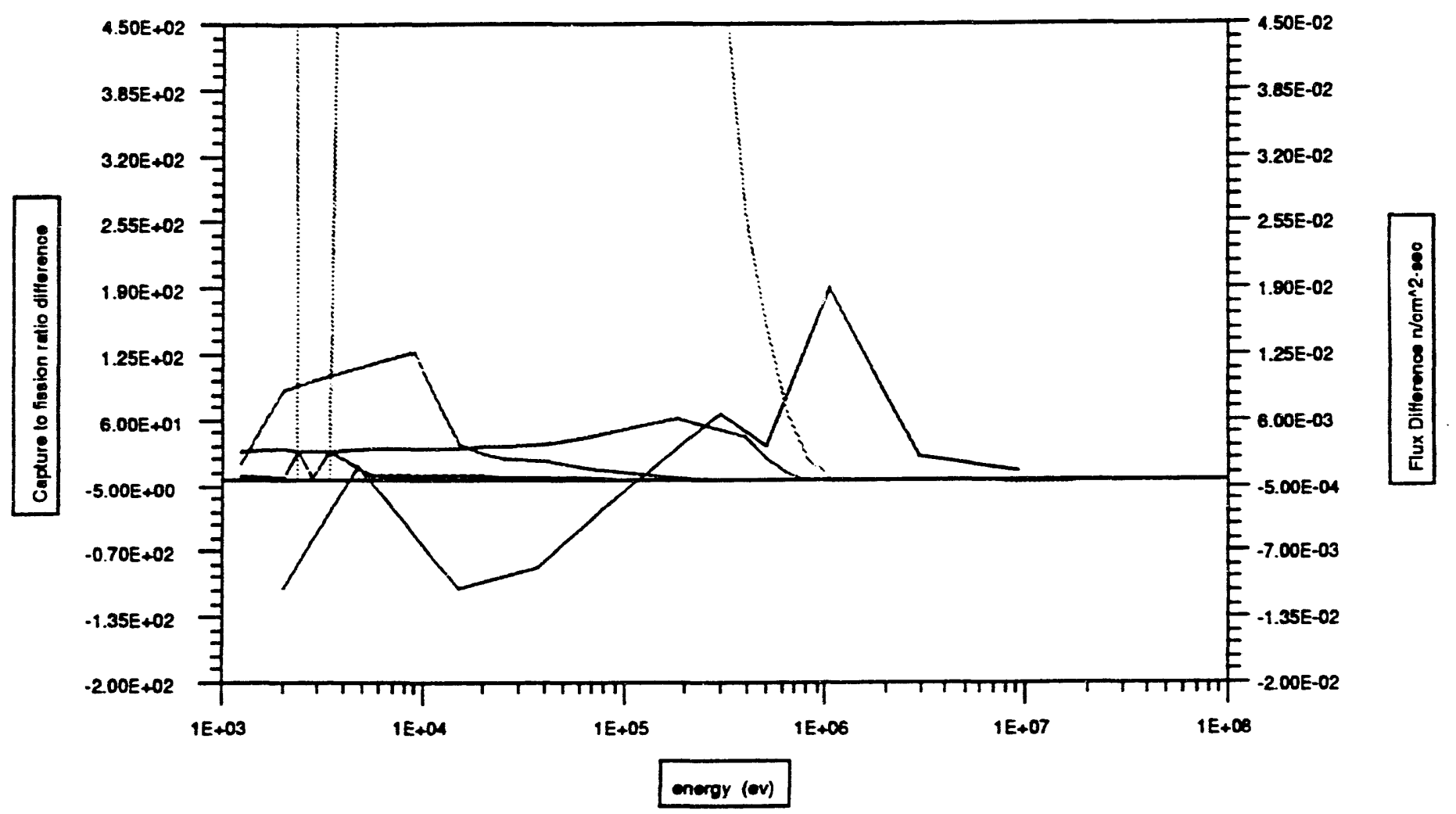




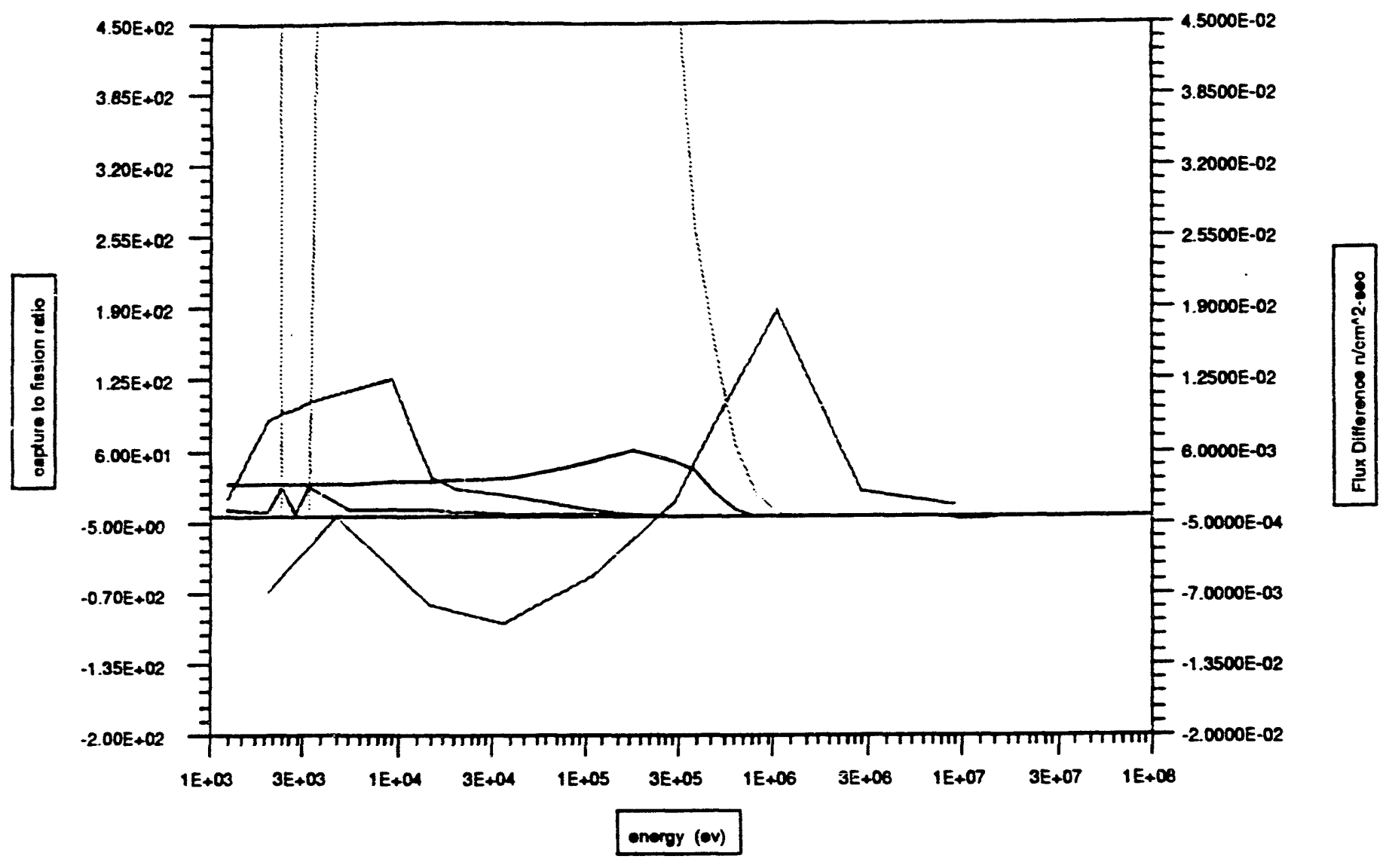

$\begin{array}{lllll}-U 238 & -P U 240 & -P U 242 & -U 236 & - \text { thux difterenoo }\end{array}$

FIGURE 26: Nitride Core Inner Fuel Nonfissile Material Capture-to-Fission Ratio. 


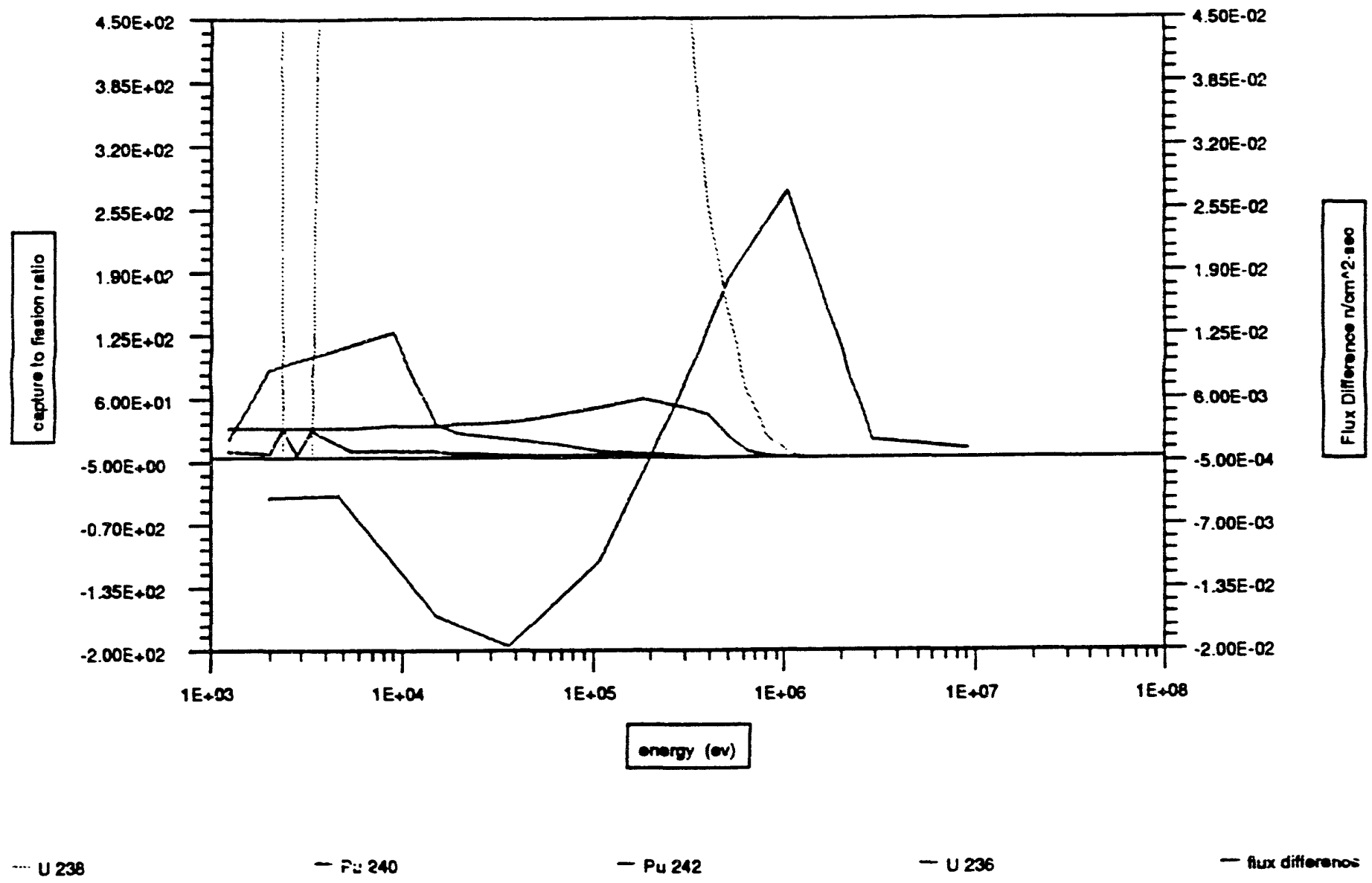

FIGURE 27: Metal Core Inner Fuel Nonfissile Material Capture-to-Fission Ratio. 


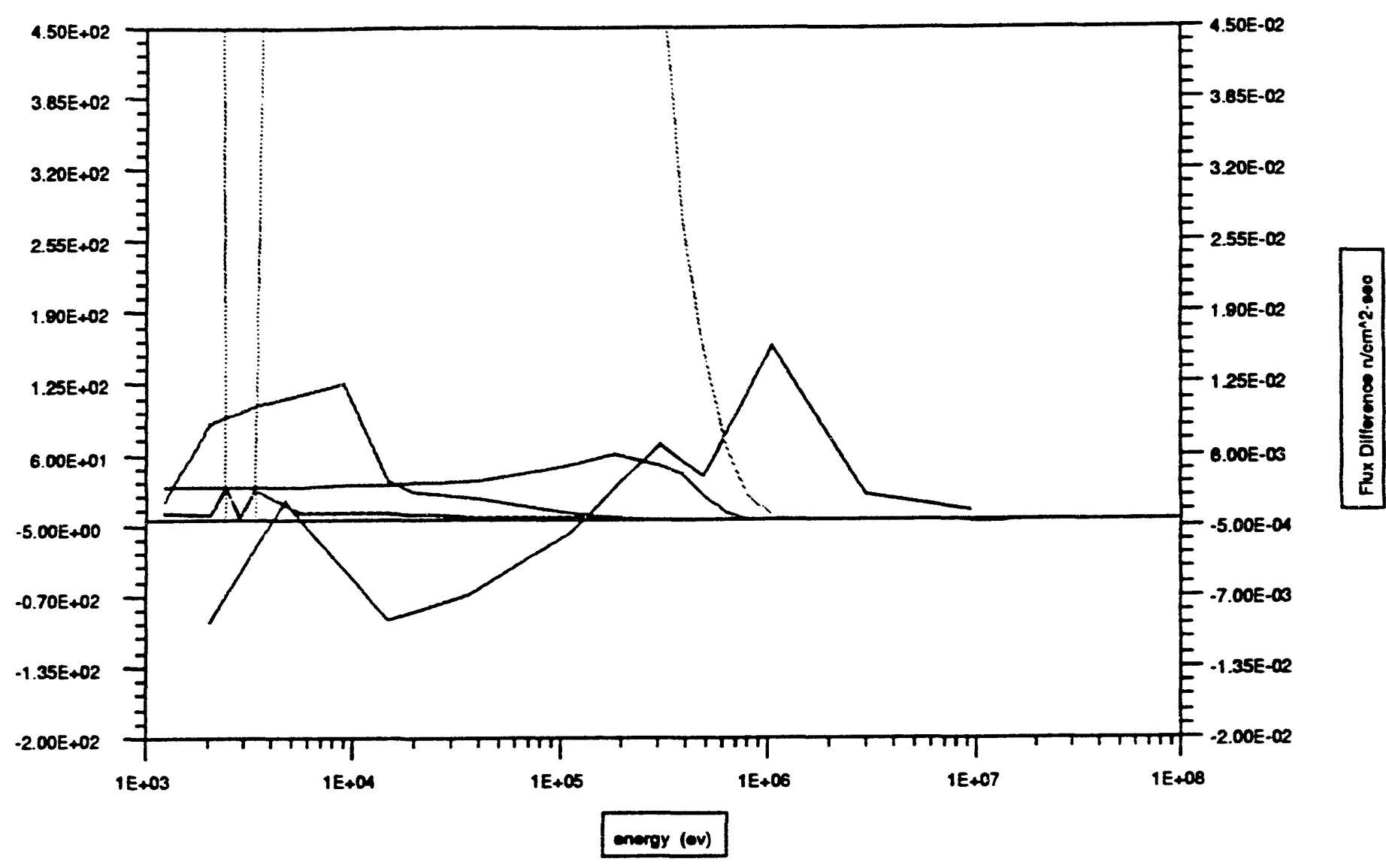

FIGURE 28: 0xide Core 2-Cycle Radial Blanket Nonfissile Material Capture-to-Fission Ratio. 


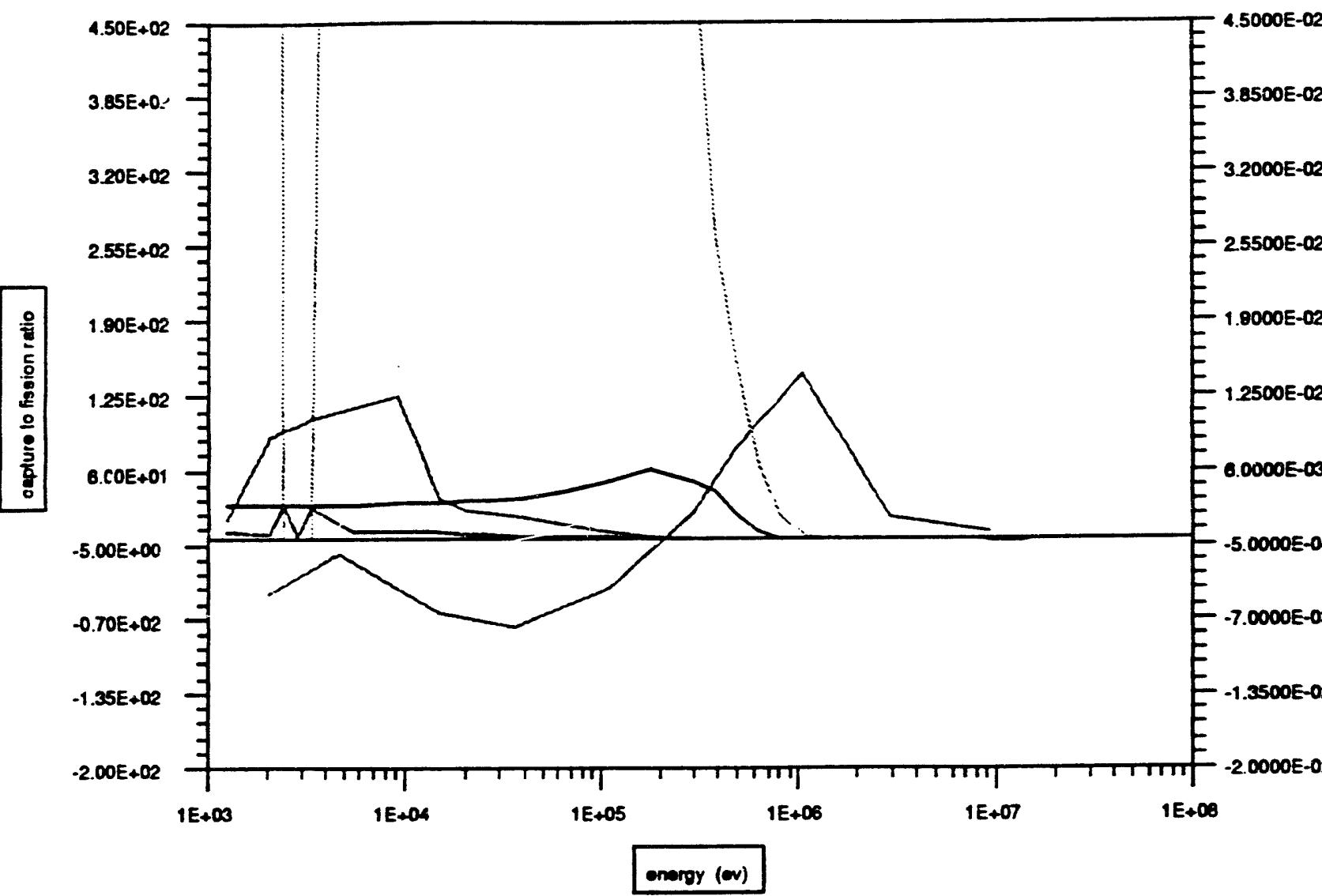

FIGURE 29: Nitride Core 2-Cycle Radial Blanket Nonfissile Material Capture-to-Fission Ratio. 


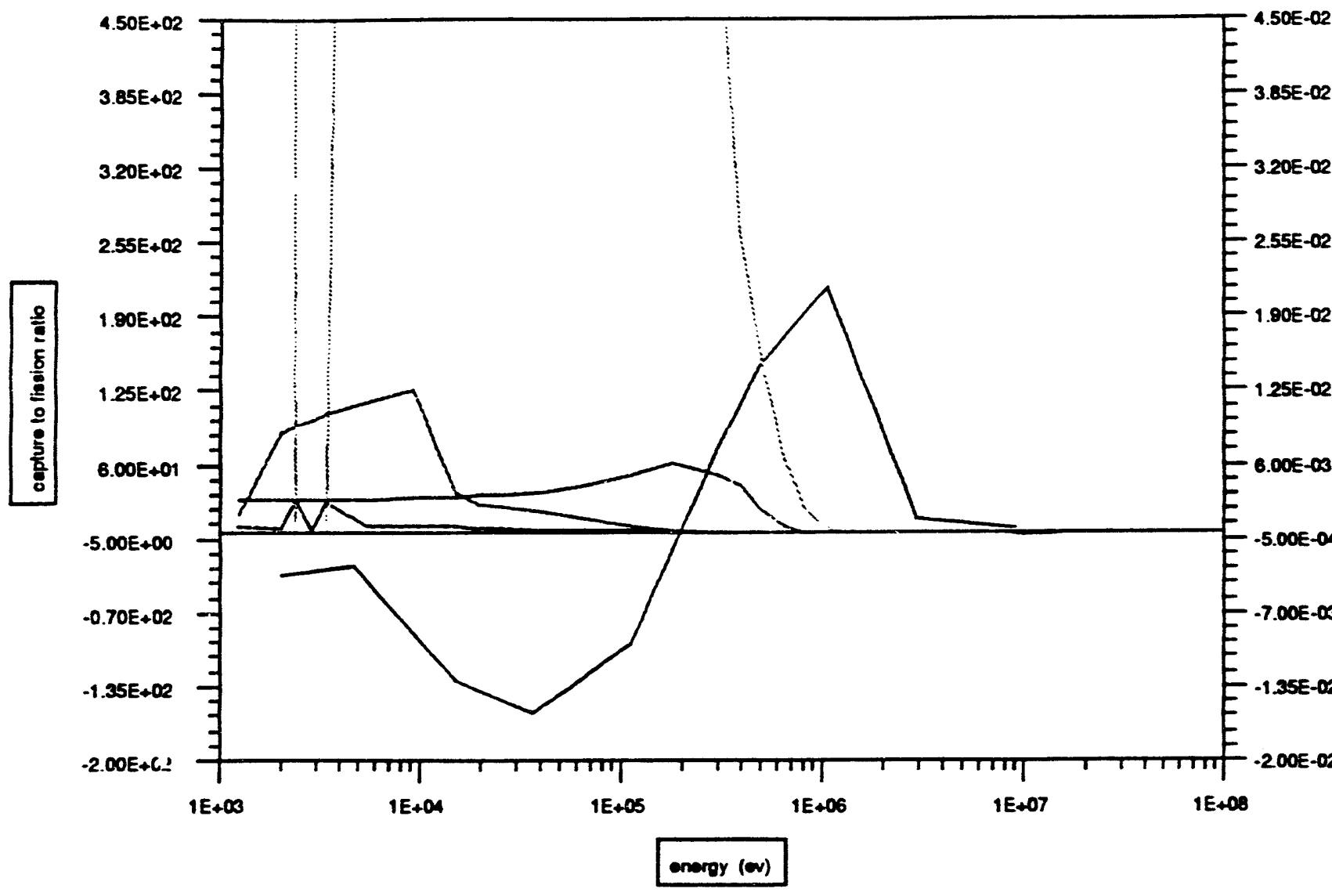

FIGURE 30: Metal Core 2-Cycle Radial Blanket Nonfissile Material Capture-to-Fission Ratio. 
Another term used in thermal reactor physics is the moderating ratio which is defined as the SDP divided by the macroscopic absorption cross section, $\Sigma_{a}$. For this investigation, it was desired to separate fission from capture and the SDP was divided by the macroscopic capture cross section, $\Sigma_{c}$. The modified moderating ratio generated by this method was referred to by Russian participants at the 1990 International Fast Reactor Safety meeting held in Snowbird Utah ${ }^{27}$. In a question and answer session, they claimed that this ratio was the reason for the lower void coefficient in nitride fuel. The results of this investigation support the hypothesis that $\xi \Sigma_{s} / \Sigma_{c}$ is a major contributor to the sodium void worth, but also that there are other major contributors. The specific results of this investigation are contained in Tables 7 through 9 for sodium-flooded and sodium-voided cores. Note that for the sodium bonded pins, the bond region is not voided with the coolant. In the metal core, the irradiated fuel and blanket pins are assumed to have expanded into the bond region displacing the sodium. The contribution to the total SDP of the HT-9 steel was considered to be minimal and not included for any core. All macroscopic cross sections were taken from three dimensional analyses of each core and normalized to 1,000 neutrons.

The SDP for the heavy metal in the three fuel types is similar and changes little when sodium is voided. The same is true for capture in the heavy metal. As expected, the SDP for the sodium is greater than that for the heavy metal, but is of the same magnitude for all cores. Capture in sodium for all cores is insignificant. Consider the SDP for the other elements in the fuel matrix. Both the nitrogen and the oxygen have SDP's a factor of ten greater than that for zirconium, a relationship which is constant for sodium-flooded and -voided cores. It is apparent that the major contributor to the SDP in the nitride and oxide cores is the nitrogen and oxygen 
respectively while the major contributor in the metal core is the sodium. Also of interest is the slight increase in $(n, p)$ and $(n, \alpha)$ reactions in the $n i t r o g e n$ as sodium is voided. These reactions are not major contributors to the SVRE.

Table 10 is a summary of Tables 7 through 9 using a modified moderating ratio generated by dividing the SDP by $\Sigma_{c}$. The oxide core always has the highest ratio with the metal core having the smallest. Since the sodium is not the major contributor to the SDP in the nitride and oxide cores, voiding of sodium changes the total core SDP approximately 20\%. This increases to approximately $60 \%$ for the metal core. This analysis points out that the presence of a moderating atom in the fuel matrix acts to limit spectral hardening for both the nitride and oxide cores when sodium is voided. The effect is that the sodium void reactivity worth is lower in nitride and oxide cores than the metal cores of the same general design.

\section{F. Reaction Rates}

A comparison of macroscopic reaction rates between sodiumflooded and sodium-voided cores also illustrates the effect of a spectral shift on the sodium void coefficient. The program RATE was written to calculate these reaction rates averaged over an assembly, by using a standard 3DB input deck, cross section file, and the flux file generated by the 3DB analysis. Figures 31 through 36 show the difference in the absorption, capture, and fission reaction rates between the sodium-flooded and sodium-voided cores. Only the ${ }^{239} \mathrm{Pu}$ and the ${ }^{238} \mathrm{U}$ are shown. One conclusion which may be made is that, in the nitride and oxide cores, which have less spectral hardening than the metal core, the reaction rate differences are smaller. A second conclusion is that the ${ }^{238} \mathrm{U}$ is a contributor to the positive sodium void since its fission reaction rate difference is negative at low neutron energies 
TABLE 7. Slowing Down Power for the 0xide Core.

(Based on $10^{3}$ Neutrons)

\begin{tabular}{|c|c|c|c|c|c|c|c|c|}
\hline \multirow[b]{2}{*}{ Material } & \multicolumn{3}{|c|}{ Flooded } & \multicolumn{5}{|c|}{ Voided } \\
\hline & $\xi$ & $\Sigma_{s}$ & $\xi \Sigma_{s}$ & $\Sigma_{c}$ & $\xi$ & $\Sigma_{s}$ & $\xi \Sigma_{s}$ & $\Sigma_{c}$ \\
\hline Heavy & 0.00834 & 13578.1 & 113.241 & 473.08 & 0.00834 & 13763.73 & 114.79 & 442.63 \\
\hline \multicolumn{9}{|l|}{ Metal } \\
\hline Sodium & 0.0845 & 4150.93 & 350.754 & 1.70 & 0.0845 & 654.79 & 55.33 & 0.29 \\
\hline Oxygen & 0.12 & 10189.6 & 1222.75 & 2.61 & 0.12 & 10472.98 & 1256.75 & 2.86 \\
\hline \multicolumn{5}{|c|}{$\frac{\xi \Sigma_{s}}{\Sigma_{c}}=\frac{113.241+1222.75+350.754}{473.08+2.61+1.70}=\frac{1686.74}{477.39}=3.53$} & \multicolumn{4}{|c|}{$\frac{\xi \Sigma_{s}}{\Sigma_{c}}=\frac{114.79+1256.75+55.33}{442.63+2.86+0.29}=\frac{1426.87}{445.63}=3}$. \\
\hline
\end{tabular}


TABLE 8. Slowing Down Power for the Nitride Core.

(Based on $10^{3}$ Neutrons)

\begin{tabular}{ccccccccc}
\multicolumn{3}{c}{ Flooded } \\
Material & $\xi$ & $\Sigma_{s}$ & $\xi \Sigma_{s}$ & $\Sigma_{c}$ & $\xi$ & $\Sigma_{s}$ & $\xi \Sigma_{s}$ & $\Sigma_{c}$ \\
$\begin{array}{l}\text { Heavy } \\
\text { Metal }\end{array}$ & 0.00834 & 13531.05 & 112.85 & 419.40 & 0.00834 & 13095.18 & 109.21 & 380.58 \\
Sodium & 0.0845 & 3413.88 & 288.45 & 1.327 & 0.0845 & 497.49 & 42.04 & 0.192 \\
Nitrogen & 0.1364 & 6080.20 & 829.34 & 37.47 & 0.1364 & 5744.90 & 783.60 & 40.47 \\
$\frac{\xi \Sigma_{s}}{\Sigma_{c}}=\frac{112.85+829.34+288.45}{419.40+37.47+1.3274}$ & $=2.686$ & & $\frac{\xi \Sigma_{s}}{\Sigma_{c}}=\frac{109.21+783.60+42.04}{380.58+40.47+0.1922}=2.219$
\end{tabular}


TABLE 9. Slowing Down Power for the Metal Core.

(Based on $10^{3}$ Neutrons)

\begin{tabular}{|c|c|c|c|c|c|c|c|c|}
\hline \multirow[b]{2}{*}{ Material } & \multicolumn{4}{|c|}{ Flooded } & \multicolumn{4}{|c|}{ Voided } \\
\hline & $\xi$ & $\Sigma_{s}$ & $\xi \Sigma_{s}$ & $\Sigma_{c}$ & $\xi$ & $\Sigma_{s}$ & $\xi \Sigma_{s}$ & $\Sigma_{c}$ \\
\hline Heavy & 0.00834 & 15024.88 & 125.31 & 395.02 & 0.00834 & 14306.58 & 119.32 & 335.04 \\
\hline \multicolumn{9}{|l|}{ Metal } \\
\hline \multirow[t]{2}{*}{ Sodium } & 0.0845 & 4121.49 & 348.27 & 1.1545 & 0.0845 & 303.95 & 25.68 & 0.0808 \\
\hline & & & & & & & & 6 \\
\hline Zirconium & 0.02206 & 3831.41 & 84.52 & 8.97 & 0.02206 & 3743.75 & 82.59 & 7.81 \\
\hline \multicolumn{5}{|c|}{$\frac{\xi \Sigma_{s}}{\Sigma_{c}}=\frac{125.31+84.52+348.27}{395.02+8.97+1.1545}=1.378$} & \multicolumn{4}{|c|}{$\frac{\xi \Sigma_{s}}{\Sigma_{c}}=\frac{119.32+82.59+25.68}{335.04+7.81+0.08086}=0.6637$} \\
\hline
\end{tabular}


TABLE 10. Slowing Down Power Summary.

$$
\xi \Sigma_{s} / \Sigma_{c} \quad \begin{aligned}
& \text { Fractional Contribution for } \\
& \text { Sodium Flooded Core }
\end{aligned}
$$

$\begin{array}{lccccc}\text { Core Type } & \text { Sodium } & \text { Sodium } & \text { Heavy } & N / Z r / 0 & \text { Sodium } \\ \text { Flooded } & \text { Voided } & \text { Metal } & & \\ \text { Nitride } & 2.686 & 2.219 & 0.092 & 0.674(N) & 0.234 \\ \text { Metal } & 1.378 & 0.664 & 0.225 & 0.151(\mathrm{Zr}) & 0.624 \\ \text { Oxide } & 3.533 & 3.201 & 0.067 & 0.725(0) & 0.208\end{array}$





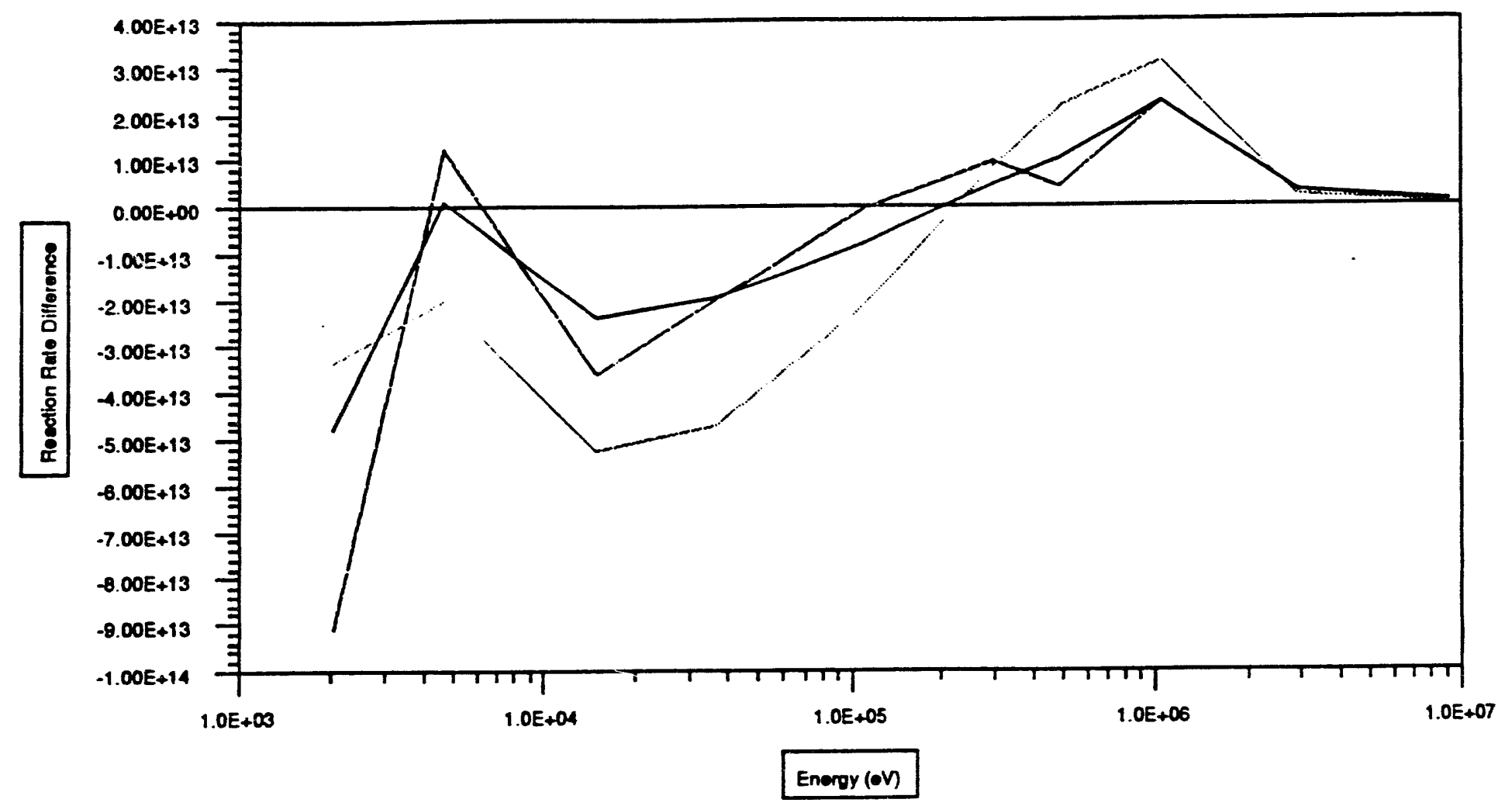

FIGURE 32: ${ }^{241} \mathrm{Pu}$ Absorption Reaction Rate Difference in an Inner Fuel Assembly. 


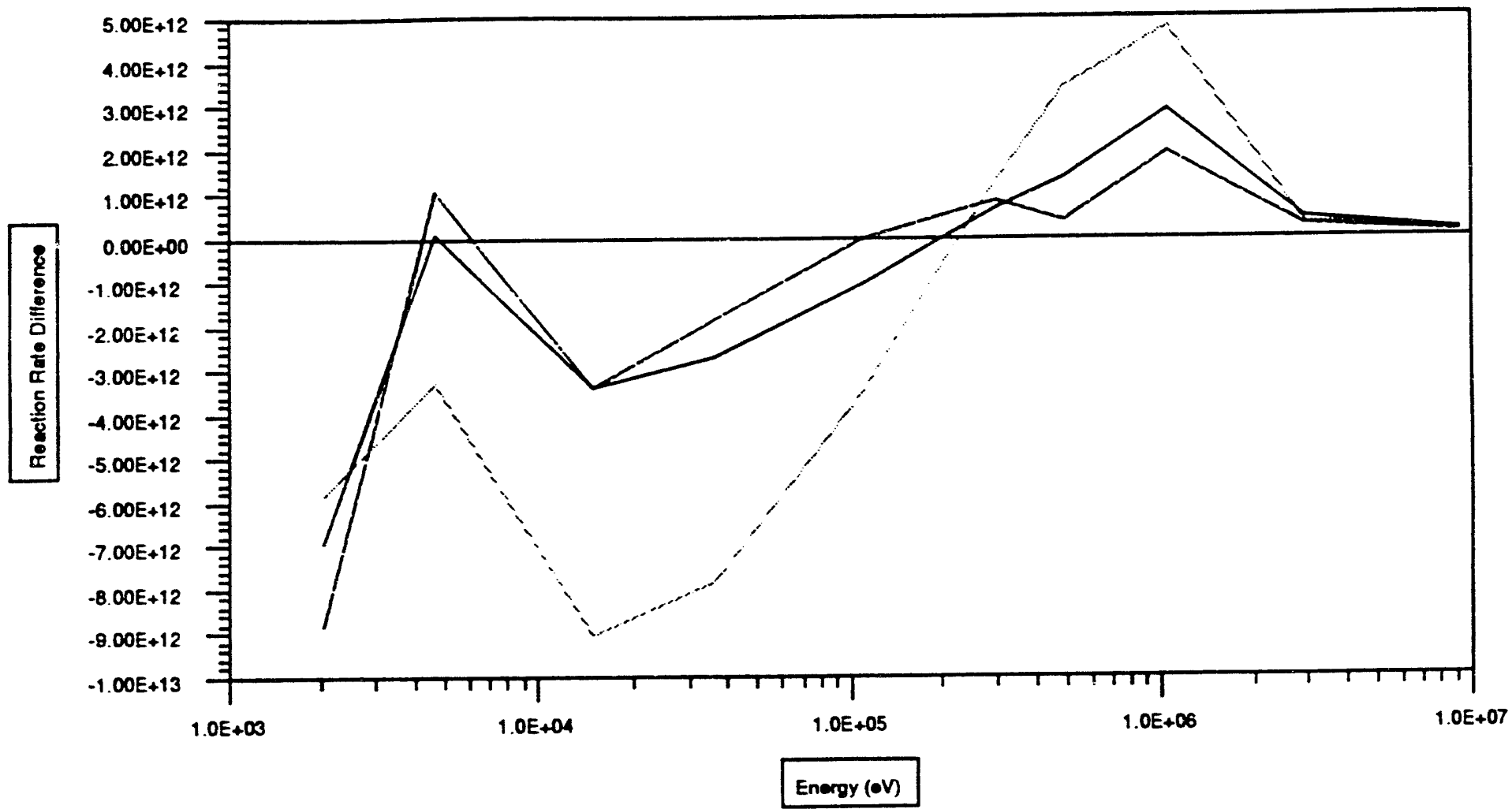

$$
\text { - Nitride -... Matel - oxide }
$$

FIGURE 33: ${ }^{235} \mathrm{U}$ Absorption Reaction Rate Difference in an Inner Fuel Assembly. 


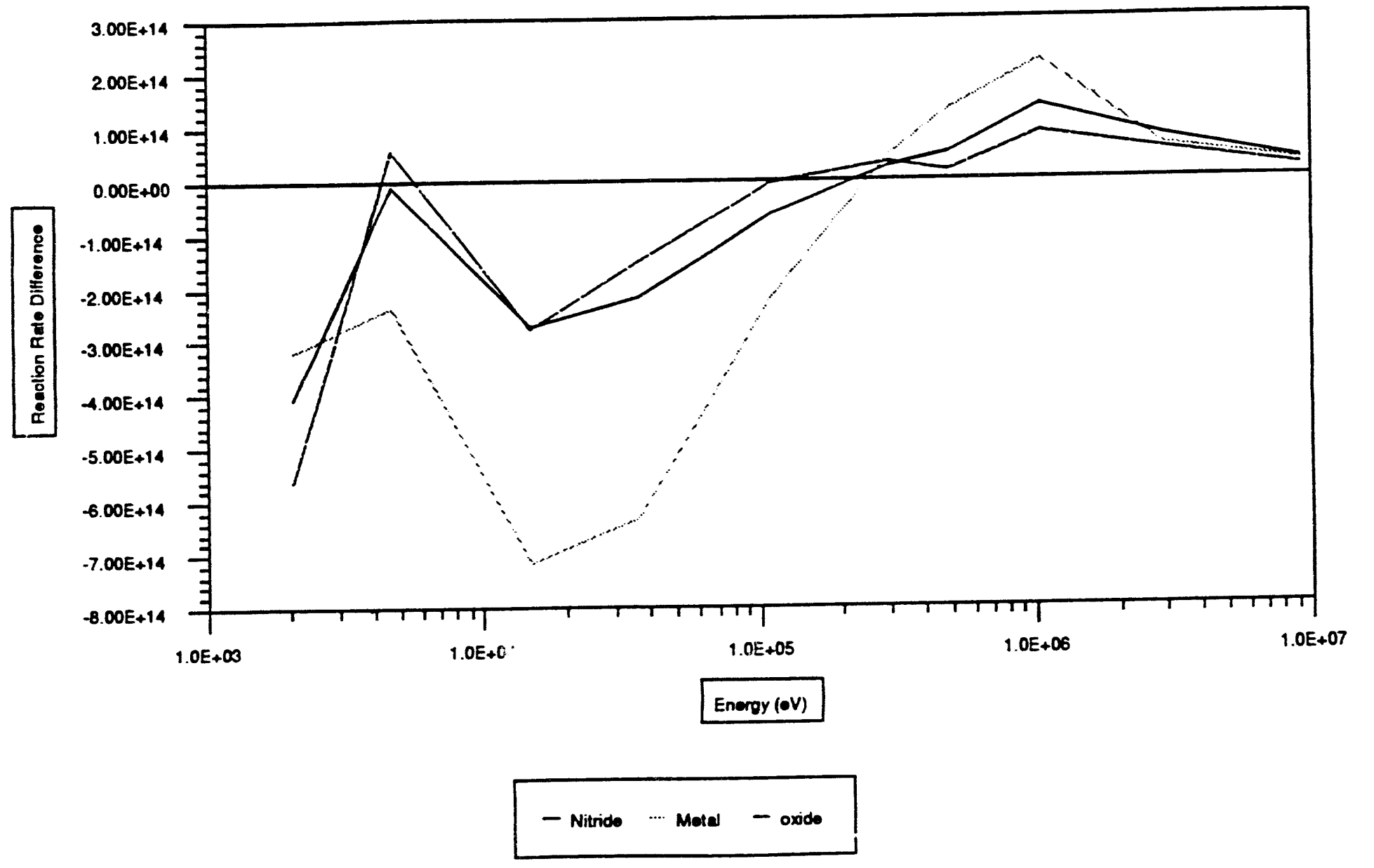

FIGURE 34: ${ }^{238} \mathrm{U}$ Absorption Reaction Rate Difference in an Inner Fuel Assembly. 



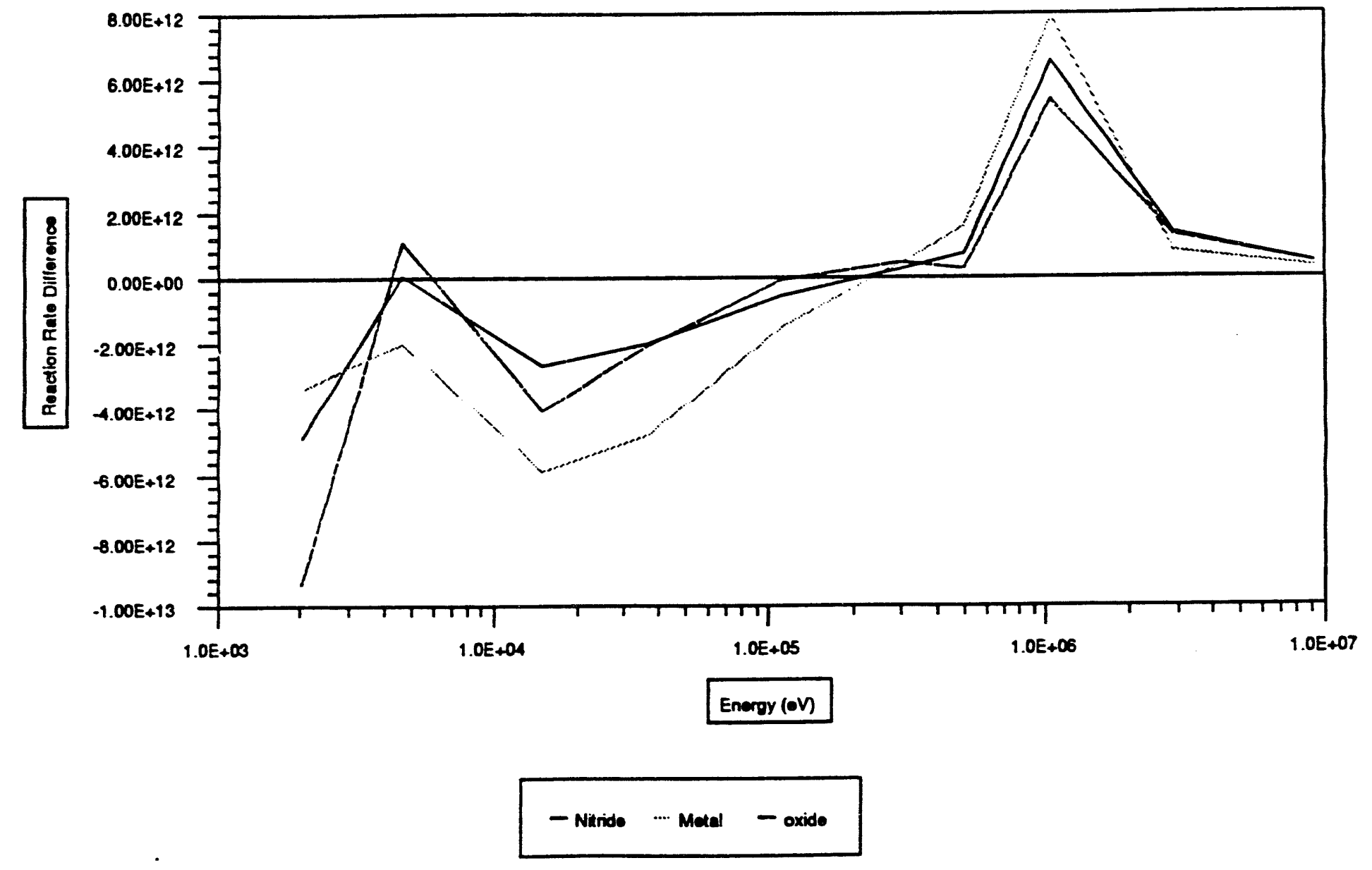

FIGURE 36: ${ }^{242} \mathrm{Pu}$ Absorption Reaction Rate Difference in an Inner Fuel Assembly. 
but becomes positive as neutron energy increases. The ${ }^{238} \mathrm{U}$ is a significant contributor to the SVRE as is the ${ }^{240} \mathrm{Pu}$. The contribution of the ${ }^{242} \mathrm{Pu}$ is several orders of magnitude smalier than either of the other isotopes. This seems to support the hypothesis in Reference 4 that replacing the ${ }^{240} \mathrm{Pu}$ with ${ }^{241} \mathrm{Pu}$ may help lower the void coefficient. However, the positive contribution of the ${ }^{238} \mathrm{U}$ is so much higher than that of the ${ }^{240} \mathrm{Pu}$, other void reduction techniques must be used to design a breeder reactor with a near zero sodium void worth. Appendix $C$ contains the figures from the detailed study of these reaction rates.

The fission reaction rates of the fissile isotopes remain significant as neutron energy increases. Unlike the non-fissile isotopes, the fissile isotopes fission reaction rates are significant over the entire range of neutron energies. Therefore, the reduction in the capture reaction rates for the fissile isotopes is accompanied by a corresponding reduction in the fission reaction rates. For the non-fissile isotopes, the reduction in the capture reaction rates are accompanied by an increase in the fission reaction rates. This also points to the fission to capture ratio as being a major contributor to the sodium void. As discussed previously, the ${ }^{238} \mathrm{U}$ has the largest affect on the void coefficient.

\section{G. Effects of Increased Capture in Nitrogen}

Previow; work ${ }^{28}$ claimed that the reason for a lower SVRE in nitride fuels was due to increased capture in nitrogen as neutron energy increases. Nitrogen does have an increased absorption cross section for both an $(n, p)$ and an $(n, \alpha)$ at neutron energies above $0.4 \mathrm{MeV}$ and $1 \mathrm{MeV}$ respectively. Figure $3 \%$ shows the difference macroscopic capture reaction rate between sodium-voided and sodium-flooded cores for the 


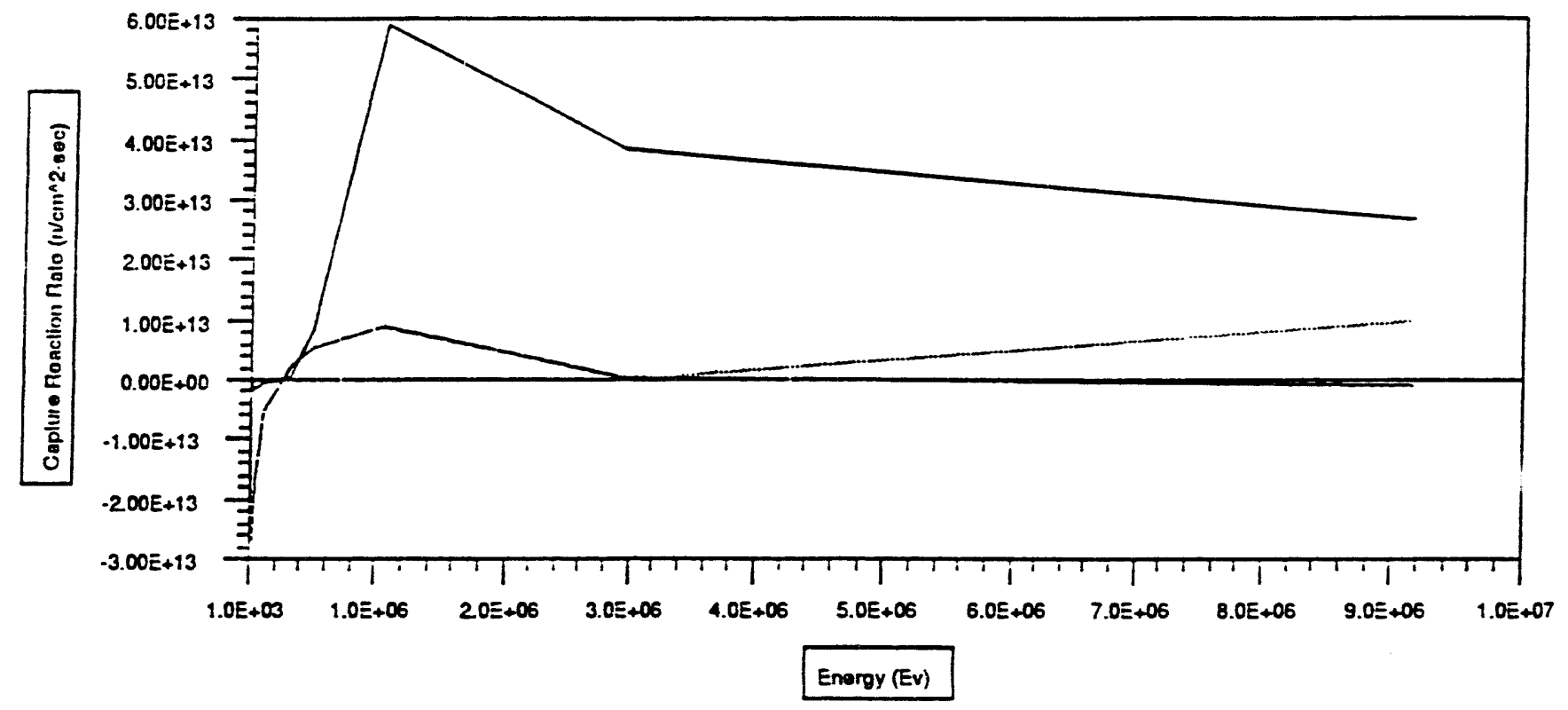

FIGURE 37: Voided to Flooded Capture Reaction Rate Difference. 
nitrogen in the model used for this thesis. This difference is small compared to the difference in total core capture presented in Table 5. While the increase in capture in the voided core aids in lowering the void coefficient, it does not appear to be a major contributor. Figure 37 shows the macroscopic capture reaction rates for oxygen and zirconium. There is no significant high energy absorption in either element. 
H. Derivation of the Sodium Void Reactivity Worth

Consider a two region reactor with a core and a reflector.

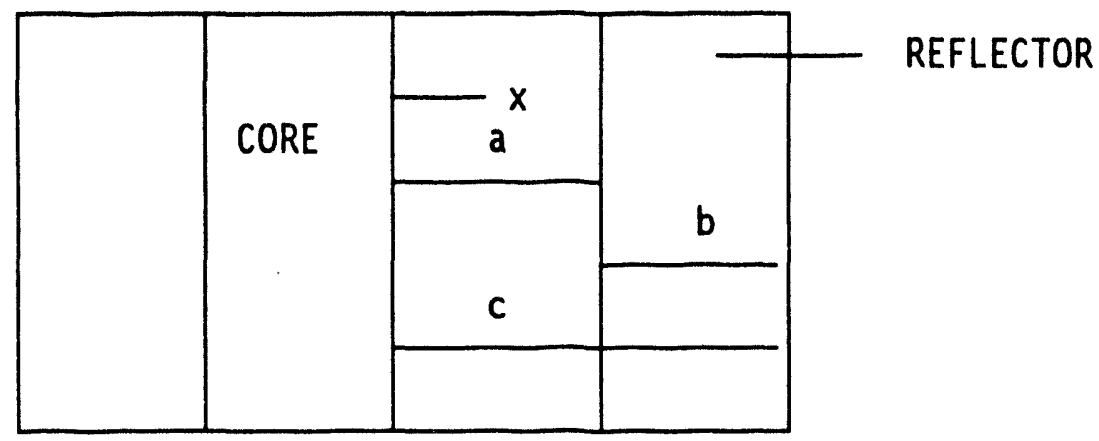

FIGURE 38: Two Region Reactor with a Core and Reflector

The one-group diffusion equation is:

$\frac{\partial n(r, t)}{\partial t}=S(r, t)-\Sigma_{a}(r) \Phi(r, t)+\nabla \cdot D(r) \nabla \Phi(r, t)$

In steady state and one dimension, assuming constant $\Sigma_{\mathrm{a}}$ and D, Equation 1 reduces to:

$$
0=S(x)-\Sigma_{a} \Phi(x)+D \frac{d^{2}}{d x^{2}} \Phi(x)
$$

The volumetric source in this core is:

$$
S(x)=K_{a} \Sigma_{a} \Phi(x)=v \Sigma_{f} \Phi(x)
$$


Rewriting the diffusion equation:

$$
0=K_{\infty} \Sigma_{a} \Phi(x)-\Sigma_{a} \Phi(x)+D \frac{d^{2}}{d x^{2}} \Phi(x)
$$

or

$$
D \frac{d^{2}}{d x^{2}} \Phi(x)+\left(K_{-}-1\right) \Sigma_{a} \Phi(x)=0
$$

Let $L^{2}=D / \Sigma_{B}$ and $B^{2}=\left(K_{\infty}-1\right) / L^{2}$. Then the diffusion equation becomes:

$$
\frac{d^{2}}{d x^{2}} \Phi(x)+B^{2} \Phi(x)=0
$$

For the reflector, the diffusion equation is:

$$
\frac{d n(t)}{d t}=S(x)-\Sigma_{a} \Phi(x)+D \frac{d^{2}}{d x^{2}} \Phi(x)
$$

In steady state and, since there is no source in the reactor:

$$
\begin{gathered}
0=-\Sigma_{a} \Phi(x)+D \frac{d^{2}}{d x^{2}} \Phi(x) \\
\frac{d_{2}}{d x^{2}} \Phi(x)-\frac{1}{L^{2}} \Phi(x)=0
\end{gathered}
$$

The boundary conditions are:

$$
\begin{aligned}
\boldsymbol{J}_{\text {core }}(0) & =0 \rightarrow-D_{\text {core }} \frac{d}{d x} \Phi_{\text {core }}(x)=0 \rightarrow \frac{d}{d} \Phi_{\text {core }}(x)=0 \\
\Phi_{\text {reflector }}(c) & =0 \\
\Phi_{\text {core }}(a) & =\Phi_{\text {reflector }}(a) \\
\boldsymbol{J}_{\text {core }}(a) & =\boldsymbol{J}_{\text {reflector }}(a) \Rightarrow-D_{\text {core }} \frac{d}{d x} \Phi_{\text {core }}(a)=-D_{\text {reflector }} \frac{d}{d x} \Phi_{\text {refler }}
\end{aligned}
$$




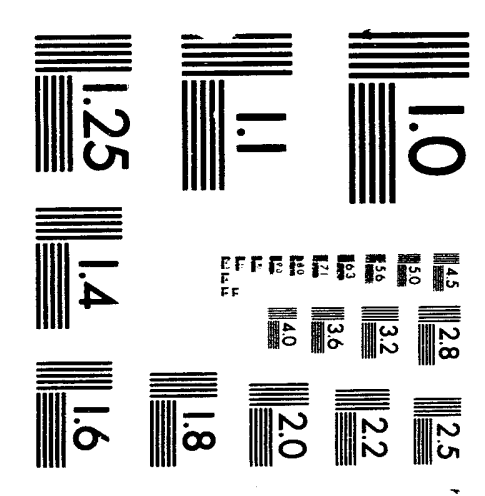



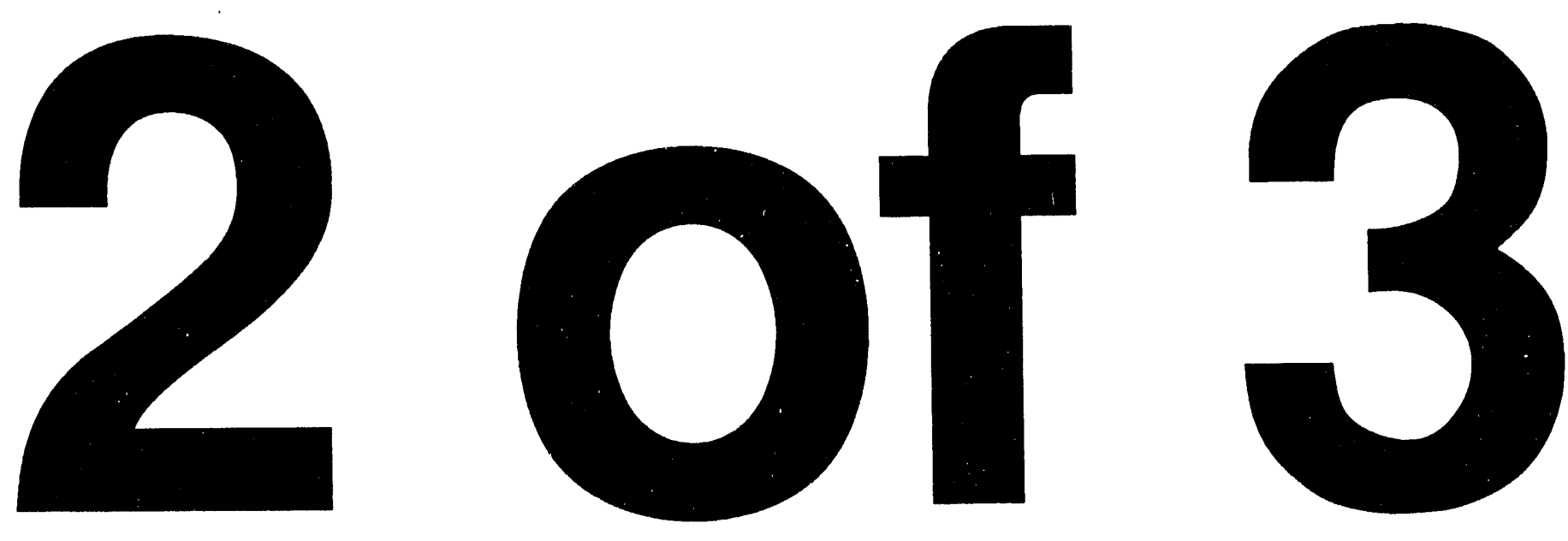
These differential equations may be solved using Euler's technique. Solving for the flux in the core:

$$
\begin{aligned}
C \alpha^{2} e^{\alpha x}+B^{2} C e^{\alpha x} & =0 \quad \Phi(x)=C e^{\alpha x} \\
\alpha^{2}+B^{2} & =0 \\
\alpha^{2} & =-B^{2}-\alpha= \pm i B \\
\Phi_{\operatorname{cor} \theta}(x) & =C_{1} e^{i B x}+C_{2} e^{-i B x} \\
e^{ \pm i x} & =\cos x \pm i \sin x \\
\Phi_{\operatorname{cor} \theta}(x) & =C_{1}(\cos B x+i \sin B x)+C_{2}(\cos B x-i \sin B x) \\
& =\left(C_{1}+C_{2}\right) \cos B x+\left(C_{1}-C_{2}\right) i \sin B x \\
& =A \cos B x+C s i n B x
\end{aligned}
$$

Solving for the flux in the reflector:

$$
\begin{aligned}
C \alpha^{2} e^{\alpha x}-\frac{1}{L^{2}} C e^{\alpha x} & =0 \\
\alpha^{3}-\frac{1}{L^{2}} & =0 \\
\alpha^{2} & =\frac{1}{L^{2}}-\alpha= \pm \frac{1}{L} \\
\Phi_{\text {roflector }}(x) & =C_{1} e^{\frac{x}{L}}+C_{2} e^{-\frac{x}{L}} \\
e^{ \pm x} & =\cosh x \pm \sinh x \\
\Phi_{\text {roflector }}(x) & =C_{1}\left(\cosh \frac{x}{L}+\sinh \frac{x}{L}\right)+C_{2}\left(\cosh \frac{x}{L}-\sinh \frac{x}{L}\right) \\
& =\left(C_{1}+C_{2}\right) \cosh \frac{x}{L}+\left(C_{1}-C_{2}\right) \sinh \frac{x}{L} \\
& =E \cosh \frac{x}{L}+F \sinh \frac{x}{L}
\end{aligned}
$$

Therefore:

$$
\begin{gathered}
\Phi_{\text {core }}=A \cos B x+C \sin B x \\
\Phi_{\text {reflector }}=E \cosh \frac{x}{L}+F \sinh \frac{x}{L}
\end{gathered}
$$


The boundary conditions are now applied:

$$
\begin{aligned}
& \text { at } x=0, \frac{d}{d x} \Phi_{\text {core }}(x)=0 \\
& -A B \sin (0)+C B \cos (0)=0 \rightarrow C=0 \\
& \therefore \Phi_{\text {cor } \theta}(x)=A \cos B x \\
& \text { at } x=c, \Phi_{\text {reflector }}(x)=0 \\
& E \cosh \frac{C}{L}+F \sinh \frac{C}{L}=0 \\
& F=-E \frac{\cosh \frac{C}{L}}{\sinh \frac{C}{L}} \\
& \Phi_{\text {reflector }}(x)=E \cosh \frac{x}{L}-E \frac{\cosh \frac{C}{L}}{\sinh \frac{C}{L}} \sinh \frac{x}{L} \\
& \Phi_{\text {reflector }}(x)=\frac{E}{\sinh \frac{C}{L}}\left(\cosh \frac{x}{L} \sinh \frac{C}{L}-\sinh \frac{x}{L} \cosh \frac{C}{L}\right) \\
& \sinh (x \pm y)=\sinh x \cosh y \pm \sinh y \cosh x \\
& \therefore \Phi_{\text {reflector }}(x)=\frac{E}{\sinh \frac{C}{L}} \sinh \left(\frac{c-x}{L}\right)=G \sinh \left(\frac{c-x}{L}\right) \\
& \text { where } G=\frac{E}{\sinh \frac{C}{L}}
\end{aligned}
$$

$$
\text { Now } \begin{aligned}
& \Phi_{\text {cor } \theta}(x)=A \cos B x \\
& \Phi_{\text {reflector }}(x)=G \sinh \frac{c-x}{L}
\end{aligned}
$$

$$
\begin{gathered}
a t x=a \Phi_{\text {core }}(a)=\Phi_{\text {reflector }}(a) \\
A \cos B a=G \sinh \frac{c-a}{L_{\text {reflector }}}=G \sinh \frac{b}{L_{\text {reflector }}}
\end{gathered}
$$

also at $x=a, D_{\text {core }} \frac{d}{d x} \Phi_{\text {core }}(a)=D_{\text {reflector }} \frac{d}{d x} \Phi_{\text {reflector }}(a)$

$$
D_{\text {core }} A B \sin B a=\frac{D_{\text {reflector }} G}{L_{\text {reflector }}} \cosh \frac{b}{L_{\text {reflector }}}
$$


This gives two equations in two unknowns:

$$
\begin{array}{r}
\operatorname{cosBa\times A-\operatorname {sinh}} \frac{b}{L_{\text {reflector }}} \times G=0 \\
D_{\text {core }} \sin B a \times A-\frac{d_{\text {reflector }}}{L_{\text {reflector }}} \cosh \frac{b}{L_{\text {reflector }}} \times G=0
\end{array}
$$

Using Cramer's rule and setting the determinant of the coeff cients equal to zero:

$$
\left|\begin{array}{cc}
\cos B a & -\sinh \frac{b}{L_{\text {reflector }}} \\
D_{\text {core }} B \operatorname{sinBa} & -\frac{D_{\text {reflector }}}{I_{\text {reflector }}} \cosh \frac{b}{L_{\text {reflector }}}
\end{array}\right|=0
$$

$$
\begin{aligned}
& -\frac{D_{\text {reflector }}}{L_{\text {reflector }}} \cos B \cos \cosh \frac{b}{L_{\text {reflector }}}+D_{\operatorname{cor} \theta} B \sin B a \sinh \frac{b}{L_{\text {reflector }}}=0 \\
& \frac{D_{\text {reflector }}}{I_{\text {reflector }}} \cos B a \cosh \frac{b}{L_{\text {reflector }}}=D_{\text {core }} B \operatorname{sinBasinh} \frac{b}{I_{\text {reflector }}} \\
& \frac{D_{\text {reflecto-r }}}{L_{\text {roflector }}} \frac{\cosh \frac{b}{L_{\text {reflector }}}}{\sinh \frac{b}{L_{\text {reflector }}}}=D_{\operatorname{cor} \theta} B \frac{\sin B a}{\cos B a} \\
& \frac{D_{\text {re }}: \text { lector }}{L_{\text {reflector }} \tanh \frac{b}{L_{\text {reflector }}}}=D_{\text {core }} B \tan B a
\end{aligned}
$$

Recall the diffusion equation:

$$
\begin{gathered}
\frac{d^{2}}{d x^{2}} \Phi(x)+B^{2} \Phi(x)=0 \\
B^{2}=\frac{K_{-}-I}{I_{\text {cor }}^{2}}
\end{gathered}
$$

This is a relationship between the dimensions and its composition. 
Consider a bare reactor:

$$
\begin{aligned}
& \text { as } b \rightarrow 0, \sinh \frac{b}{L_{\text {xeflector }}} \rightarrow 0, \tanh \frac{b}{L_{\text {reflector }}} \rightarrow 0 \\
& \therefore D_{\text {core }} B \tan B a \rightarrow \infty \\
& \text { as } B a-\frac{\pi}{2} \tan B a \rightarrow \infty \\
& \text { Let } B a=\frac{\pi}{2} \\
& \text { then } B=\frac{\pi}{2 a} \\
& B^{2}=\left(\frac{\pi}{2 a}\right)^{2}=\frac{K_{m}-1}{L_{\text {core }}^{2}} \\
& K_{-}-1=\left(\frac{\pi}{2 a}\right)^{2} L^{2} \text { core } \\
& K_{\infty}=1+\left(\frac{\pi}{2 a}\right)^{2} L^{2} \text { core } \\
& \frac{K_{\infty}}{1+\left(\frac{\pi}{2 a}\right)^{2} L_{\text {core }}^{2}}=1
\end{aligned}
$$

The final equation is the criticality condition for a bare slab reactor. Recall that $K_{\text {eff }}$ is the effective multiplication constant and, when it equals 1 , the reactor is said to be critical. This equation is also for the lowest harmonic of the solution. Higher harmonics are not considered. Therefore, the critical condition for the bare slab reactor is:

$$
\begin{aligned}
K_{e f f} & =\frac{K_{\infty}}{1+\left(\frac{\pi}{2 a}\right)^{2} L_{\cos \theta}^{2}} \\
& =\frac{K_{\infty}}{1+B^{2} L^{2}}
\end{aligned}
$$


The sodium void reactivity effect, $\alpha_{\mathrm{Na}}$, may be defined as:

$$
\alpha_{v} \equiv \alpha_{\mathrm{Na}_{\mathrm{a}}}=\frac{\partial \rho}{\partial N_{\text {sodium }}}
$$

Recall that $\rho$ is defined as:

$$
\rho=\frac{K_{\text {eff }}-1}{K_{\text {eff }}}=1-\frac{1}{K_{\text {eff }}}=1-K_{\text {eff }}^{-1}
$$

Now $\alpha_{v}$ may be written as:

$$
\alpha_{v}=\frac{\partial \rho}{N_{\text {sodium }}}=\frac{1}{K_{\text {eff }}^{2}} \times \frac{\partial K_{\text {eff }}}{\partial N_{\text {sodium }}}
$$

Since $K_{\text {eff }}$ is approximately equal to 1 , the equation may be simplified to:

$$
\frac{\partial \rho}{N_{\text {sodium }}}=\frac{1}{K_{\text {eff }}} \times \frac{\partial K_{\text {eff }}}{\partial N_{\text {sodium }}}
$$

In one-group, the critical condition for a bare reactor is:

$$
K_{\text {eff }}=\frac{K_{0}}{1+L^{2} \times B^{2}}
$$

Where the nonleakage probability may be defined as:

$$
\begin{gathered}
P_{n l}=\frac{1}{1+L^{2} \times B^{2}} \\
\therefore K_{\text {eff }}=K_{\infty} \times P_{n l} \\
\text { Recall that } K_{\infty}=\frac{V \times \Sigma_{f}}{\Sigma_{0}}
\end{gathered}
$$




$$
\text { Then } K_{\text {eff }}=\frac{v \Sigma_{f}}{\Sigma_{a}} \times P_{n l}
$$

Take the natural $\log$ of $K_{\text {eff }}$

$$
\begin{aligned}
\ln K_{\text {eff }} & =\ln \left(\frac{v \Sigma_{f}}{\Sigma_{a}} \times P_{n l}\right)=\ln \left(\frac{v \Sigma_{f}}{\Sigma_{a}}\right)+\ln P_{n l} \\
& =\ln v+\ln \Sigma_{f}-\ln \Sigma_{a}+\ln P_{n l}
\end{aligned}
$$

Differentiating with respect to $N_{\mathrm{Na}}$, the number of sodium atoms:

$$
\alpha_{v}=\frac{1}{K_{\text {eff }}} \frac{\partial K_{\text {eff }}}{\partial N_{\mathrm{Na}}}=\frac{1}{v} \frac{\partial v}{\partial N_{\mathrm{Na}}}+\frac{1}{\Sigma_{f}} \frac{\partial \Sigma_{f}}{\partial N_{\mathrm{Na}}}-\frac{1}{\Sigma_{a}} \frac{\partial \Sigma_{\mathrm{a}}}{\partial N_{\mathrm{Na}}}+\frac{1}{P_{\mathrm{nl}}} \frac{\partial P_{\mathrm{nl}}}{\partial N_{\mathrm{Na}}}
$$

Rewriting:

$$
\alpha_{v}=\alpha_{v}(v)+\alpha_{v}\left(\Sigma_{f}\right)-\alpha_{v}\left(\Sigma_{a}\right)+\alpha_{v}\left(P_{n l}\right)
$$

The nonleakage probability may be broken down:

$$
P_{n I}=\frac{1}{1+L^{2} B^{2}}
$$

Taking the natural $\log$ and differentiating:

$$
\ln P_{n I}=\ln \frac{1}{1+L^{2} B^{2}}=-\ln \left(1+L^{2} B^{2}\right)
$$




$$
\begin{aligned}
\frac{1}{P_{n 1}} \frac{\partial P_{n 1}}{\partial N_{N a}} & =-\frac{1}{1+L^{2} B^{2}} \frac{\partial\left(1+L^{2} B^{2}\right)}{\partial N_{N a}} \\
& =-\frac{1}{1+L^{2} B^{2}}\left(L^{2} \frac{\partial B^{2}}{\partial N_{N a}}+B^{2} \frac{\partial L^{2}}{\partial N_{N a}}\right) \\
& =-\frac{L^{2} B^{2}}{1+L^{2} B^{2}}\left(\frac{1}{B^{2}} \frac{\partial B^{2}}{\partial N_{N a}}+\frac{1}{L^{2}} \frac{\partial L^{2}}{\partial N_{N a}}\right) \\
& =\left(P_{n I}-1\right)\left(\alpha_{v}\left(B^{2}\right)+\alpha_{v}\left(L^{2}\right)\right)
\end{aligned}
$$

The equation for the sodium void reactivity worth may now be written as:

$$
\begin{gathered}
\alpha_{v}=\frac{1}{v} \frac{\partial v}{\partial N_{N a}}+\frac{1}{\Sigma_{f}} \frac{\partial \Sigma_{f}}{\partial N_{N a}}-\frac{1}{\Sigma_{a}} \frac{\partial \Sigma_{a}}{\partial N_{N a}}+\left(P_{n I}-1\right)\left(\frac{1}{B^{2}} \frac{\partial B^{2}}{\partial N_{N a}}+\frac{1}{L^{2}} \frac{\partial L^{2}}{\partial N_{N a}}\right)(37 \\
\alpha_{v}=\alpha_{v}(v)+\alpha_{v}\left(\Sigma_{f}\right)-\alpha_{v}\left(\Sigma_{a}\right)+\left(P_{n I}-1\right)\left(\alpha_{v}\left(B^{2}\right)+\alpha_{v}\left(L^{2}\right)\right)
\end{gathered}
$$

$$
\text { Recall that } L^{2}=\frac{D}{\Sigma_{0}}
$$

Taking the natural $\log$ and differentiating:

$$
\begin{gathered}
\ln \left(L^{2}\right)=\ln \left(\frac{D}{\Sigma_{a}}\right)=\ln (D)-\ln \left(\Sigma_{a}\right) \quad(40) \\
\frac{1}{L^{2}} \frac{\partial L^{2}}{\partial N_{N a}}=\frac{1}{D} \frac{\partial D}{\partial N_{N a}}-\frac{1}{\Sigma_{a}} \frac{\partial \Sigma_{a}}{\partial N_{N a}} \\
\therefore \alpha_{v}\left(L^{2}\right)=\alpha_{v}(D)-\alpha_{v}\left(\Sigma_{a}\right)
\end{gathered}
$$


Recall that:

$$
D \approx \frac{1}{3 \Sigma_{t r}}
$$

and that:

$$
\Sigma_{t r}=\Sigma_{a}+(1-\bar{\mu}) \Sigma_{s}
$$

where $\bar{\mu}$ is the average value of the scattering angle

Assuming the scattering angle is very small, this equation may be rewritten as:

$$
\Sigma_{t I}=\Sigma_{a}+\Sigma_{s}
$$

or:

$$
\begin{gathered}
D=\frac{1}{3\left(\Sigma_{a}+\Sigma_{s}\right)} \\
\ln D=\ln \frac{1}{3(\Sigma a+\Sigma s)}=-\ln 3-\ln \left(\Sigma_{a}+\Sigma_{s}\right) \\
\frac{1}{D} \frac{\partial D}{\partial N_{N a}}=-\frac{1}{\Sigma_{a}+\Sigma_{s}} \frac{\partial\left(\Sigma_{a}+\Sigma_{s}\right)}{\partial N_{N a}} \\
=-\frac{\partial \Sigma_{a}}{\left(\Sigma_{t r}\right)}\left(\frac{\left.\partial \Sigma_{s}\right)=-\frac{\Sigma_{a}}{\partial N_{N a}} \frac{1}{\Sigma_{t r}} \frac{\partial \Sigma_{a}}{\partial N_{N a}}-\frac{\Sigma_{s}}{\Sigma_{t r}} \frac{1}{\Sigma_{s}} \frac{\partial \Sigma_{s}}{\partial N_{N a}}}{\alpha_{v}(D)=-\frac{\Sigma_{a}}{\Sigma_{t r}} \alpha_{v}\left(\Sigma_{a}\right)-\frac{\Sigma_{s}}{\Sigma_{t r}} \alpha_{v}\left(\Sigma_{s}\right)}\right.
\end{gathered}
$$

This result may be substituted into Equation 41 . 


$$
\therefore \alpha_{v}\left(L^{2}\right)=-\frac{\Sigma_{a}}{\Sigma_{t I}} \alpha_{v}\left(\Sigma_{a}\right)-\frac{\Sigma_{s}}{\Sigma_{t I}} \alpha_{v}\left(\Sigma_{s}\right)-\alpha_{v}\left(\Sigma_{a}\right)
$$

Assuming that the buckling is only a function of core geometry and does not contribute to the sodium void reactivity worth, Equation 38 becomes:

$$
\alpha_{v}=\alpha_{v}(v)+\alpha_{v}\left(\Sigma_{f}\right)-\alpha_{v}\left(\Sigma_{a}\right)+\left(P_{n I}-1\right)\left(-\frac{\Sigma_{a}}{\Sigma_{t I}} \alpha_{v}\left(\Sigma_{a}\right)-\frac{\Sigma_{s}}{\Sigma_{t r}} \alpha_{v}\left(\Sigma_{s}\right)-\alpha_{v}\left(\Sigma_{a}\right)\right)
$$

Simplifying Equation 51 further :

$$
\begin{gathered}
\alpha_{v}=\alpha_{v}(v)+\alpha_{v}\left(\Sigma_{f}\right)-\alpha_{v}\left(\Sigma_{a}\right)-\left(P_{n 1}-1\right)\left(-\frac{\Sigma_{a}}{\Sigma_{t r}} \alpha_{v}\left(\Sigma_{a}\right)\right) \\
-\left(P_{n 1}-1\right)\left(\frac{\Sigma_{s}}{\Sigma_{t r}} \alpha_{v}\left(\Sigma_{s}\right)\right)-P_{n 1} \alpha_{v}\left(\Sigma_{a}\right)+\alpha_{v}\left(\Sigma_{a}\right) \\
\alpha_{v}=\alpha_{v}(v)+\alpha_{v}\left(\Sigma_{f}\right)-\left(P_{n 1}+\frac{\left(P_{n I}-1\right) \Sigma_{a}}{\Sigma_{t r}}\right) \alpha_{v}\left(\Sigma_{a}\right)-\frac{\left(P_{n 1}-1\right) \Sigma_{s}}{\Sigma_{t r}} \alpha_{v}\left(\Sigma_{s}\right)
\end{gathered}
$$

The effects of the leakage, spectral, and capture components on the SVRE may be seen in Equation 53. Increasing the leakage reduces $P_{n l}$. A reduction in $P_{n l}$ reduces the coefficient of $\alpha_{v}\left(\Sigma_{a}\right)$ reducing its contribution to the total SVRE. The coefficient of $\alpha_{v}\left(\Sigma_{s}\right)$ becomes more negative reducing the SVRE. Therefore, increasing leakage reduces the total SVRE as expected.

Refer to Table 2 for the effects of hardening the spectrum on the SVRE. The net effect is to make the SVRE more positive. 
As seen in the third term of Equation 53, a reduction in capture, reducing $\Sigma_{a}$, has a positive effect on the SVRE. Equation 53 also points out an important difference between the three fuel types. In normal operation, moderation of neutrons is not important in a fast reactor. However, when the sodium voids, the presence of a moderator in the fuel is significant. For a metal fueled reactor, the scattering cross section of the sodium is a large fraction of the total scattering cross section of all the core materials. Voiding the sodium removes the moderator causing significant spectral hardening. The harder the spectrum, the more positive the absorption term in Equation 53 becomes resulting in a more positive SVRE. In an oxide or a nitride fueled ALMR, the oxygen or nitrogen in the fuel constitute the largest fraction of the total scatter cross section. Thus, when the sodium voids, their presence serves to limit the spectral hardening and the absorption term has a smaller positive effect on the SVRE than for metal fuel. The net result is that a metal fueled ALMR will always have the most positive SVRE when compared to an oxide or nitride fueled ALMR of similar design. Likewise, core design changes to reduce the SVRE will always be more severe and consequently less durable in a metal fueled ALMR. 
I. The Near Zero Sodium Void Worth Core

The safety enhanced nitride core was shortened from $135 \mathrm{~cm}$ to $75 \mathrm{~cm}$ in order to lower the void coefficient to less than one dollar. The oxide core and metal core were not shortened because this would have required that the reactor vessel diameter be increased to prevent exceeding the 1 inear power capability of each fuel type. Nitride fuel has a linear power capability of $28 \mathrm{kw} / \mathrm{ft}$ which allows the core to be shortened without increasing reactor vessel diameter or exceeding the limit. For this part of the study, the model was reduced from full core to a one-sixth core and sodium was voided from only the fuel and blanket assemblies to be consistent with analyses performed by the lead designer. The void coefficient was reduced from $\$ 2.97$ and $\$ 0.77$ as shown on Figure 39. No attempt was made to optimize this core which retains the same configuration as the safety-enhanced reference core. The disadvantage to shortening the core is that the breeding ratio drops from approximately 1.1 to 0.93 . Peak linear power increases from $11 \mathrm{kw} / \mathrm{ft}$ to $19 \mathrm{kw} / \mathrm{ft}$ for the fuel, and $8 \mathrm{kw} / \mathrm{ft}$ tc $16 \mathrm{kw} / \mathrm{ft}$ for the blankets, within the capability of nitride fuel. An additional advantage to shortening the nitride core is that the design requirement of rail transportability is not compromised.

\section{J. The ALMR as an Actinide Burner}

Configuring the ALMR to burn actinides by replacing fuel and blanket assemblies with assemblies containing actinides is a possible solution to the problem of the storage and handling of high level waste. Cross sections for some minor actinides were not available in the ENDF/B-V 22 library and were created by combining actinides with similar one-group cross sections. While this increases the inaccuracy of the analysis, it does give an indication of the affect of actinides on the SVRE as 


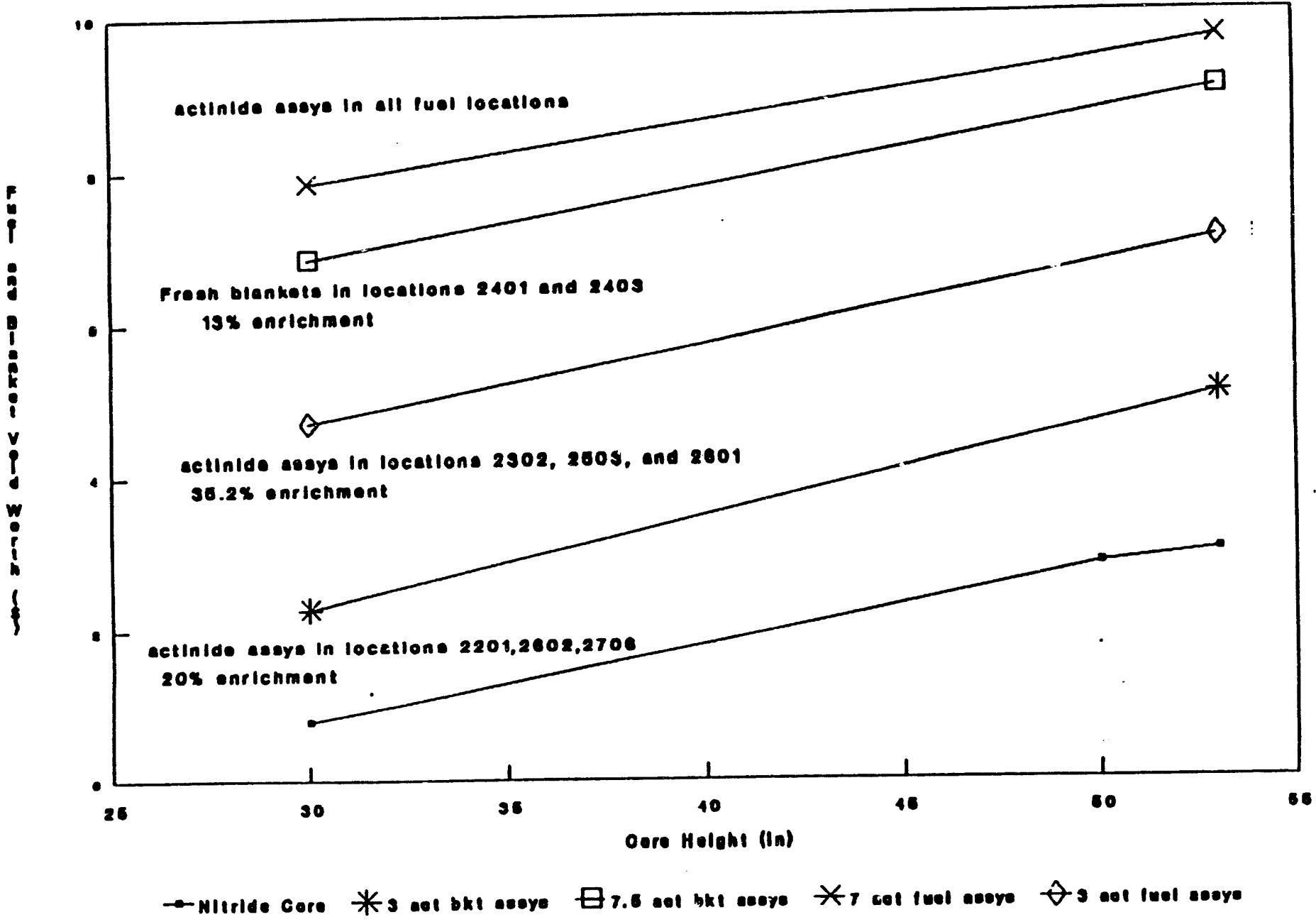

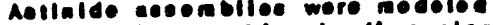

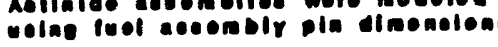

FIGURE 39: Sodium Void Reactivity Effect of a Minor Actinide Burner. 
88

shown on Figure 39. The SVRE for various loadings of actinide target, fuel, and blanket assemblies could not be reduced to less than two dollars. 


\section{REFERENCES}

1. K. D. Dobbin, S. F. Kessler, J. V. Nelson, and R. P. Omberg, "Comparative Sodium Void Effects for Different Advanced Liquid Metal Reactor Fuel and Core Designs," WHC-SA-1093-FP, Transactions of the American Nuclear Society, Summer Meeting, Orlando, F1., 1991.

2. V. I. Mateev, S. B. Bobrov, and V. A. Eliseev, "The Concept of BN-1600 Reactor Core with the Zero Sodium Void Reactivity Effect and Minimum Burn-up Reactivity Margin," Proceedings of the International Conference on Fast Reactors and Related Fuel Cycles, Kyoto, Japan, 1991.

3. S. B. Belov and V. A. Vasilyev, "Oxide, Carbide, Nitride, and Metal-A Comparison of Fuel Types by Safety Parameters."

4. M. L. Thompson "The Modular ALMR (PRISM) Fuel Cycle," Proceedings of the American Nuclear Society Special Cluster Session - - LMR: Decade of LMR Progress and Promise, Washington DC, November 8, 1990.

5. R. W. Hardy, et al, Preliminary Safety Information Document, General Electric Report GEFR-00793, May 1990

6. D. Okrent, "On the History of Fast Reactor Safety in the United States," Proceedings of the International Fast Reactor Safety Meeting, Snowbird, Ut, 1990.

7. H. S. Khalil, R. N. Hill, "Evaluation of Liquid-Metal Reactor Design Options for Reduction of Sodium Void Worth," Nuclear Science and Engineering, 109, (221-266), 1991.

8. T. Kamei, M. Yamaoka, "An Axially Multilayered Low Void Worth LiquidMetal Fast Breeder Reactor Core Concept, "Nuclear Technology,97, (264-271), 1992.

9. V. I. Mateev, S. B. Bobrov, I. V. Bakhleav, M. F. Vorotyntsev, A. V. Danilytchev, and V. A. Eliseev, "Physical Grounds for Further Improvement of Fast Sodium Power Reactor Safety," Proceedings of the International Fast Reactor Safety Meeting, Snowbird, Ut, 1990.

10. M. Kawashima, M. Suzuki, and R. N. Hill, "A Core Design for "ZeroSodium-Void-Worth" Cores," Internat "onal Conference on Design and Safety of Advanced Nuclear Power Plants, Tokyo, Japan, 1992.

11. T. Jevremovic, Y. Oka, and S. Koshizuka, "Negative Void Reactivity in Fast Breeder Reactors Realized by Adding Thin Zirconium-Hydride Layers Between Seeds and Blankets," International Conference on Design and Safety of Advanced Nuclear Power Plants, Tokyo, Japan, 1992 . 
12. S. F. Kessler, "Reduction of the Sodium-Void Coefficient of Reactivity by Using a Technetium Layer," WHC-SA-1793-FP, Proceedings of the Global ' 93 International Conference and Technology Exhibition, Seattle, Wa, 1993.

13. A. Trave11i and J. C. Beitel, "Analys is of Sodium-Void Experiments in the FTR Engineering Mockup Critical Assembly," Proceedings $0^{-}$the National Topical Meeting on New Developments in Reactor Physi is and Shielding, Kiamesha Lake, N. Y., 1972.

14. A, E. Walter, A. B. Reynolds, "Fast Breeder Reactors," Pergermon Press, New York, N. Y. 1981

15. J. J. Laidler, J. E. Battles, W. E. Miller, E. C. Gay, "Development of IFR Pyroprocessing Technology, "Proceedings of the Global '93 International Conference and Technology Exhibition, Seattle, Wa., 1993.

16. R. R. Landry, T. L. King, J. N. Wilson "Draft Preapplication Safety Evaluation Report for Power Reactor Inherently Safe Module Liquid Metal Reactor," NUREG 1368, Washington DC, September 1989.

17. A. A. Bauer, "Nitride Fuels: Properties and Potentials," Reactor Technology, 15 (2), 1972.

18. H. H. Hummel, D. Okrent, Reactivity Coefficients in Larqe Fast Power Reactors, American Nuclear Society, 1970.

19. K. D. Dobbin, S. F. Kessler, J. V. Nelson, S. R. Gedeon, R. P. Omberg Comparative Sodium Void Effects for Different Advanced Liquid Metal Reactor Fuel and Core Designs, WHC-SA-1093-FP, "Transactions of the American Nuclear Society," Summer Meeting, Orlando, Florida (1991).

20. W. W. Little, Jr., R. W. Hardie, 2DB User's Manual -- Revision 1, BNWL-831 Rev 1, Pacific Northwest Laboratory, Richland, Washington USA, 1969.

21. R. W. Hardie, W. W. Little, Jr., 3DB, A Three-Dimensional Diffusion Theory Burnup Code, BNWL-1264, Pacific Northwest Laboratory, Richland, Washington USA, 1970.

22. F. M. Mann, ETR Set 500, a Multigroup Cross Section Set for FTR Analysis, HEDL-TME-81-31, Hanford Engineering Development Laboratory, Richland, WA, 1982.

23. F. M. Mann, MIDX, A One-Dimensional Diffusion Code for Generating Effective Nuclear Cross Sections, HEDL-TME-82-12, Hanford Engineering Development Laboratory, Richland, WA, 1982. 
24. R. W. Hardie, W. W. Little, Jr., 3DP, A Three-Dimensional Perturbation Theory Code, HEDL-TME-72-134, Hanford Engineering Development Laboratory, Richland, Washington USA, 1972.

25. W. F. Lyon, R. B. Baker, R. D. Leggett, R. B Matthews, Advancing Liquid Metal Technology with Nitride Fuels, WHC-SA-1067-FF, Presented at the International Conference on Fast Reactors and Related Fuel Cycles, Kyoto, Japan, 1991.

26. M. J. Bell, "ORIGEN -- The ORNL I sotope Generation and Depletion Code," ORNL-4628, Oak Ridge National Laboratory (May 1973).

27. V. I. Matveyev, A. V Danilychev, I. V. Bakhlayev, S. B. Bobrov, V. V. Korobeynileov, Problem of the Sodium Void Effect of Reactivity in Fast Reactors and Its Resolution, paper presented at the 1990 International Fast Reactor Safety Meeting, Snowbud, Utah USA, 1990.

28. J. F. Fletcher, J. Greenborg, Nitride Fuels for Fast Breeder Reactors: Ful1 Cycle Considerations, BNWL-606, Pacific Northwest Laboratory, Richland, Washington 1968. 


\section{APPENDIX A: Ratio Program}

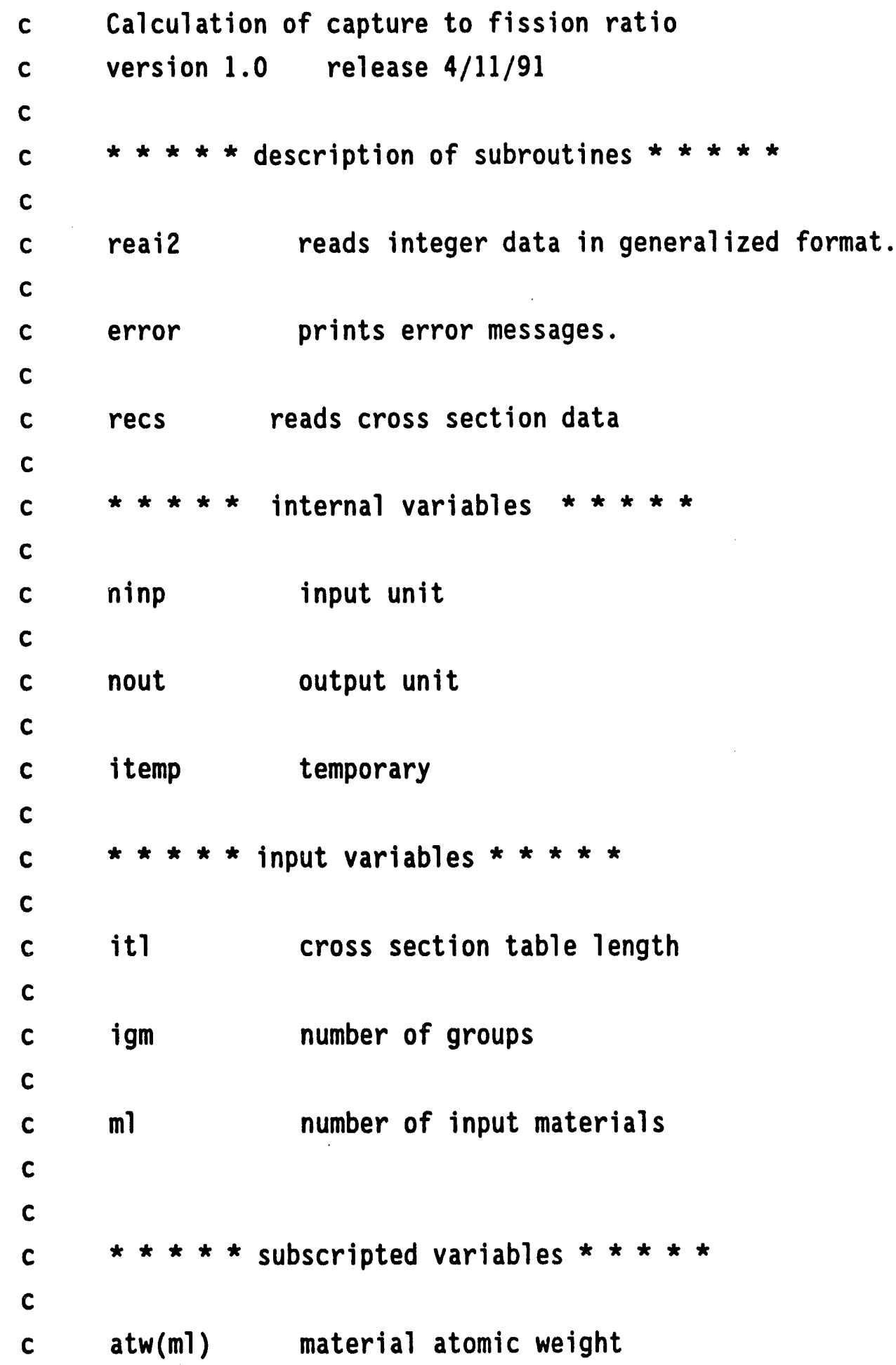




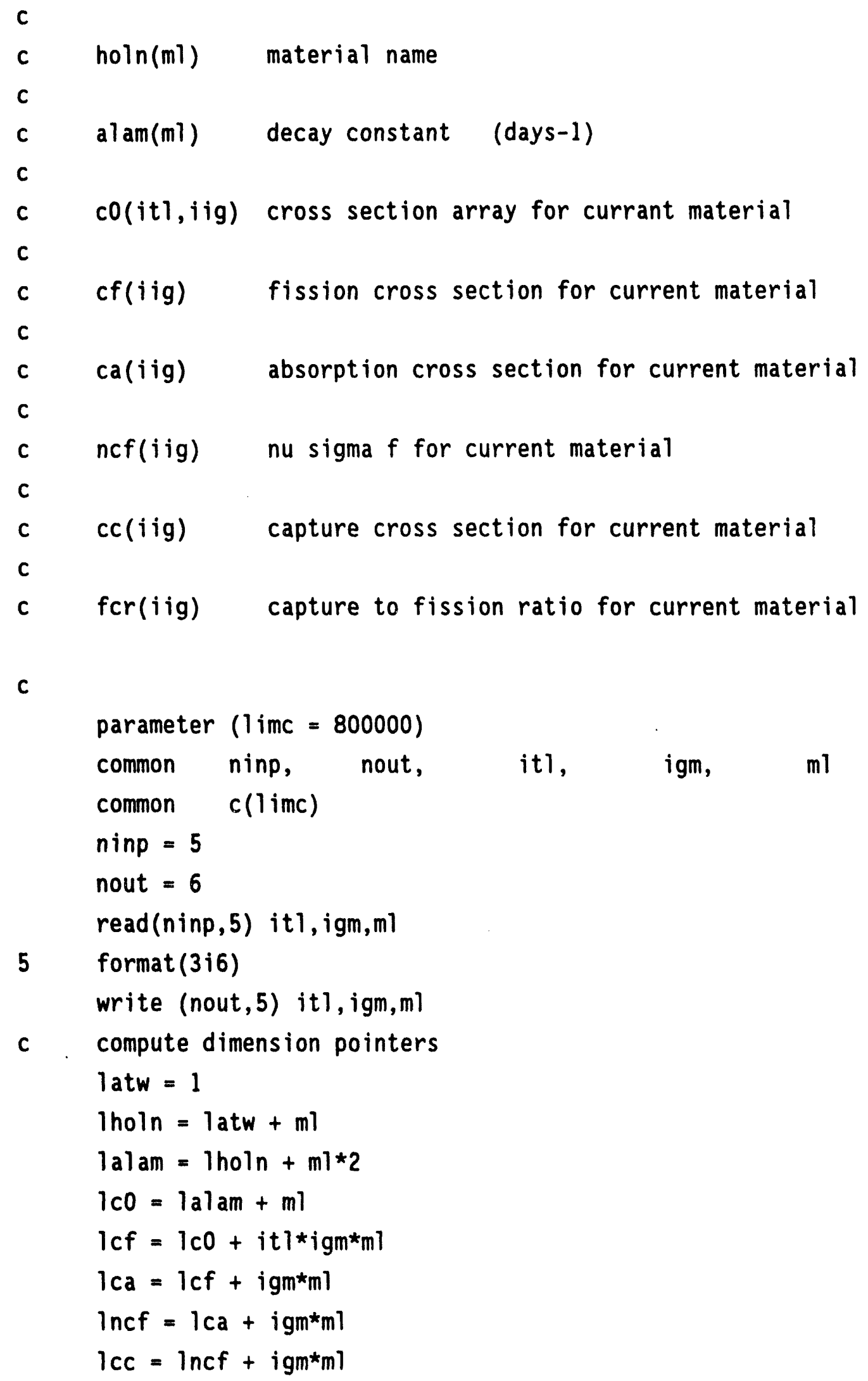




$$
\begin{aligned}
& \text { lfcr }=1 c c+i g m \star m l \\
& \text { leta }=1 \mathrm{fcr}+i g m * m 1 \\
& \text { lidxs }=1 \text { eta }+i g m * 2 \\
& \text { lident }=1 i d \times s+m 1 * 100 \\
& \text { last }=1 \text { ident }+\mathrm{ml} \\
& \text { if } 1 \text { last .ge. 1imc) then }
\end{aligned}
$$$$
\text { write(nout, 6) }
$$

6 format ('memory limit exceeded')

$$
\text { stop }
$$

endif

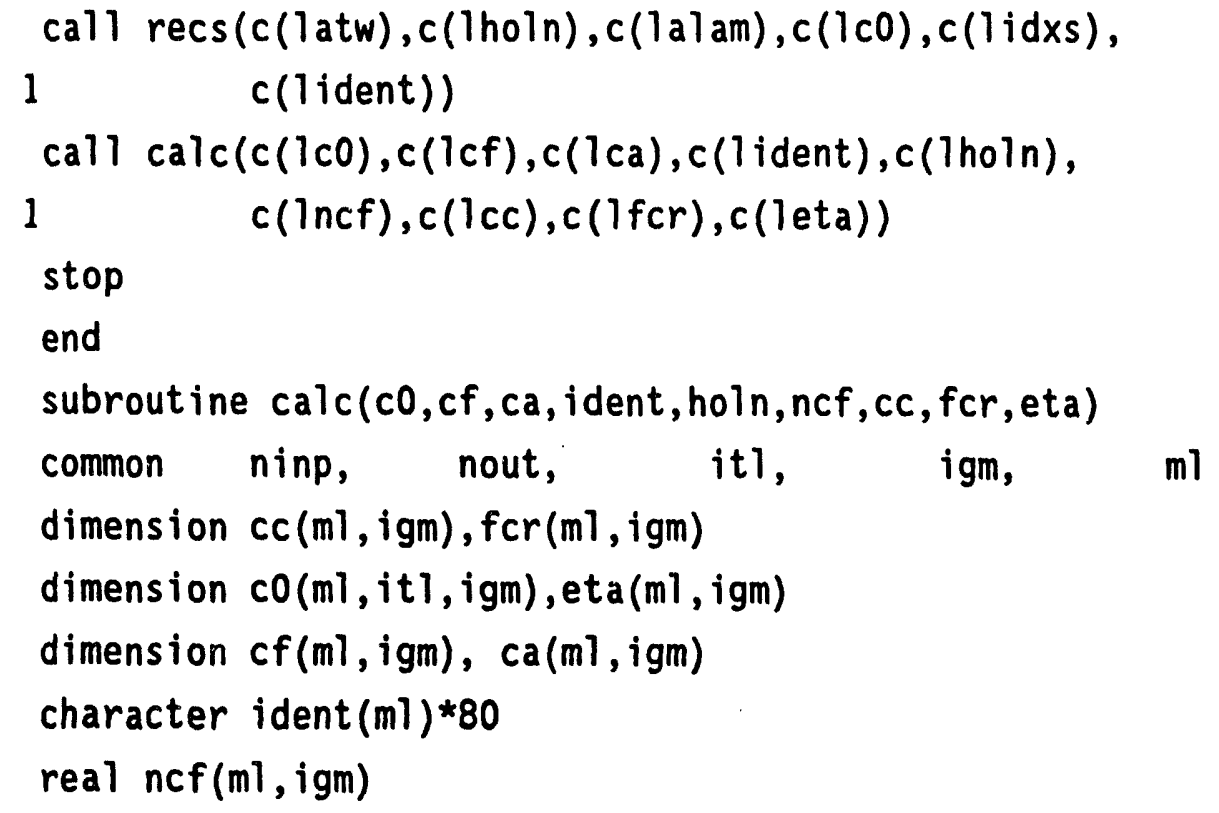


$i=((i g m+1)-i i g)$

$c f(m, i i g)=c 0(m, 1, i i g)$

$\mathrm{ca}(\mathrm{m}, \mathrm{iig})=\mathrm{co}(\mathrm{m}, 2, \mathrm{i} i \mathrm{~g})$

$\operatorname{ncf}(\mathrm{m}, \mathrm{iig})=\mathrm{co}(\mathrm{m}, 3, \mathrm{i} i \mathrm{~g})$

$c c(m, i i g)=c a(m, i i g)-c f(m, i i g)$

if $(n c f(m, i i g)$.ne. 0) go to 65

$n c f(m, i i g)=0.0$

go to 66

$65 f \mathrm{fr}(\mathrm{m}, \mathrm{i} i \mathrm{~g})=\mathrm{cc}(\mathrm{m}, \mathrm{iig}) / \mathrm{ncf}(\mathrm{m}, \mathrm{i} i \mathrm{~g})$

eta $(m, i i g)=n c f(m, i i g) / c a(m, i i g)$

66 write(nout,70) i, cc(m,iig), ncf(m,iig), fcr(m,iig), eta(m,iig)

70 format $(i 6,6 x, 1 p l e 12.5,2 x, 1 p l e 12.5,5 x, 1 p 1 e 12.5,5 x, 1 p l e 12.5)$

75 continue

100 continue

return

end

subroutine reai2(hol1, iarray, ncount,jpr)

common ninp, nout, itl, igm, $\mathrm{ml}$

dimension iarray(1), iv(12), k(12), in(12)

character holl*(*)

$\mathrm{jflag}=0$

$j=1$

1 if(jflag) $2,10,2$

2 do $4 j j=1,6$

$k(j j)=k(j j+6)$

in $(j j)=i n(j j+6)$

$4 \quad i v(j j)=i v(j j+6)$

jflag $=0$

go to 21

$10 \operatorname{read}(n i n p, 20)(k(i), i n(i), i v(i), i=1,6)$

$20 \operatorname{format}(6(i 1, i 2, i 9))$

21 do $70 \quad i=1,6$

$1=k(i)+1$

go to $(30,40,52,80,62,70,22), 1$

c fill 
$22 \quad j j=j$

do $25 m=j j$, ncount

$i \operatorname{array}(j)=i v(i)$

$25 \quad j=j+1$

go to 80

c no modification

$30 \quad i \operatorname{array}(j)=i v(i)$

$j=j+1$

go to 70

c repeat

$40 \quad 1=$ in (i)

do $50 \mathrm{~m}=1,1$

$\operatorname{iarray}(j)=i v(i)$

$j=j+1$

50 continue

go to 70

c interpolate

52 if(i-6) $54,53,53$

$53 \operatorname{read}(\operatorname{ninp}, 20)(k(m), i n(m), i v(m), m=7,12)$

jflag $=1$

$54 \quad 1=$ in $(i)+1$

$i d e l=(i v(i+1)-i v(i)) / 1$

do $56 \mathrm{~m}=1,1$

$\operatorname{iarray}(j)=\operatorname{iv}(i)+i d e 1 *(m-1)$

$56 j=j+1$

go to 70

c cycle

$621=\ln (i)$

$n=i v(i)$

do $65 \quad 11=1,1$

do $65 n n=1, n$

$\operatorname{iarray}(j)=\operatorname{iarray}(j-n)$ 


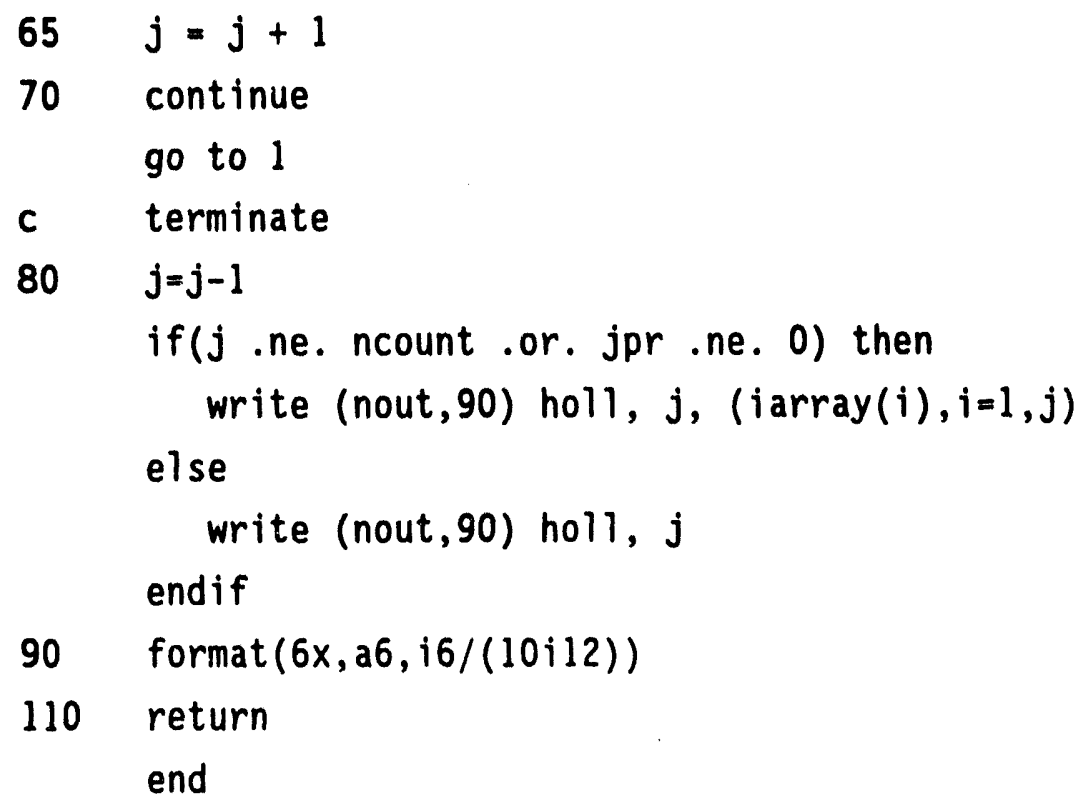


$m=n$

$35 \operatorname{read}(15$, end $=500)$ holnx, atwx, al amx, aa

$\operatorname{read}(a a, 36)$ itemp

36 format $(49 x, i 5)$

do $45 \mathrm{j}=1, \mathrm{ml}$

if(itemp .ne. idxs(j)) go to 45

$m=\mathbf{j}$

$\operatorname{holn}(m)=\operatorname{holn} x$

$\operatorname{atw}(m)=\operatorname{atwx}$

$\operatorname{al} \operatorname{am}(m)=\operatorname{al} a m x$

$i d x s(m)=-i d x s(m)$

$\operatorname{read}(15)((\mathrm{co}(\mathrm{m}, \mathrm{i}, \mathrm{i} i \mathrm{~g}), i=1, i \mathrm{t} 1), \mathrm{i} \mathrm{ig}=1, \mathrm{igm})$

go to 48

45 continue

$\operatorname{read}(15)$

go to 35

48 write(ident $(m), 55) m$, holn $(m)$, aa

write(nout,55) $m, \operatorname{holn}(m)$, aa

50 continue

55 format (i4, 6x, a6, 6x, a54)

return

500 write(nout, 510)

510 format ('requested materials not in library: ' /)

do $520 \mathrm{j}=1, \mathrm{ml}$

if (idxs $(j), g e .0)$ write(nout,530) $j, i d x s(j)$

520 continue

530 format $(i 6,1 h \star, i 8)$

540 call error('**xs ',540,1)

end 


\section{APPENDIX B: Reaction Rate Program}

program $r \times n$

c version 1.0 release $5 / 9 / 90$

C

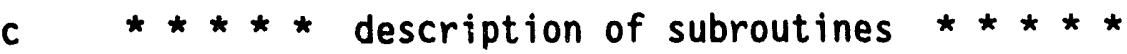

C

c rxn main routine - controls the operation of the code.

C

$c$

c

C

c

C

c

c

c

c

c

C

c

c

c

C

c

c

$c$

c nout

controls the reading and printing of all input data and computes the variable dimension pointers.

erro2 prints error messages.

recs reads cross sections from cards and writes cross sections to drum.

reag

reads floating point data in generalized format.

reai2

reads integer data in generalized format.

clear

sets an array of a given length equal to a given constant.

c e01

c $\mathrm{eO2}$

c e03

c igp

c iha

c ihf

c ins

internal variables $* \star \star \star * *$

c imjm

input unit

output unit

temporary

temporary

temporary

igm +1

position of absorption cross section

position of fission cross section

position of sigma self scatter

im*jm 


$\begin{array}{lll}\text { c } & \text { ip } & \text { im }+1 \\ c & \text { itemp } & \text { temporary } \\ c & \text { itempl } & \text { temporary } \\ c & \text { itemp2 } & \text { temporary } \\ c & \text { itl } & \text { cross section table length } \\ c & \text { itlmt } & \text { itl*mt } \\ c & \text { izp } & \text { izm }+1 \\ c & \text { jp } & \text { jm }+1 \\ c & \text { kp } & \text { km }+1 \\ c & \text { ml } & \text { absolute value of mcr } \\ c & \text { ngoto } & \text { temporary } \\ c \quad \text { ninit } & \text { temporary } \\ c \quad & \end{array}$

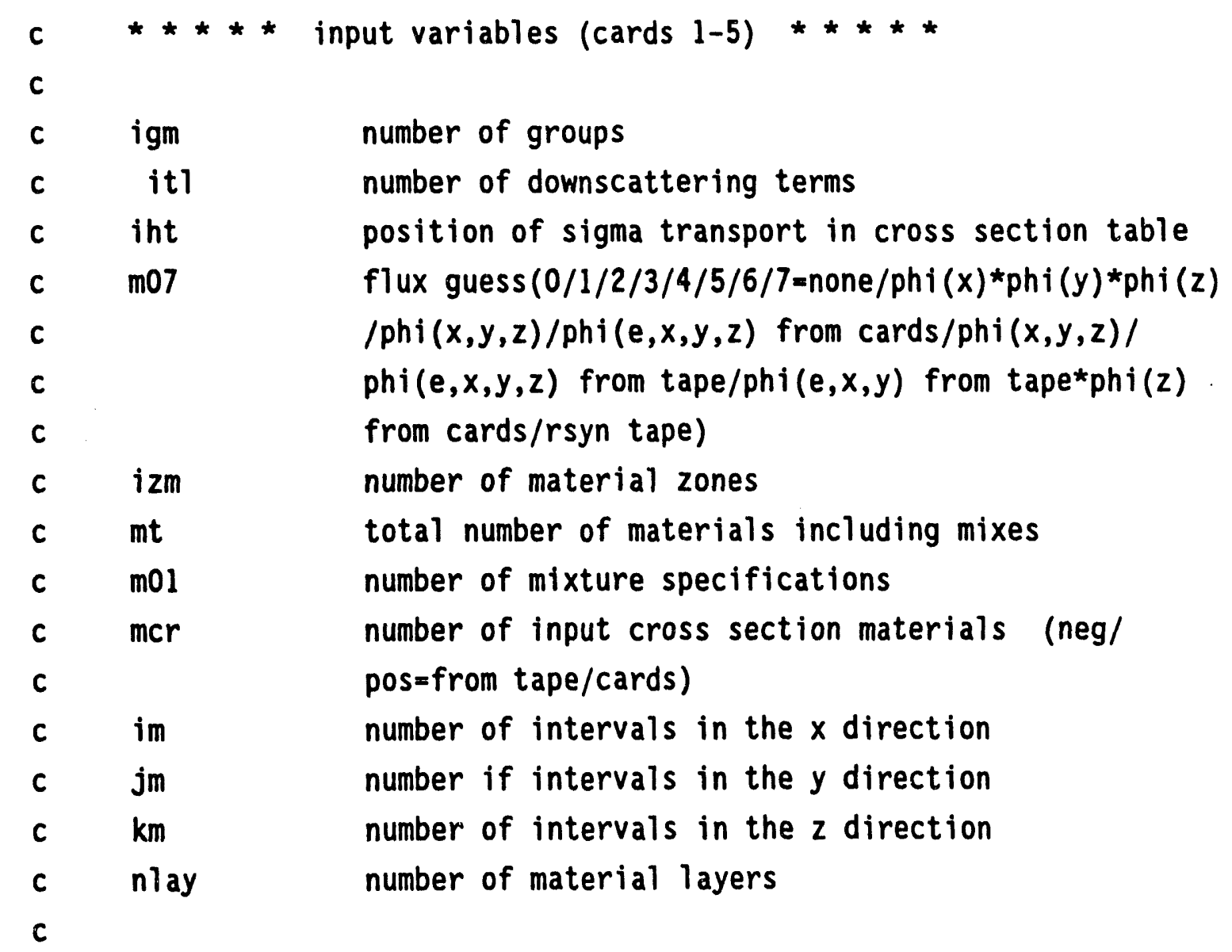


101

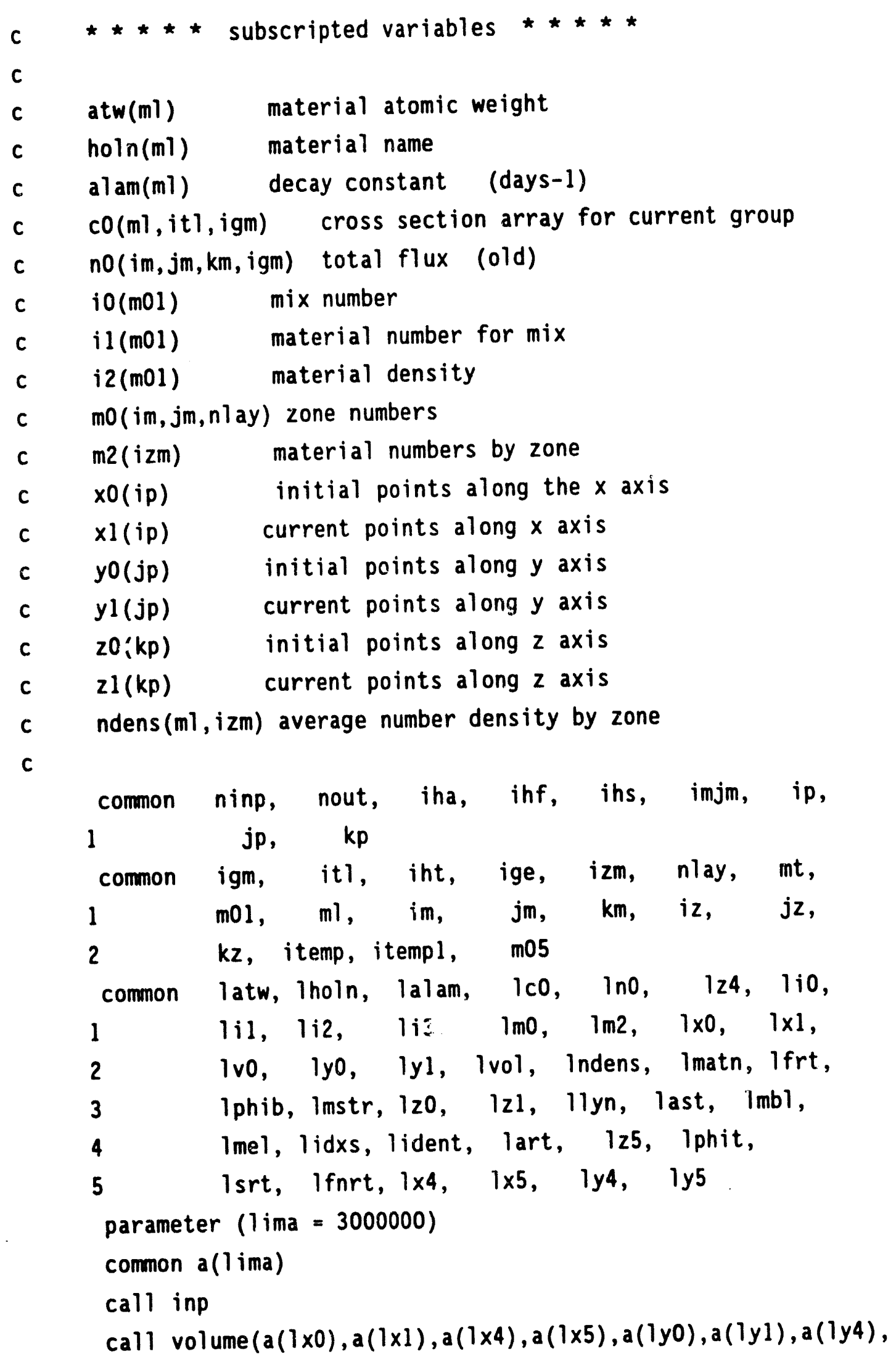


2

$$
\begin{aligned}
& a(1 y 5), a(1 z 0), a(1 z 1), a(1 z 4), a(1 z 5), \\
& a(1 \vee 0), i m)
\end{aligned}
$$

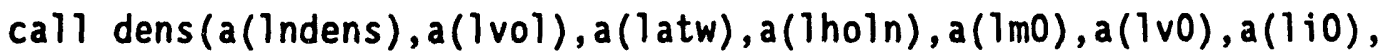
1

2

$$
a(1 i 1), a(1 i 2), a(1 z 5), a(11 y n), a(1 m b 1), a(1 m e 1), a(1 m a t n),
$$
$a(1 \mathrm{~m} 2), a(1 i 3))$

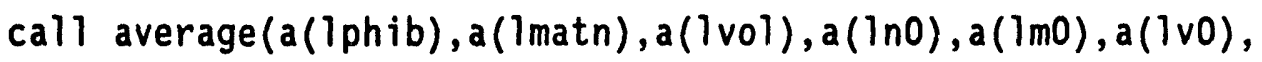

1 $a(125), a(11 y n), a(1 p h i t))$

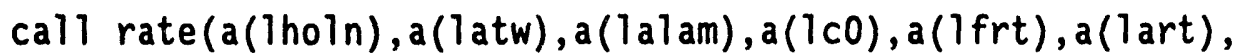
1

2 $a(1 s r t), a(1$ fnrt ), a (1 ident), a (1ndens), a (1phib),

2 $a(1 m a t n))$

320 format(10e12.5)

end

subroutine inp

common ninp, nout, iha, ihf, ihs, imjm, ip,

1

common igm, itl, iht, ige, izm, nlay, mt,

$1 \mathrm{m01}, \mathrm{ml}, \mathrm{im}, \mathrm{jm}, \mathrm{km}, \mathrm{iz}, \mathrm{jz}$,

2 kz, itemp, itempl, m05

common latw, lholn, lalam, lco, lno, 1z4, 1io,

$1 \quad 1 \mathrm{il}, 1 \mathrm{i} 2,1 \mathrm{i3}, 1 \mathrm{~m} 0,1 \mathrm{~m} 2,1 \times 0,1 \times 1$,

2 Ivo, lyo, lyl, ivol, Indens, Imatn, Ifrt,

3 Iphib, Imstr, 1zo, 1zl, 11yn, last, 1mbl,

4 Imel, lidxs, lident, lart, 125, lphit,

$5 \quad$ 1srt, ifnrt, 1x4, 1x5, 1y4, 1y5

parameter $(1$ ima $=3000000)$

common a( 1 ima)

character $i d^{\star} 66$

c this subroutine controls the reading and printing of initial data

ninp $=5$

nout $=6$

write(nout, 10)

10 format('1'/20x,'RATE Version 1.0 Release $5 / 9 / 90$ '/

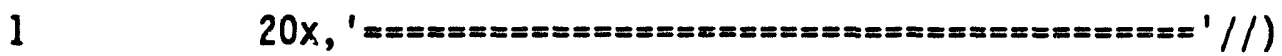

read(ninp, 20) id, igm, itl,

1 iht, izm, 
$2 \mathrm{mt}, \mathrm{m01}, \mathrm{mcr}, \mathrm{im}, \mathrm{jm}, \mathrm{km}, \mathrm{nlay}, \mathrm{m05}$

20 format $(266 / 12 i 6)$

write (nout, 30) id

30 format $(/ 10 x, a 66, i 6)$

write(nout,60) igm, itt, int

60 format(

1' igm number of groups

2

$3^{1}$ itl cross section table length

4

'i9/

$5^{\prime}$ iht position of sigma transport in cross section table

6

write(nout, 80) izm, mt, m0l, mcr

80 formats

$1^{\prime} \quad$ izm number of material zones

2 'i9/

$3^{\prime} \quad \mathrm{mt} \quad$ total number of materials including mixes

$4 \quad 1 i 9 /$

$5^{\prime} \mathrm{mol}$ number of mixture specifications

6 'ig/

7. mcr number of input cross section materials (neg/pos=fr

8om tape/cards) ' 'i9)

write(nout, 90) im, jm, km, nlay, m05

90 format (

1' im number of intervals in the $x$ direction

2 'i9/

$3^{\prime}$ jm number of intervals in the $y$ direction

4 'i9/

$5^{\prime} \mathrm{km}$ number of intervals in the $\mathrm{z}$ direction

$6 \mathrm{ig/}$

7' nlay number of material layers

8 'i9/

9. m05 number of materials for reaction rate calculations 
1

$$
\begin{aligned}
& i h s=i h t+1 \\
& i h a=i h t-2 \\
& i h f=i h t-3 \\
& i z p=i z m+1 \\
& i p=i m+1 \\
& j p=j m+1 \\
& k p=k m+1 \\
& m l=i a b s(m c r) \\
& i g p=i g m+1 \\
& i m j m=i m * j m \\
& i t 1 m l=i t l * i g m * m l
\end{aligned}
$$

ala $=.0$

c compute dimension pointers

1 atw $=1$

lholn $=1$ atw $+m 1$

lalam $=1$ holn $+m 7 *(11 / 4)$

$1 c 0=1 \mathrm{a} l \mathrm{am}+\mathrm{ml}$

lv $0=1 \mathrm{co}+i \mathrm{t} l \mathrm{ml}$

$1 \mathrm{~m} 0=1 v 0+i \mathrm{mjm}$

$1 \mathrm{n} 0=1 \mathrm{~m} 0+i m j m * n l a y$

ifrt $=$ inotimjm

lart $=1 \mathrm{frt}+m 05 * i g m * i z m$

1 srt $=1$ art $+m 05 * i g m * i z m$

$1 \mathrm{fnrt}=1 \mathrm{srt+m05*igm*izm}$

$1 \times 0=1 \mathrm{fnrt}+\mathrm{m05}$ *igm*izm

$1 \times 1=1 \times 0+i p$

$1 \times 4=1 \times 1+i p$

$1 \times 5=1 \times 4+i m$

$7 y 0=1 \times 5+i m$

$1 y l=1 y 0+j p$

$1 y 4=1 y 1+j p$

$1 y 5=1 y 4+j m$

$120=1 y 5+j m$

$1 \mathrm{zl}=120+\mathrm{kp}$ 


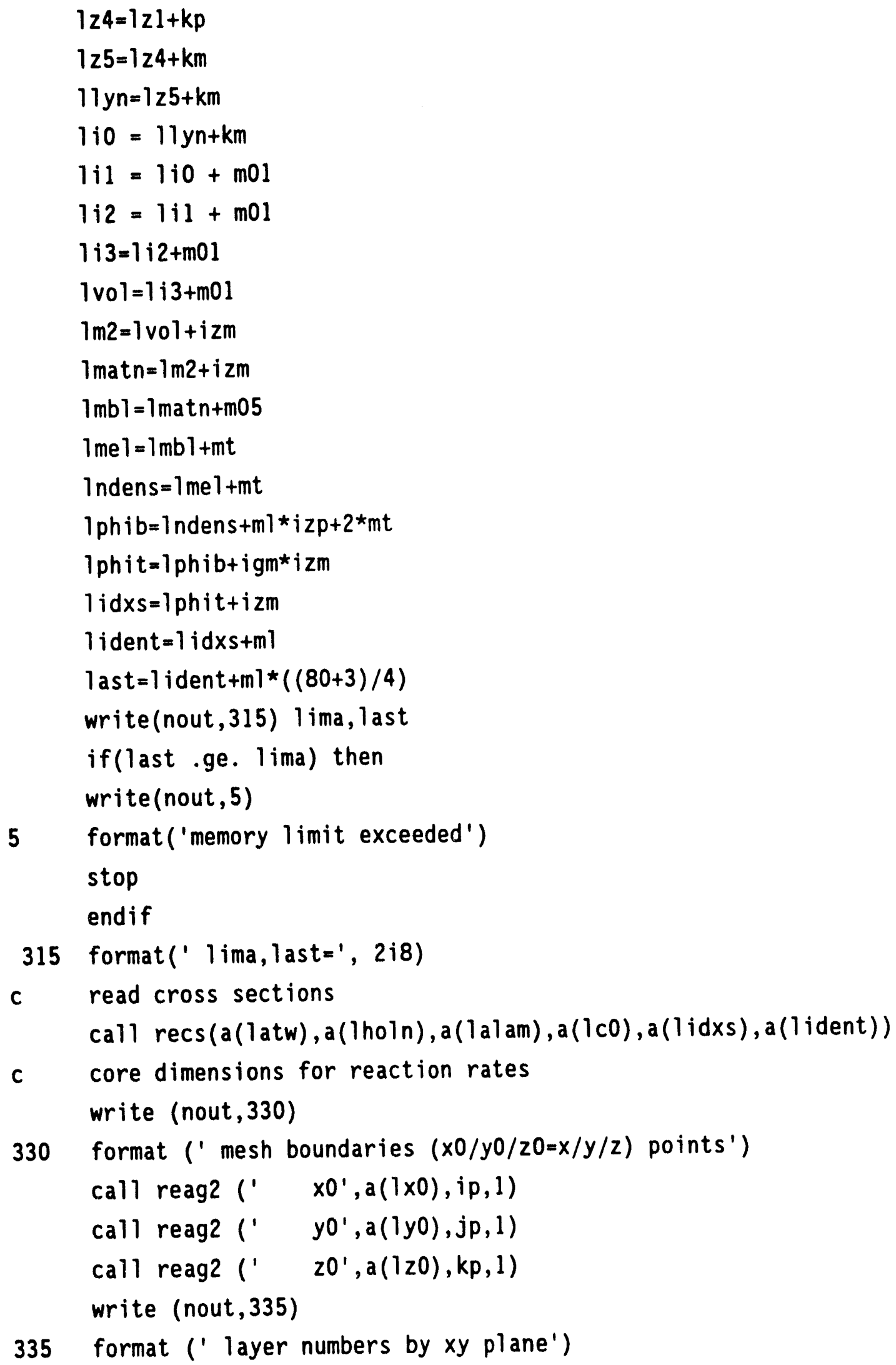


call reai2 (' lyn', a(11yn), km, 1)

itemp $=0$

do $345 n=1, n 1$ ay

write (nout,340) $n$

340 format(' zone numbers by mesh interval for layer'i3)

call reai2 (' mo',a(1m0+itemp), imjm,0)

345 itemp $=i$ temp $+i m j m$

write (nout, 350)

350 format (' material numbers by zone')

call reai2 (' $\left.\mathrm{m} 2{ }^{\prime}, \mathrm{a}(1 \mathrm{~m} 2), \mathrm{izm}, 1\right)$

write (nout, 360)

360 format (' mixture specifications ( $i 0 / i 1 / i 2=m i x$ number/mat. number'

1 'for mix/material density)')

call reaiz (' $\left.i 0^{\prime}, a(1 i 0), m 01,0\right)$

call reai2 (' $\left.i 1^{\prime}, a(1 i 1), \mathrm{m01}, 0\right)$

call reag2 (' i2',a(1i2), m01,0)

write (nout, 370)

370 format(' materials used for reaction rate calculations')

call reai2 (' matn',a(1matn), m05,0)

call inpr(a(lmatn), a(lident))

570 return

end

subroutine erro2( hol, jsubr,i)

common ninp, nout, iha, ihf, ihs, imjm, ip,

1

common igm, itl, iht, ige, izm, nlay, mt,

$1 \mathrm{m0l}, \mathrm{ml}, \mathrm{im}, \mathrm{jm}, \mathrm{km}, \mathrm{iz}, \mathrm{jz}$,

$2 \mathrm{kz}$, itemp, itempl, m05

common latw, lholn, lalam, lco, lno, lz4, lio,

$1 \quad 1 \mathrm{il}, 1 \mathrm{i} 2,1 \mathrm{i}, 1 \mathrm{m0}, 1 \mathrm{~m} 2,1 \times 0,1 \times 1$,

2 1vo, lyo, lyl, Ivol, Indens, Imatn, Ifrt,

3 1phib, Imstr, 120, 1z1, 11yn, last, 1mbl,

4 Imel, lidxs, lident, lart, 125, lphit,

5 1srt, 1fnrt, 1x4, 1x5, 1y4, ly5

write (nout,1) hol,jsubr 
1 format (' *'/' error in',a6, ' at',i6/'*'/'*')

go to $(3,4), i$

3 stop

4 return

end

subroutine reag2 (holl, array, ncount, jpr)

dimension array (1), v(12), $k(12)$, in (12)

character holl*(*)

common ninp, nout, iha, ihf, ihs, imjm, ip,

1

common igm, itl, iht, ige, izm, nlay, mt,

$1 \mathrm{m01}, \mathrm{ml}, \mathrm{im}, \mathrm{jm}, \mathrm{km}, \mathrm{iz}, \mathrm{jz}$,

$2 \quad k z$, itemp, itempl, m05

common latw, lholn, lalam, lco, lno, 124, lio,

1 1il, 1i2, 1i3, 1mo, 1m2, $1 \times 0,1 \times 1$,

2 Ivo, lyo, lyl, 1vol, Indens, Imatn, Ifrt,

3 Iphib, Imstr, 120, 1zl, 11yn, 1ast, 1mbl,

4 Imel, lidxs, lident, lart, 125, lphit,

$5 \quad$ 1srt, 1 fnrt, $1 \times 4, \quad 7 \times 5, \quad 7 y 4, \quad 7 y 5$

$j f l a g=0$

$j=1$

10 if (jflag) $20,40,20$

20 do $30 j j=1,6$

$k(j j)=k(j j+6)$

$\operatorname{in}(j j)=i n(j j+6)$

$30 \quad v(j j)=v(j j+6)$

$j f l a g=0$

go to 60

$40 \operatorname{read}(n i n p, 50)(k(i), i n(i), v(i), i=1,6)$

50 format $(6(i 1, i 2, e 9.4))$

60 do $140 \quad i=1,6$

$1=k(i)+1$

go to $(70,80,100,150,132,140,62), 1$

c fill

$62 j j=j$ 
do $65 m=j j$, ncount

$$
\operatorname{array}(j)=v(i)
$$

$65 j=j+1$

go to 150

c no modification

$70 \quad \operatorname{array}(j)=v(i)$

$j=j+1$

go to 140

c repeat

$80 \quad 1=i n(i)$

do $90 \mathrm{~m}=1,1$

$\operatorname{array}(j)=v(i)$

$j=j+1$

90 continue

go to 140

c interpolate

100 if $(i-6) 120,110,110$

$110 \operatorname{read}(n i n p, 50)(k(j j), i n(j j), v(j j), j j=7,12)$

jfl ag=l

$120 \quad 1=i n(i)+1$

del $=(v(i+1)-v(1)) /$ float $(1)$

do $130 \mathrm{~m}=1,1$

$\operatorname{array}(j)=v(i)+$ de $1 *$ float $(m-1)$

$j=j+1$

130 continue

go to 140

c cycle

$132 \quad 1=i n(i)$

$n=\operatorname{int}(.00001+v(i))$

do $135 \quad 11=1,1$

do $135 n n=1, n$

$\operatorname{array}(j)=\operatorname{array}(j-n)$

$135 \quad j=j+1$

140 continue

go to 10 


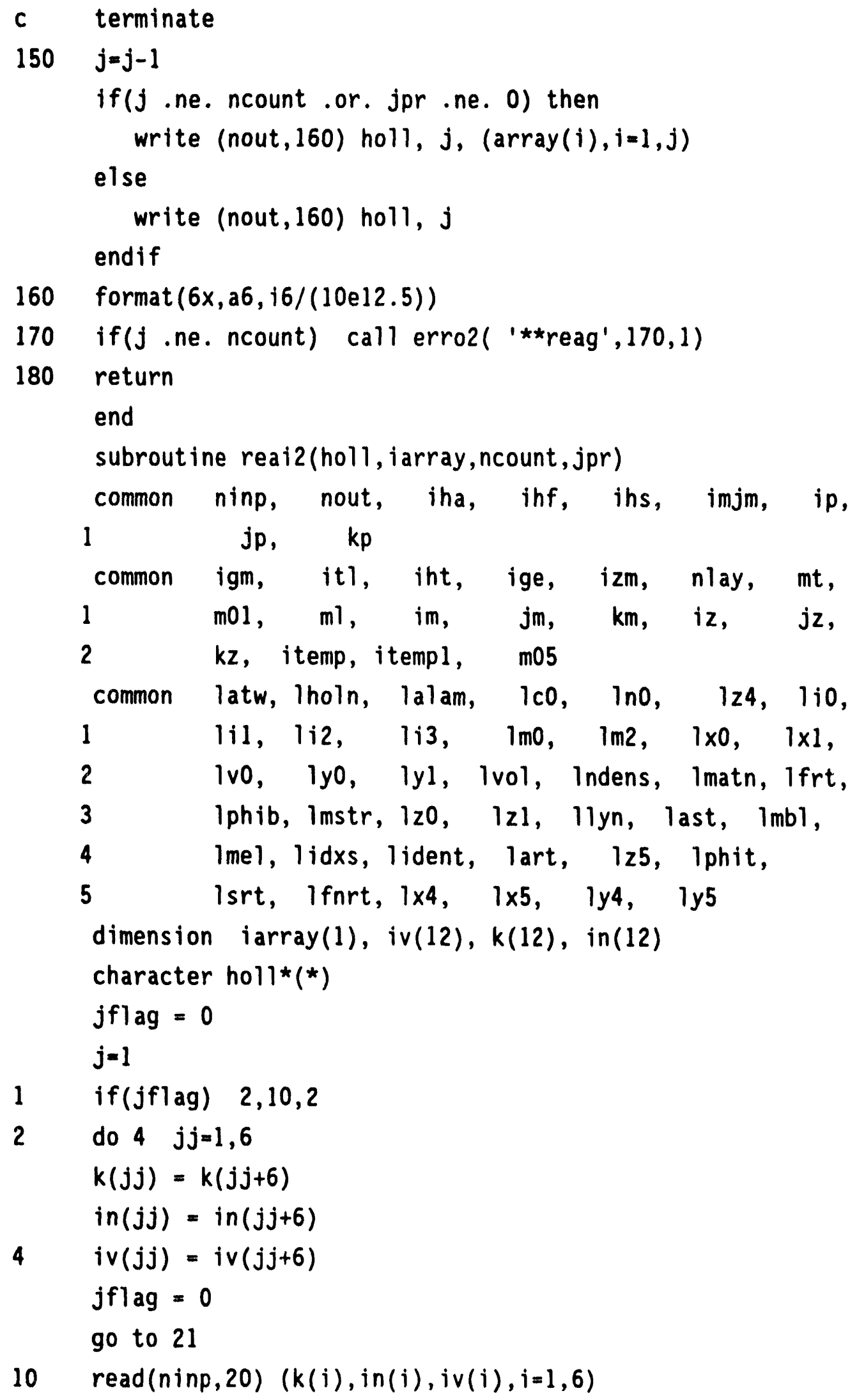




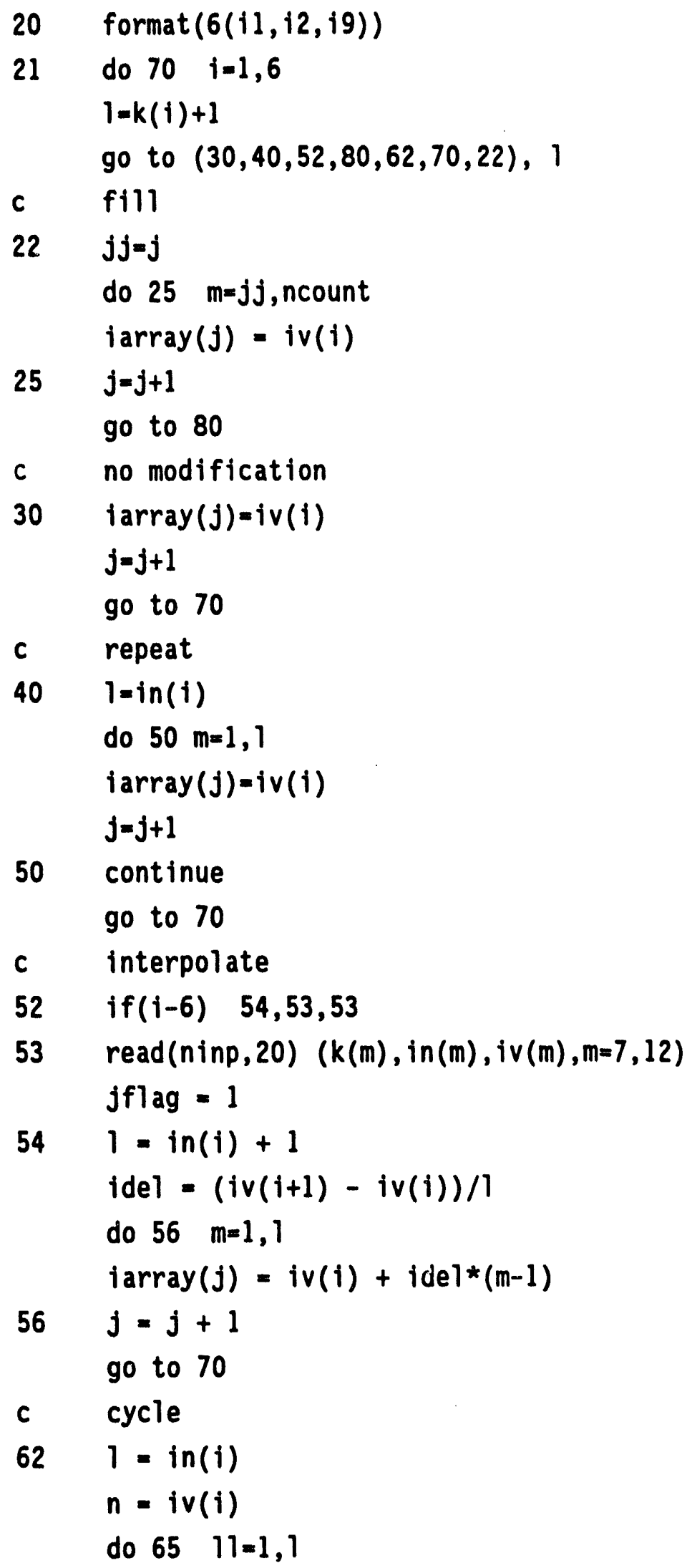




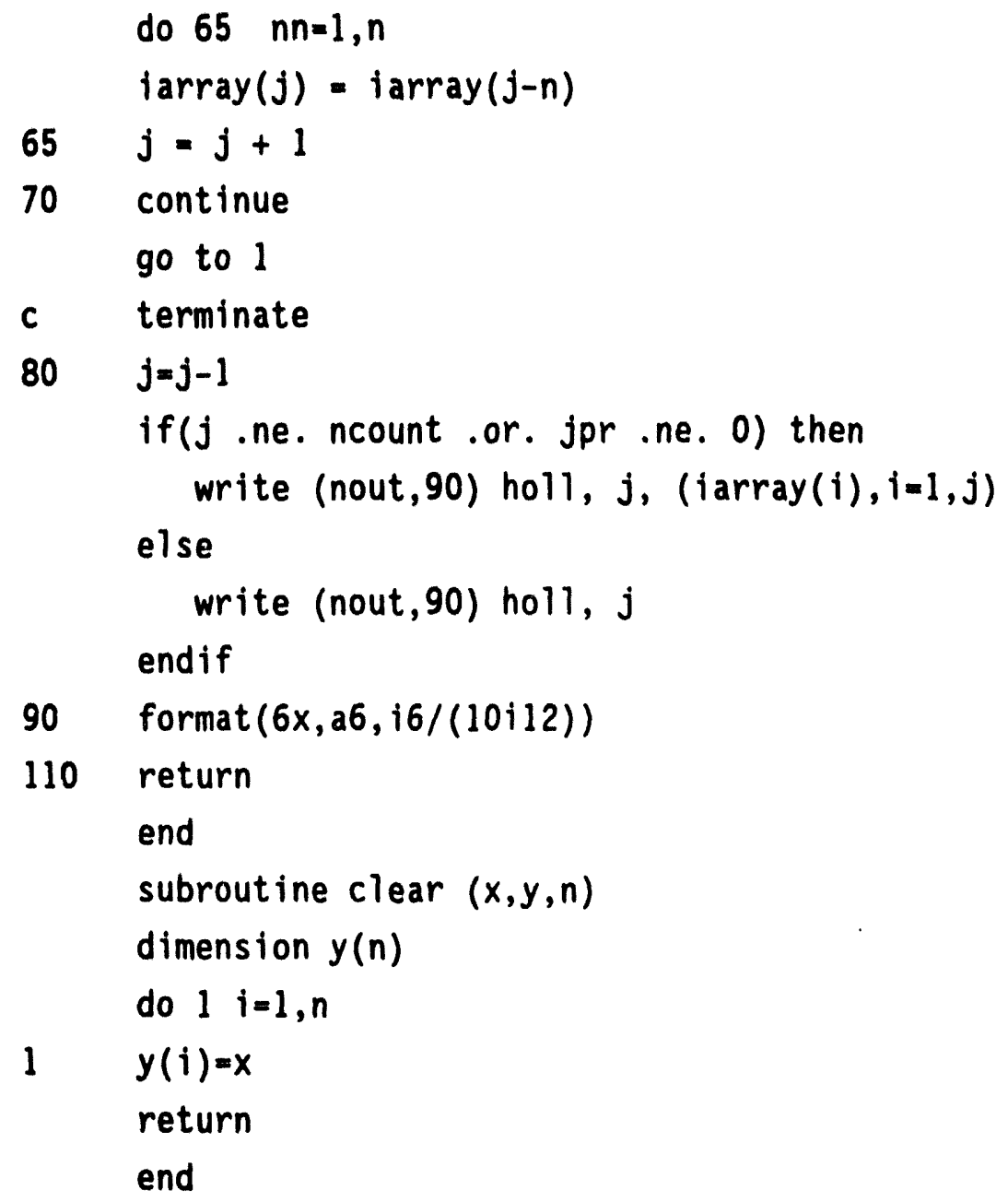


dimension $\mathrm{cO}(\mathrm{ml}, \mathrm{itt}, \mathrm{igm}), \mathrm{frt}(\mathrm{m05}, \mathrm{izm}, \mathrm{igm}), \operatorname{art}(\mathrm{m05}, \mathrm{izm}, \mathrm{igm})$ dimension srt (m05, izm, igm), fnrt (m05, izm, igm), phib(izm, igm)

dimension atw(ml), alam(ml), matn (m05)

real ndens ( $m l, i z m)$

character ident $(\mathrm{ml}) \star 80$

open $(16$, fi 1 e $=$ ' rxout ', form= ' formatted', access = ' sequent $i a 1$ ',

1 status='unknown')

do $250 i=1$, m05

$1=\operatorname{matn}(i)$

write $(16,55)$ ident $(1)$

write $(16,60)$

do $200 \mathrm{kz}=1, \mathrm{izm}$

if (ndens $(1, k z)$.eq. 0 ) go to 200

write $(16,65)$

do 200 i $\mathrm{ig}=\mathrm{igm}, 1,-1$

$i q=((i g m+1)-i i g)$

$\operatorname{frt}(1, k z, i$ ig $)=n d e n s(1, k z) *$ phib $(k z, i j g) * c 0(1,1, i$ ig $) * 1000$

$\operatorname{art}(1, k z, i i g)=n d e n s(1, k z) * \operatorname{phib}(k z, i i g) * c 0(1,2, i i g) * 1000$

$\operatorname{fnrt}(1, k z, i i g)=n d e n s(1, k z) \star \operatorname{phib}(k z, i i g) * c 0(1,3, i i g) * 1000$

$\operatorname{srt}(1, k z, i i g)=($ ndens $(1, k z) *$ phib $(k z, i i g) * c 0(1, i$ ht,$i i g) * 1000)$

$\operatorname{srt}(1, k z, i i g)=\operatorname{srt}(1, k z, i i g)-\operatorname{art}(1, k z, i i g)$

55 format (/a80)

60 format(' group zone fission reaction rate absorption reaction

Irate scatter reaction rate nu fission reaction rate')

65 format(/)

write $(16,100) i q, k z$, frt $(1, k z, i i g), \operatorname{art}(1, k z, i i g), \operatorname{srt}(1, k z, i i g)$,

1 fnrt $(1, k z, i i g)$

100 format (i6, 16,6x, 1ple12.5,12x,1ple12.5,12x,1ple12.5,12x,1ple12.5)

200 continue

250 continue

return

end

subroutine dens (ndens, vol, atw, holn, mo, vo, i0, i1, i2, 25, iyn, 1 $\mathrm{mbl}$, mel, matn, m2, i3) 


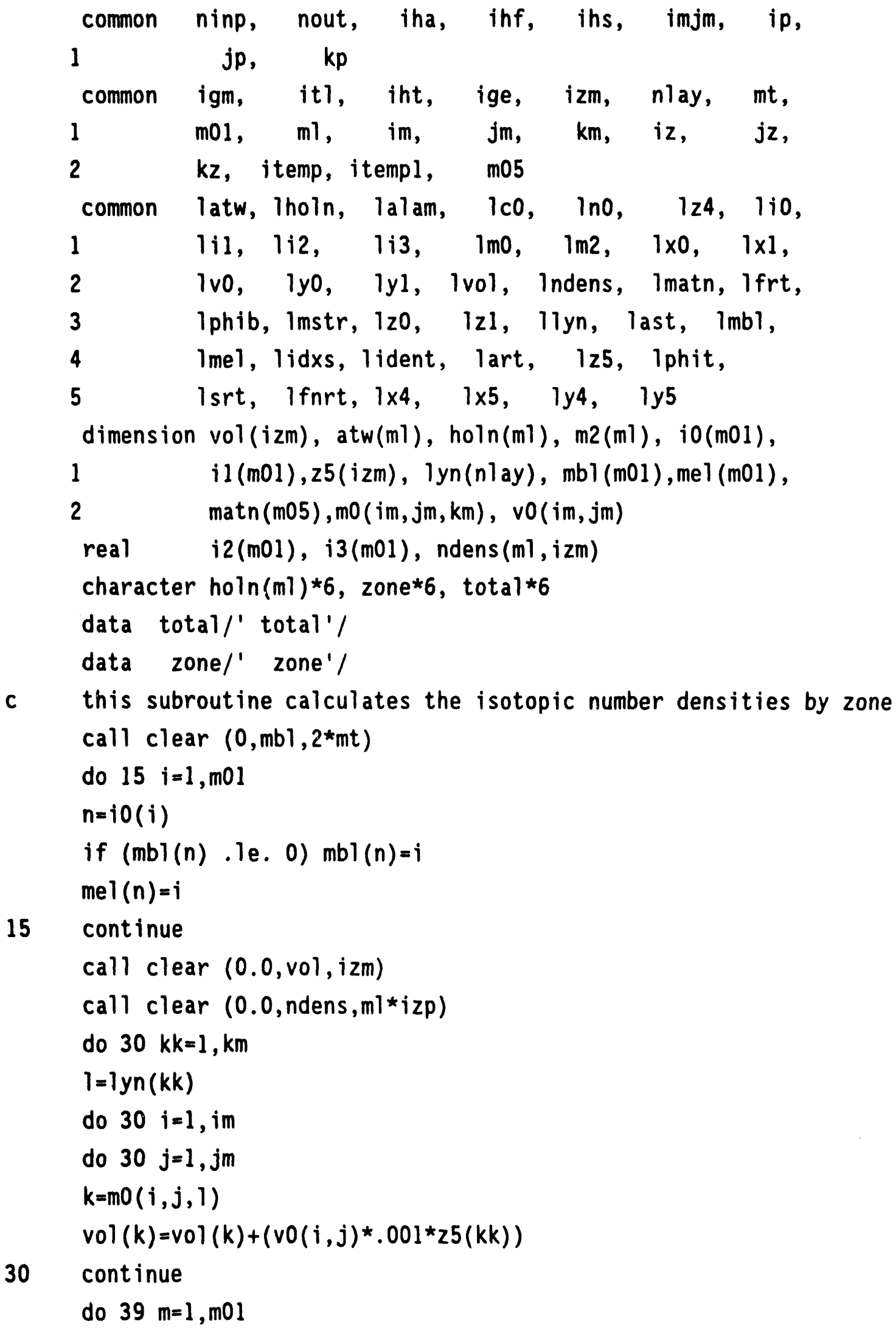




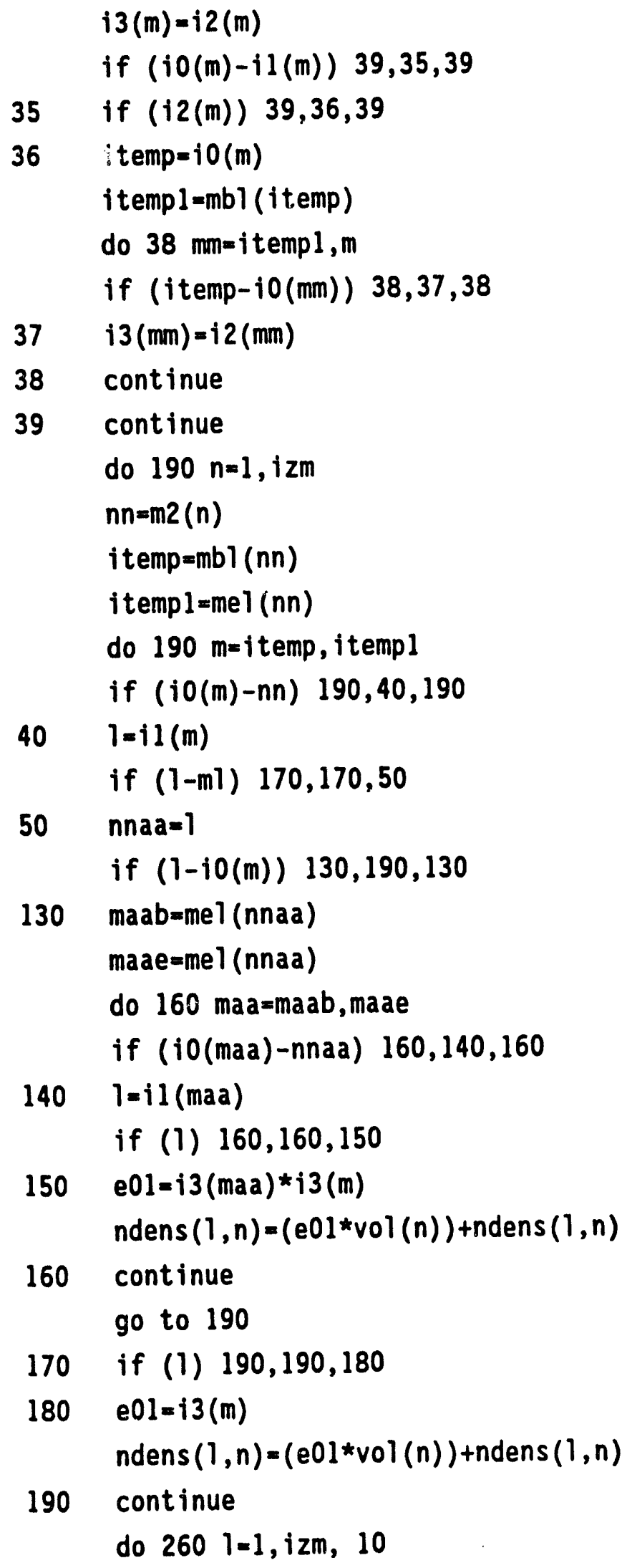




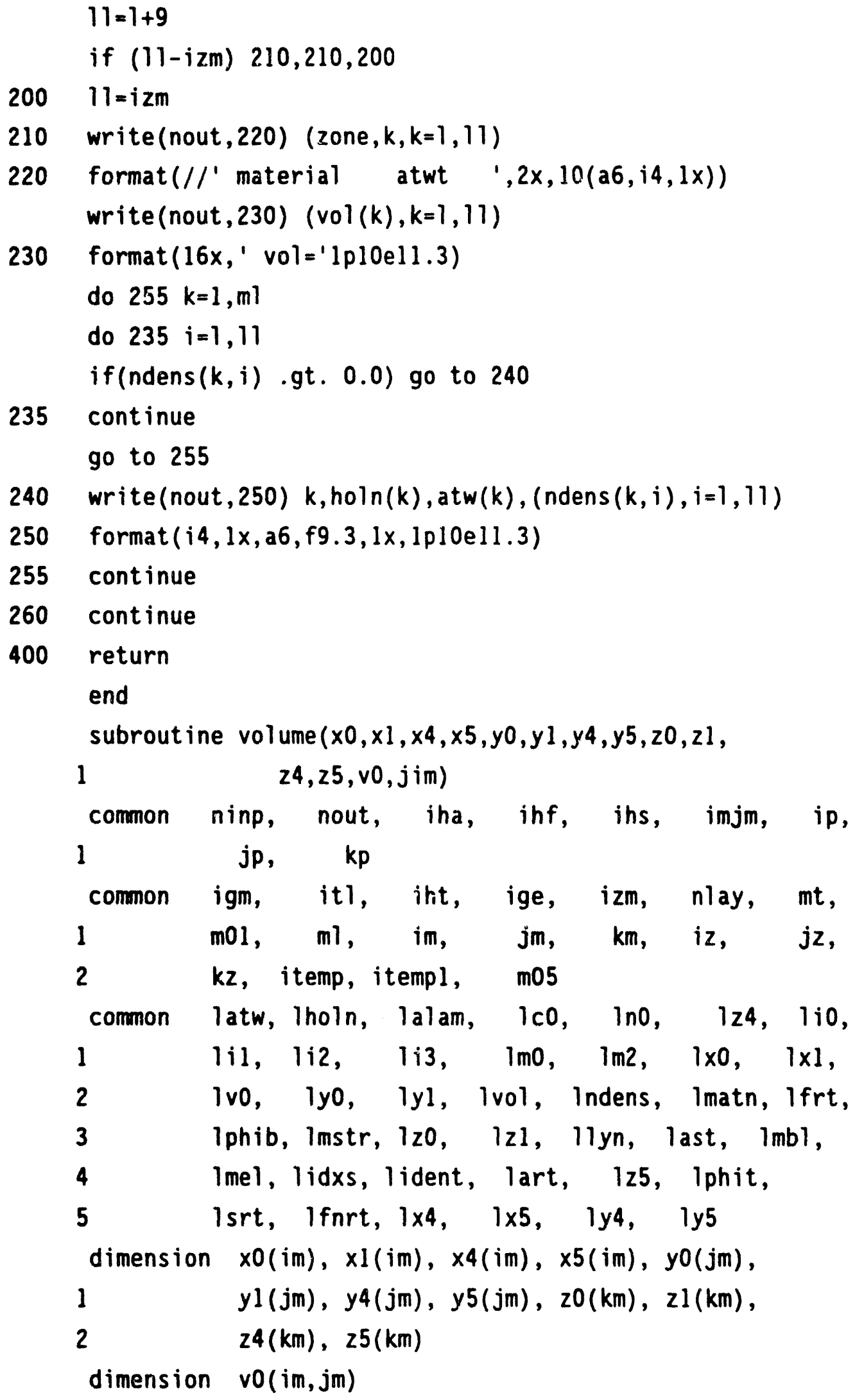


255 do $260 \quad i=1$, ip

$$
x l(i)=x O(i)
$$

260 continue

$$
\text { do } 265 j=1, j p
$$

$265 y 1(j)=y 0(j)$

do $268 k=1, k p$

$268 \quad z 1(k)=z 0(k)$

305 continue

c calculate areas and volumes.

315 continue

do $345 i=1$, im

$x 4(i)=(x 1(i+1)+x 1(i)) * 0.5$

$x 5(i)=x 1(i+1)-x 1(i)$

if $(x 5(i)) 320,320,325$

320 call erro2 $(6 h \star x 5(i), 320,1)$

325 continue

345 continue

do $370 \quad j=1, j m$

$y 4(j)=(y 1(j+1)+y 1(j)) \star 0.5$

$y 5(j)=y 1(j+1)-y 1(j)$

if $(y 5(j)) 350,350,355$

350 call erro2 $(6 h * y 5(j), 350,1)$

355 continue

do $370 \quad i=1$, im

$360 \quad v 0(i, j)=x 5(i) \star y 5(j)$

370 continue

$$
\begin{aligned}
& \text { do } 373 \quad k=1, k m \\
& z 4(k)=(z 1(k+1)+z 1(k)) * 0.5
\end{aligned}
$$$$
25(k)=21(k+1)-21(k)
$$

if $(25(k)) \quad 372,372,373$

372 call erro2 $(6 h \star 25(k), 372,1)$

373 continue

375 continue

380 return

end 
subrout ine average(phib, matn, vol, no, m0,vo, z5, lyn, phit) common ninp, nout, iha, ihf, ihs, imjm, ip, 1 common igm, itl, iht, ige, izm, nlay, mt, $1 \mathrm{m0l}, \mathrm{ml}, \mathrm{im}, \mathrm{jm}, \mathrm{km}, \mathrm{iz}, \mathrm{jz}$, $2 \quad k z$, itemp, itempl, m05 common latw, lholn, lalam, lco, lno, 124, lio, $1 \quad 1 i 1,1 i 2,1 i 3,1 \mathrm{mo}, 1 \mathrm{~m} 2,1 \times 0,1 \times 1$, 2 lvo, lyo, lyl, lvol, Indens, Imatn, ifrt, 3 Iphib, Imstr, 1zo, 1z1, 11yn, last, 1mbl, 4 Ime1, lidxs, lident, lart, 1z5, lphit, $5 \quad 1$ srt, $1 \mathrm{fnrt}, 1 \times 4,1 \times 5, \quad 1 \mathrm{y}, \quad 1 \mathrm{y} 5$ dimension phib(izm, igm), matn (m05), vol (izm), z5(km), lyn (km) dimension phit(izm), vo(imjm) dimension mo(imjm, izm) real no(imjm)

call clear (0.0,phib, izm*igm)

call clear $(0.0$, phit, izm)

open (3, file = ' fl xinp' , form= ' unformatted', access = ' sequential ' ,

1 status $=$ ' old' ')

do $105 \mathrm{i}$ ig=1, igm

do $105 \mathrm{kk}=1, \mathrm{~km}$

$1=1 \mathrm{yn}(\mathrm{kk})$

$40 \operatorname{read}(3)$ (no(i), $i=1$, imjm)

do $50 \mathrm{i} i=1$, imjm

$k z=m 0(i i, 1)$

phib $(k z, i i g)=p h i b(k z, i i g)+n 0(i i) * v 0(i i) \star z 5(k k)$

50 continue

105 continue

do $250 \mathrm{kz}=1$, izm

do 250 i $i g=1$, igm

vol $k z=v 01(k z) * 1000$

phib $(k z, i i g)=p h i b(k z, i i g) /$ volkz

phit $(k z)=p h i t(k z)+p h i b(k z, i i g)$

250 continue 


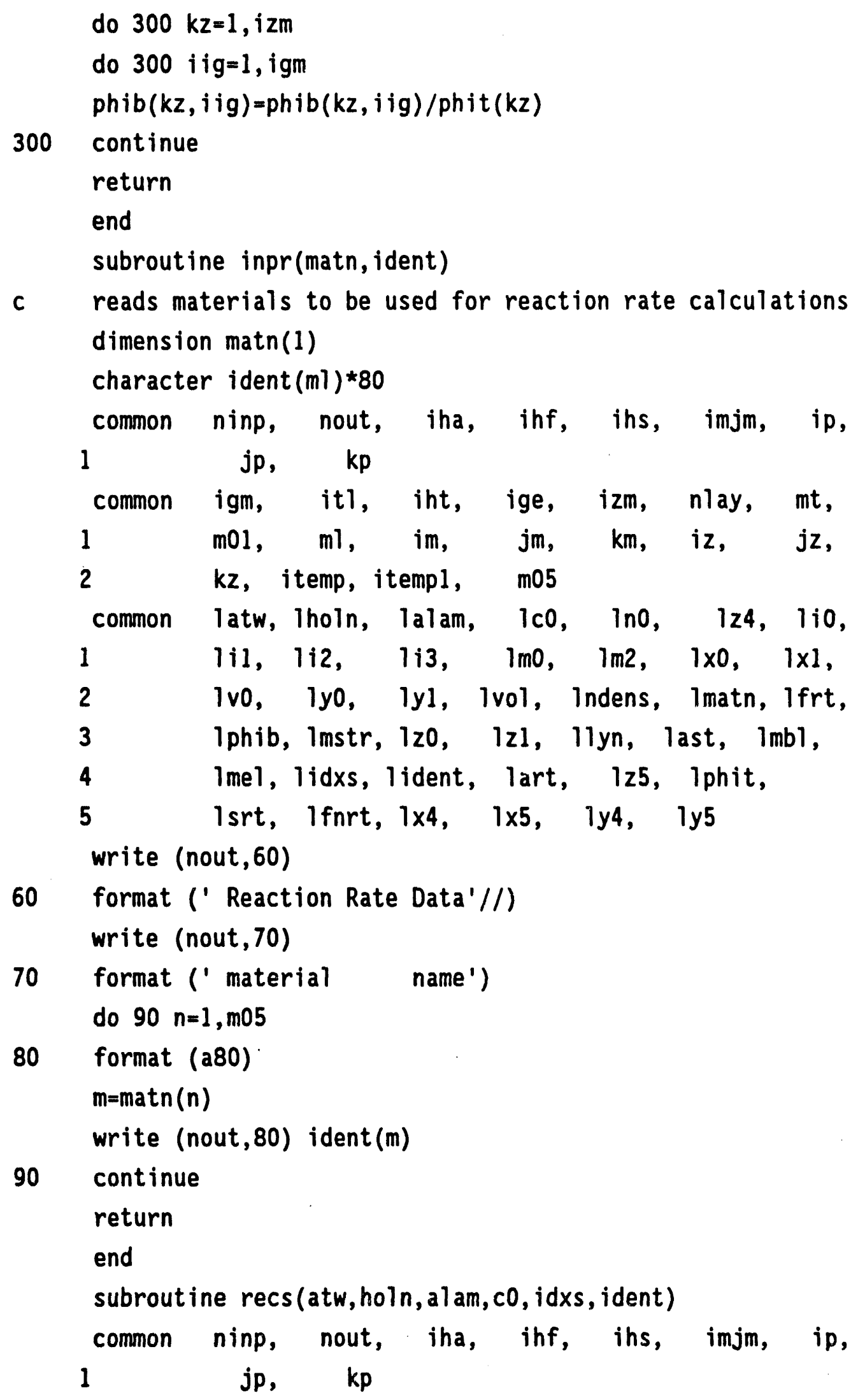




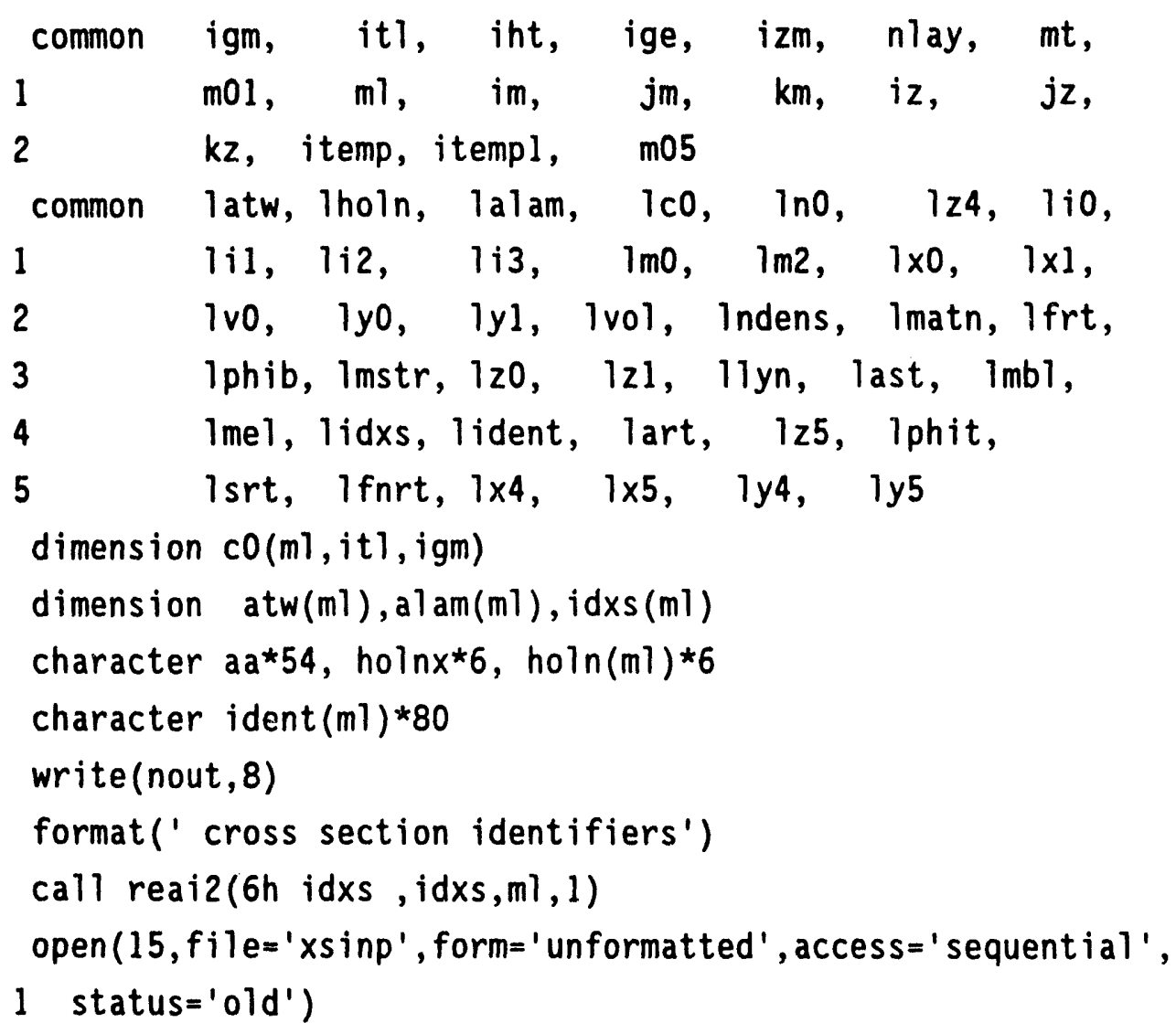

10 write(nout, 20)

20 format (' cross sections are read in for the following materials') do $50 \mathrm{n}=1, \mathrm{ml}$

$m=n$

$35 \operatorname{read}(15, e n d=500)$ holnx, atwx, al amx, aa

$\operatorname{read}(a a, 36)$ itemp

36 format $(49 x, i 5)$

do $45 \mathrm{j}=1, \mathrm{ml}$

if (itemp.ne. idxs $(j))$ go to 45

$m=j$

$h 0 \ln (m)=h_{0} \ln x$

$\operatorname{atw}(m)=\operatorname{atw} x$

a $\operatorname{am}(m)=a)$ amx

$i d x s(m)=-i d x s(m)$

$\operatorname{read}(15)((\mathrm{co}(\mathrm{m}, \mathrm{i}, \mathrm{iig}), i=1, i \mathrm{t} 1), i \mathrm{ig}=1, \mathrm{igm})$

go to 48

45 continue 
read(15)

go to 35

48 write(ident (m), 55) 


\section{APPENDIX C: Reaction Rates}

Figures $C-1$ through $C-108$ show the absorption, fission, and capture macroscopic reaction rates for the three fuel types. These figures present a detailed study of each major heavy metal isotope in the reactor to show how the reaction rates change as the neutron spectrum hardens. In the oxide and nitride cores, the oxygen and nitrogen serve to limit the spectral hardening as the sodium voids. Thus, the change in the reaction rates is small compared to the metal core. This can be seen in the figures. Also, it can be seen that all the nonfissile isotopes, i.e., ${ }^{239} \mathrm{U},{ }^{240} \mathrm{Pu}$, and ${ }^{242} \mathrm{Pu}$, contribute to the positive sodium void effect. This is due to their fission reaction rates which are not significant at low neutron energies but become significant as the neutron spectrum hardens. Therefore, the more the spectrum hardens as the sodium voids, the more positive the sodium void effect. 


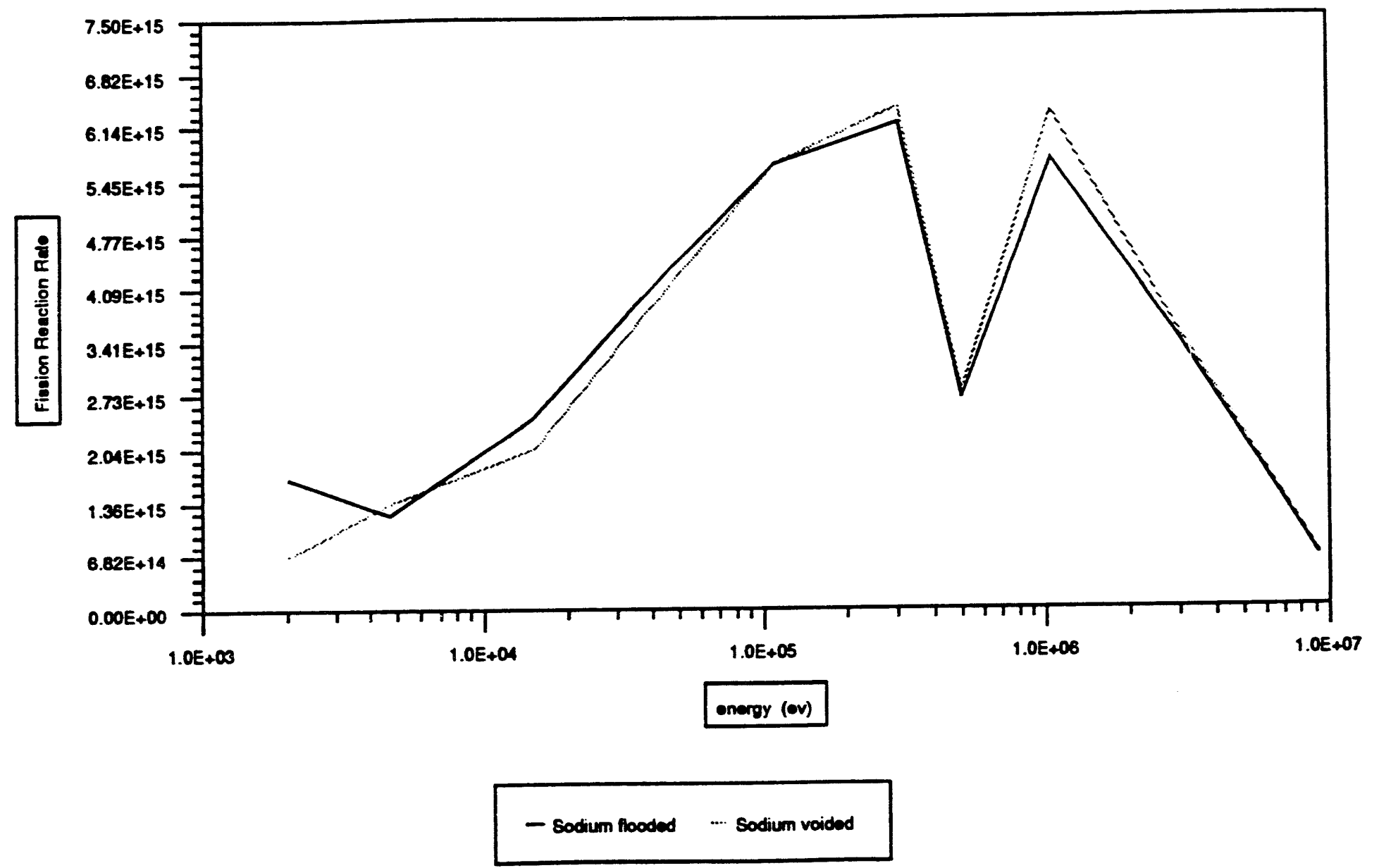

FIGURE C-1: Fission Reaction Rate for ${ }^{239} \mathrm{Pu}$ in an 0xide Inner Fuel Assembly. 


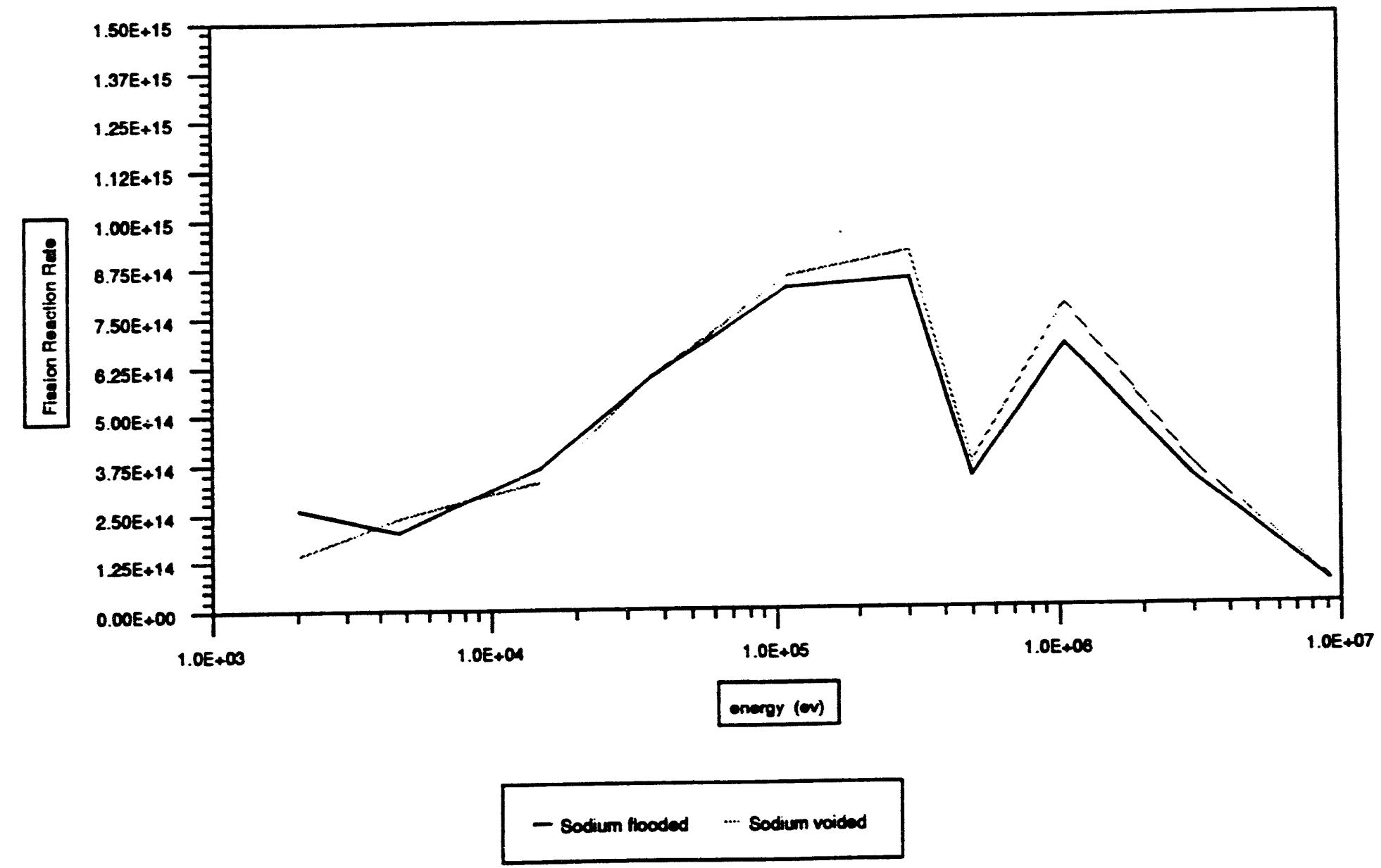

$\underset{\omega}{\sim}$

FIGURE C-2: Fission Reaction Rate for ${ }^{239} \mathrm{Pu}$ in an 0xide 2 Cycle Radial Blanket. 


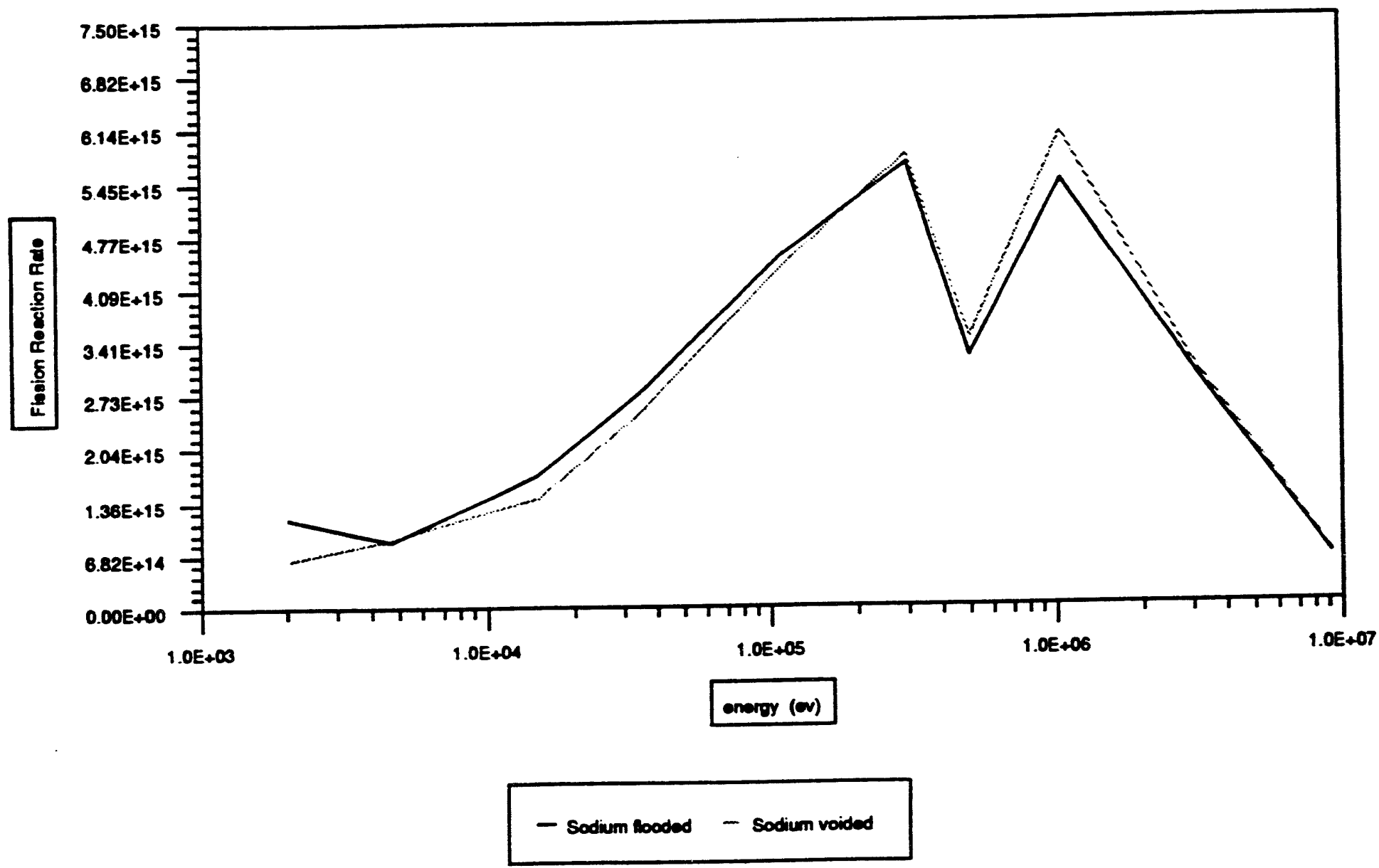

FIGURE C-3: Fission Reaction Rate for ${ }^{239} \mathrm{Pu}$ in a Nitride Inner Fuel Assembly. 


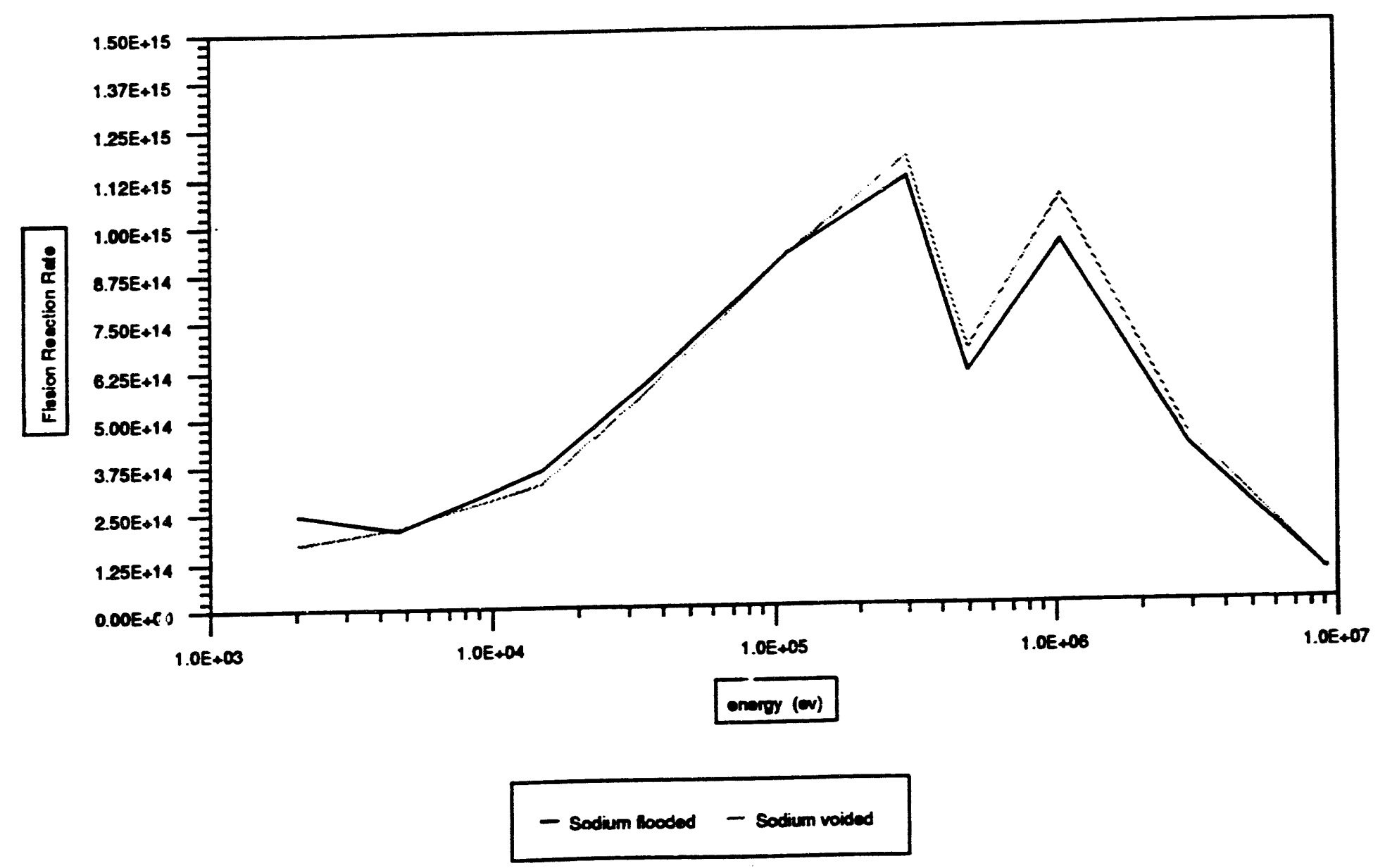

芯

FIGURE C-4: Fission Reaction Rate for ${ }^{239} \mathrm{Pu}$ in a Nitride 2 Cycle Radial Blanket. 


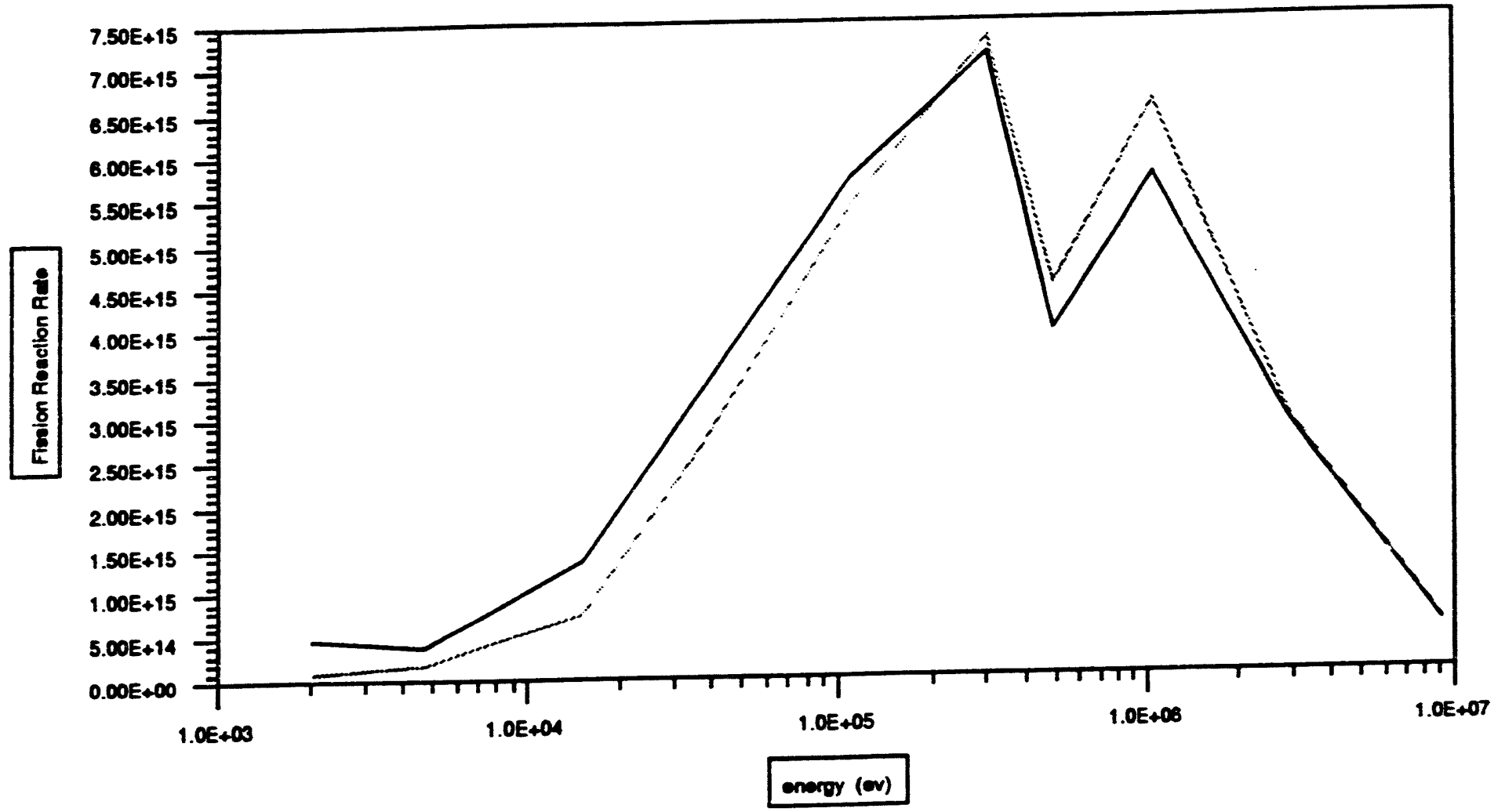

$\approx$

$$
\text { - Sodium flooded } \quad \text {.... Sodium voided }
$$

FIGURE C-5: Fission Reaction Rate for ${ }^{239} \mathrm{Pu}$ in a Metal Inner Fuel Assembly. 


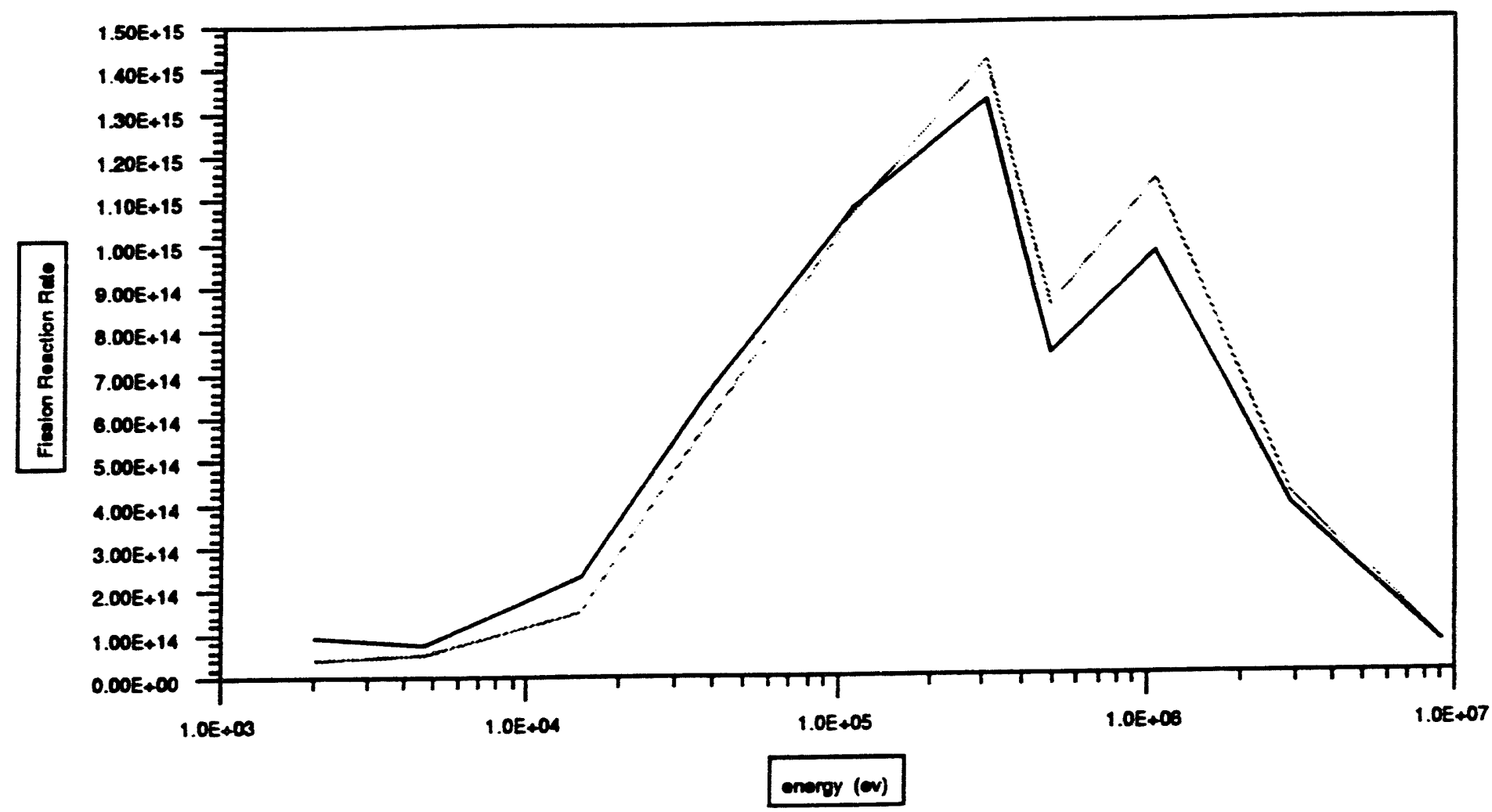

FIGURE C-6: Fission Reaction Rate for ${ }^{239} \mathrm{Pu}$ in a Metal 2 Cycle Radial Blanket. 


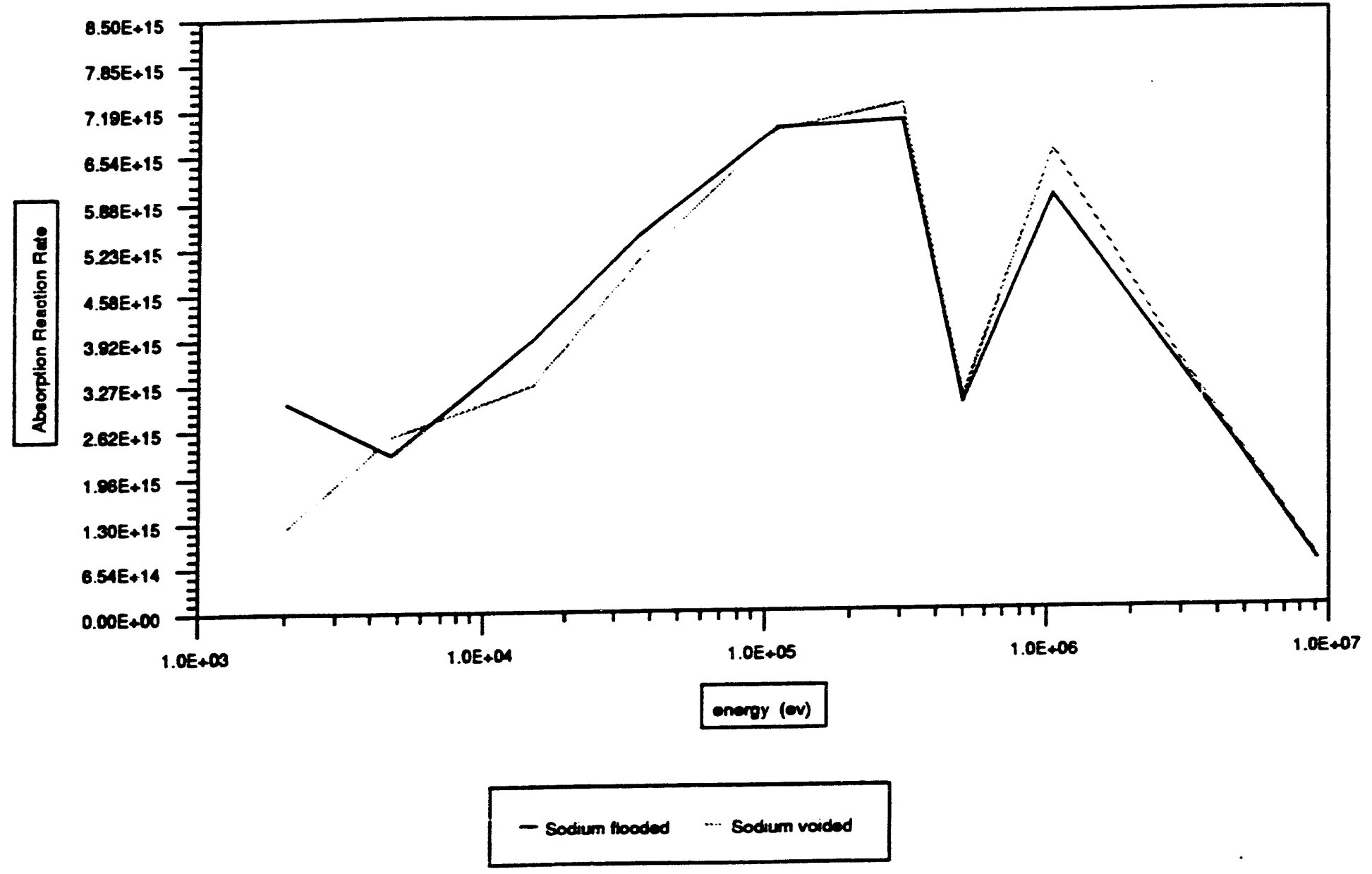

FIGURE C-7: Absorption Reaction Rate for ${ }^{239} \mathrm{Pu}$ in an Oxide Inner Fuel Assembly. 


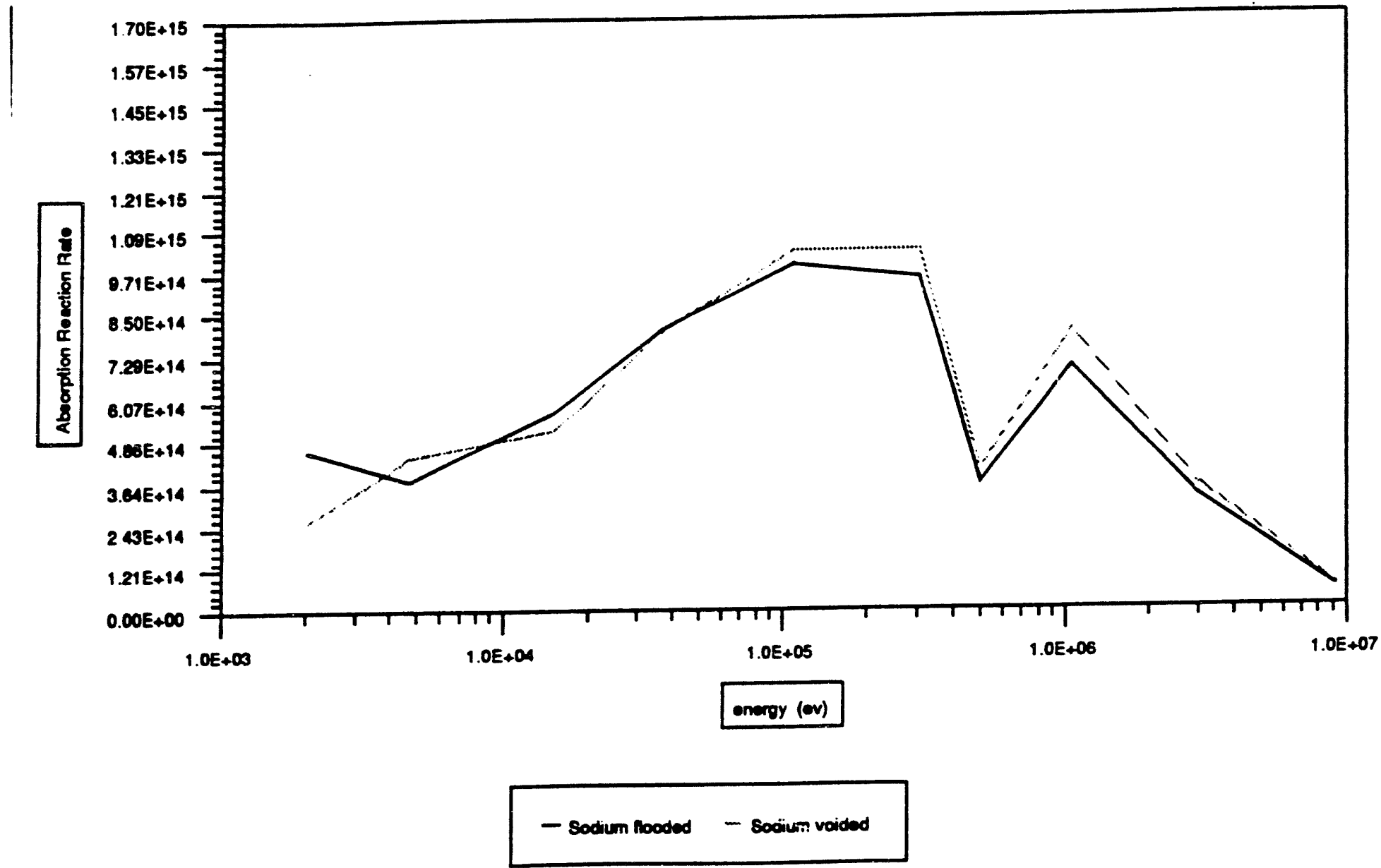

FIGURE C-8: Absorption Reaction Rate for ${ }^{239} \mathrm{Pu}$ in an 0xide 2 Cycle Radial Blanket. 


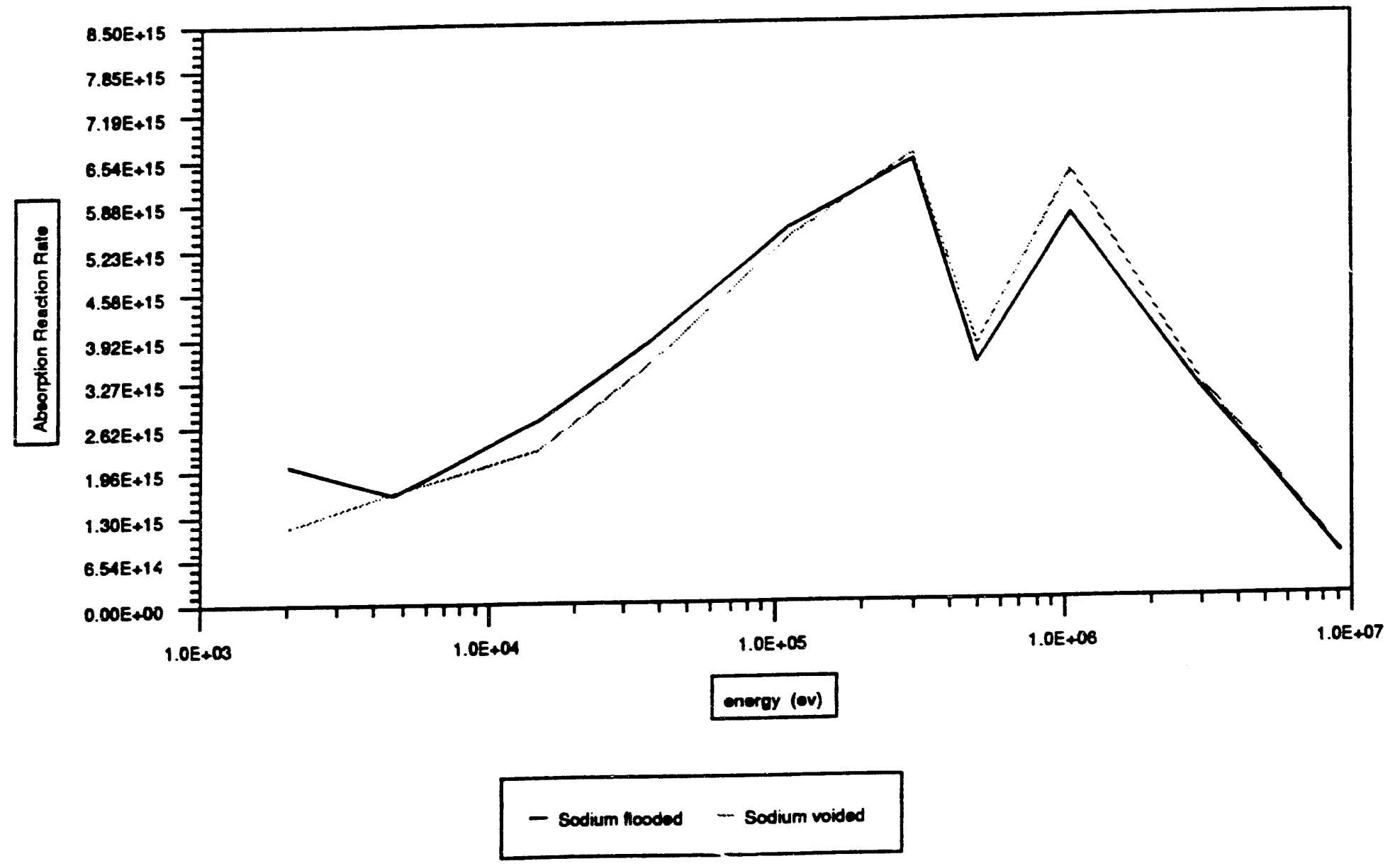

FIGURE C-9: Absorption Reaction Rate for ${ }^{239} \mathrm{Pu}$ in a Nitride Inner Fuel Assembly. 


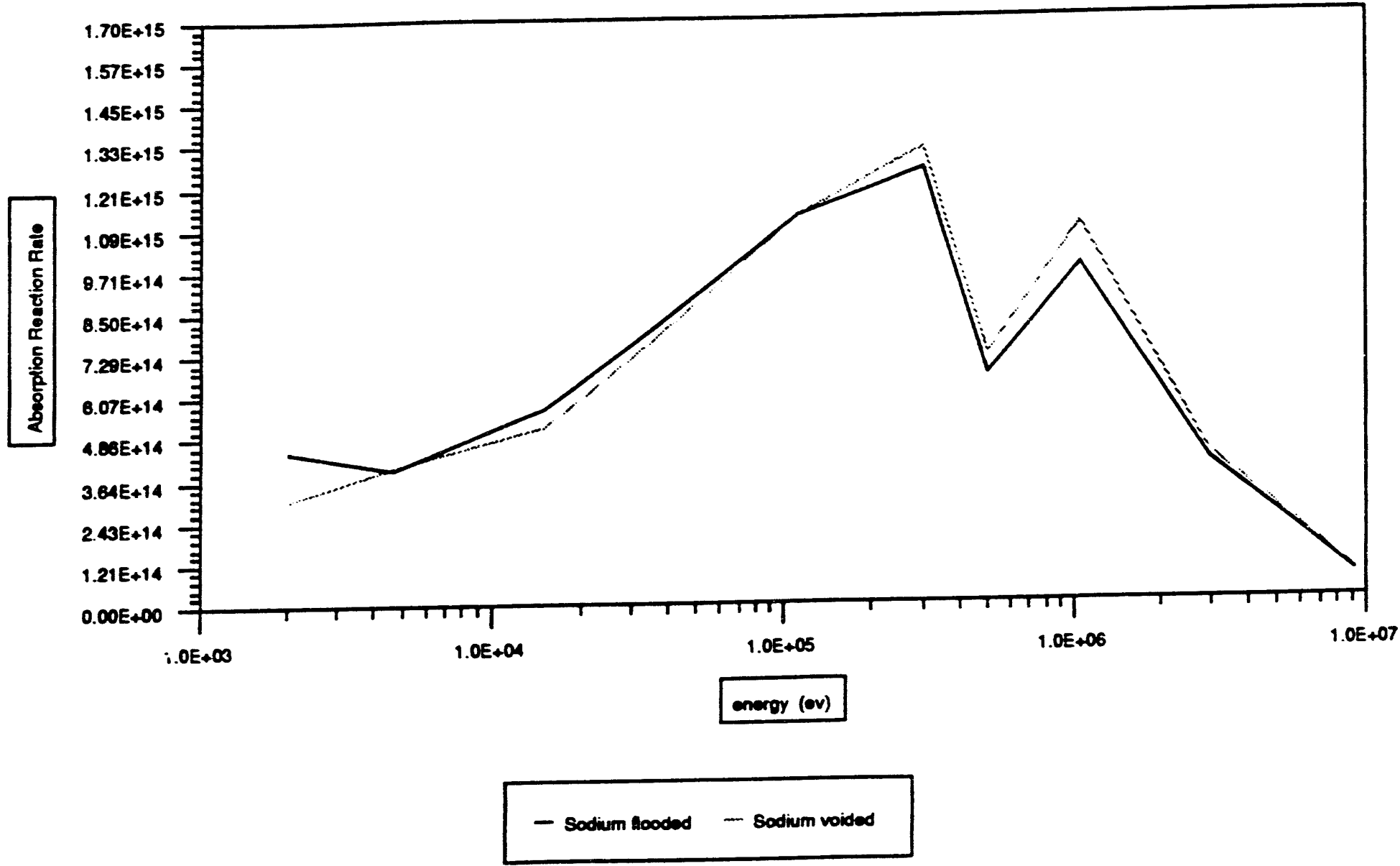

FIGURE C-10: Absorption Reaction Rate for ${ }^{239} \mathrm{Pu}$ in a Nitride 2 Cycle Radial Blanket. 


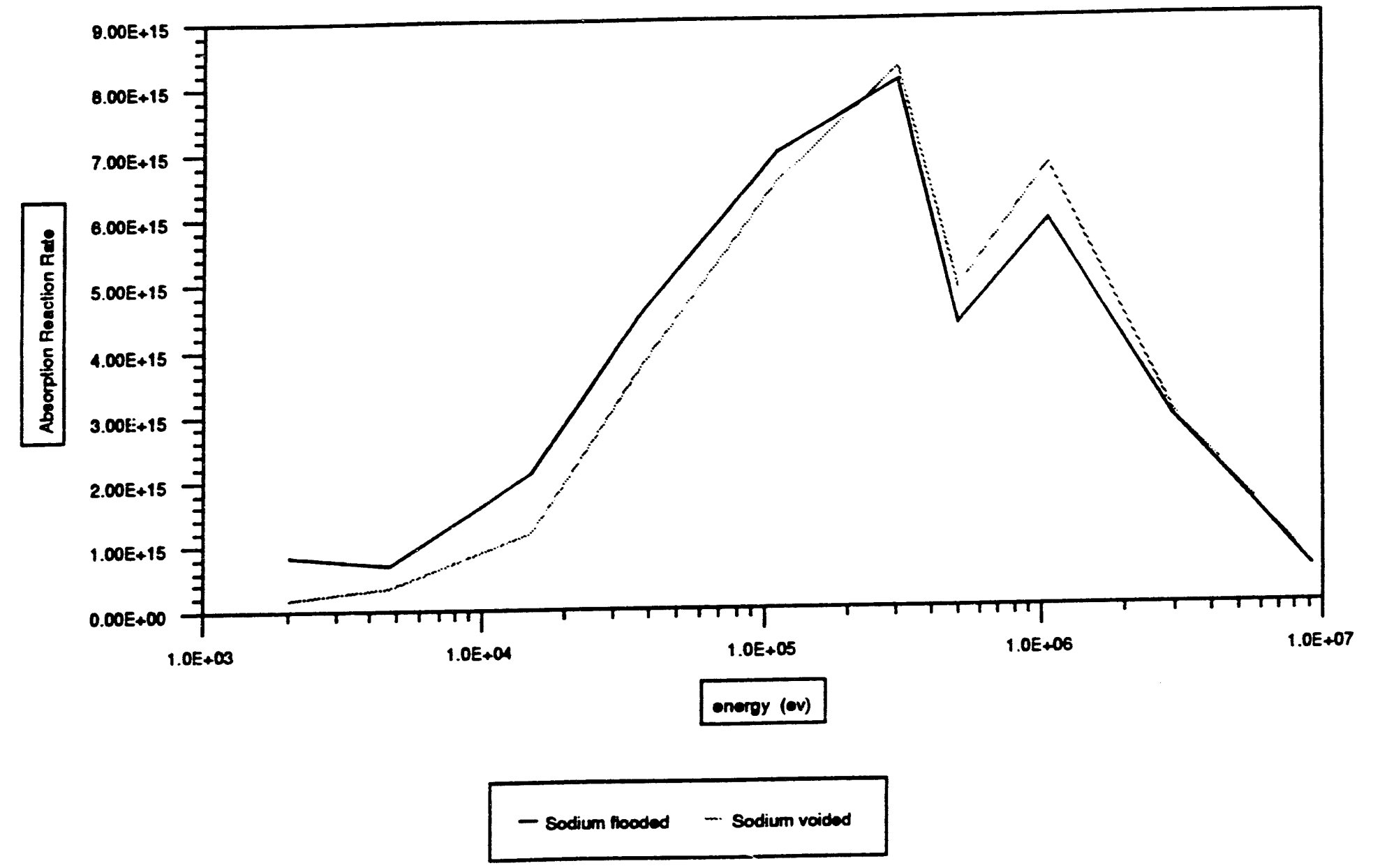

FIGURE C-11: Absorption Reaction Rate for ${ }^{239} \mathrm{Pu}$ in a Metal Inner Fuel Assembly. 


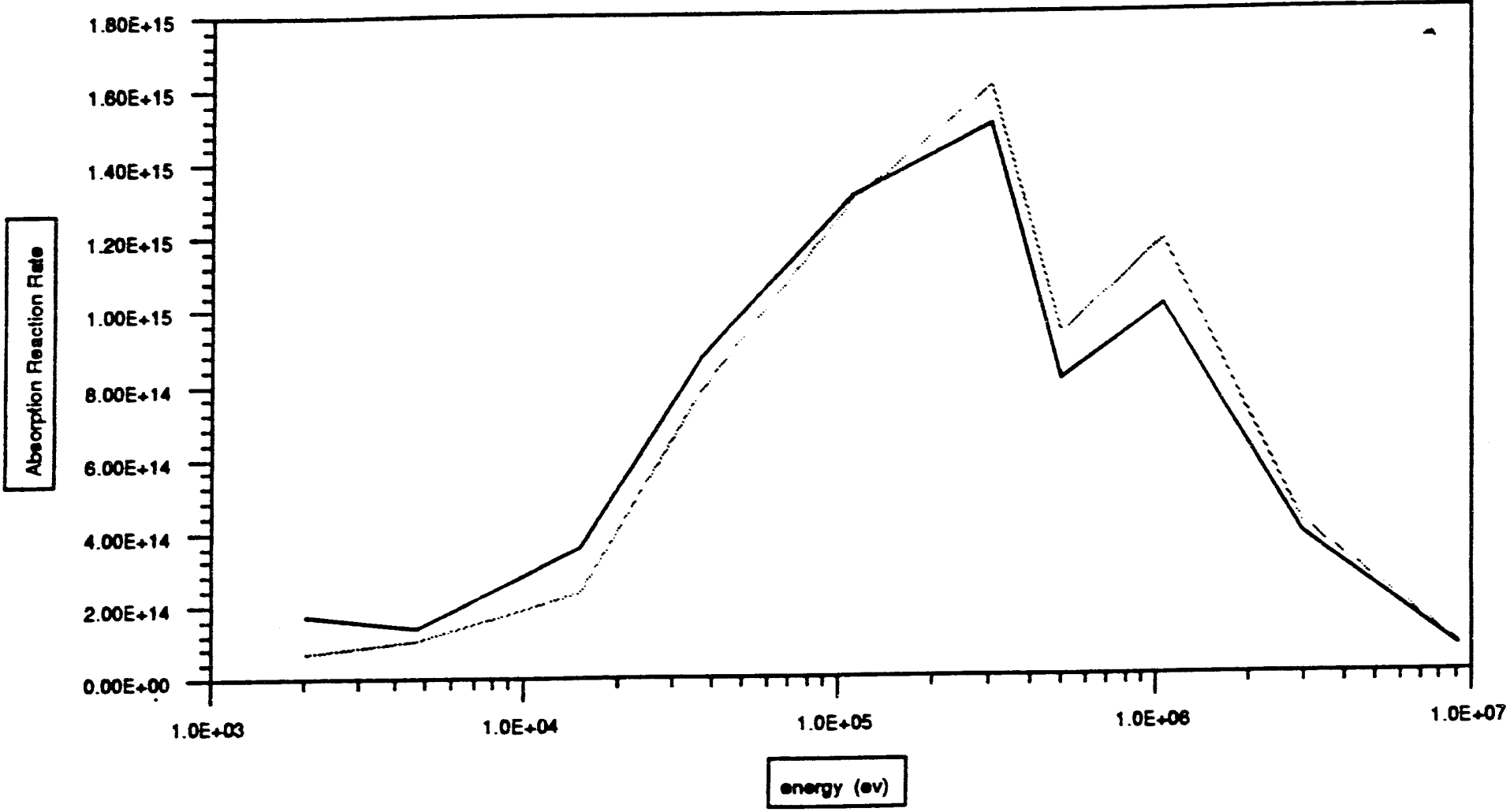

$$
\text { - Sodium flooded - Sodium voided }
$$

FIGURE C-12: Absorption Reaction Rate for ${ }^{239} \mathrm{Pu}$ in a Metal 2 Cycle Radial Blanket. 


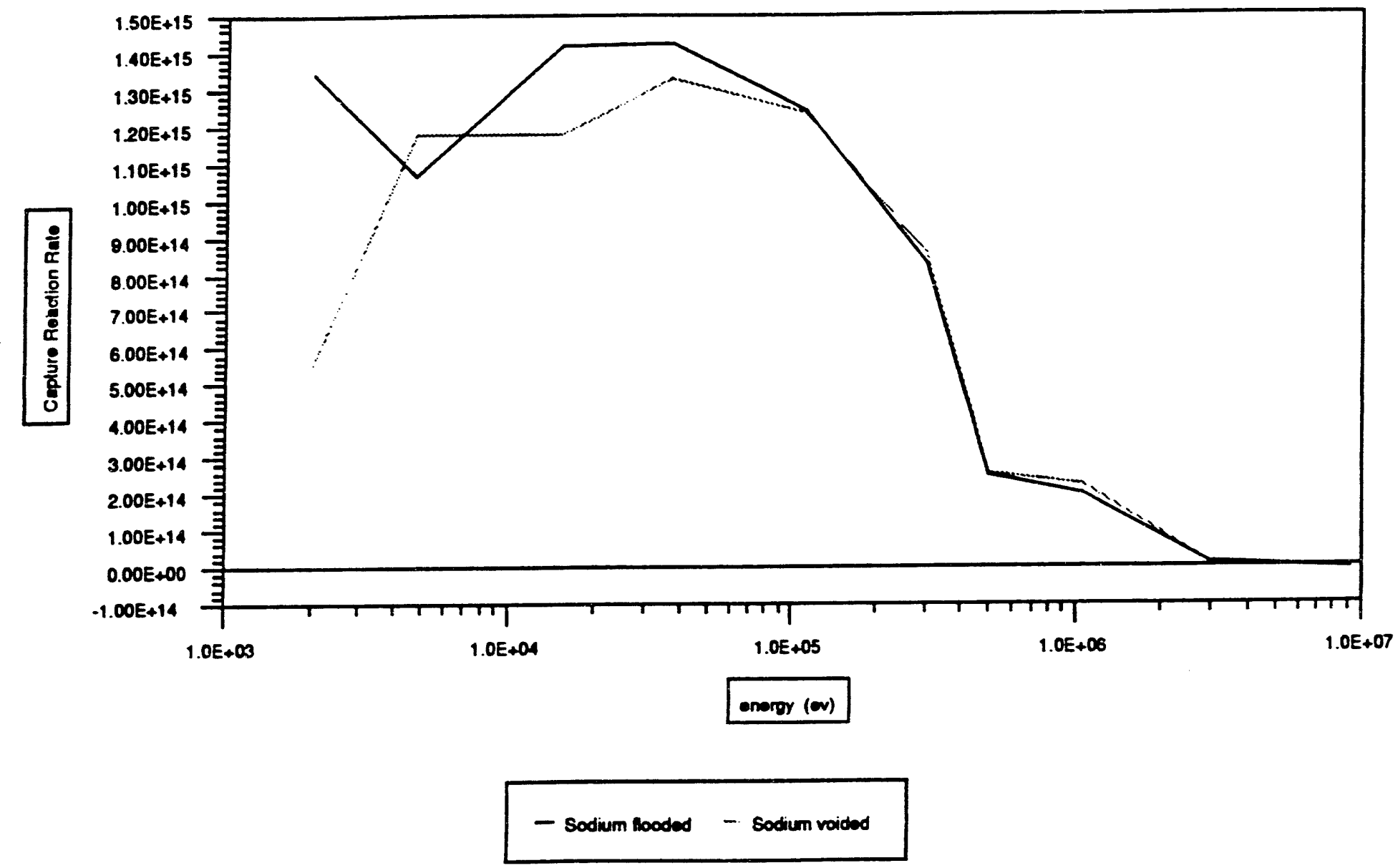

FIGURE C-13: Capture Reaction Rate for ${ }^{239} \mathrm{Pu}$ in an 0xide Inner Fuel Assembly. 


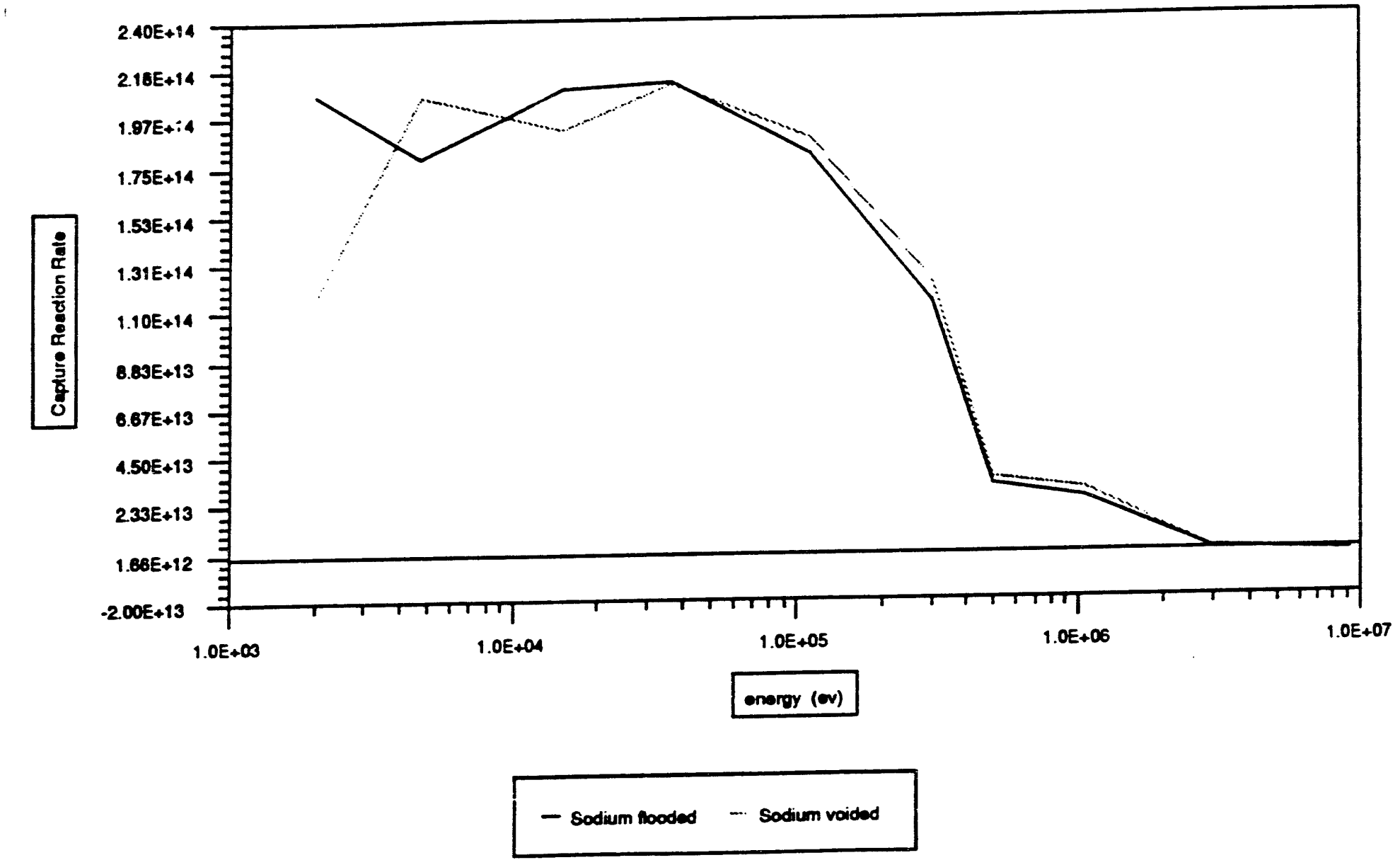

$\bar{\omega}$

FIGURE C-14: Capture Reaction Rate for ${ }^{239} \mathrm{Pu}$ in an 0xide 2 Cycle Radial Blanket. 


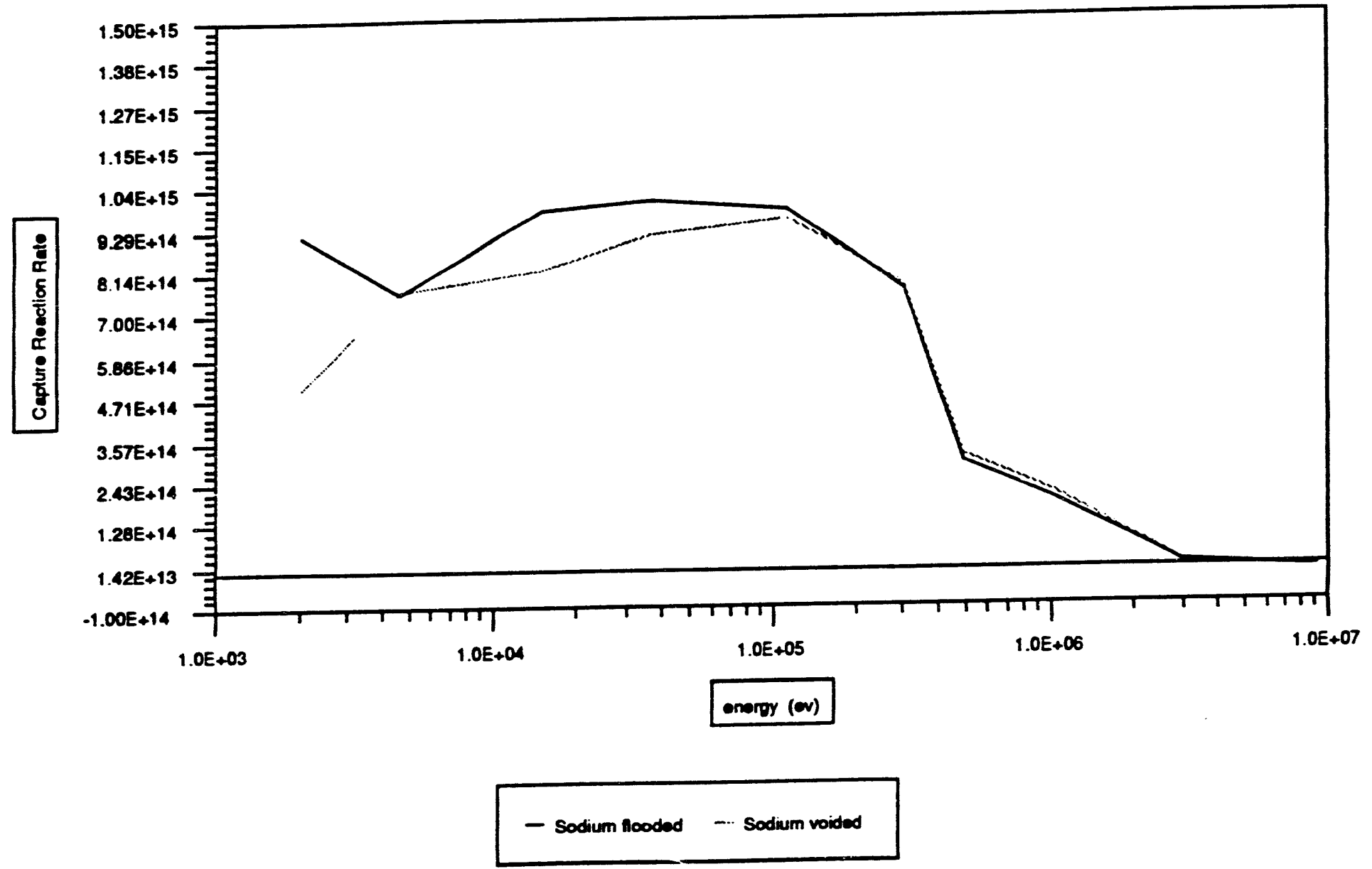

FIGURE C-15: Capture Reaction Rate for ${ }^{239} \mathrm{Pu}$ in a Nitride Inner Fuel Assembly. 


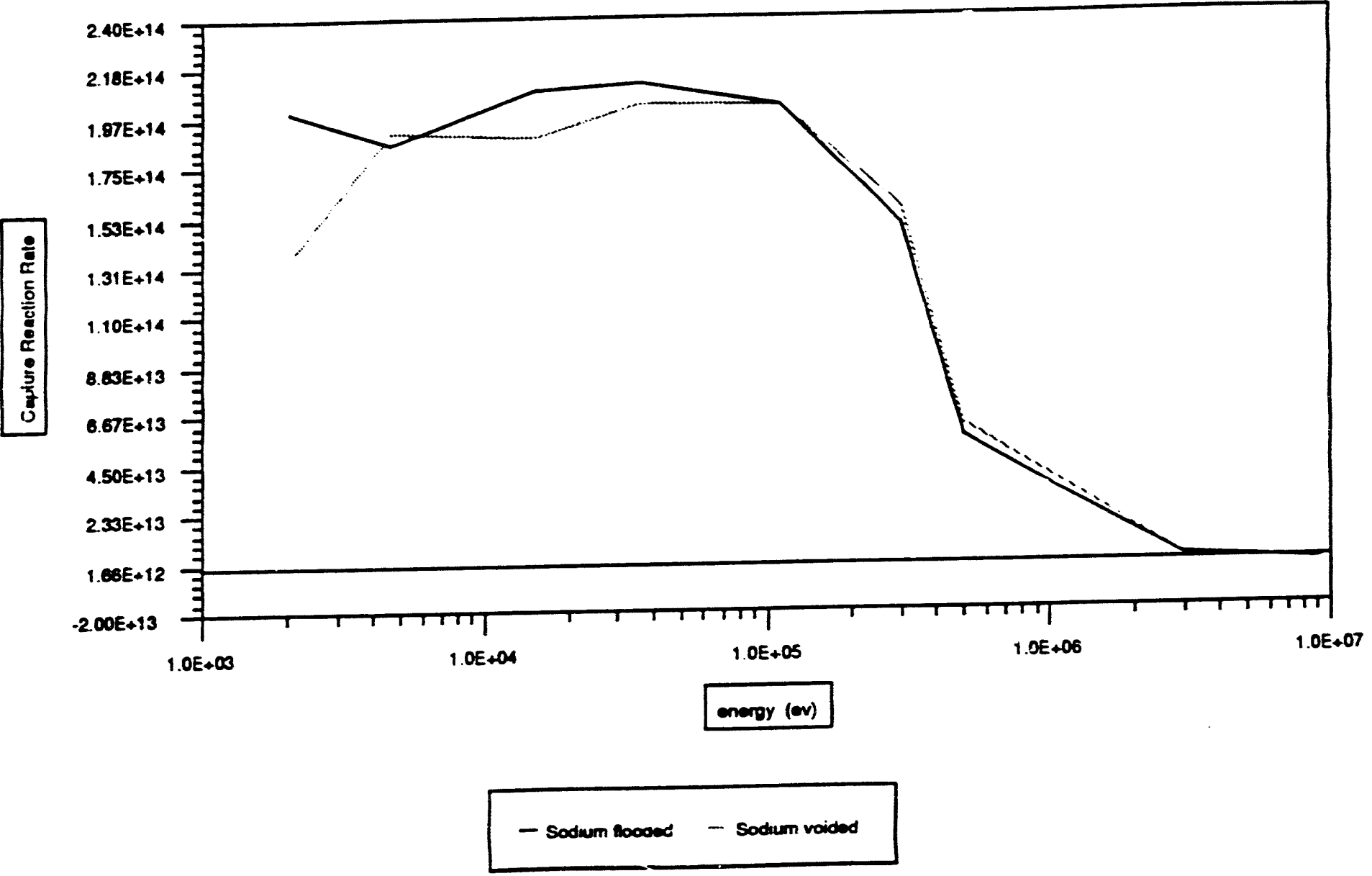

FIGURE C-16: Capture Reaction Rate for ${ }^{239} \mathrm{Pu}$ in a Nitride 2 Cycle Radial Blanket. 


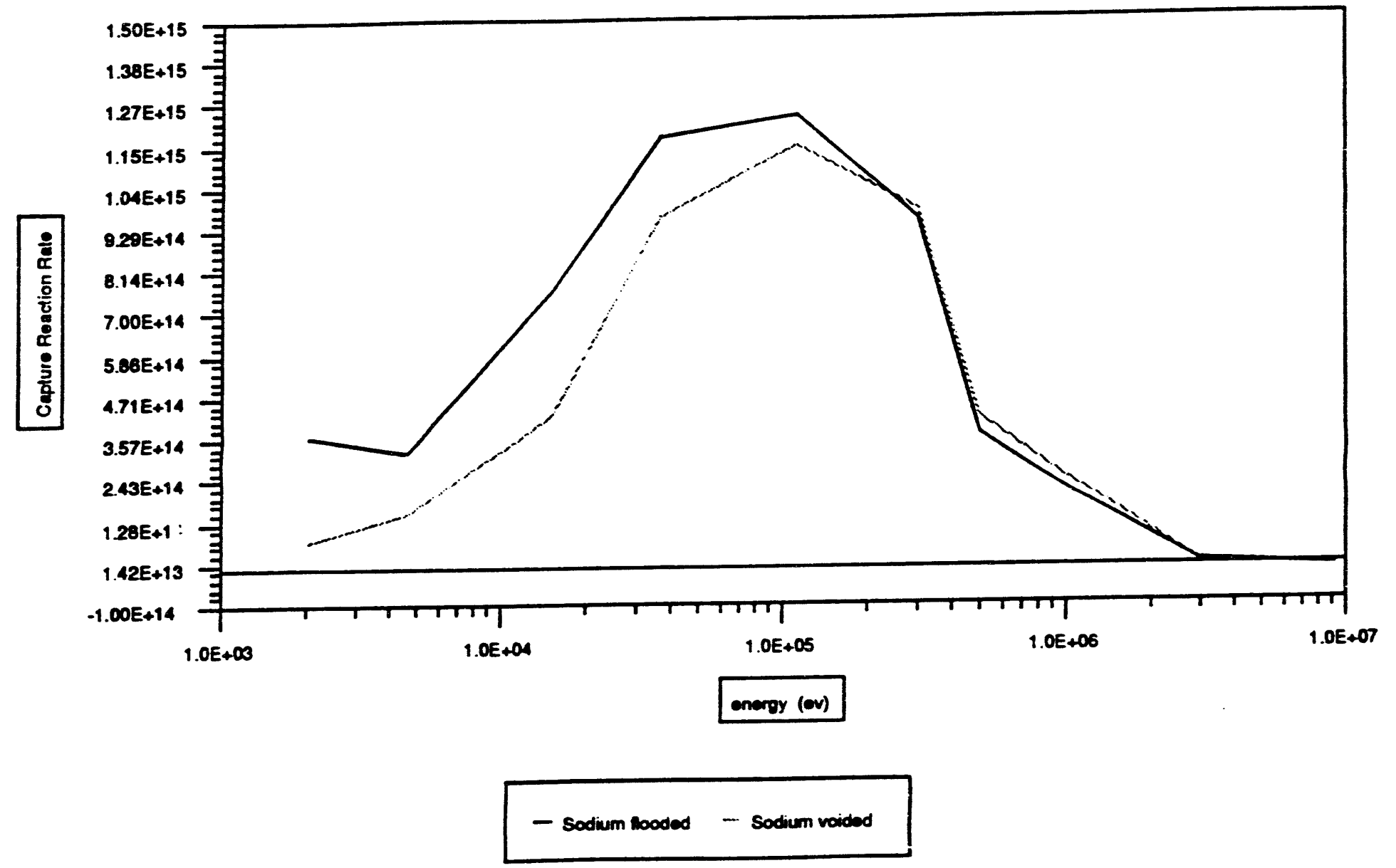

FIGURE C-17: Capture Reaction Rate for ${ }^{239} \mathrm{Pu}$ in a Metal Inner Fuel Assembly. 

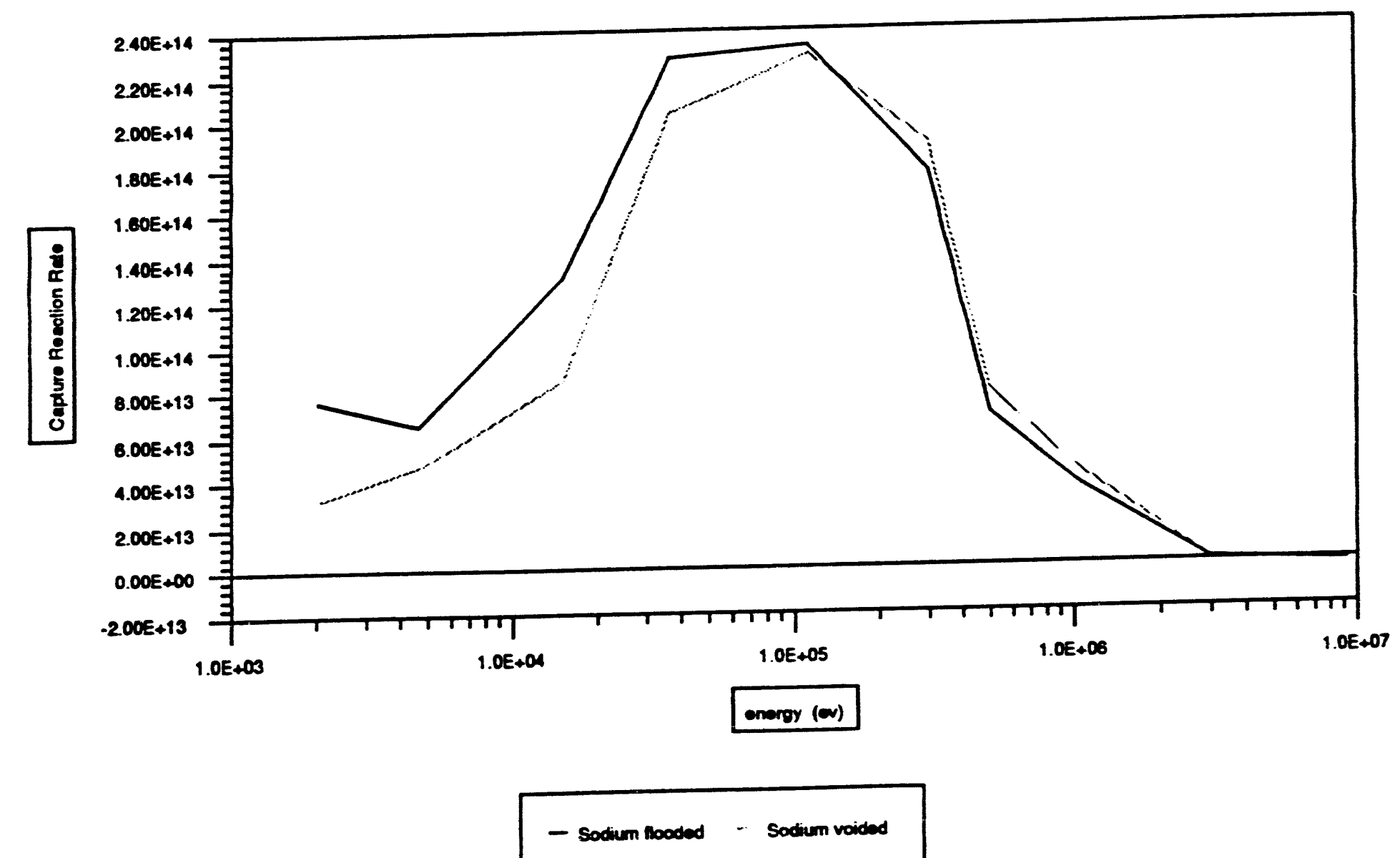

FIGURE C-18: Capture Reaction Rate for ${ }^{239} \mathrm{Pu}$ in a Metal 2 Cycle Radial Blanket. 


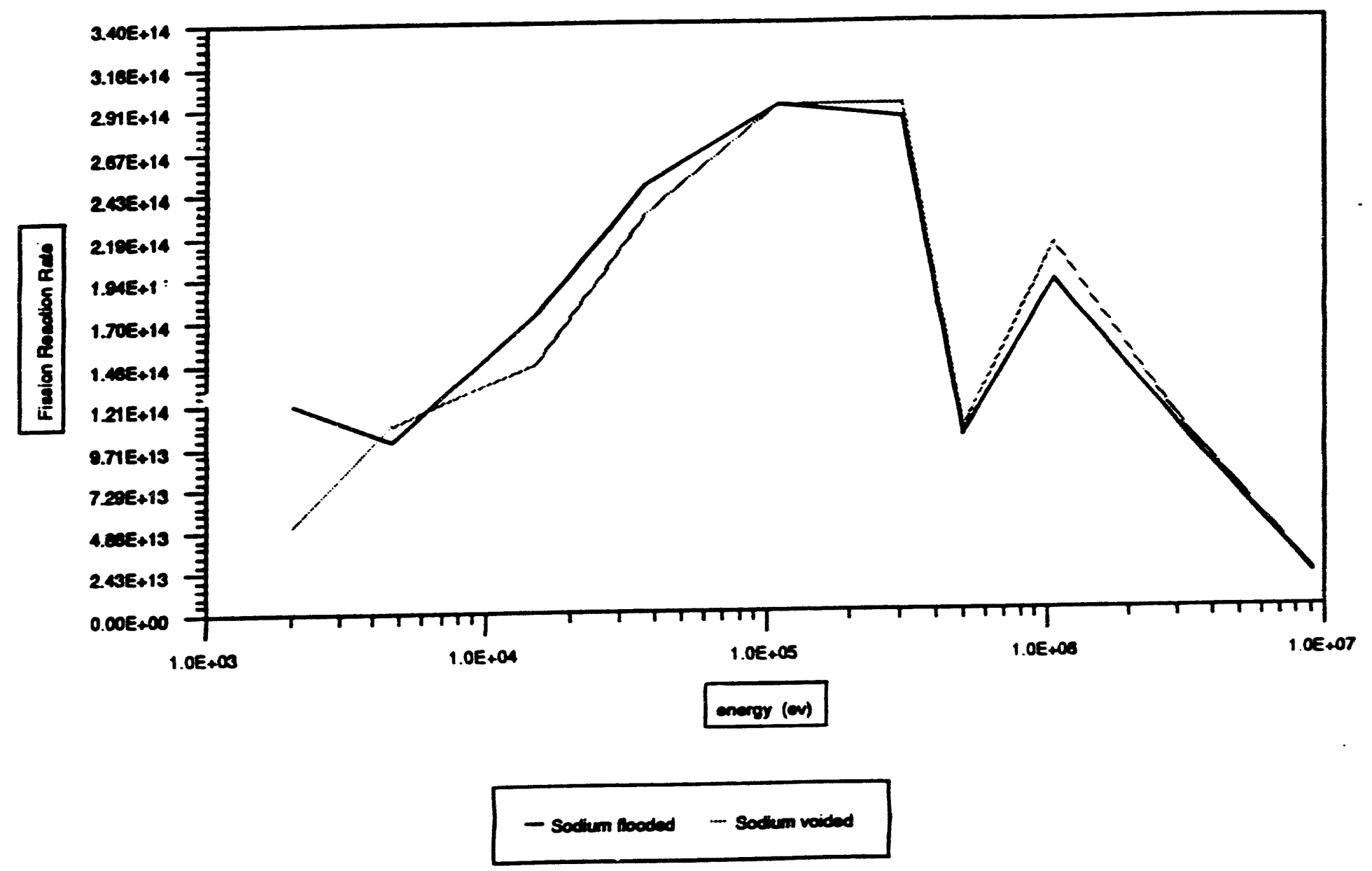

官

FIGURE C-19: Fission Reaction Rate for ${ }^{241} \mathrm{Pu}$ in an 0xide Inner Fuel Assembly.

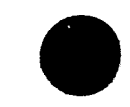




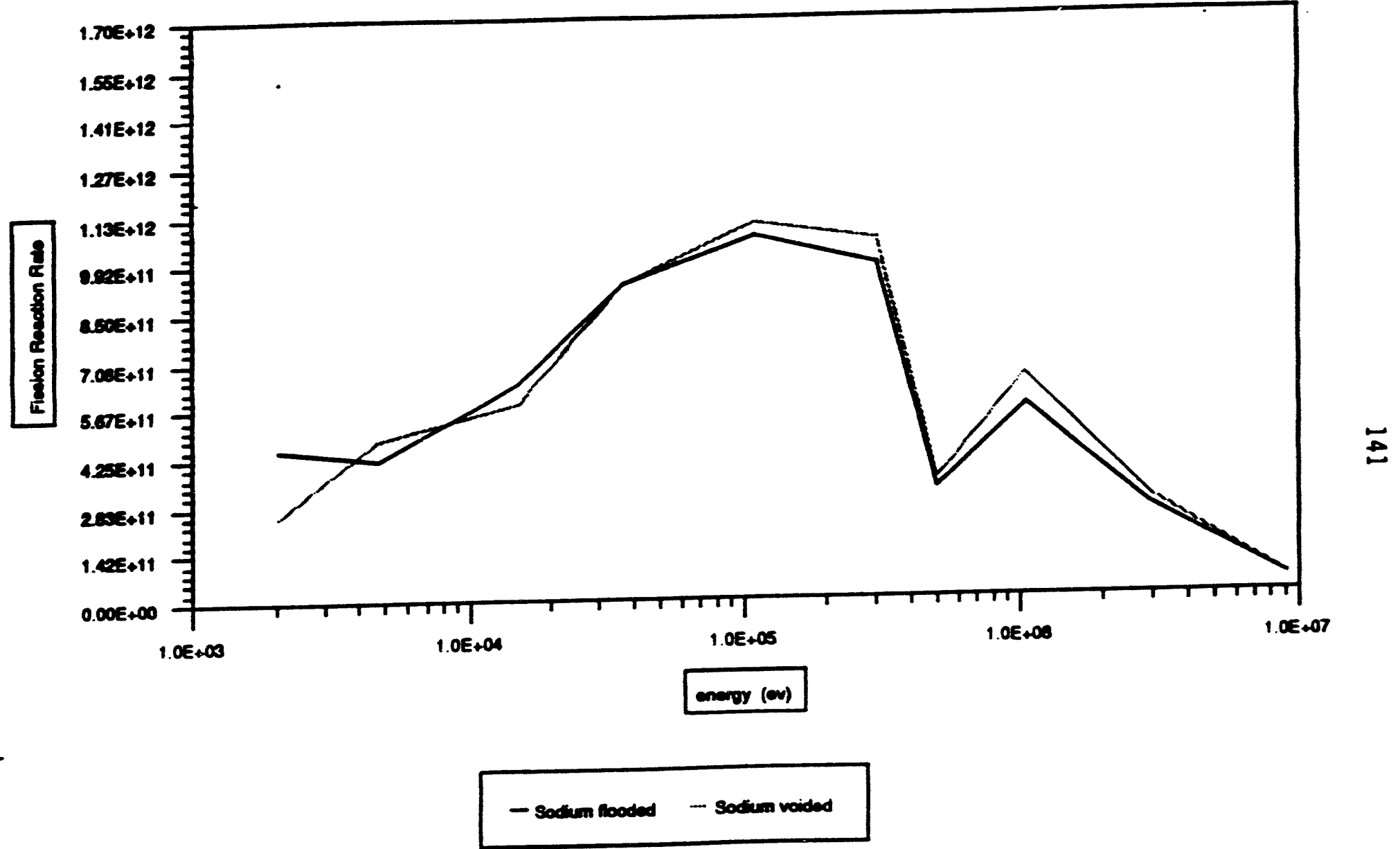

FIGURE C-20: Fission Reaction Rate for ${ }^{241} \mathrm{Pu}$ in an 0xide 2 Cycle Radial Blanket. 


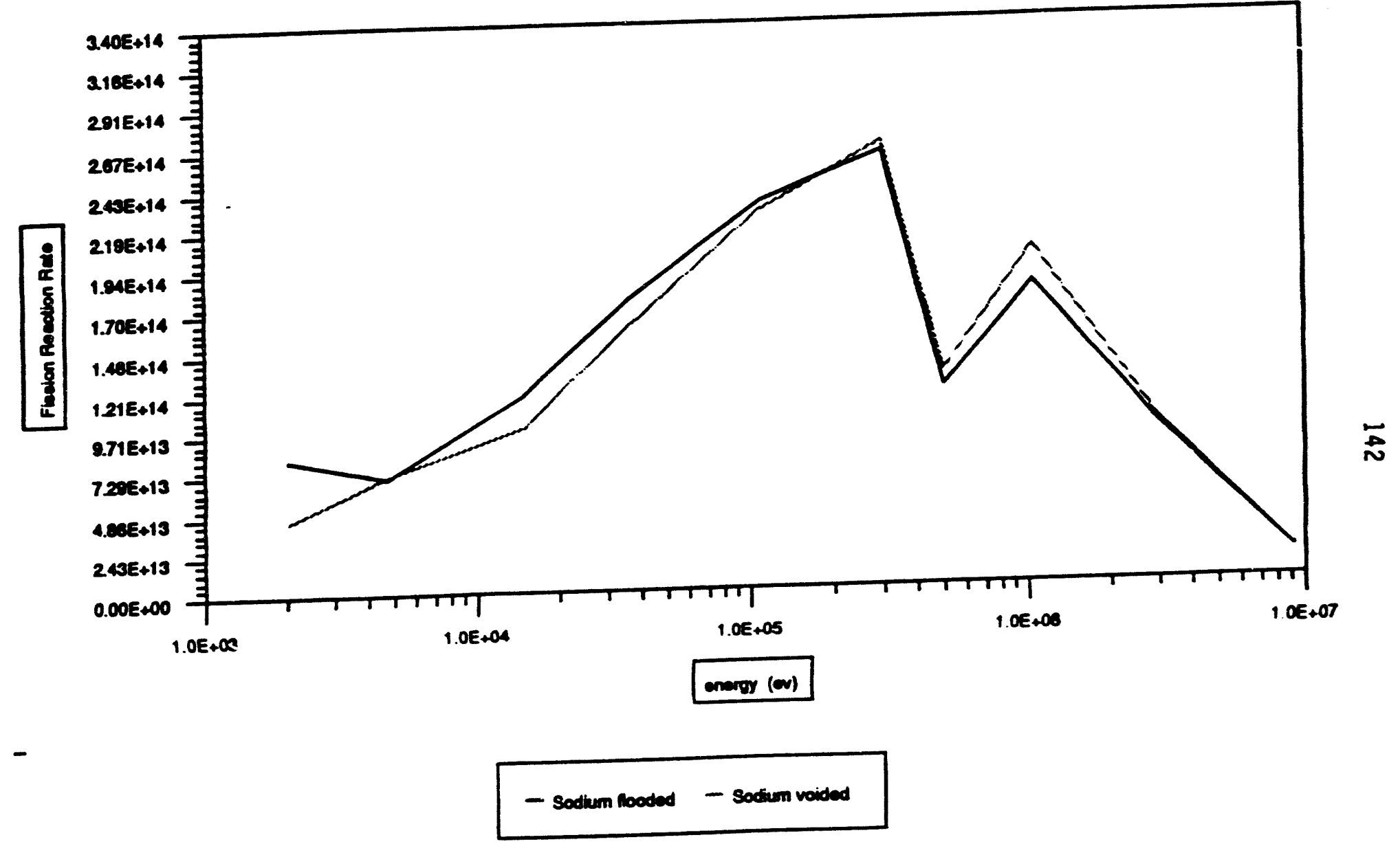

FIGURE C-21: Fission Reaction Rate for ${ }^{241} \mathrm{Pu}$ in a Nitride Inner Fuel Assembly. 


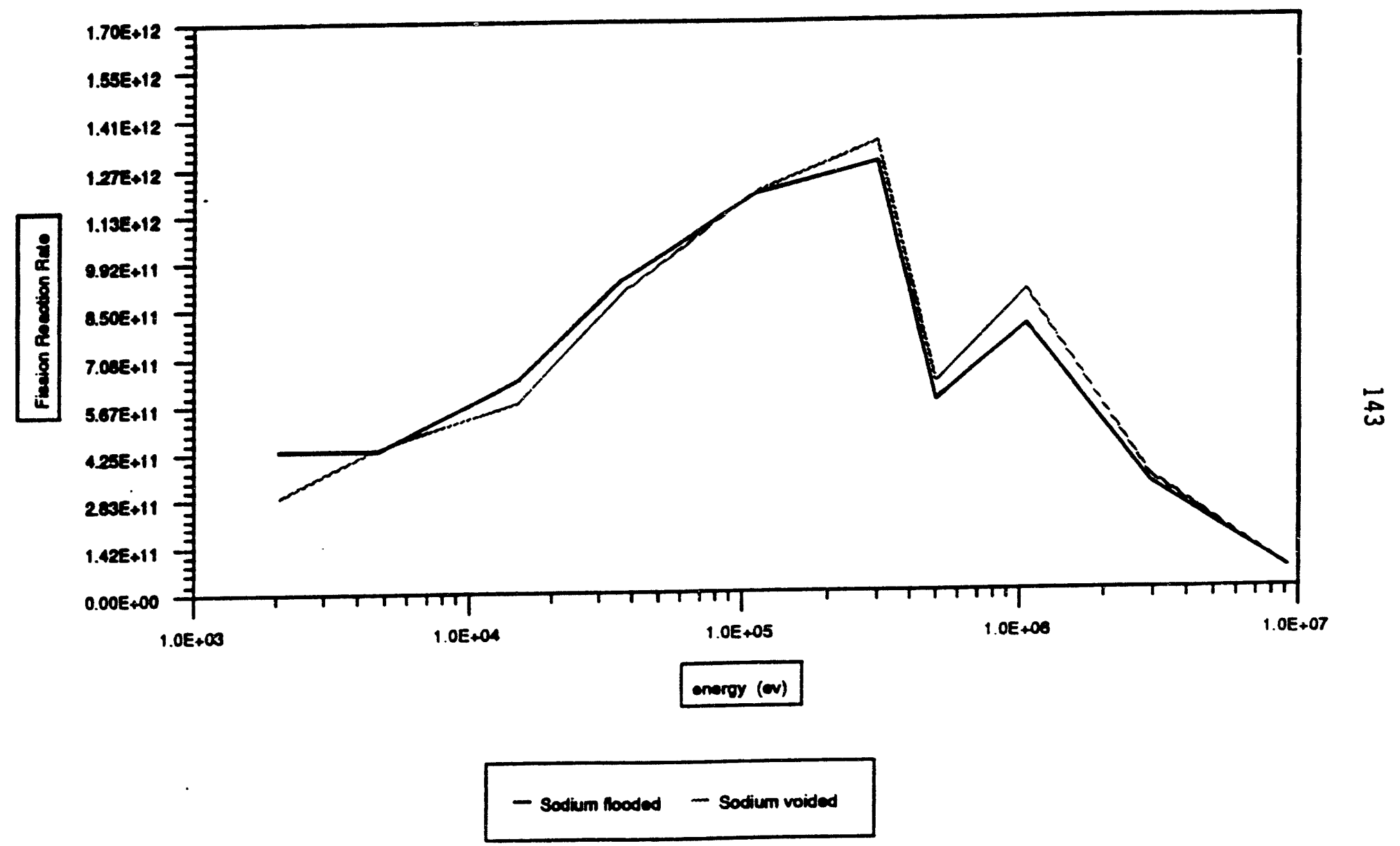

FIGURE C-22: Fission Reaction Rate for ${ }^{241} \mathrm{Pu}$ in a Nitride 2 Cycle Radial Blanket. 


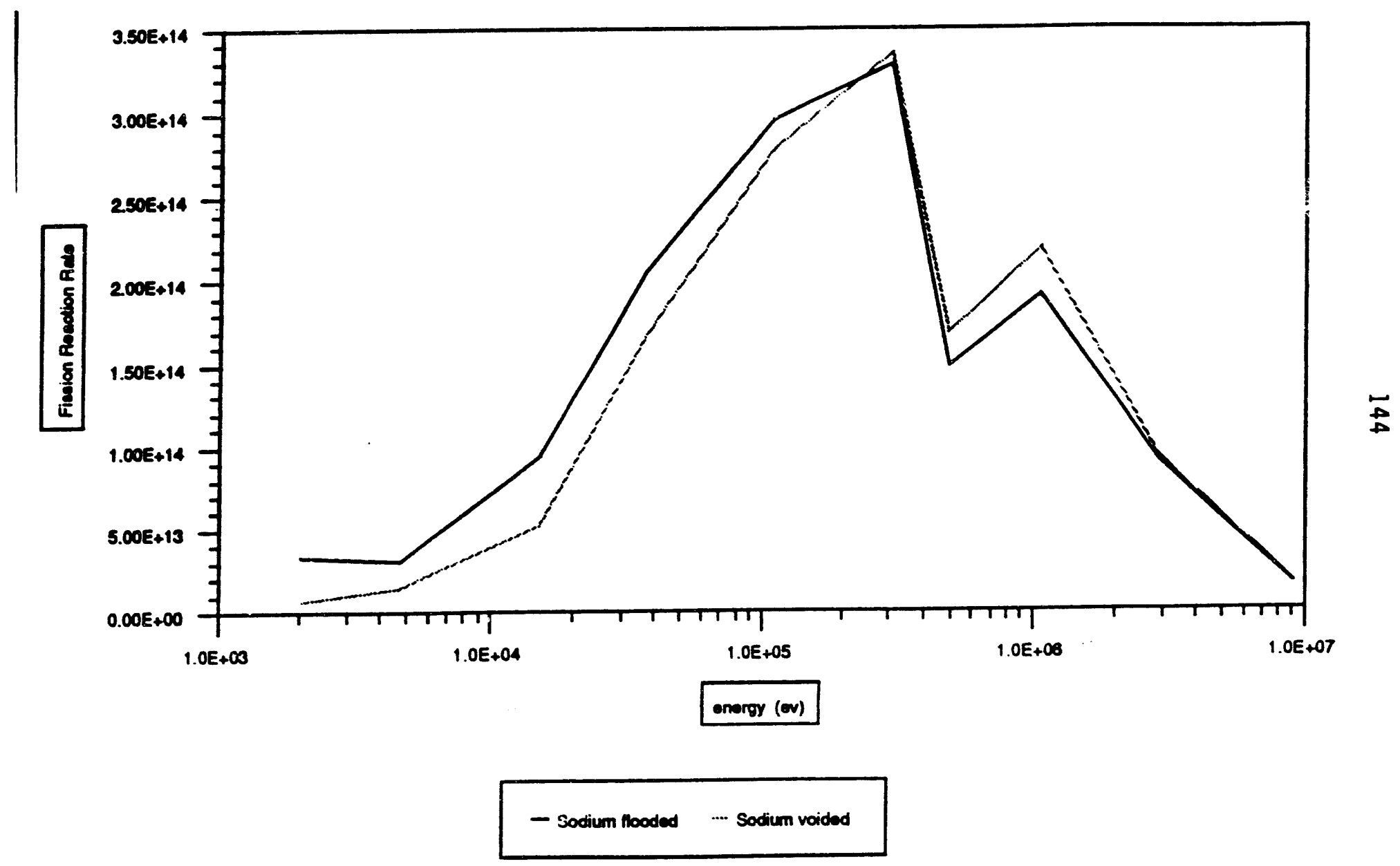

FIGURE C-23: Fission Reaction Rate for ${ }^{241} \mathrm{Pu}$ in a Metal Inner Fuel Assembly. 


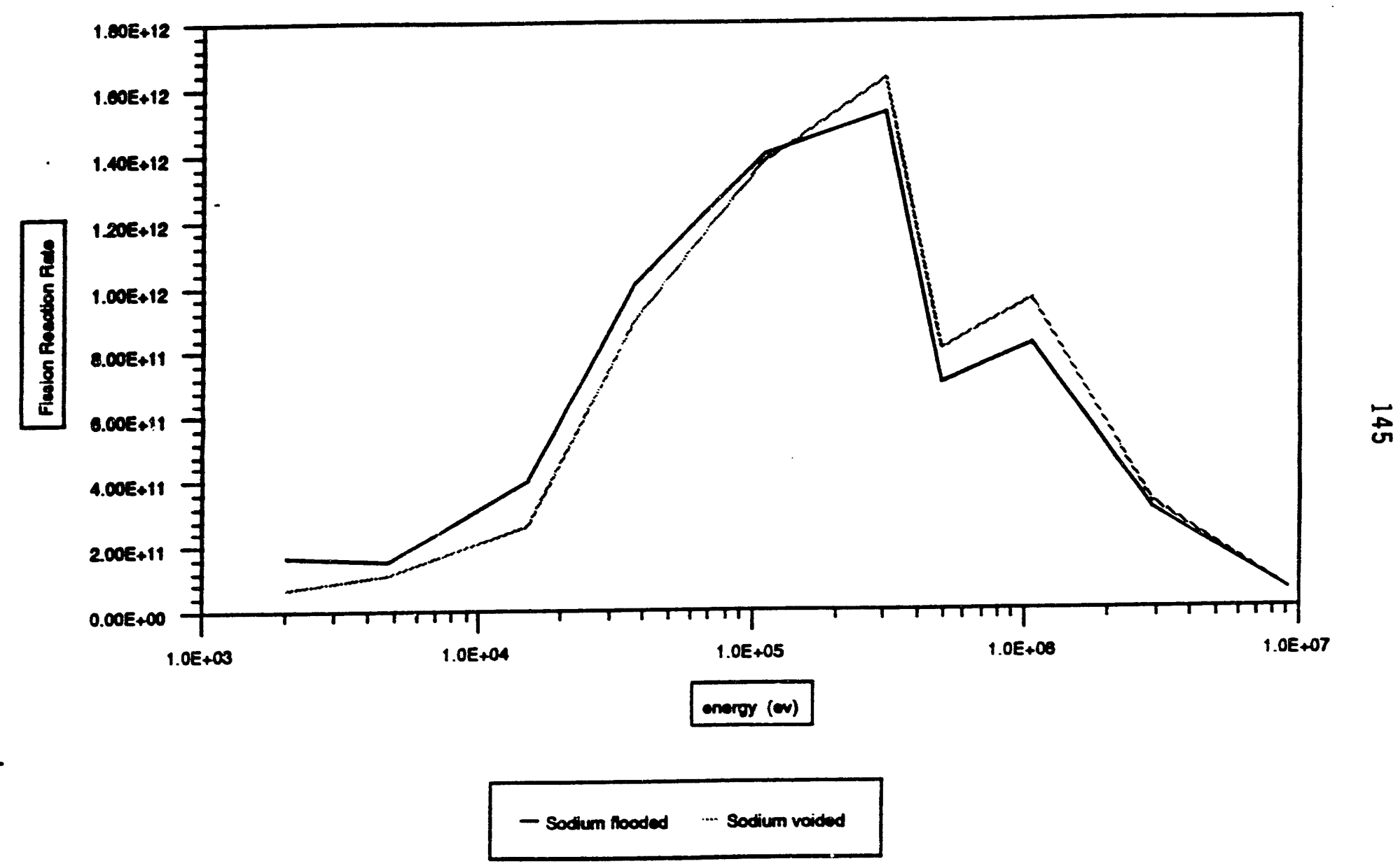

FIGURE C-24: Fission Reaction Rate for ${ }^{241} \mathrm{Pu}$ in a Metal 2 Cycle Radial Blanket. 


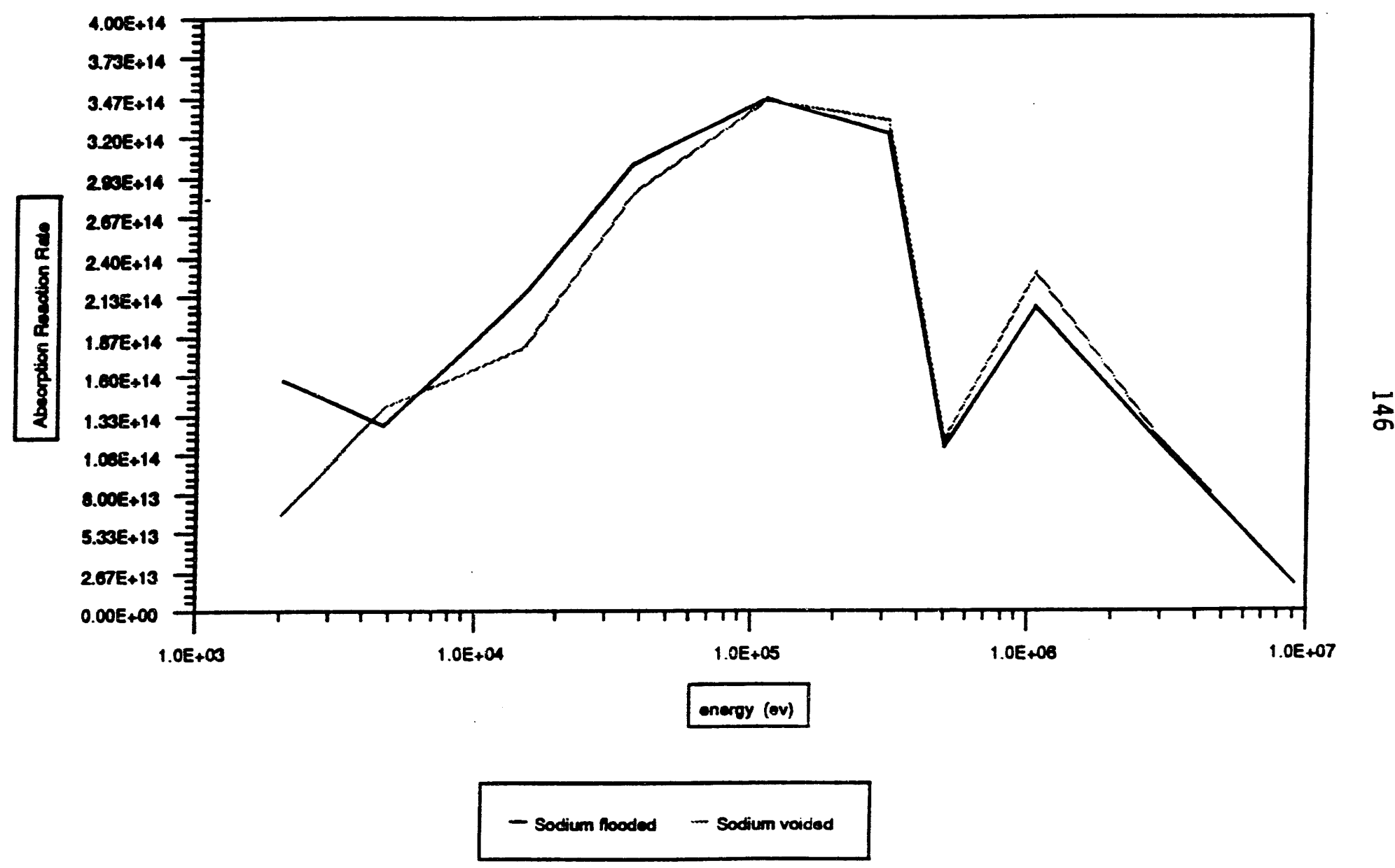

FIGURE C-25: Absorption Reaction Rate for ${ }^{241} \mathrm{Pu}$ in an 0xide Inner Fuel Assembly. 



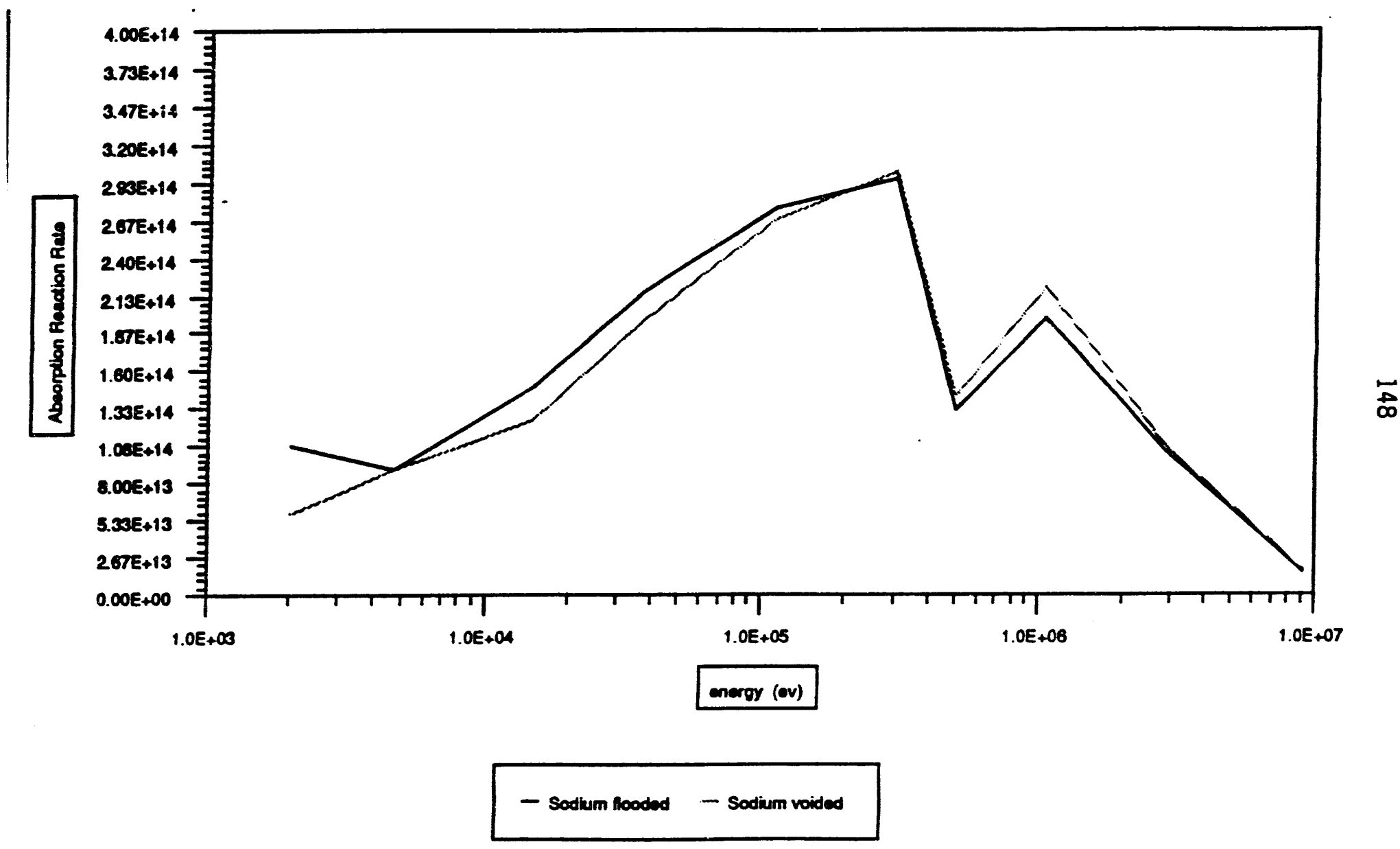

FIGURE C-27: Absorption Reaction Rate for ${ }^{241} \mathrm{Pu}$ in a Nitride Inner Fuel Assembly. 


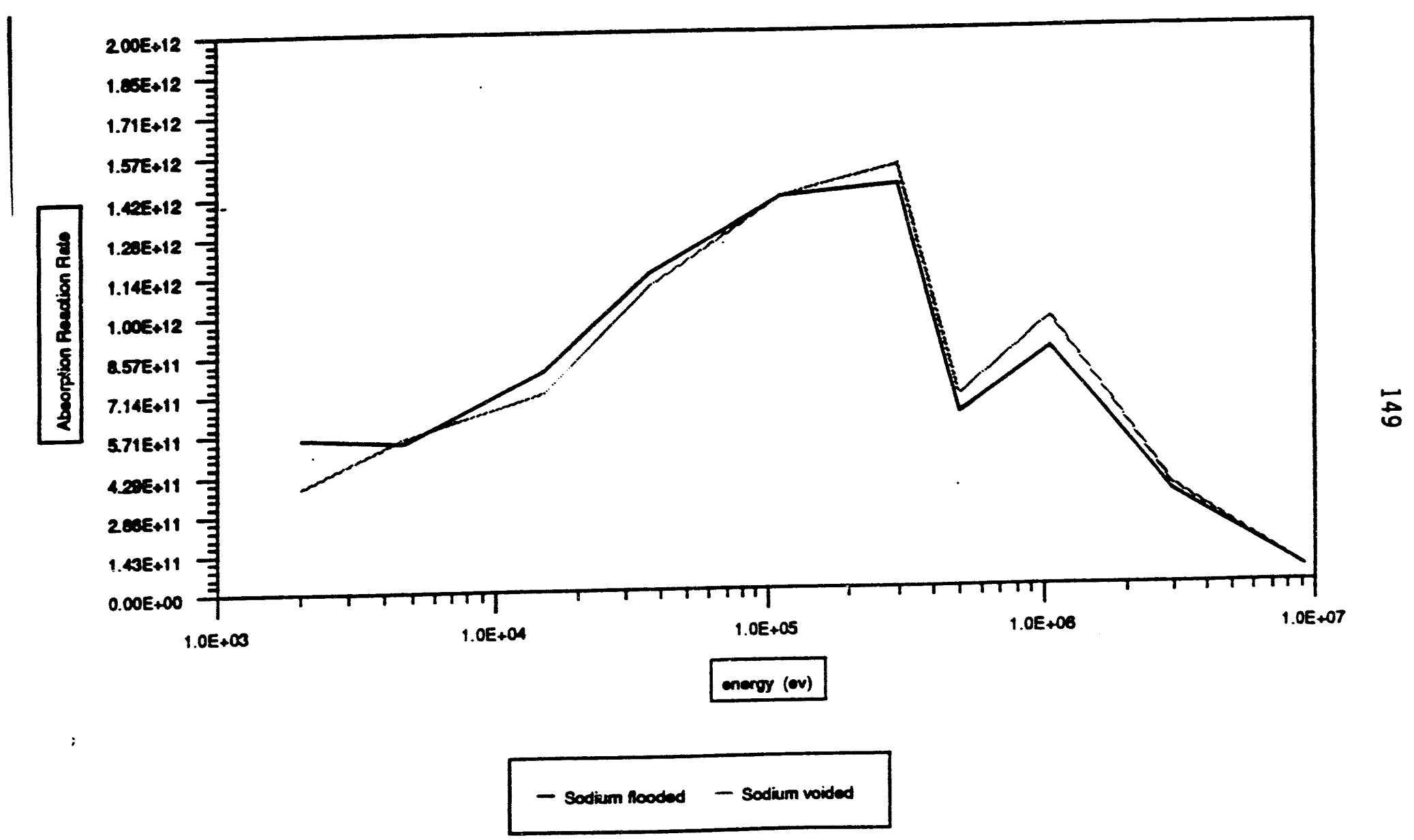

FIGURE C-28: Absorption Reaction Rate for ${ }^{241} \mathrm{Pu}$ in a Nitride 2 Cycle Radial Blanket. 


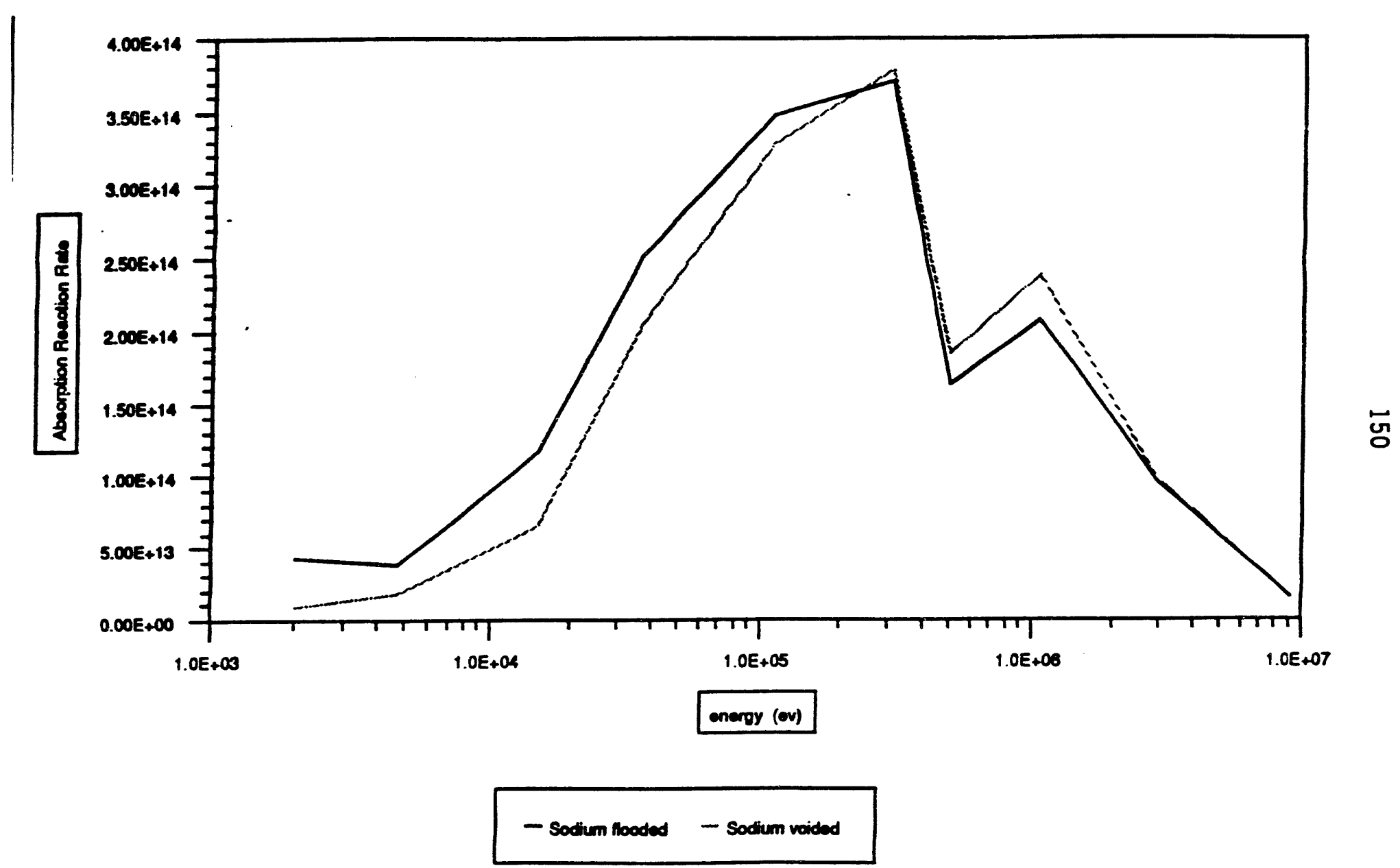

FIGURE C-29: Absorption Reaction Rate for ${ }^{24}{ }^{1} \mathrm{Pu}$ in a Metal Inner Fuel Assembly. 


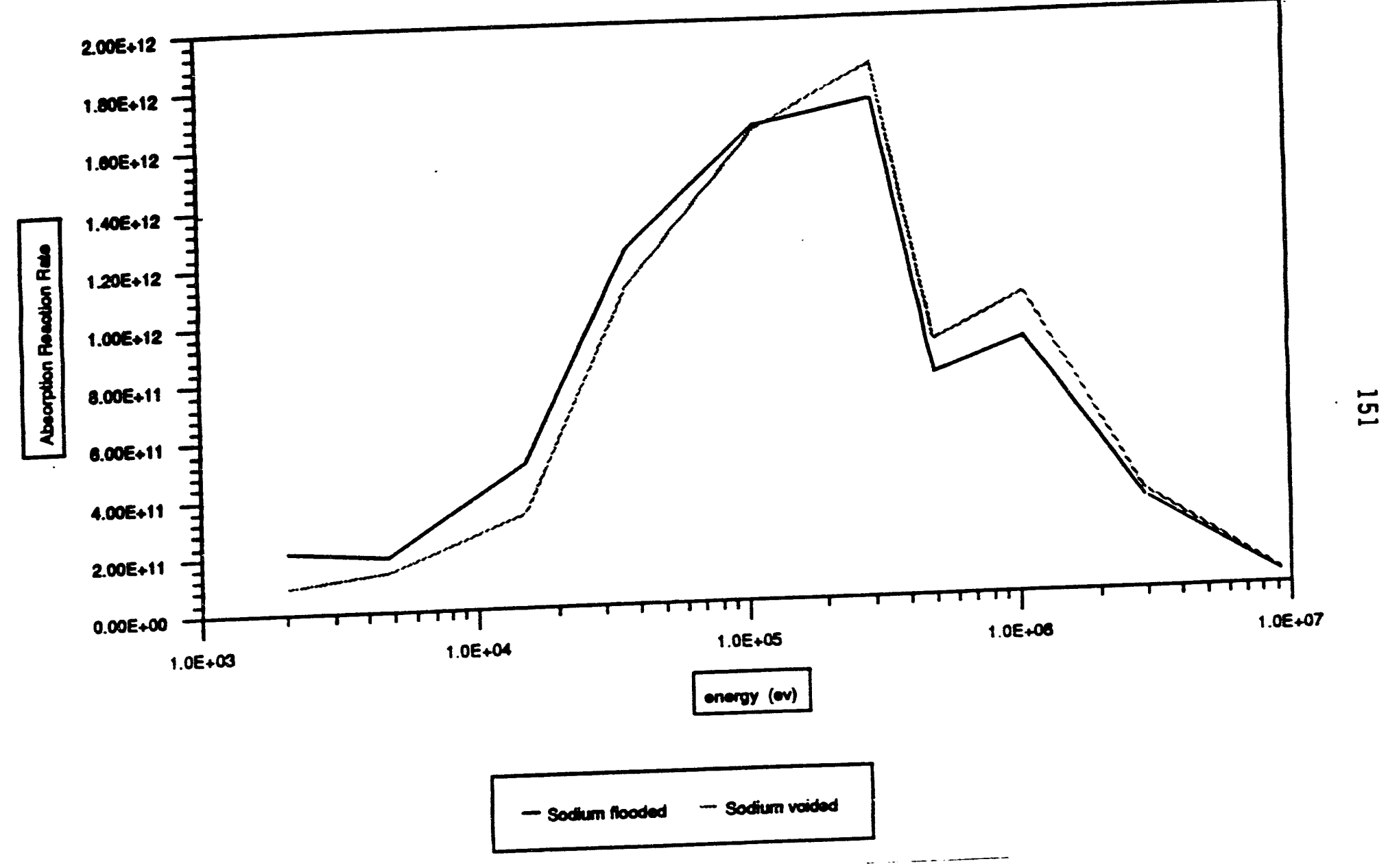

FIGURE C-30: Absorption Reaction Rate for ${ }^{241} \mathrm{Pu}$ in a Metal 2 Cycle Radial Blanket. 


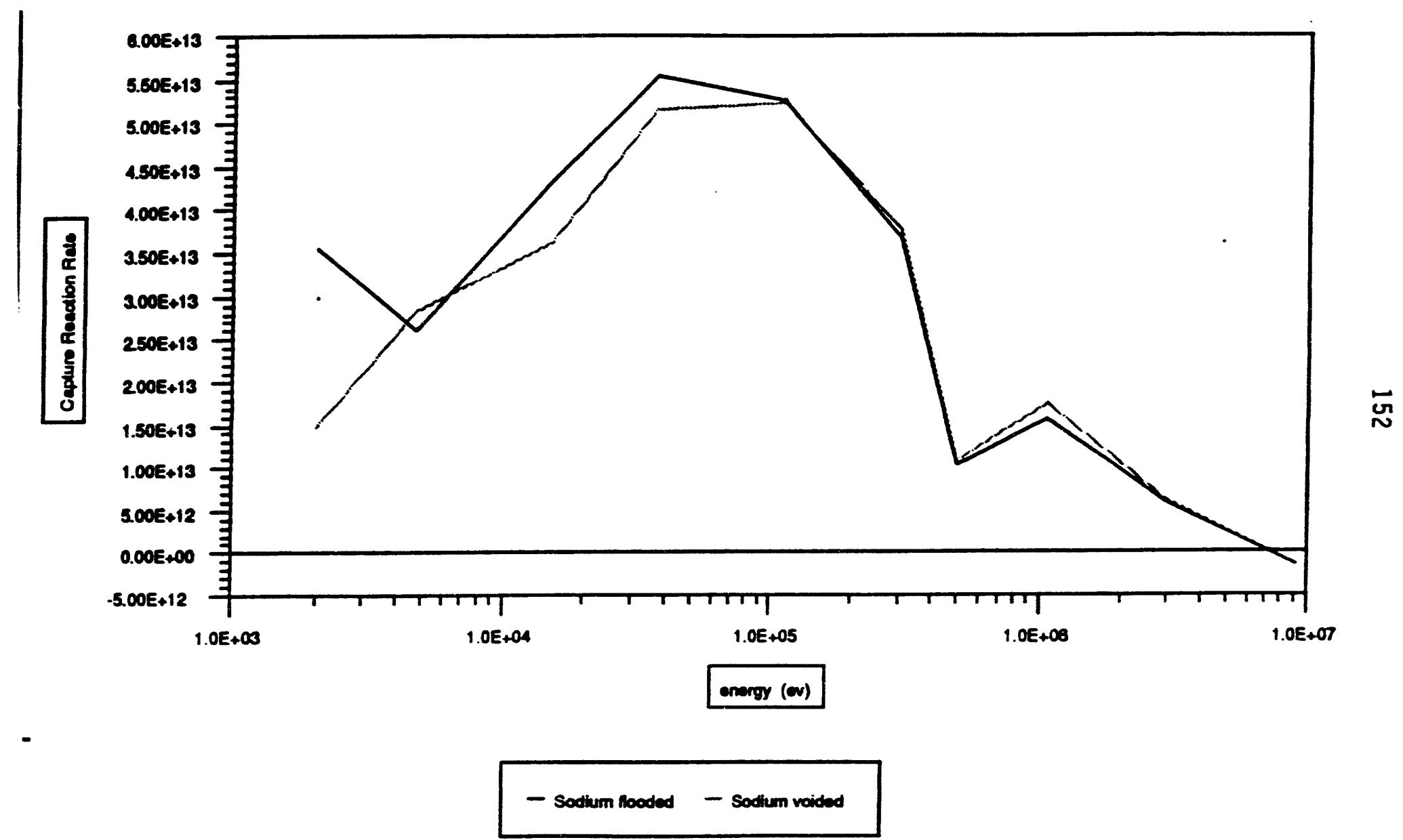

FIGURE C-31: Capture Reaction Rate for ${ }^{241} \mathrm{Pu}$ in an 0xide Inner Fuel Assembly. 


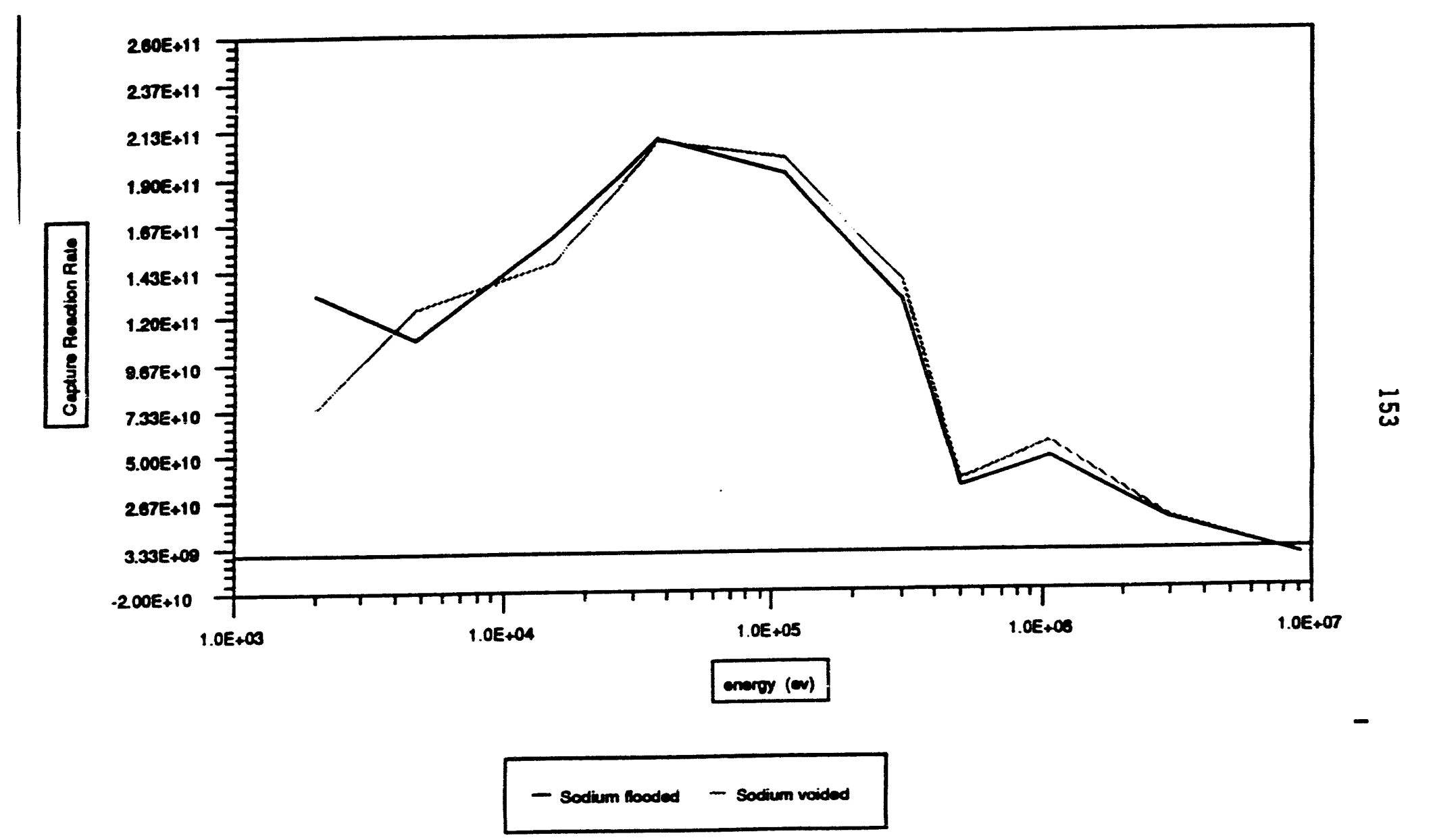

FIGURE C-32: Capture Reaction Rate for ${ }^{241} \mathrm{Pu}$ in an 0xide 2 Cycle Radial Blanket. 


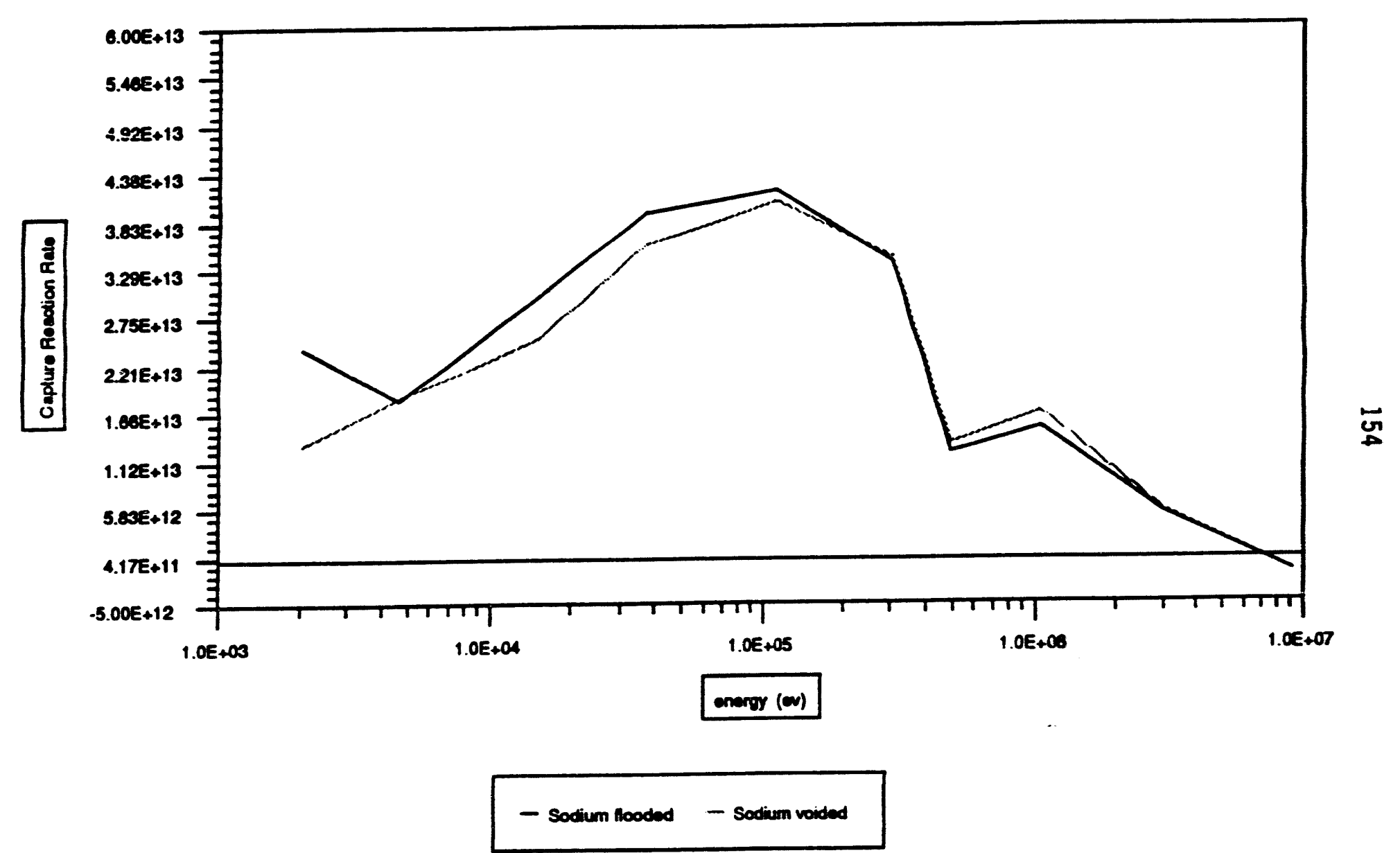

FIGURE C-33: Capture Reaction Rate for ${ }^{241} \mathrm{Pu}$ in a Nitride Inner Fuel Assembly. 


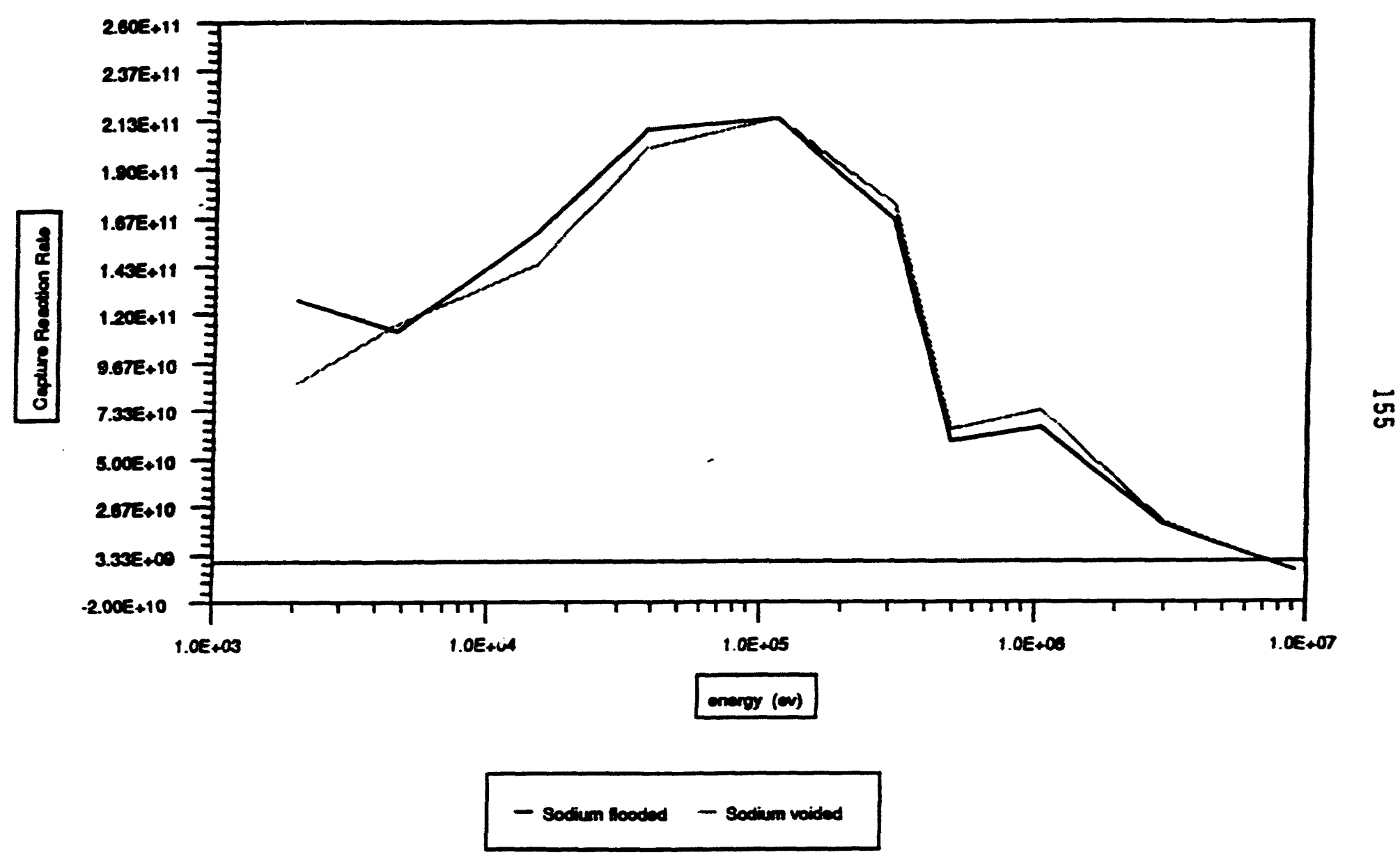

FIGURE C-34: Capture Reaction Rate for ${ }^{241} \mathrm{Pu}$ in a Nitride 2 Cycle Radial Blanket. 


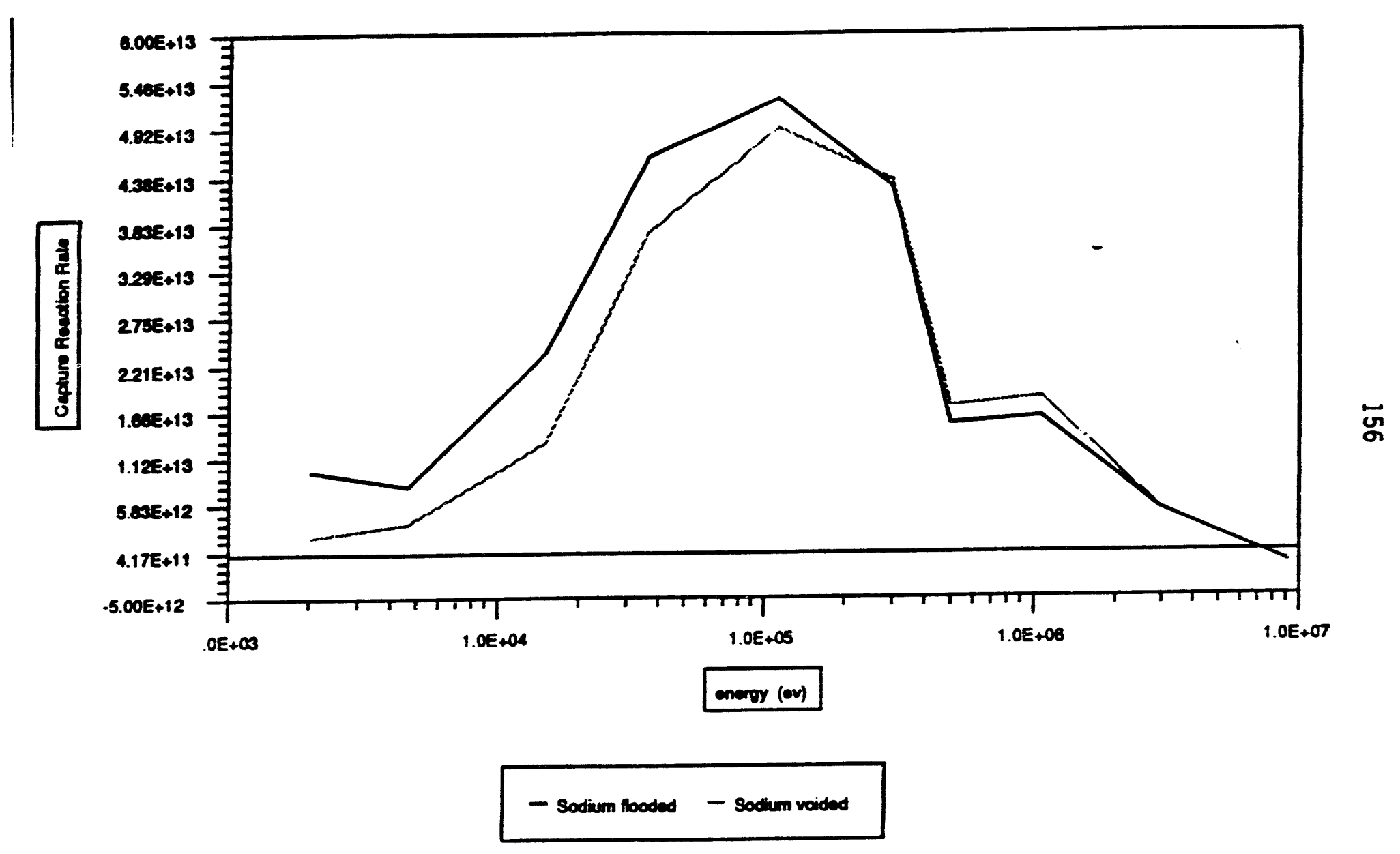

FIGURE C-35: Capture Reaction Rate for ${ }^{241} \mathrm{Pu}$ in a Metal Inner Fuel Assembly. 


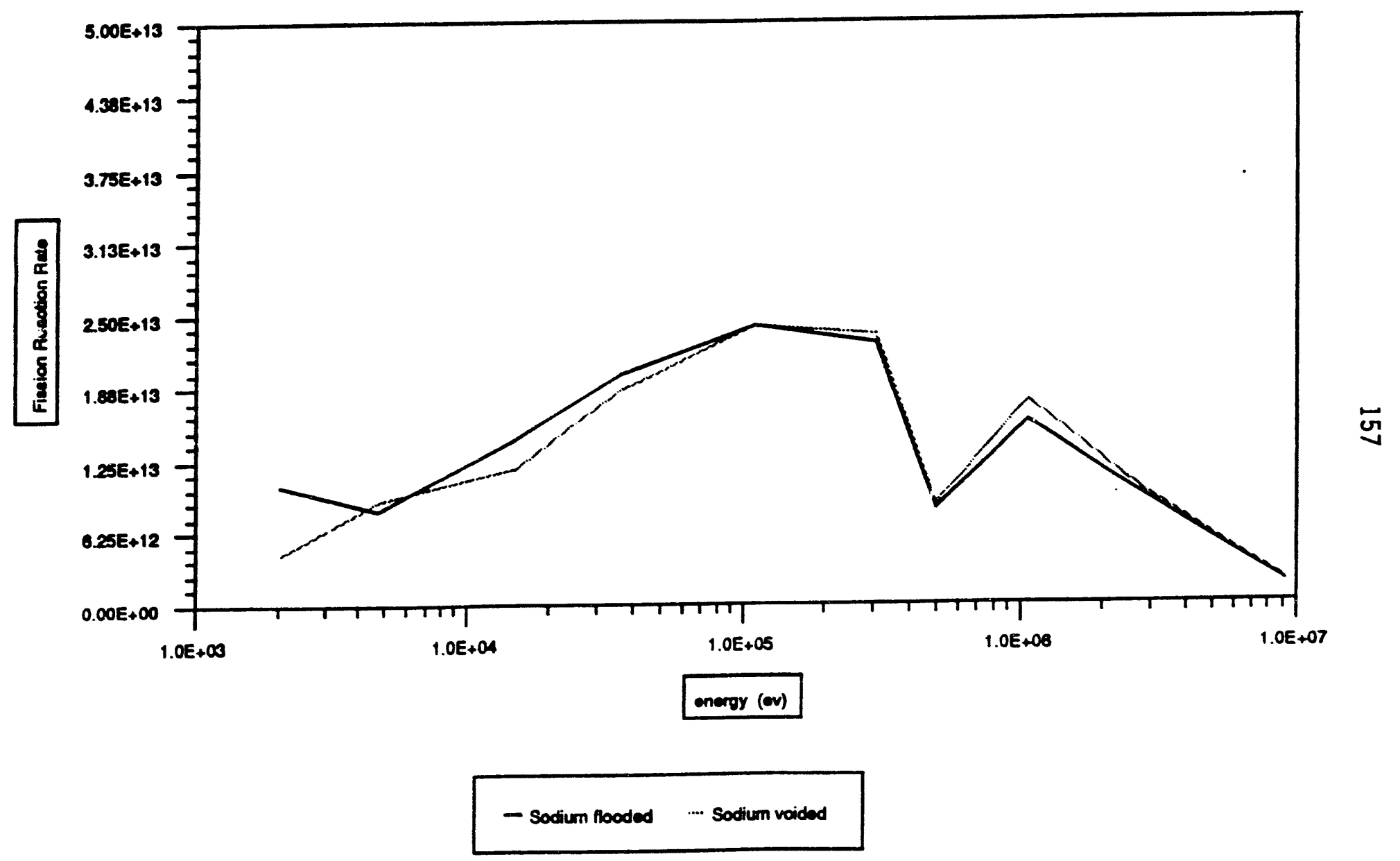

FIGURE C-36: Capture Reaction Rate for ${ }^{241} \mathrm{Pu}$ in a Metal 2 Cycle Radial Blanket. 


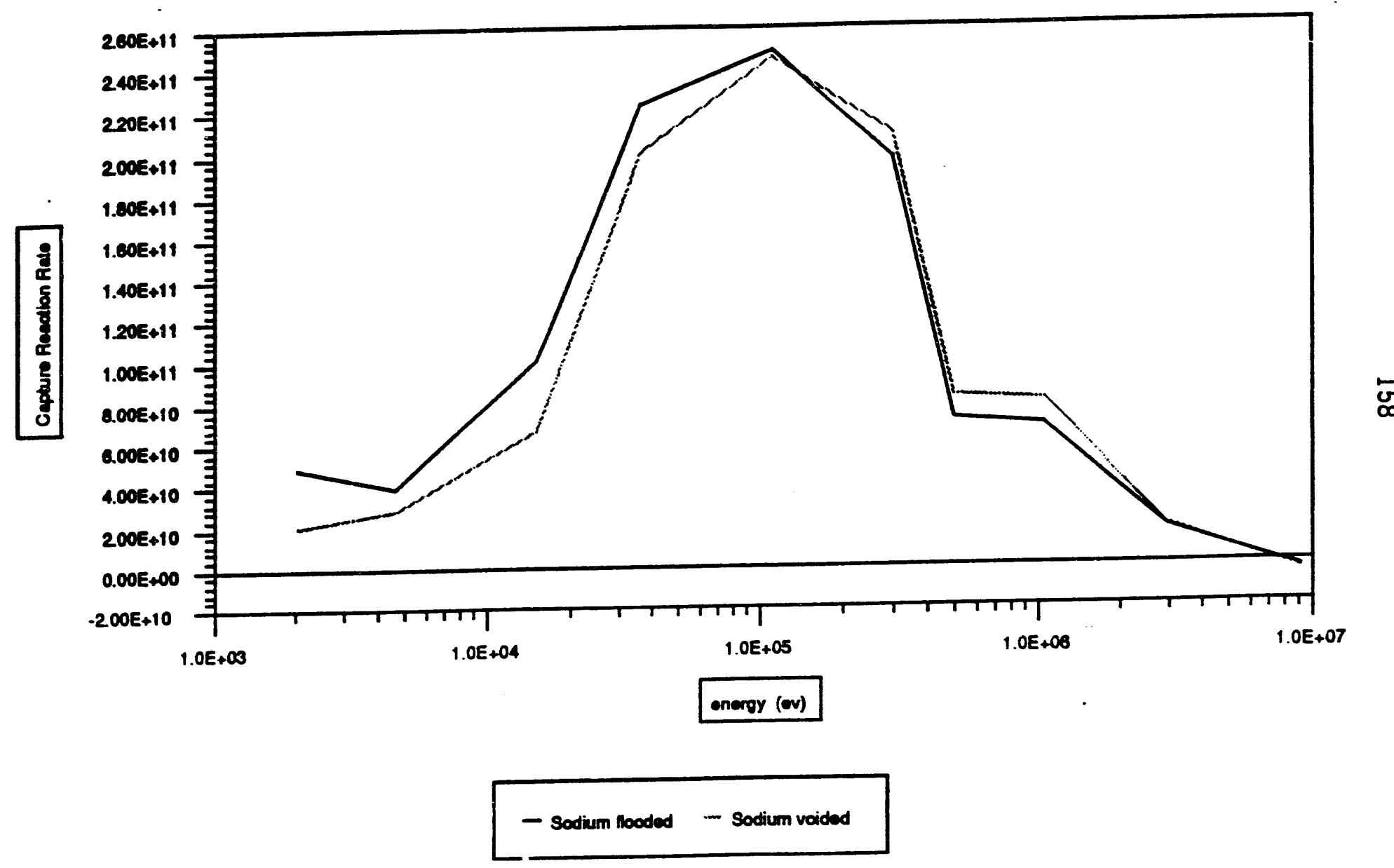

FIGURE C-37: Fission Reaction Rate for ${ }^{235} \mathrm{U}$ in an 0xide Inner Fuel Assembly. 



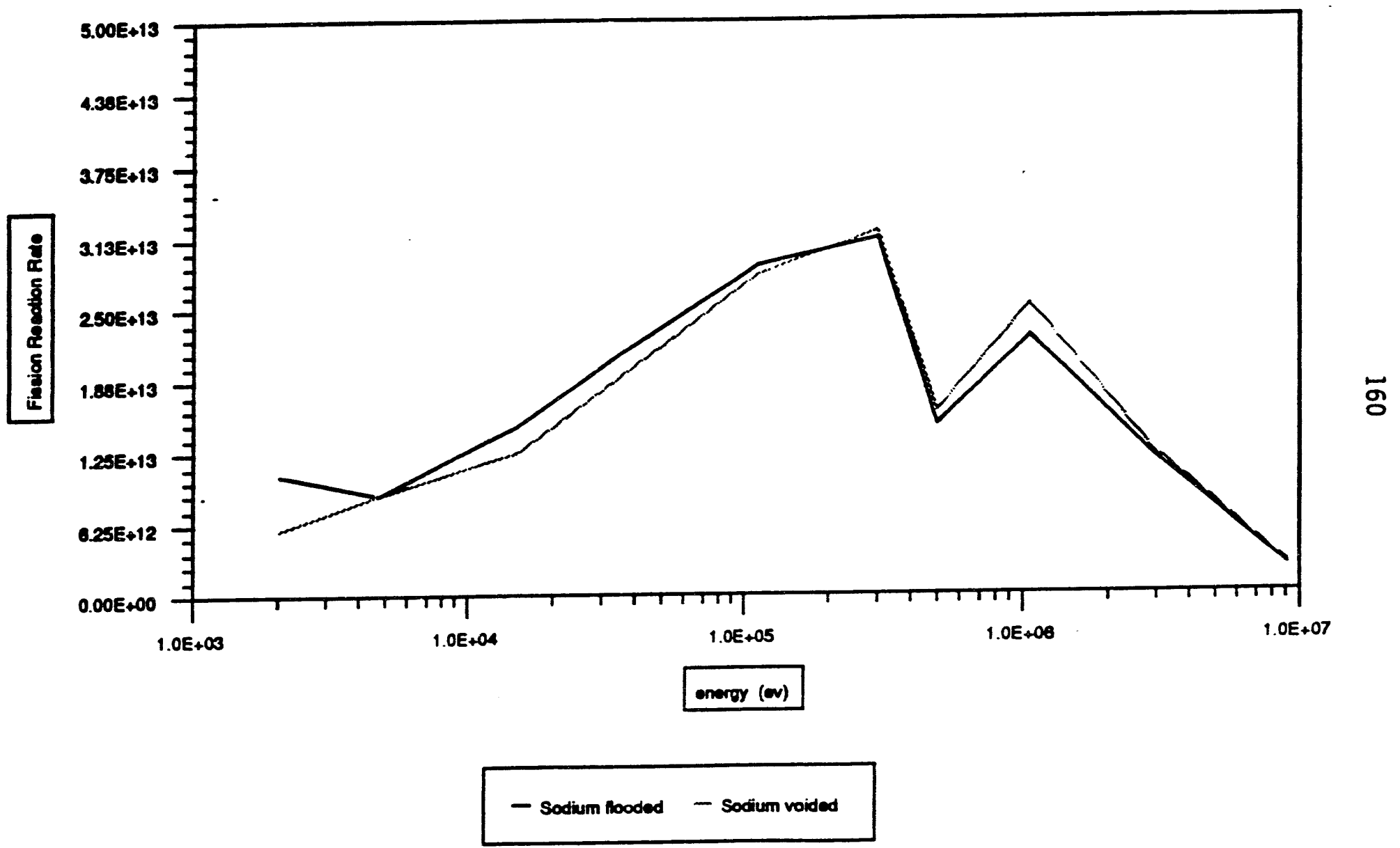

FIGURE C-39: Fission Reaction Rate for ${ }^{235} \mathrm{U}$ in a Nitride Inner Fuel Assembly. 


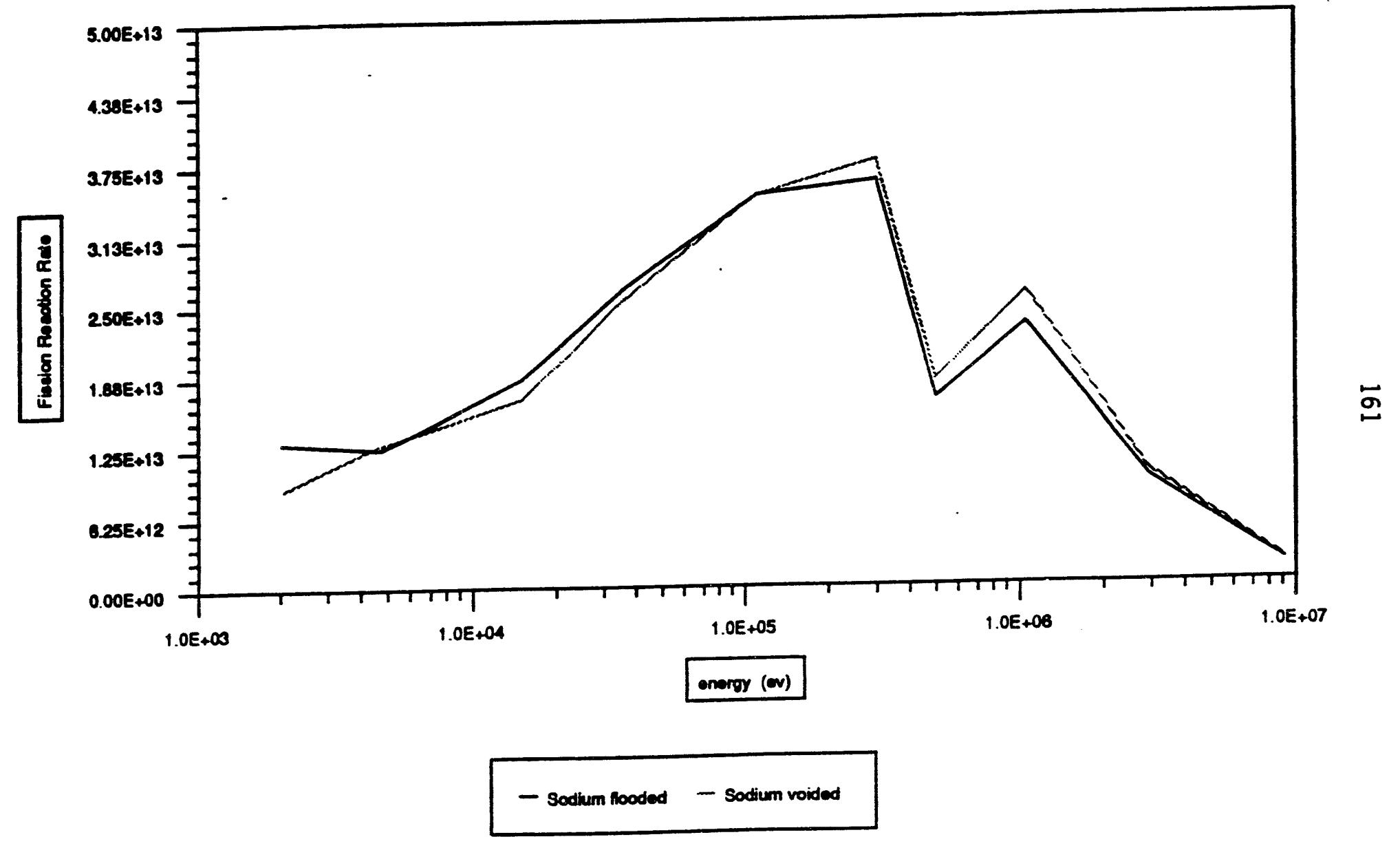

FIGURE C-40: Fission Reaction Rate for ${ }^{235} \mathrm{U}$ in a Nitride 2 Cycle Radial Blanket. 


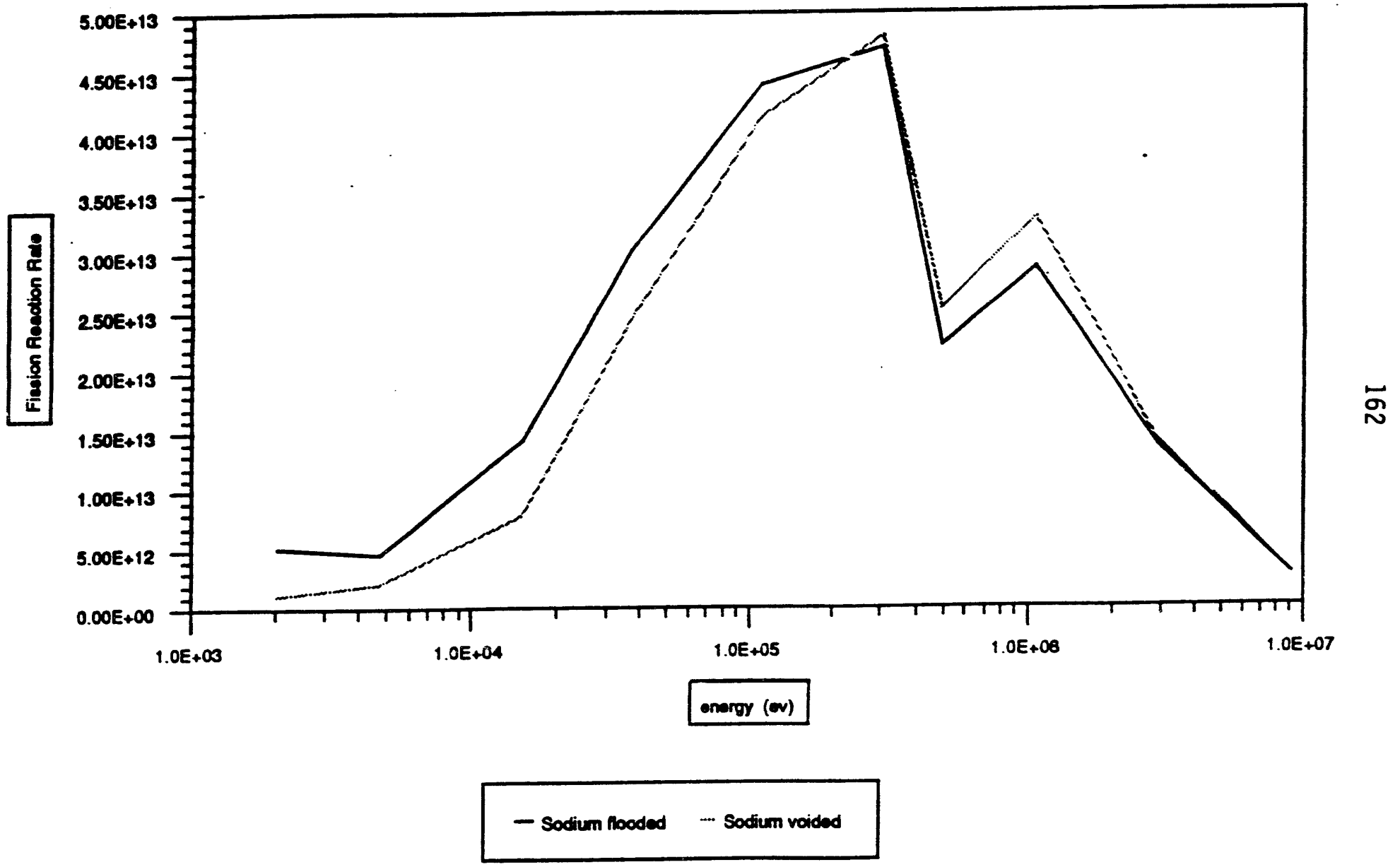

FIGURE C-41: Fission Reaction Rate for ${ }^{235} \mathrm{U}$ in a Metal Inner Fuel Assembly. 


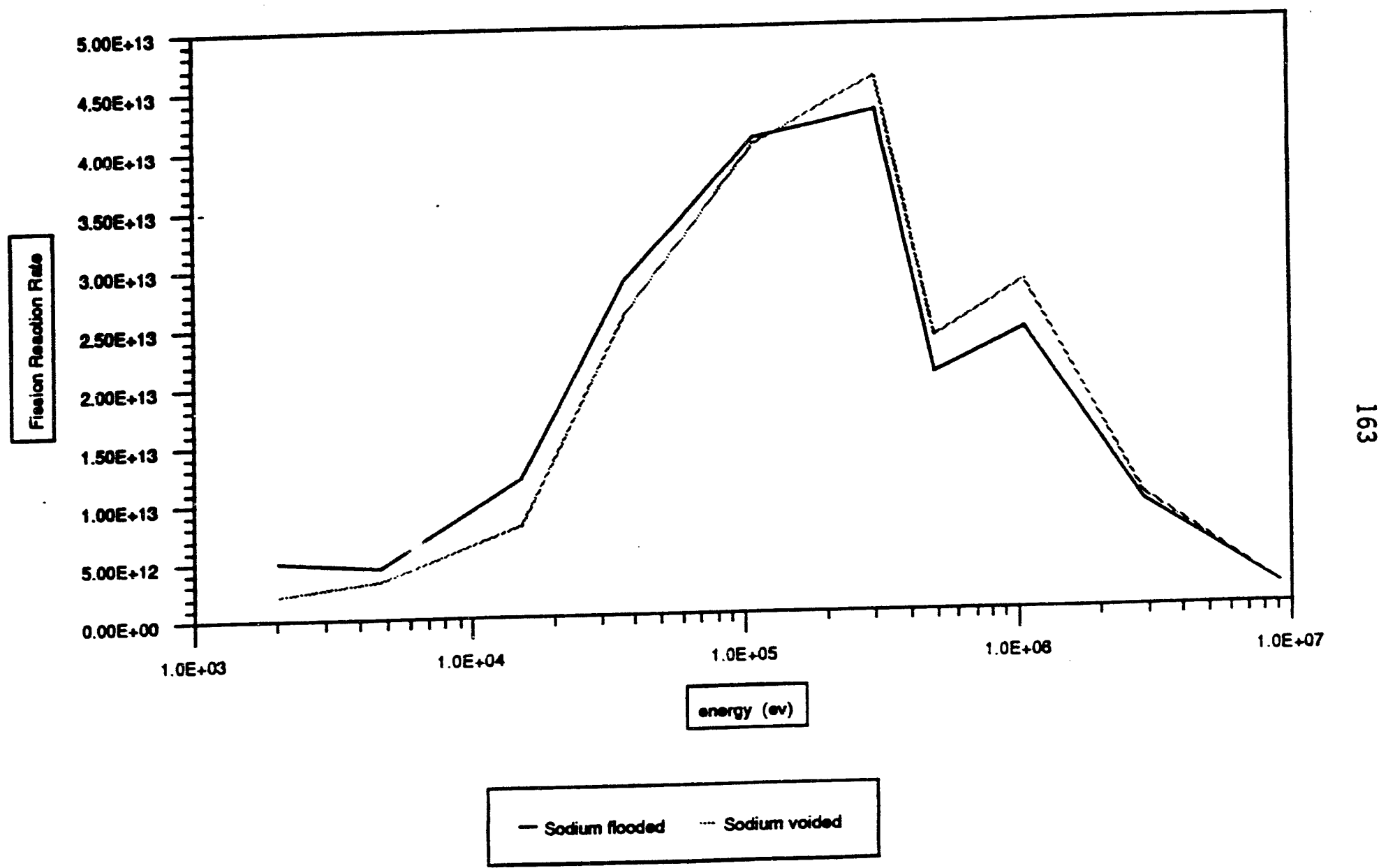

FIGURE C-42: Fission Reaction Rate for ${ }^{235} \mathrm{U}$ in a Metal 2 Cycle Radial Blanket. 


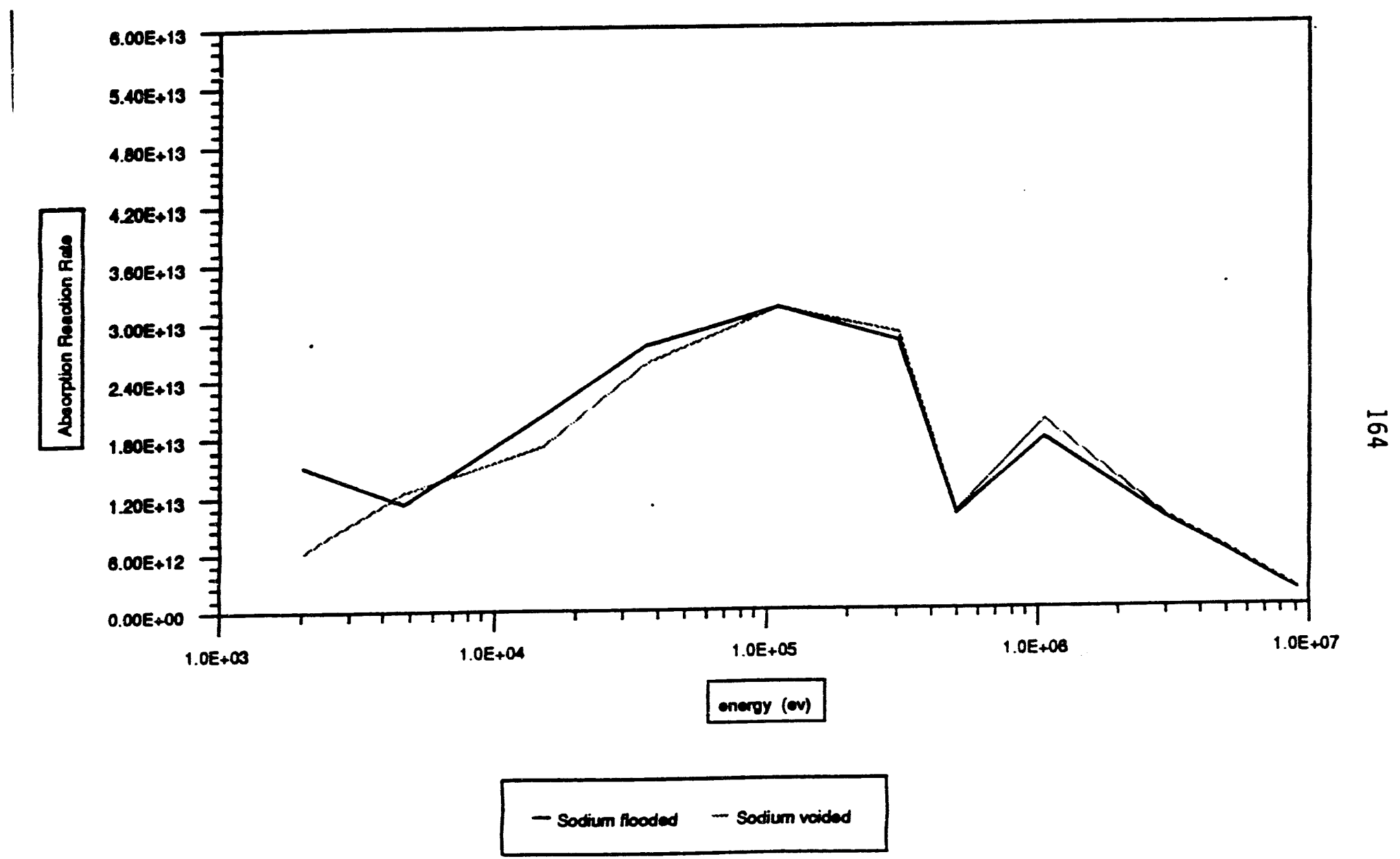

FIGURE C-43: Absorption Reaction Rate for ${ }^{235} \mathrm{U}$ in an 0xide Inner Fuel Assembly. 


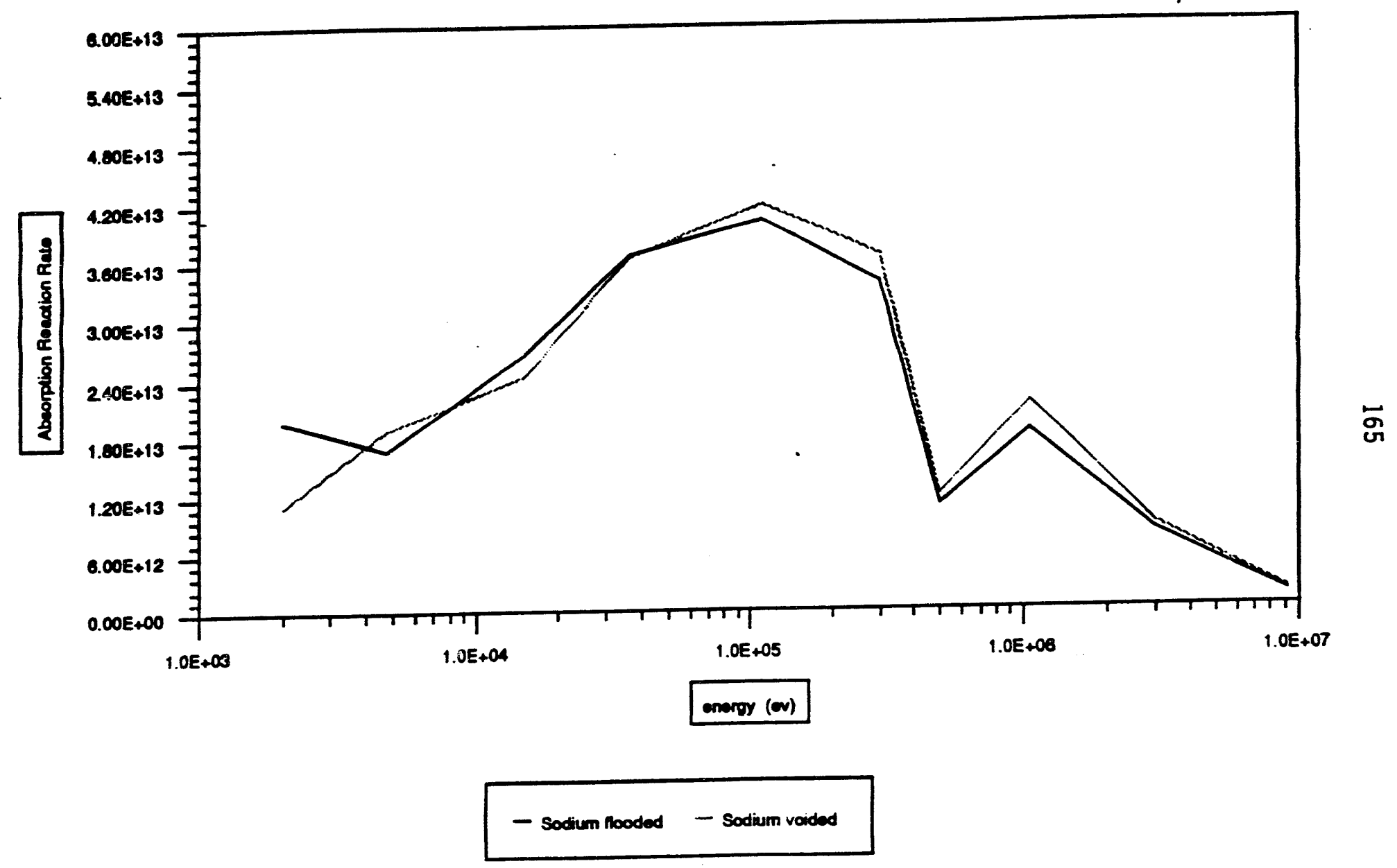

FIGURE C-44: Absorption Reaction Rate for ${ }^{235} \mathrm{U}$ in an 0xide 2 Cycle Radial Blanket. 


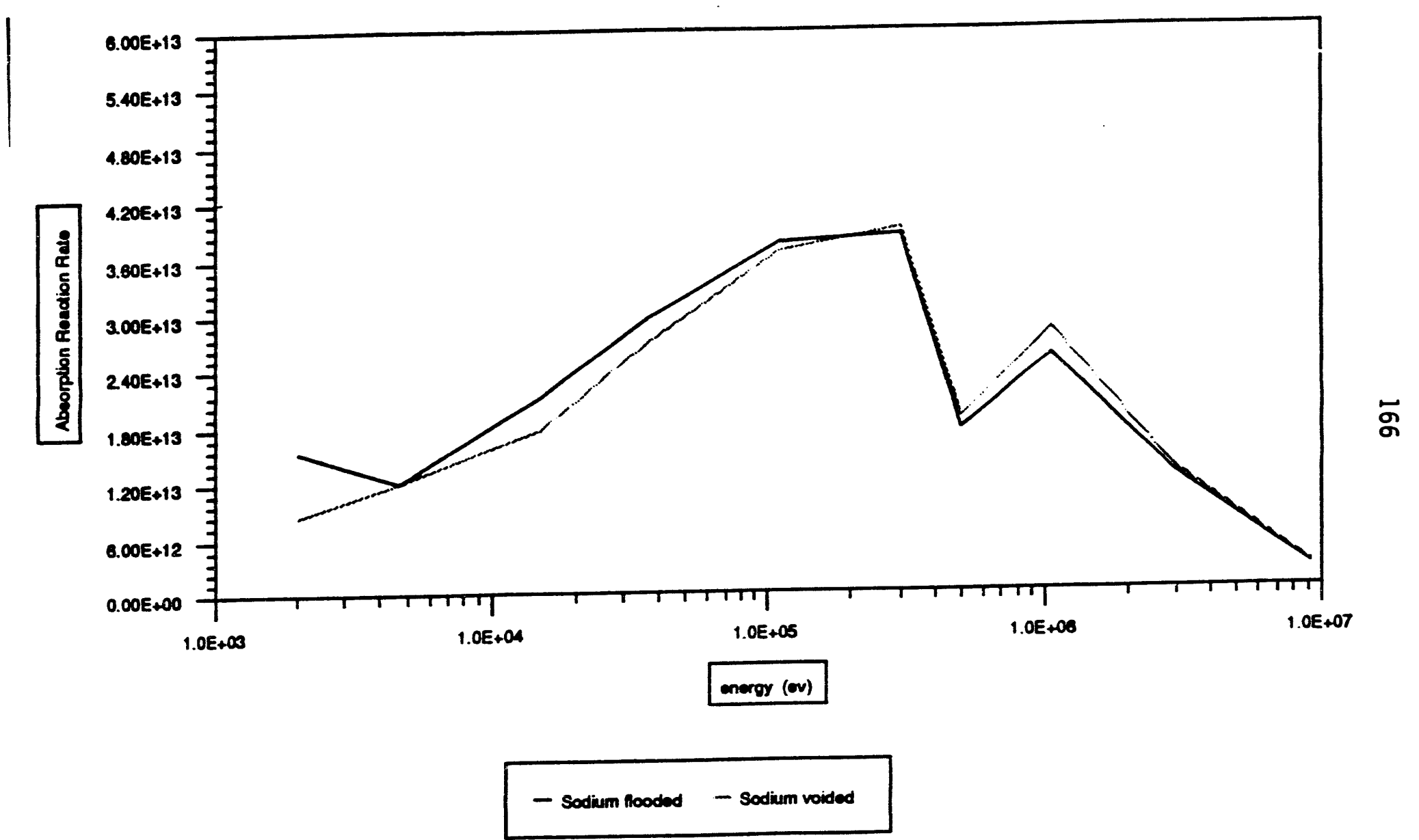

FIGURE C-45: Absorption Reaction Rate for ${ }^{235} \mathrm{U}$ in a Nitride Inner Fuel Assembly. 


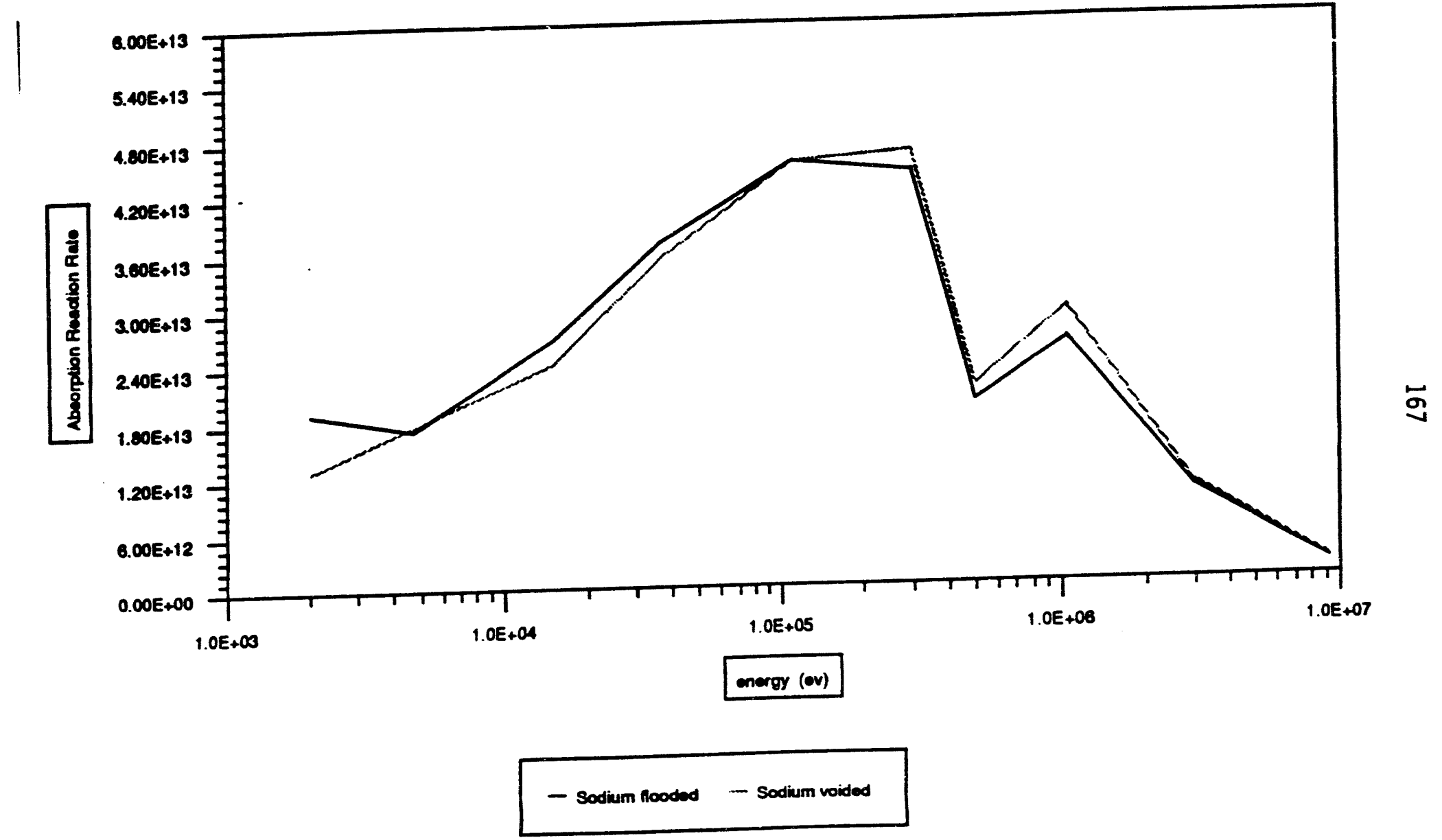

FIGURE C-46: Absorption Reaction Rate for ${ }^{235} \mathrm{U}$ in a Nitride 2 Cycle Radial Blanket. 


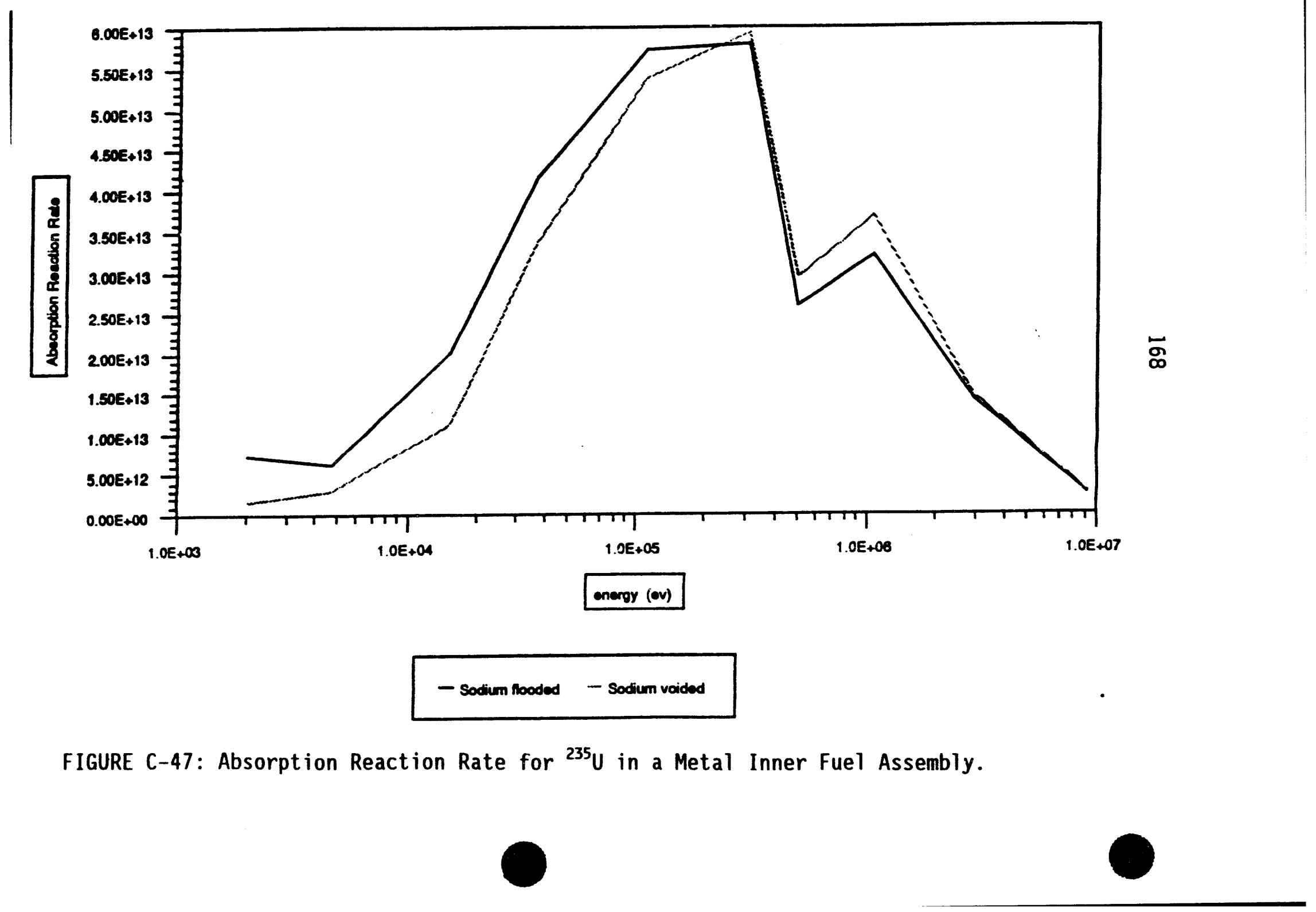




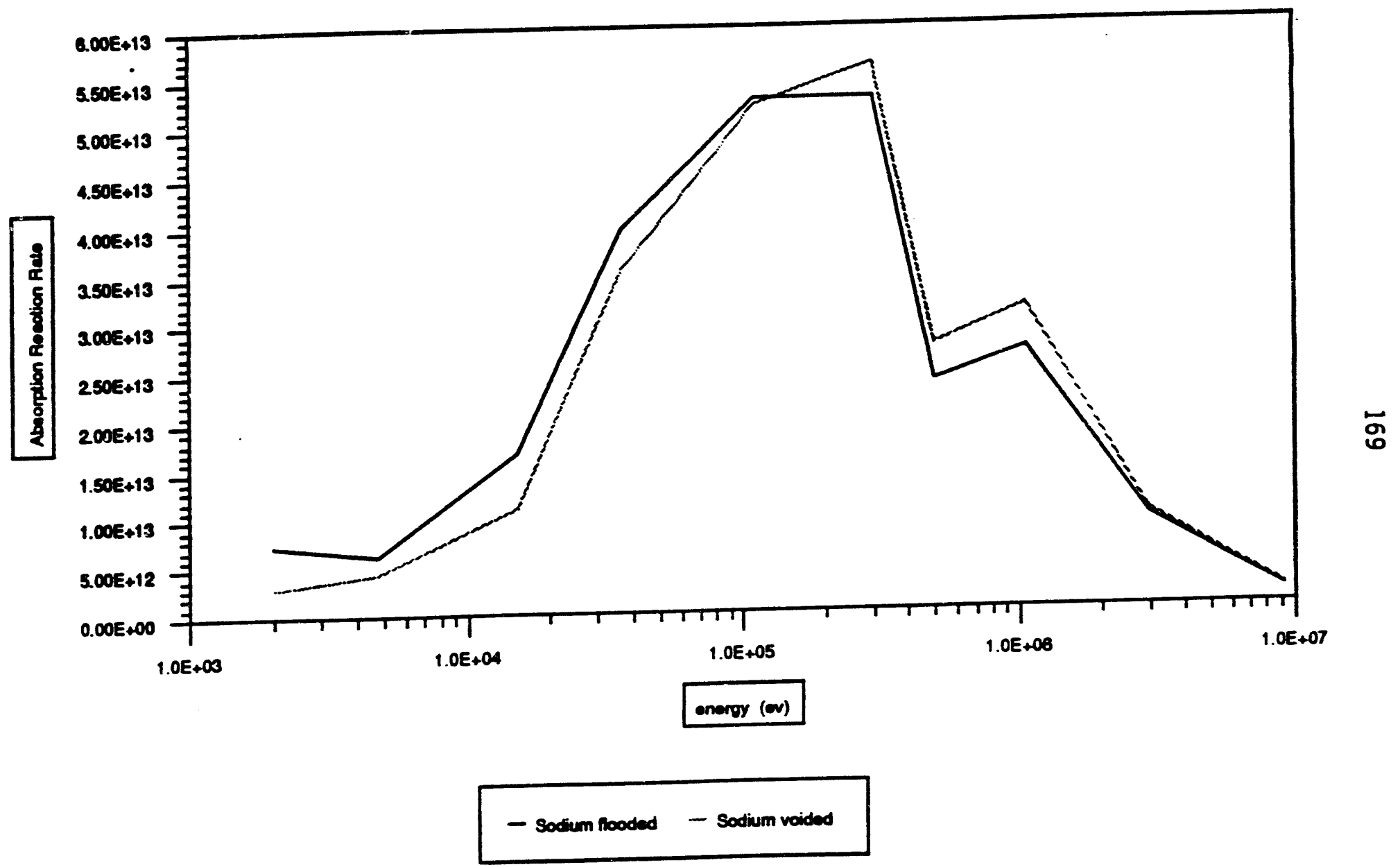

FIGURE C-48: Absorption Reaction Rate for ${ }^{235} \mathrm{U}$ in a Metal 2 Cycle Radial Blanket. 


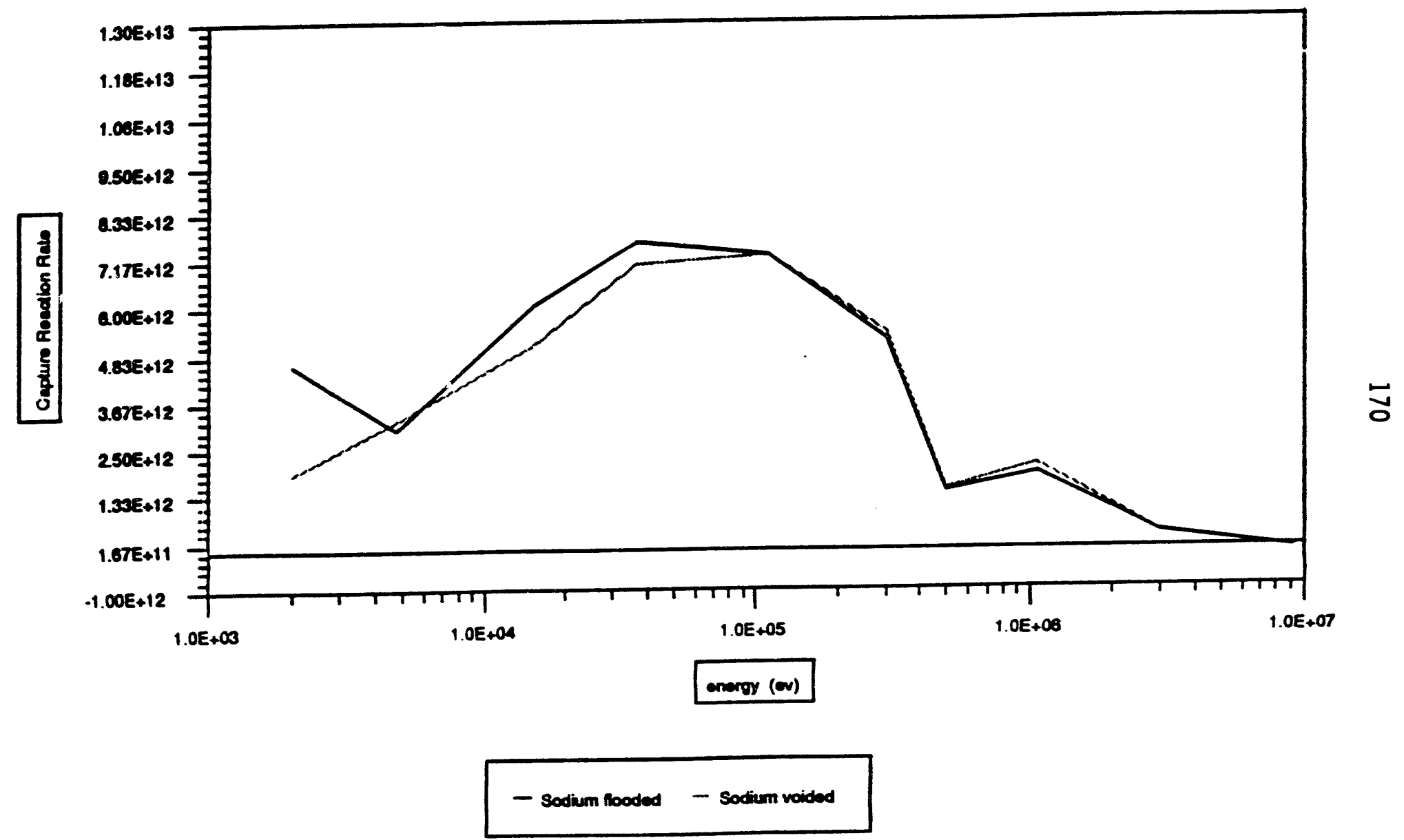

FIGURE C-49: Capture Reaction Rate for ${ }^{235} U$ in an 0xide Inner Fuel Assembly. 


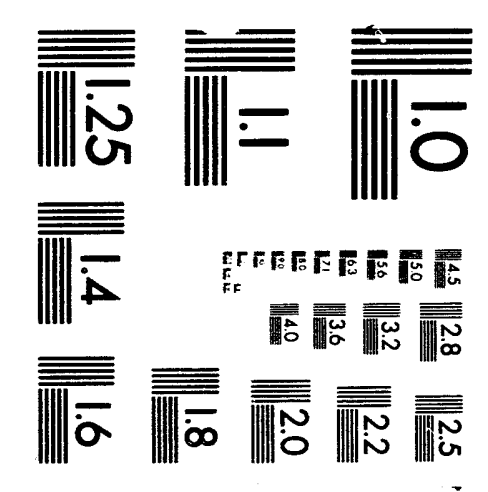



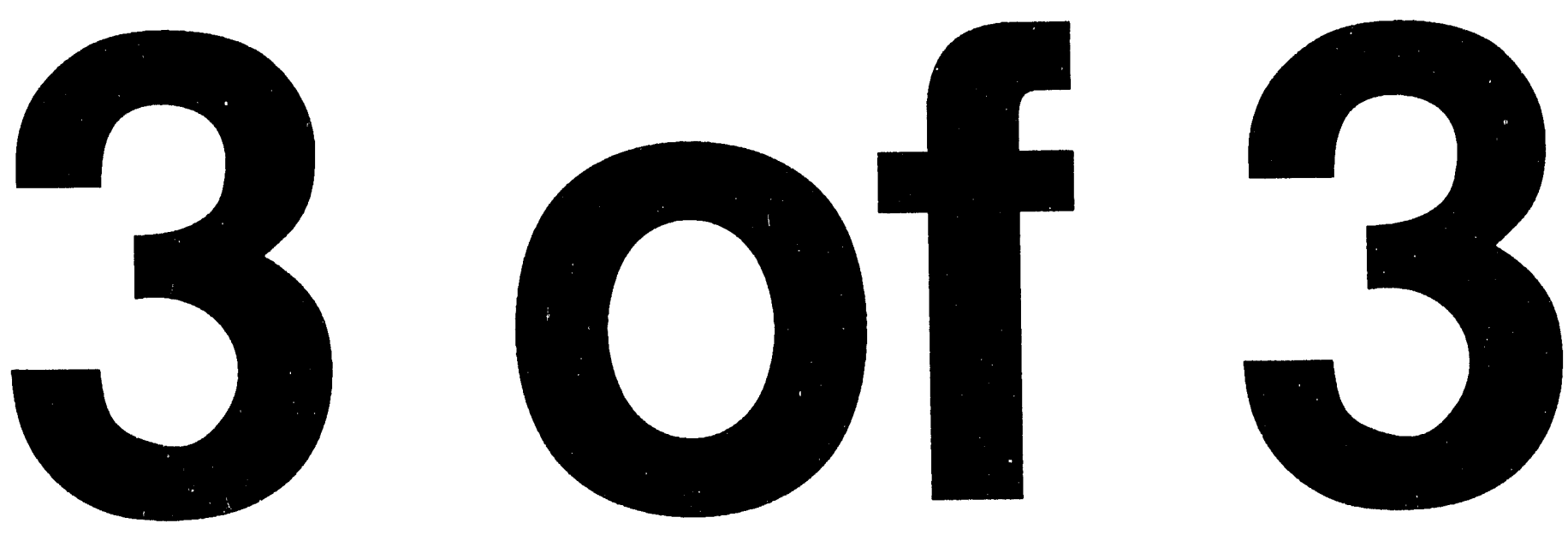


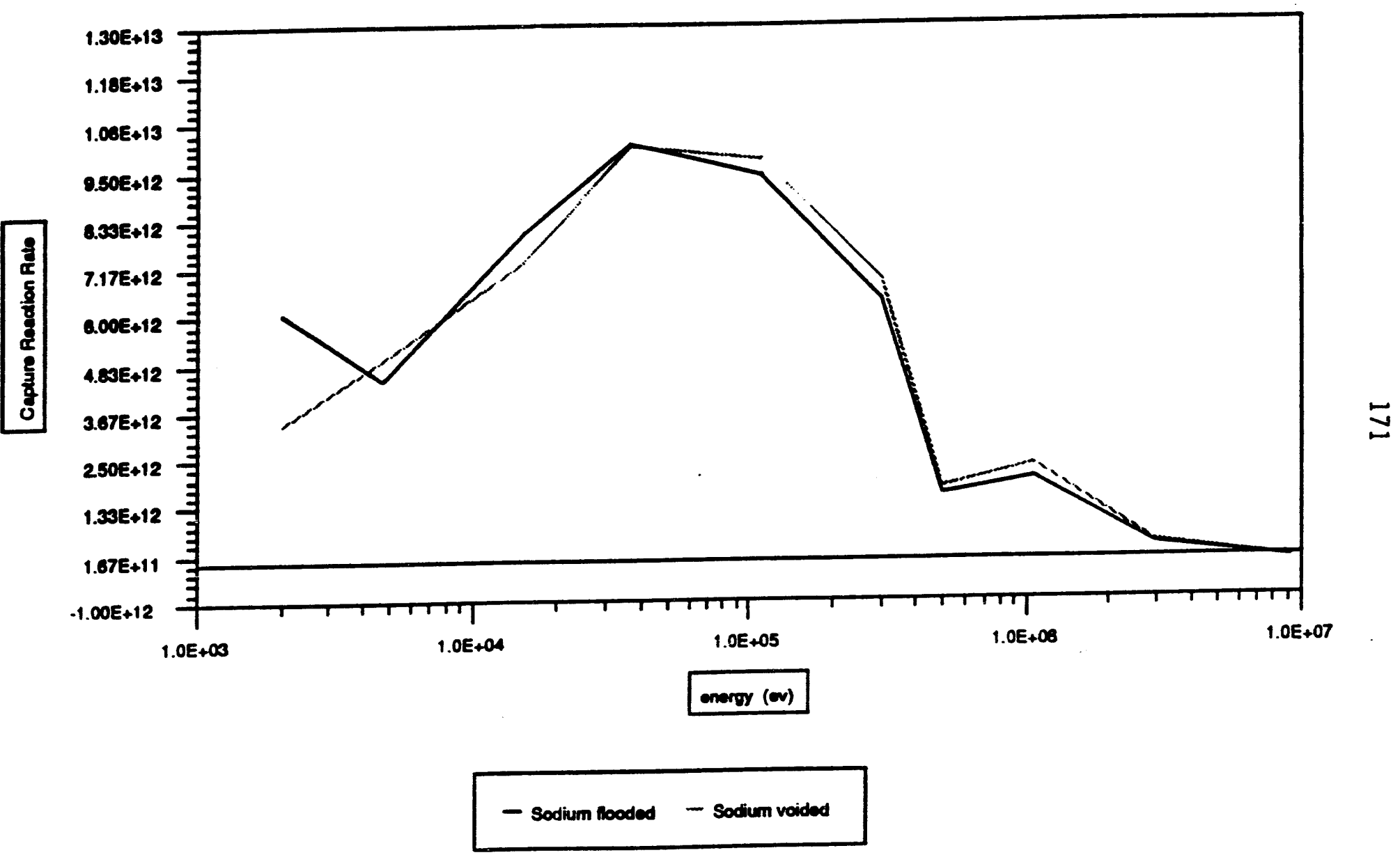

FIGURE C-50: Capture Reaction Rate for ${ }^{235} \mathrm{U}$ in an 0xide 2 Cycle Radial Blanket. 


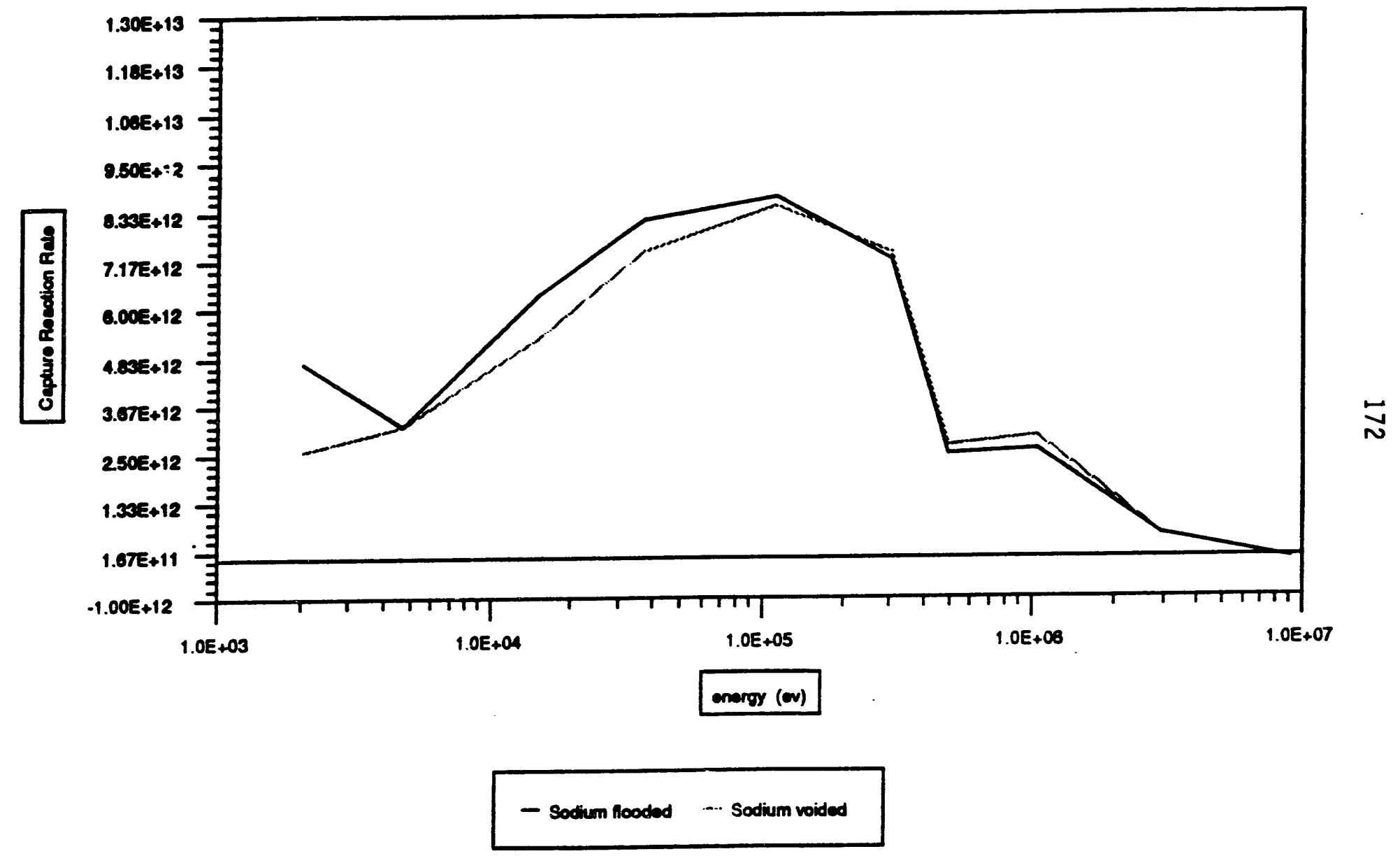

FIGURE C-51: Capture Reaction Rate for ${ }^{235} \mathrm{U}$ in a Nitride Inner Fuel Assembly. 


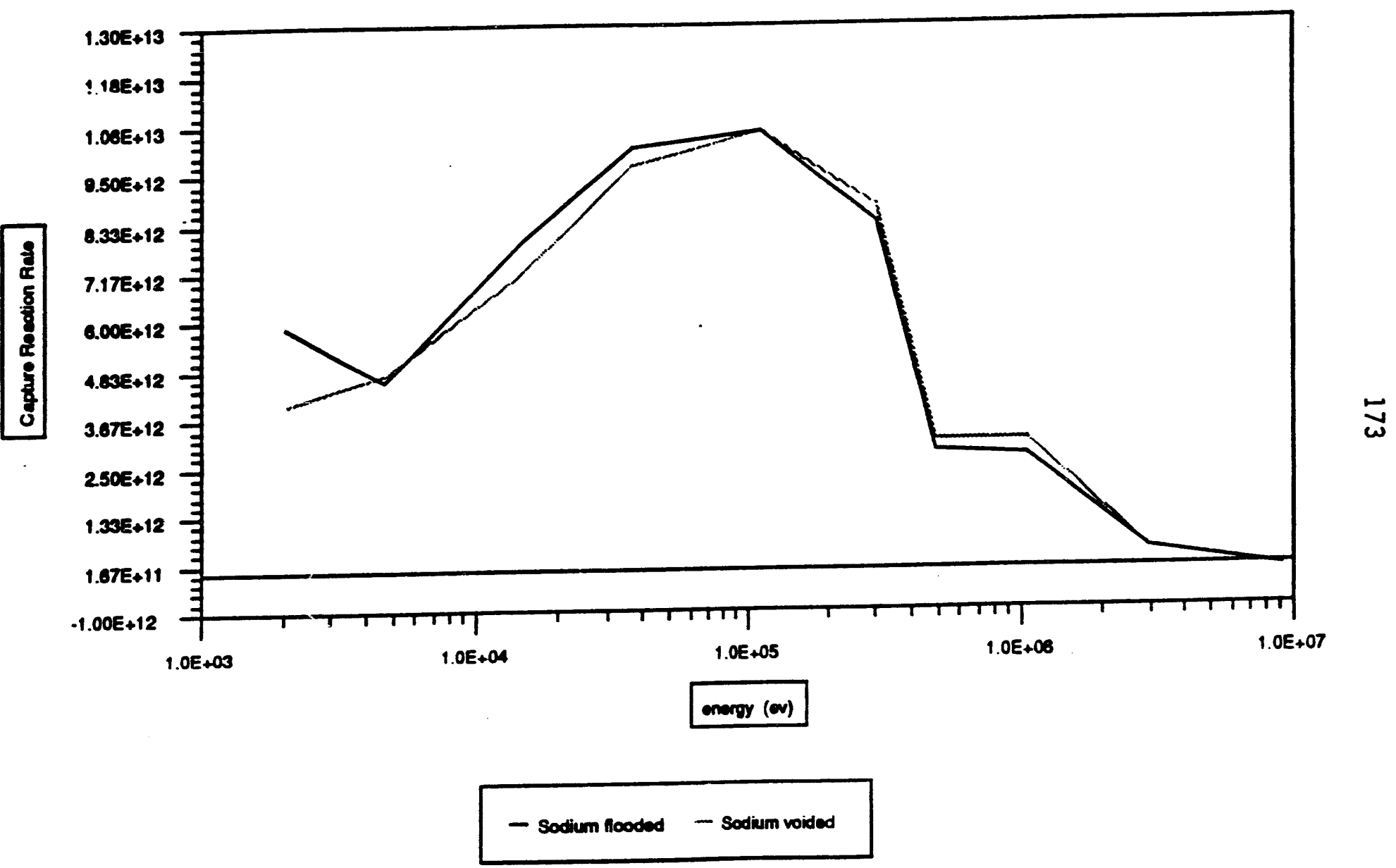

FIGURE C-52: Capture Reaction Rate for ${ }^{235} \mathrm{U}$ in a Nitride 2 Cycle Radial Blanket. 


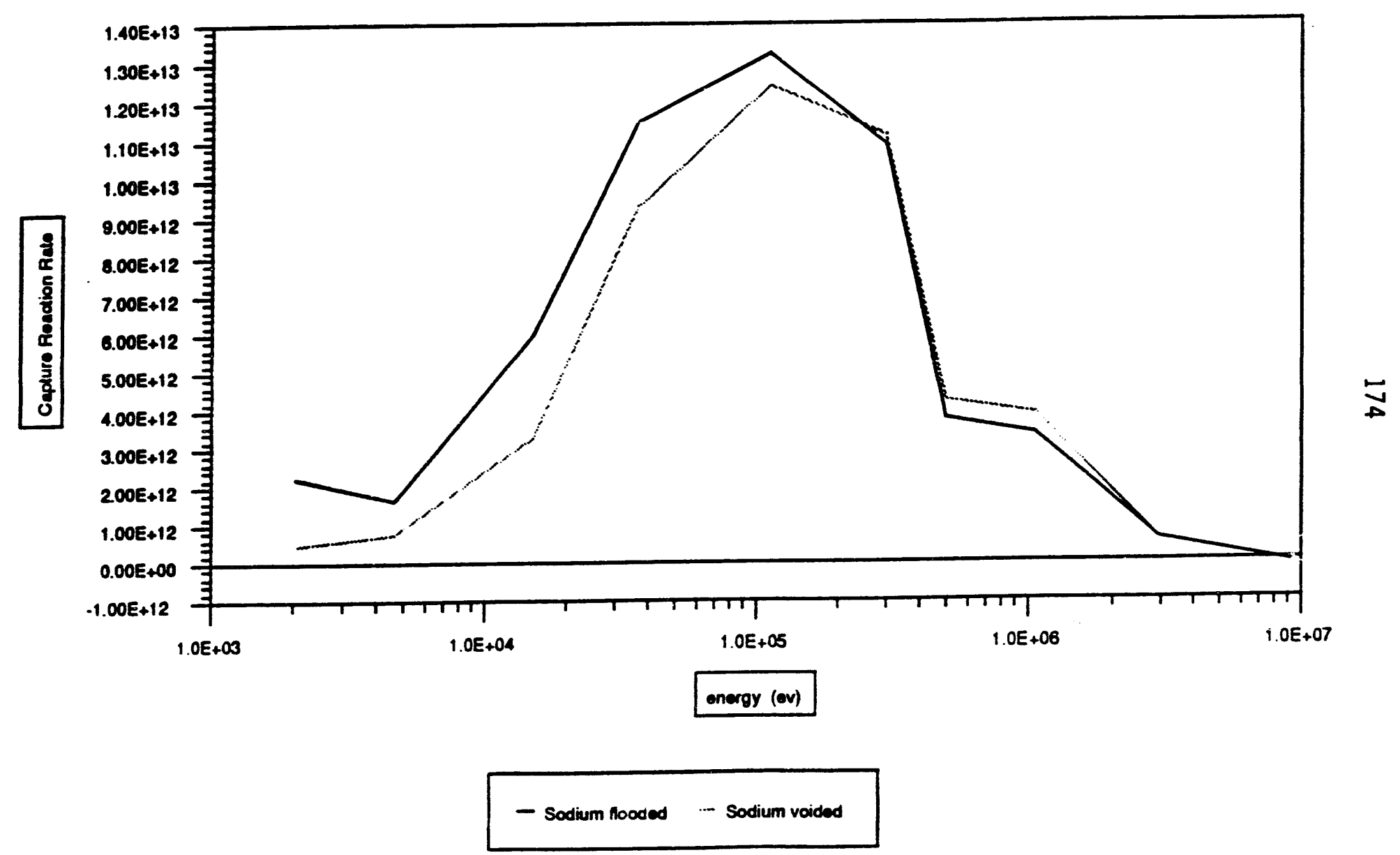

FIGURE C-53: Capture Reaction Rate for ${ }^{235} \mathrm{U}$ in a Metal Inner Fuel Assembly. 


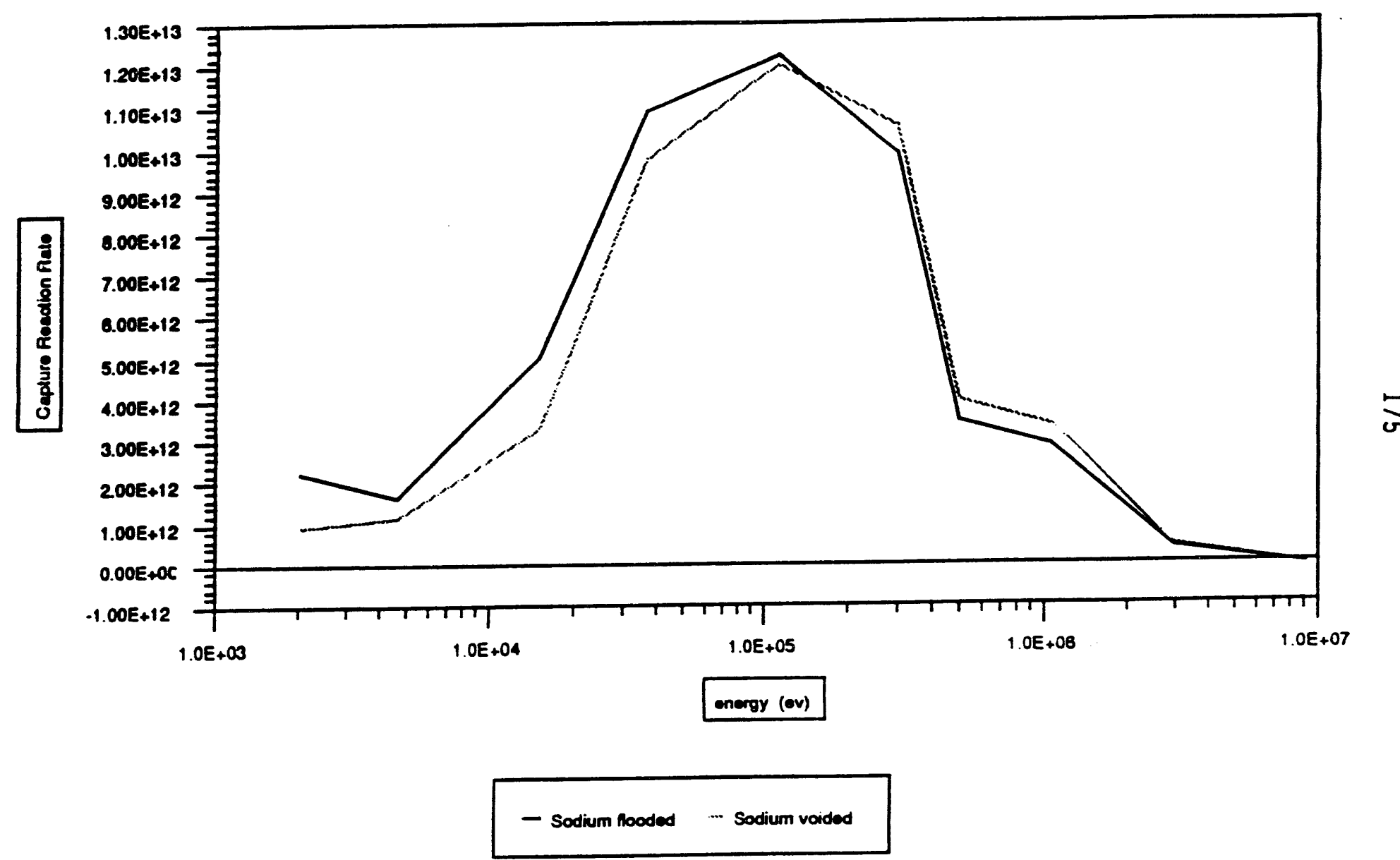

FIGURE C-54: Capture Reaction Rate for ${ }^{235} \mathrm{U}$ in a Metal 2 Cycle Radial Blanket. 


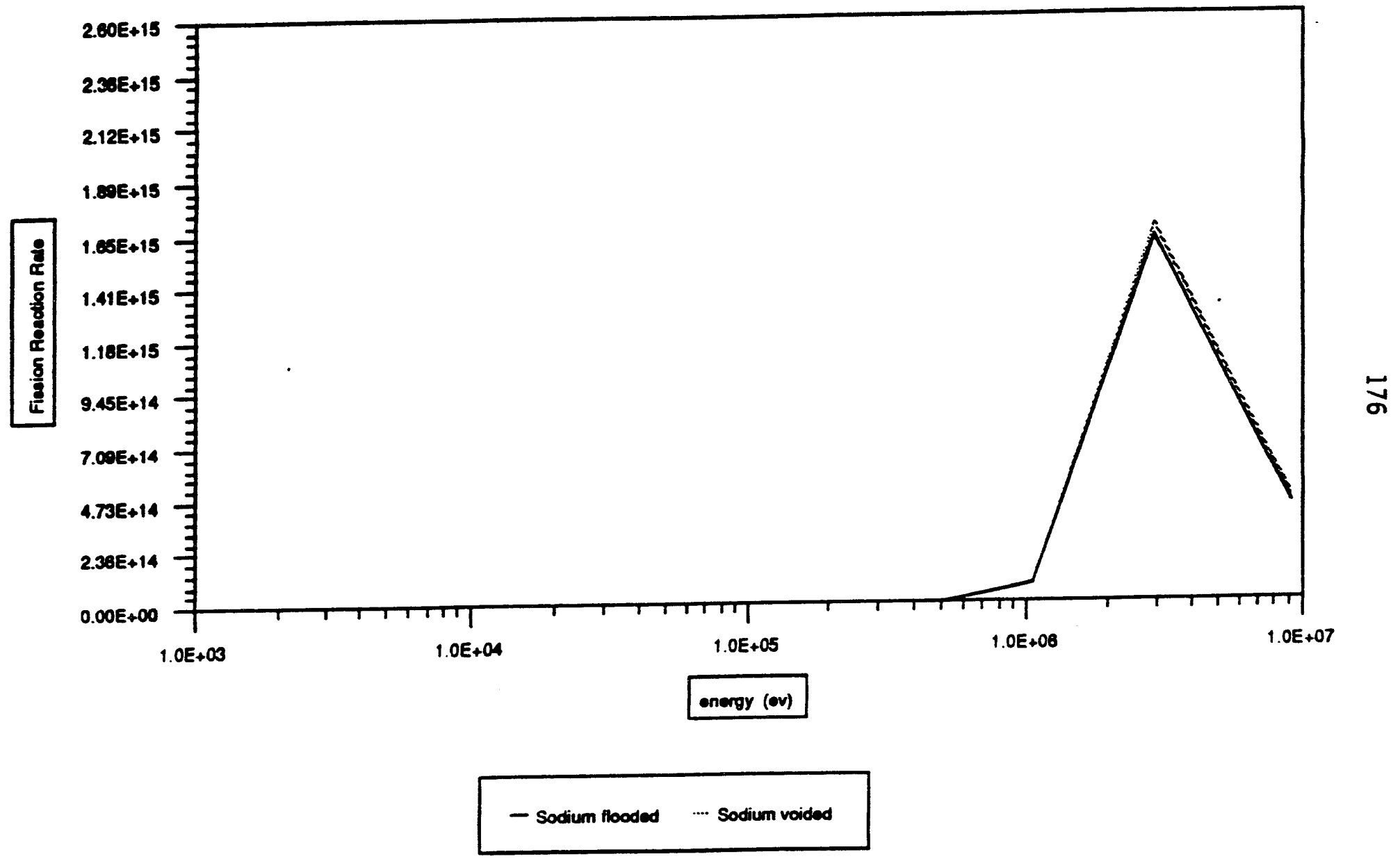

FIGURE C-55: Fission Reaction Rate for ${ }^{238} \mathrm{U}$ in an 0xide Inner Fuel Assembly. 



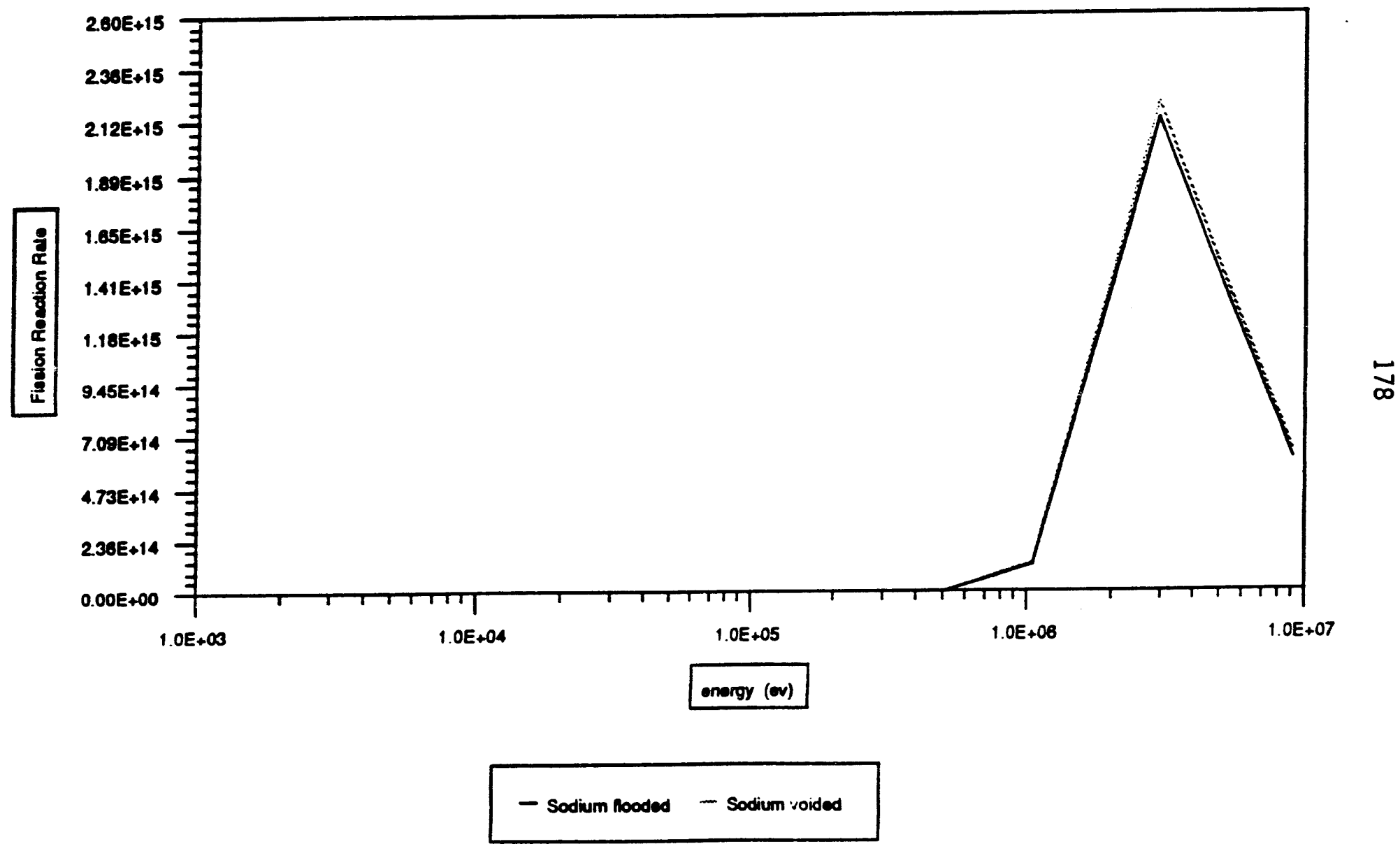

FIGURE C-57: Fission Reaction Rate for ${ }^{238} \mathrm{U}$ in a iitride Inner Fuel Assembly. 


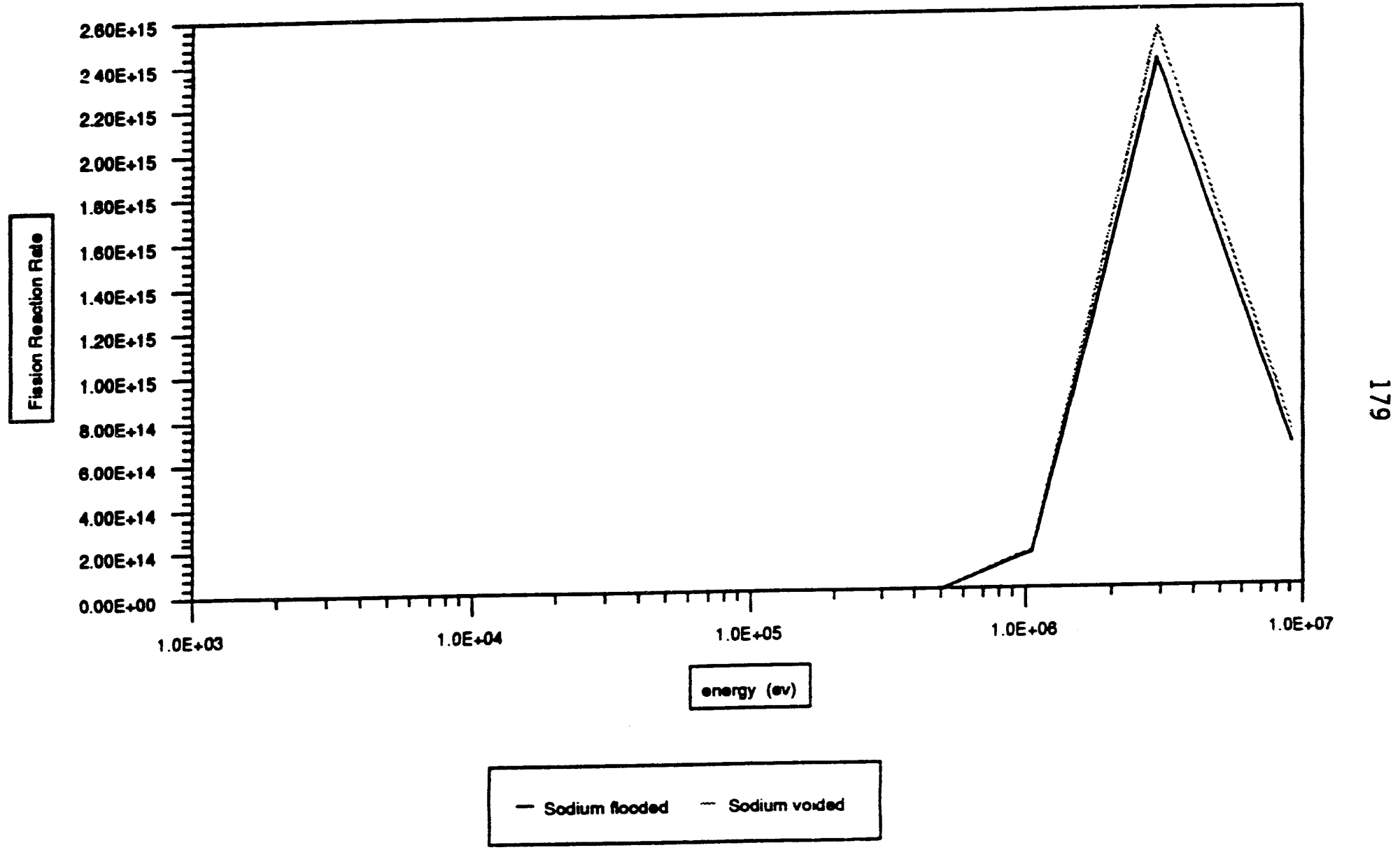

FIGURE C-58: Fission Reaction Rate for ${ }^{238} \mathrm{U}$ in a Nitride 2 Cycle Radial Blanket. 


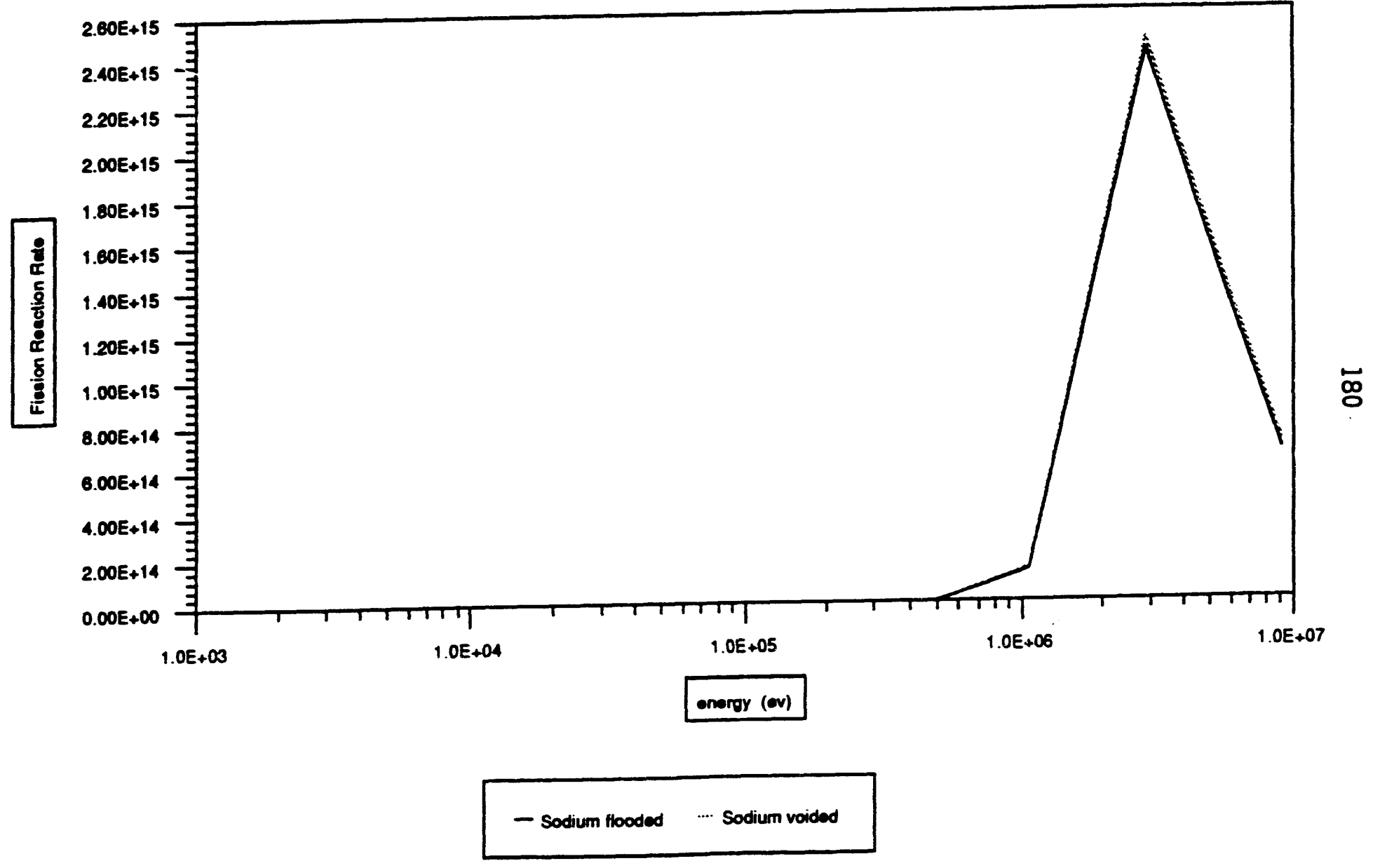

FIGURE C-59: Fission Reaction Rate for ${ }^{238} \mathrm{U}$ in a Metal Inner Fuel Assembly. 



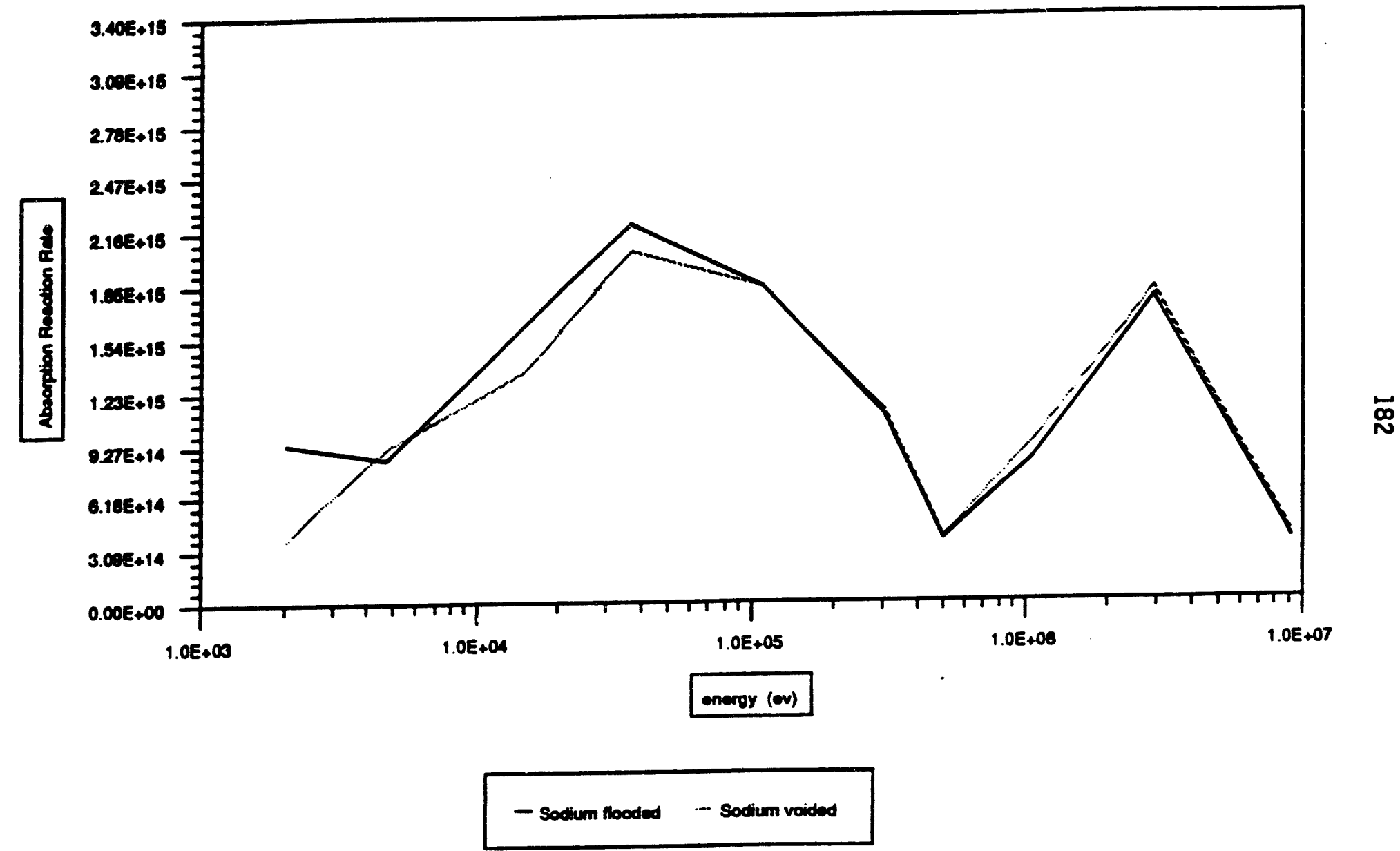

FIGURE C-61: Absorption Reaction Rate for ${ }^{238} \mathrm{U}$ in an 0xide Inner Fuel Assembly. 


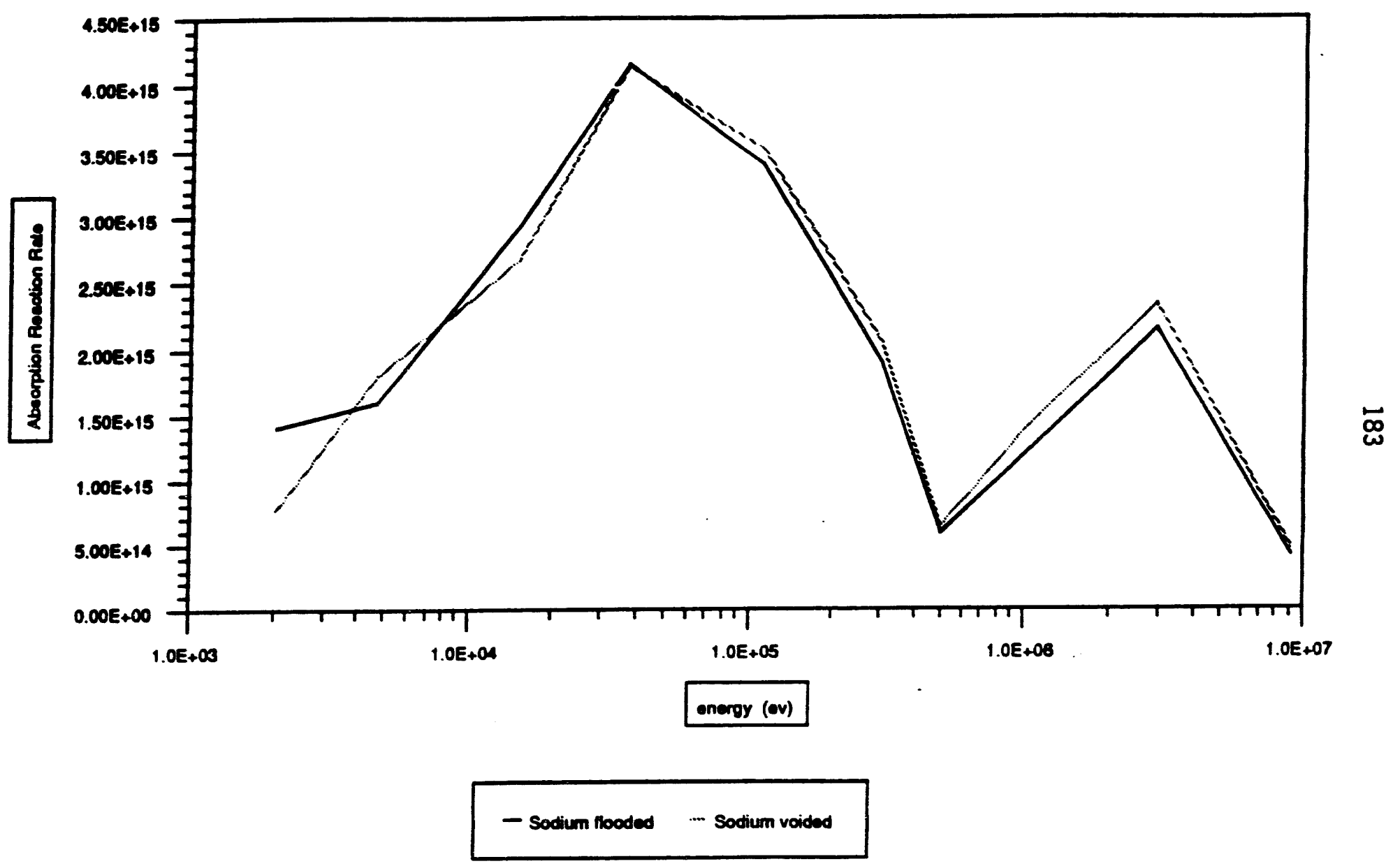

FIGURE C-62: Absorption Reaction Rate for ${ }^{238} \mathrm{U}$ in an 0xide 2 Cycle Radial Blanket. 


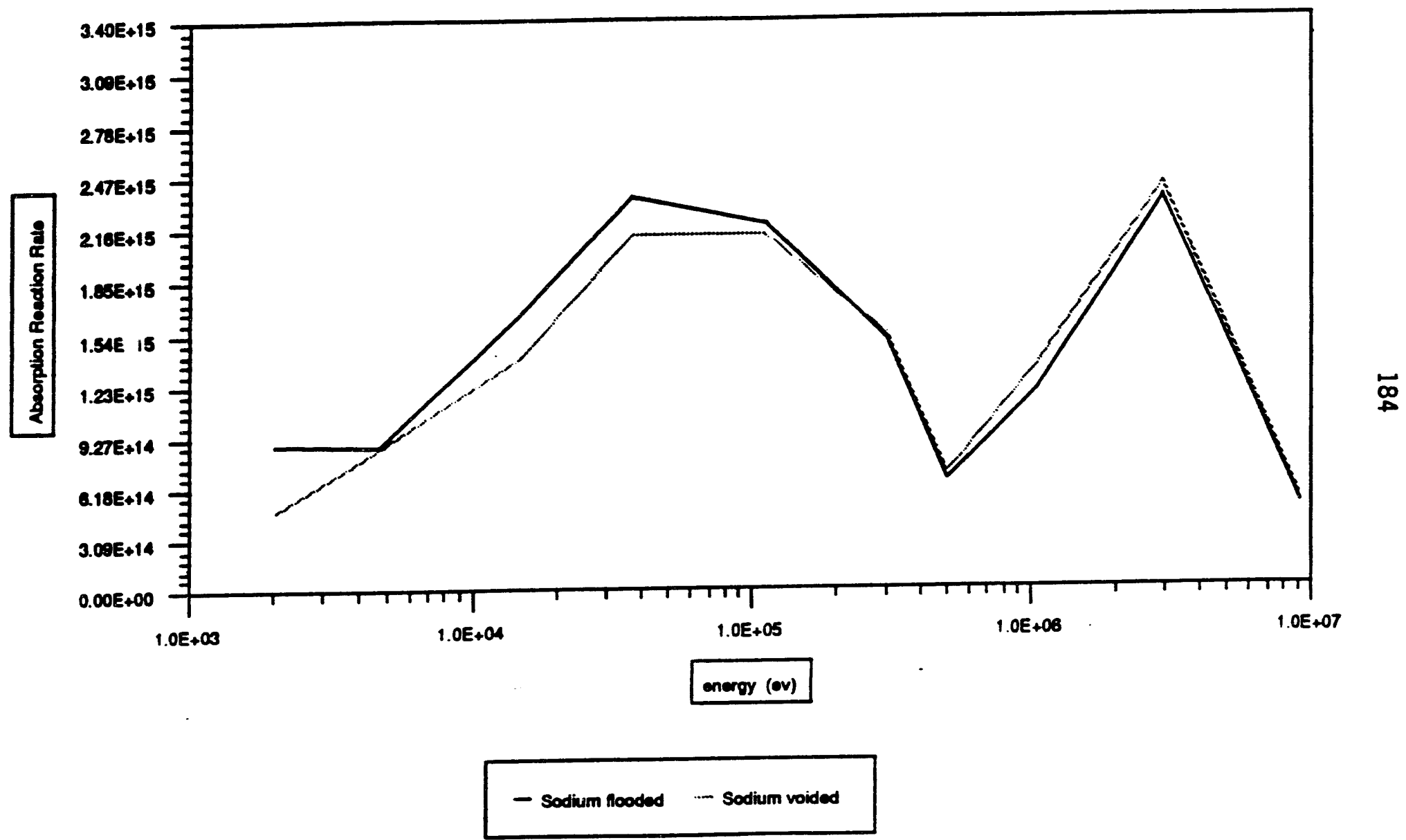

FIGURE C-63: Absorption Reaction Rate for ${ }^{238} \mathrm{U}$ in a Nitride Inner Fuel Assembly. 



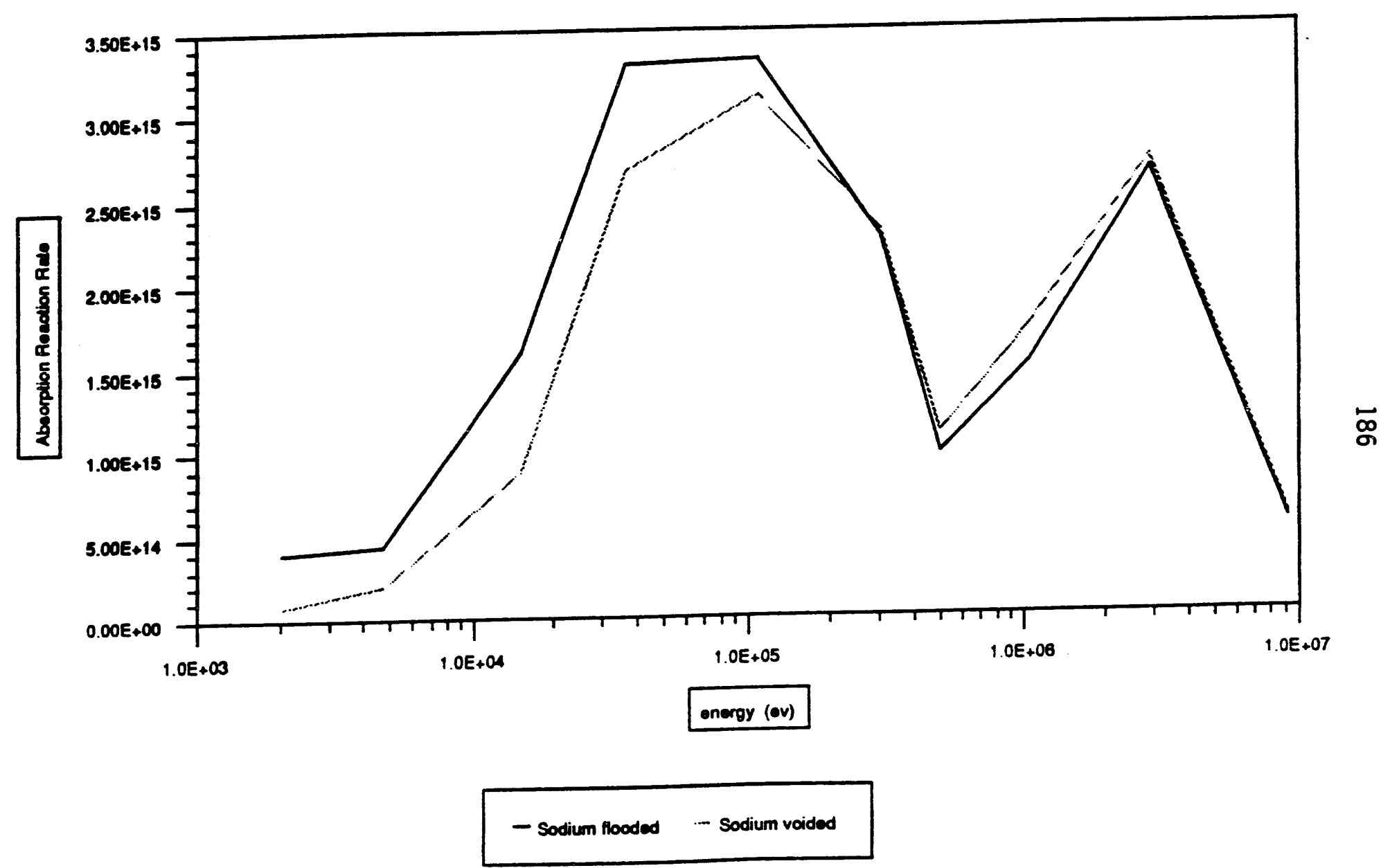

FIGURE C-65: Absorption Reaction Rate for ${ }^{238} \mathrm{U}$ in a Metal Inner Fuel Assembly. 



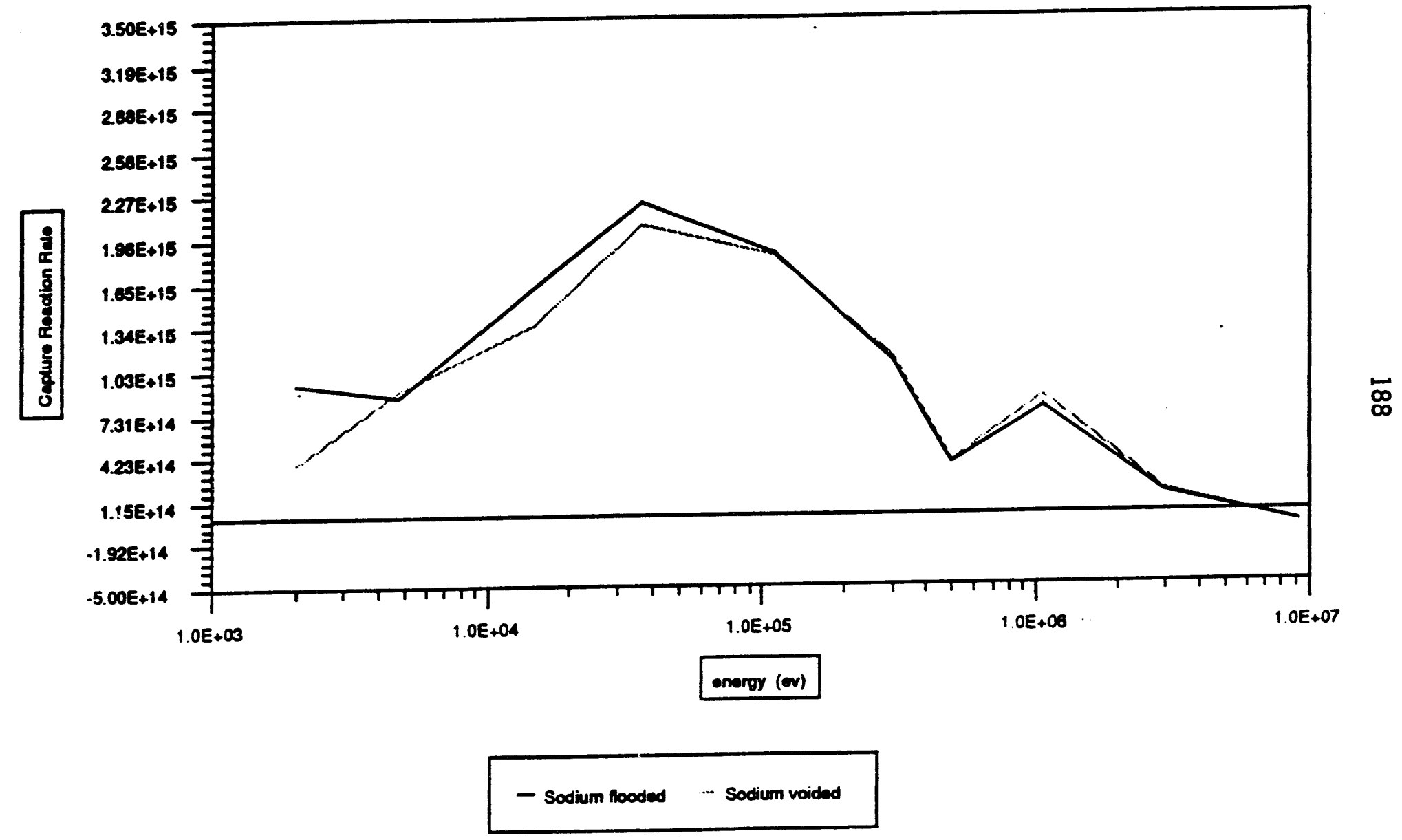

FIGURE C-67: Capture Reaction Rate for ${ }^{238} \mathrm{U}$ in an 0xide Inner Fuel Assembly. 


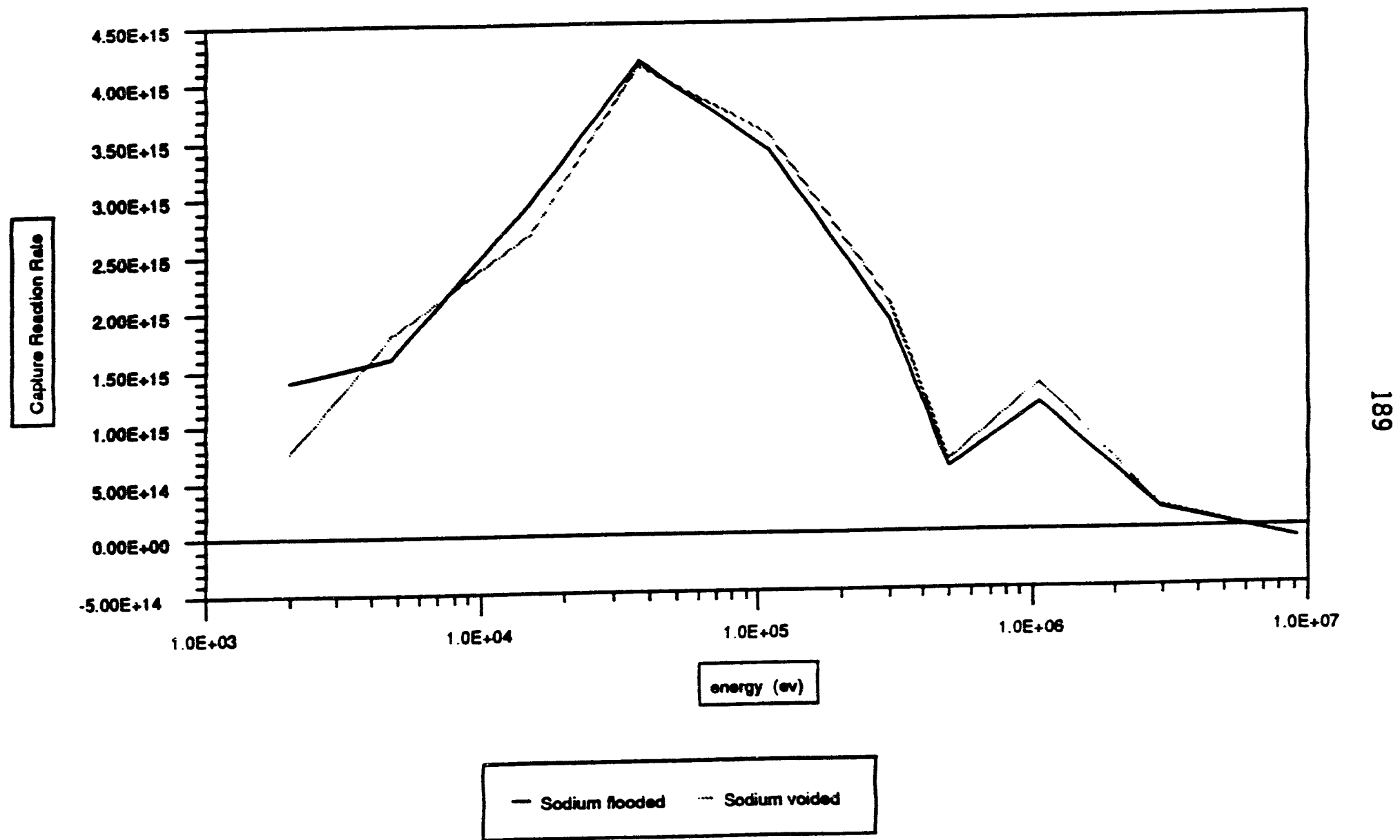

FIGURE C-68: Capture Reaction Rate for ${ }^{238} \mathrm{U}$ in an 0xide 2 Cycle Radial Blanket. 


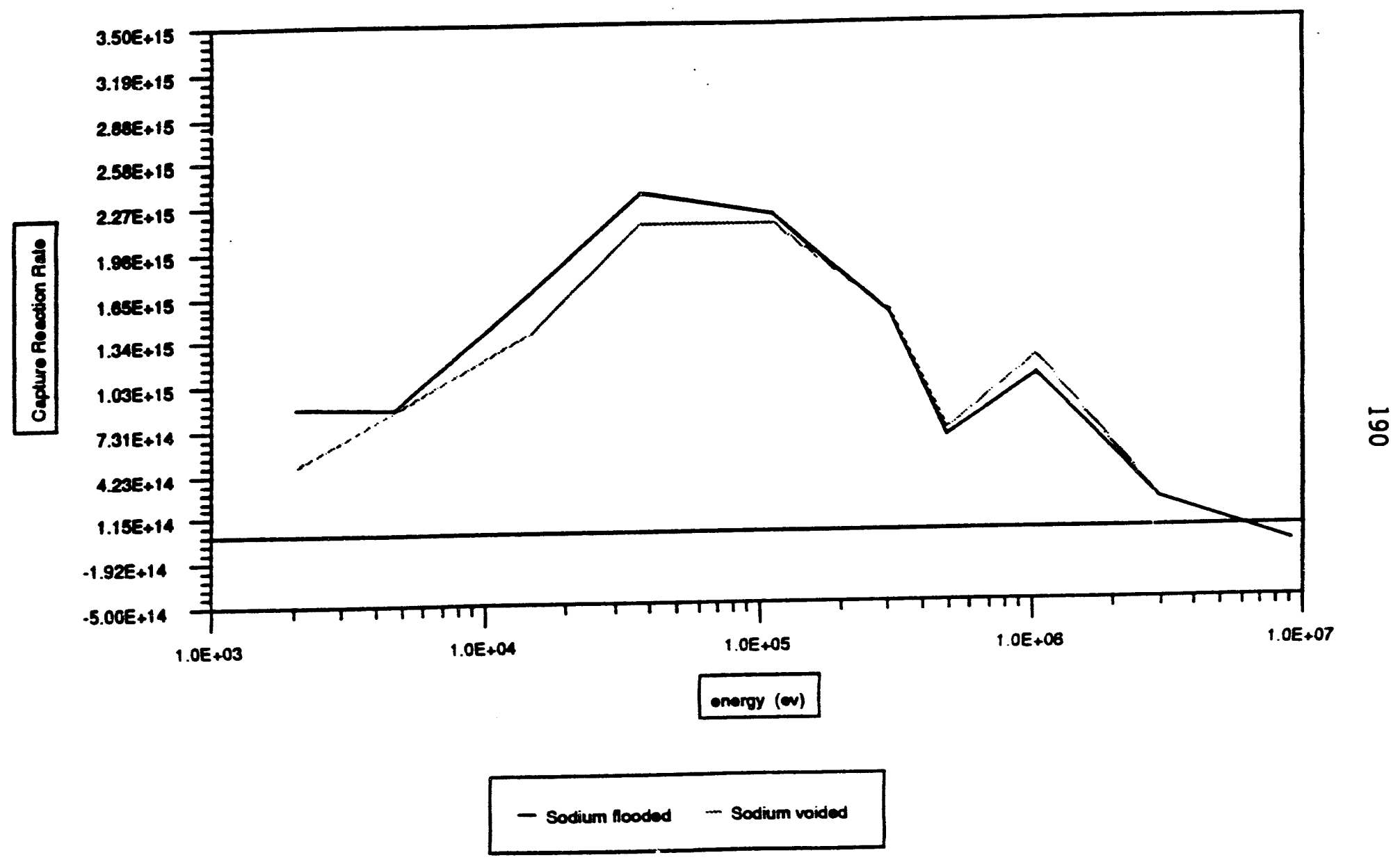

FIGURE C-69: Capture Reaction Rate for ${ }^{238} \mathrm{U}$ in a Nitride Inner Fuel Assembly. 



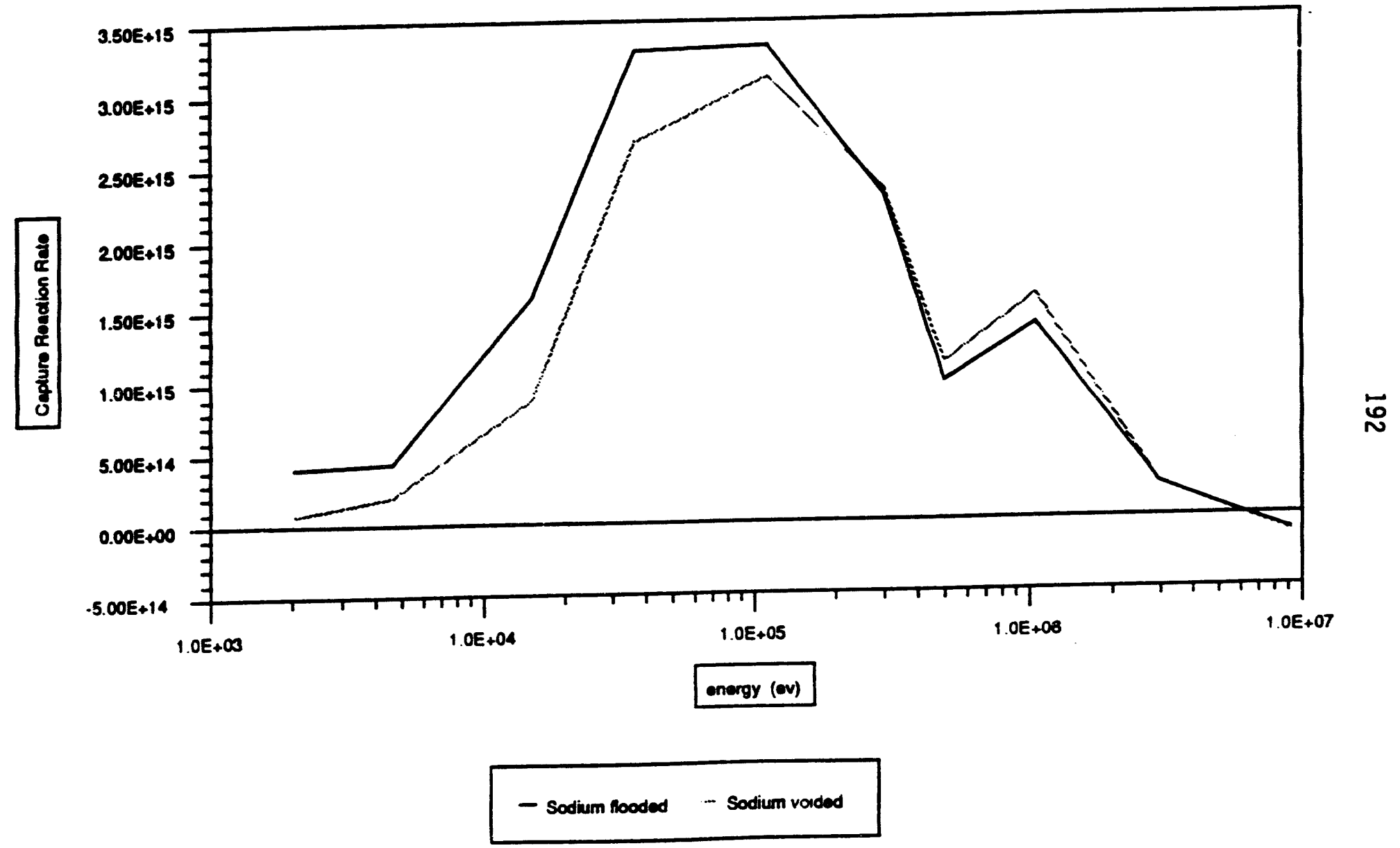

FIGURE C-71: Capture Reaction Rate for ${ }^{238} \mathrm{U}$ in a Metal Inner Fuel Assembly. 


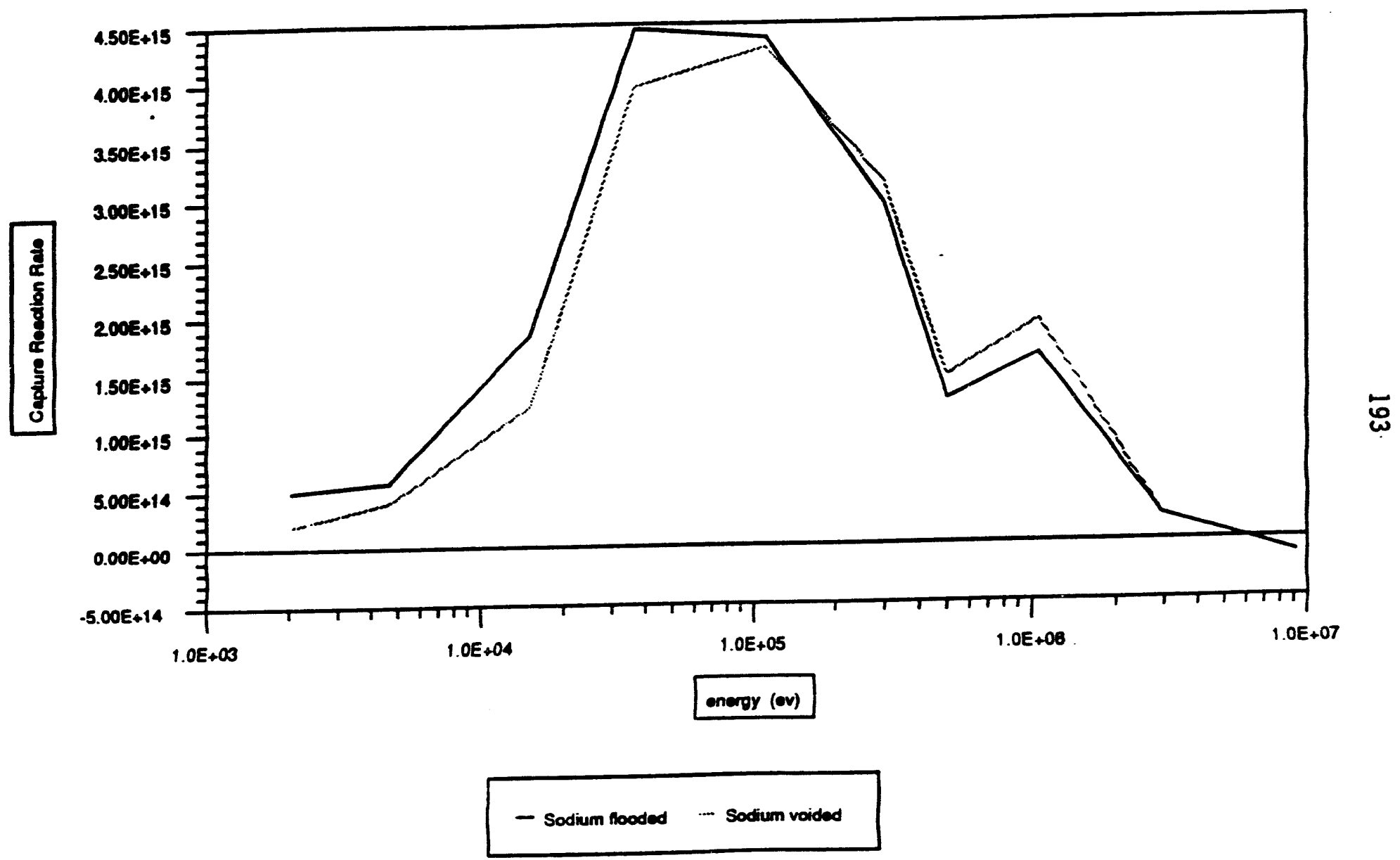

FIGURE C-72: Capture Reaction Rate for ${ }^{238} \mathrm{U}$ in a Metal 2 Cycle Radial Blanket. 


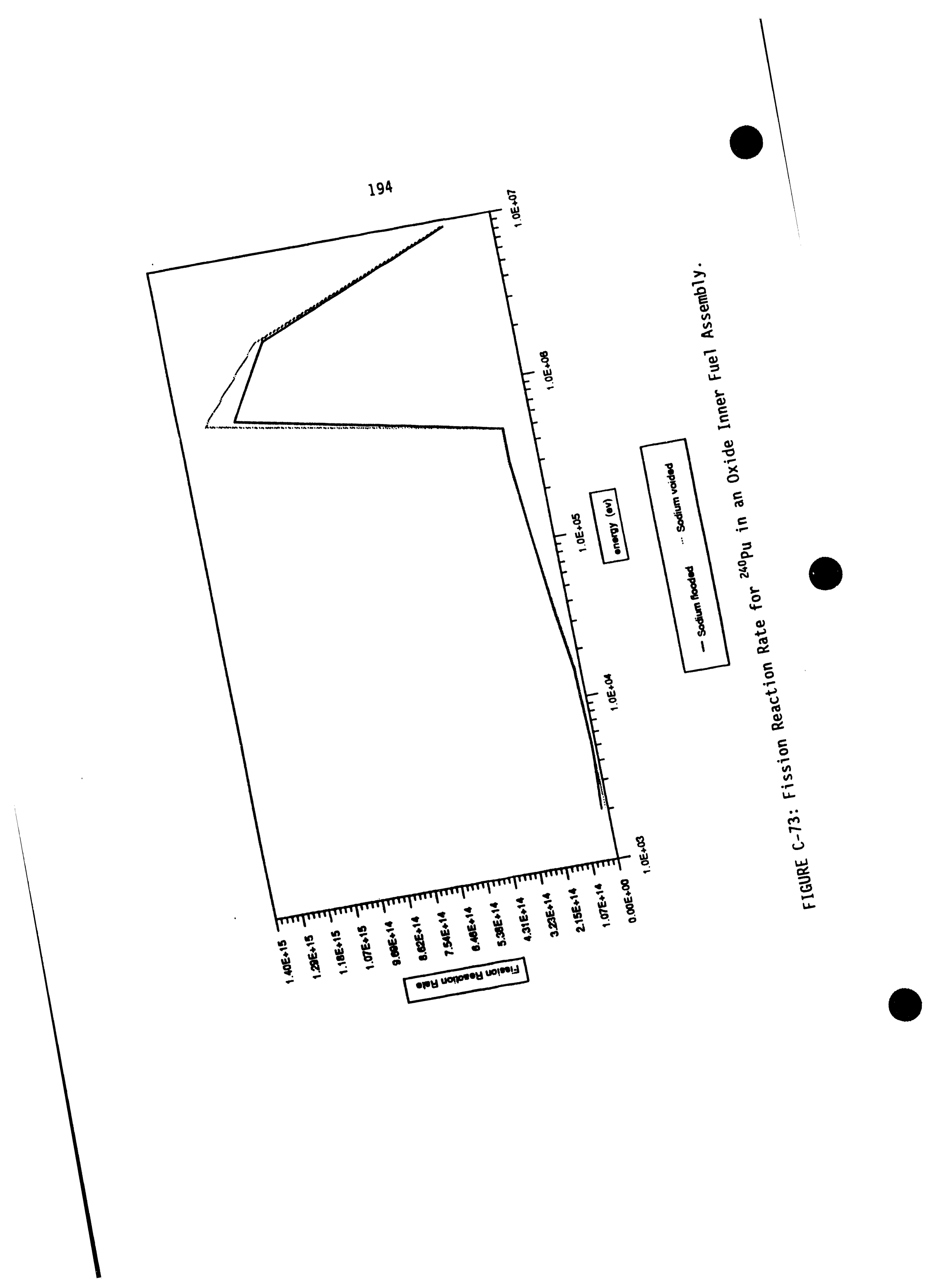




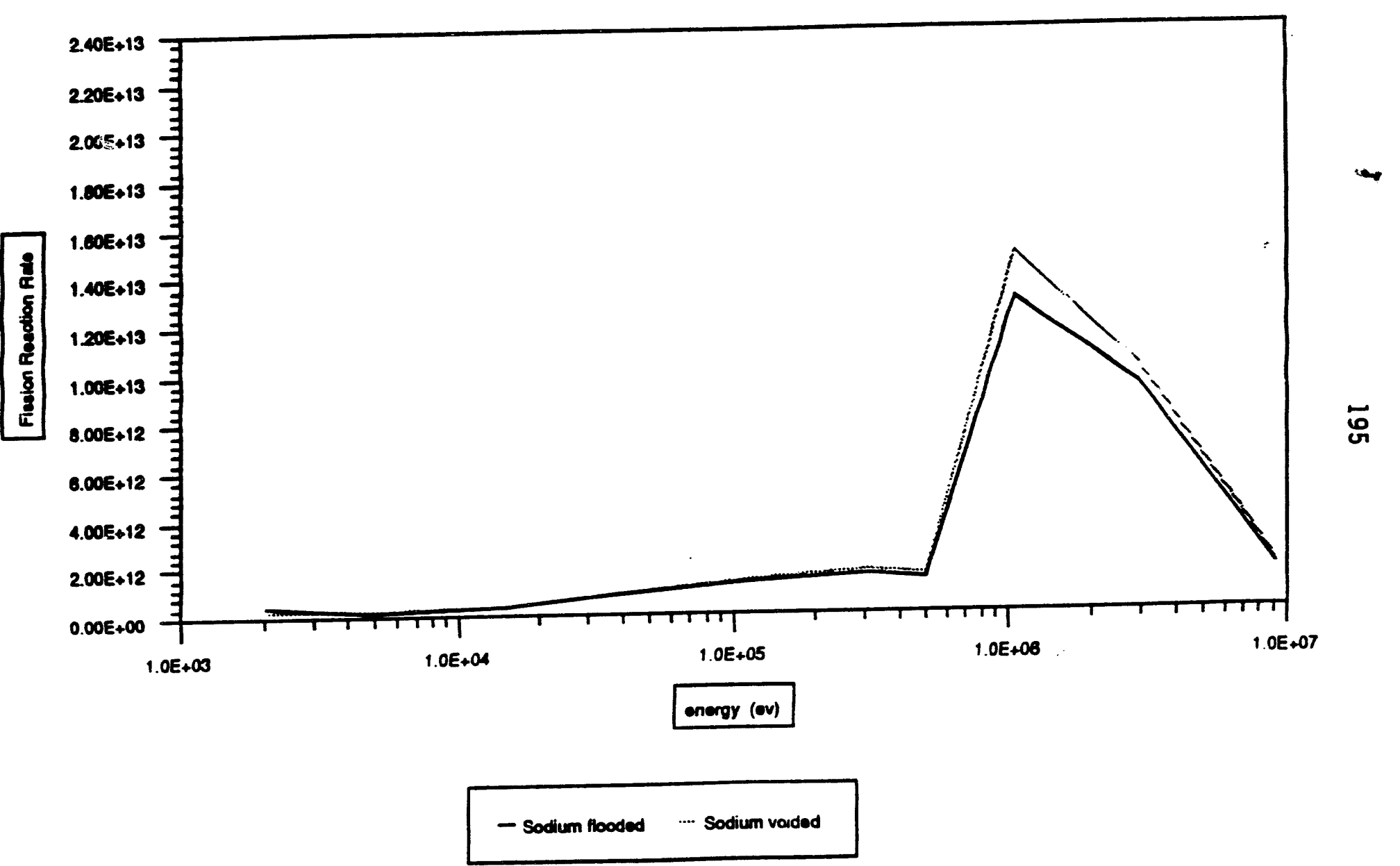

FIGURE C-74: Fission Reaction Rate for ${ }^{240} \mathrm{Pu}$ in an 0xide 2 Cycle Radial Blanket. 


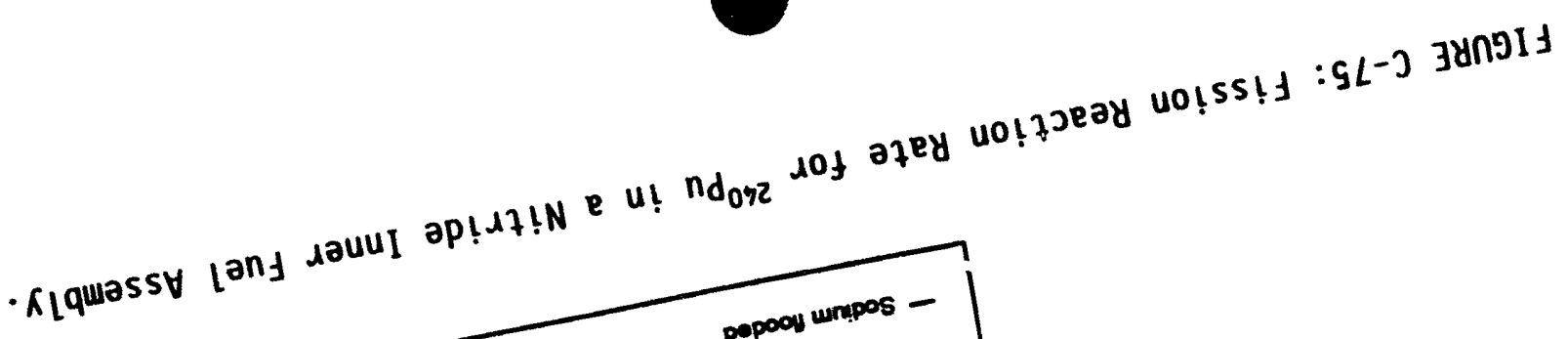

popion unpos - poposu wripos -

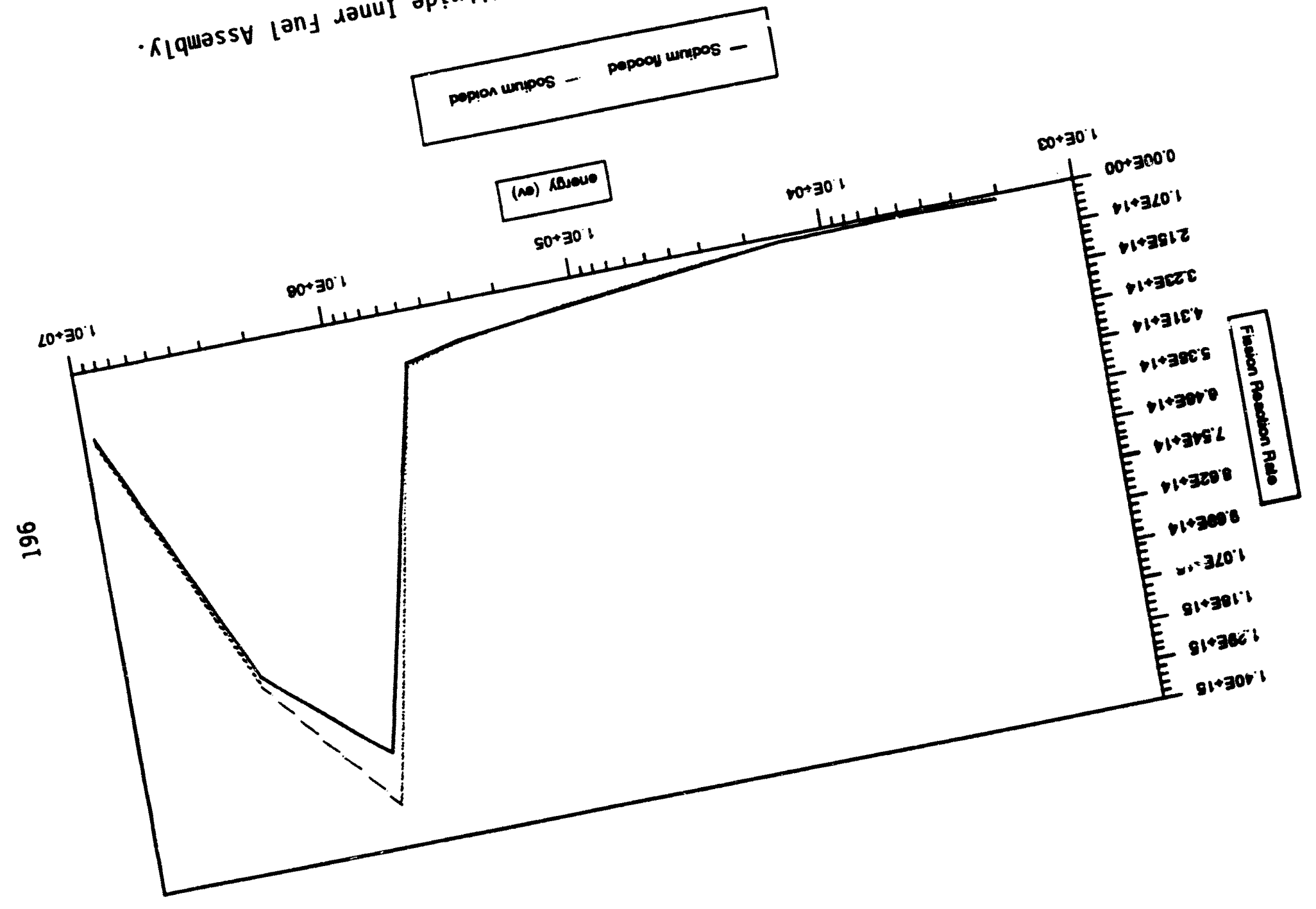




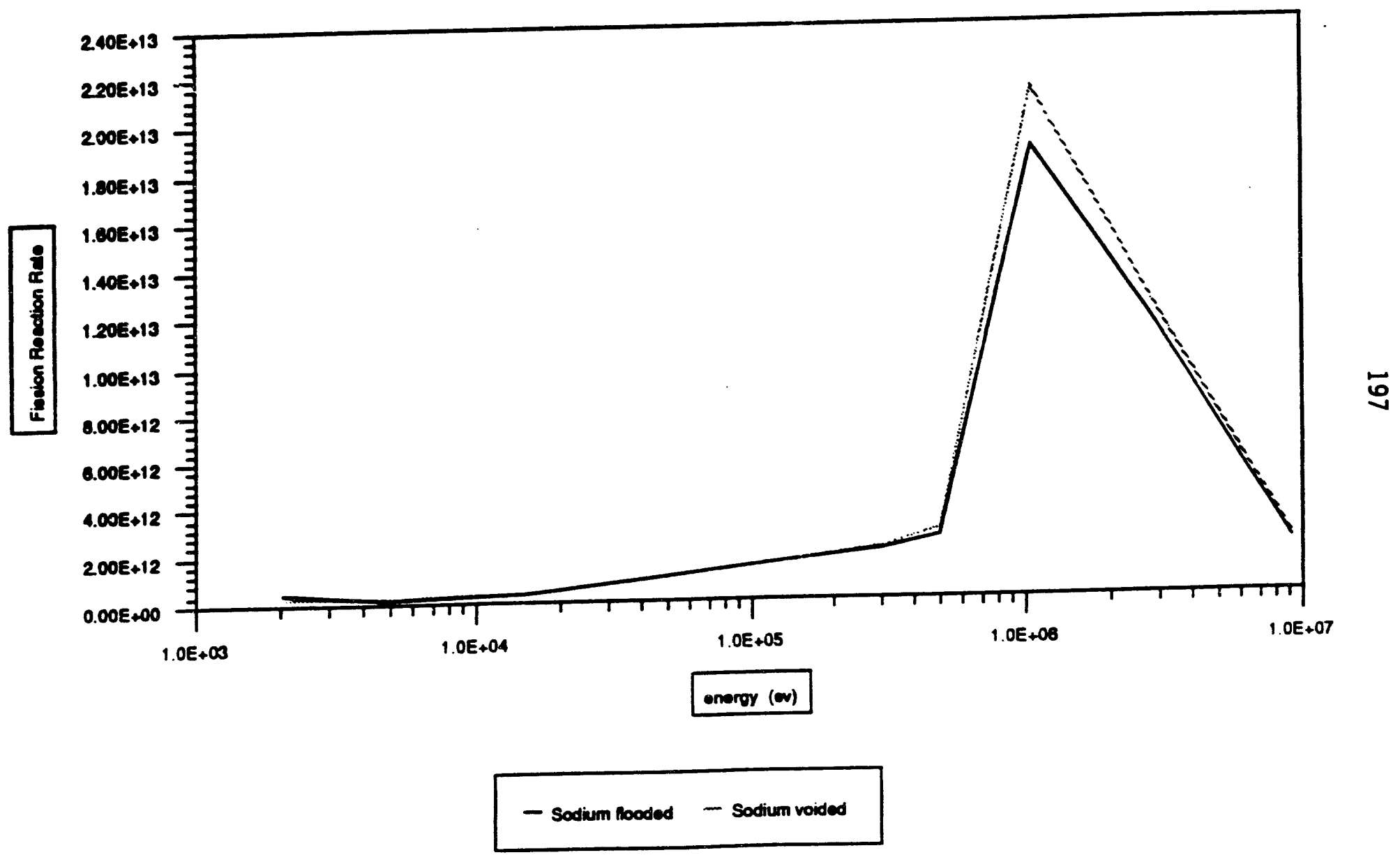

FIGURE C-76: Fission Reaction Rate for ${ }^{240} \mathrm{Pu}$ in a Nitride 2 Cycle Radial Blanket. 


\section{-}

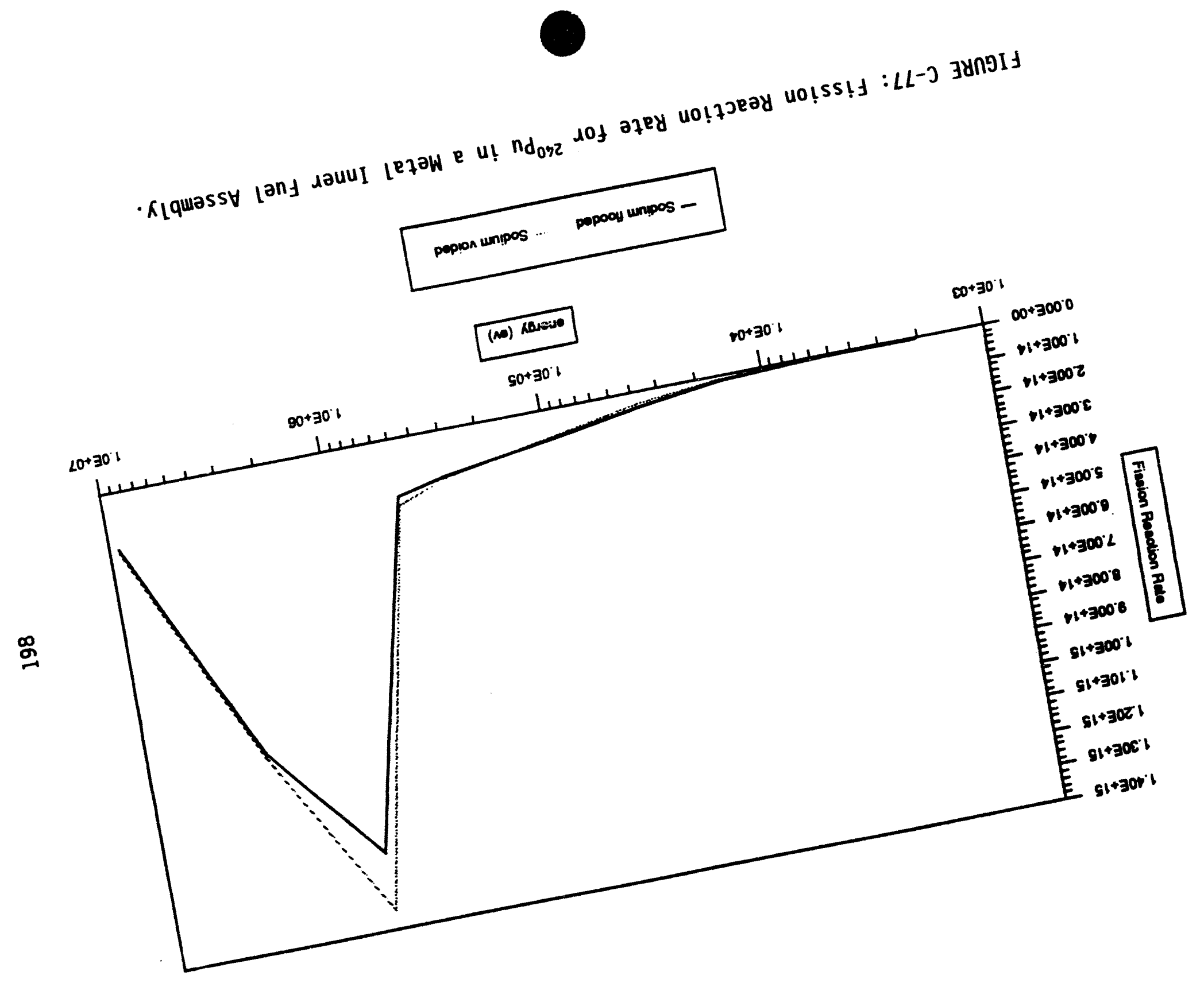




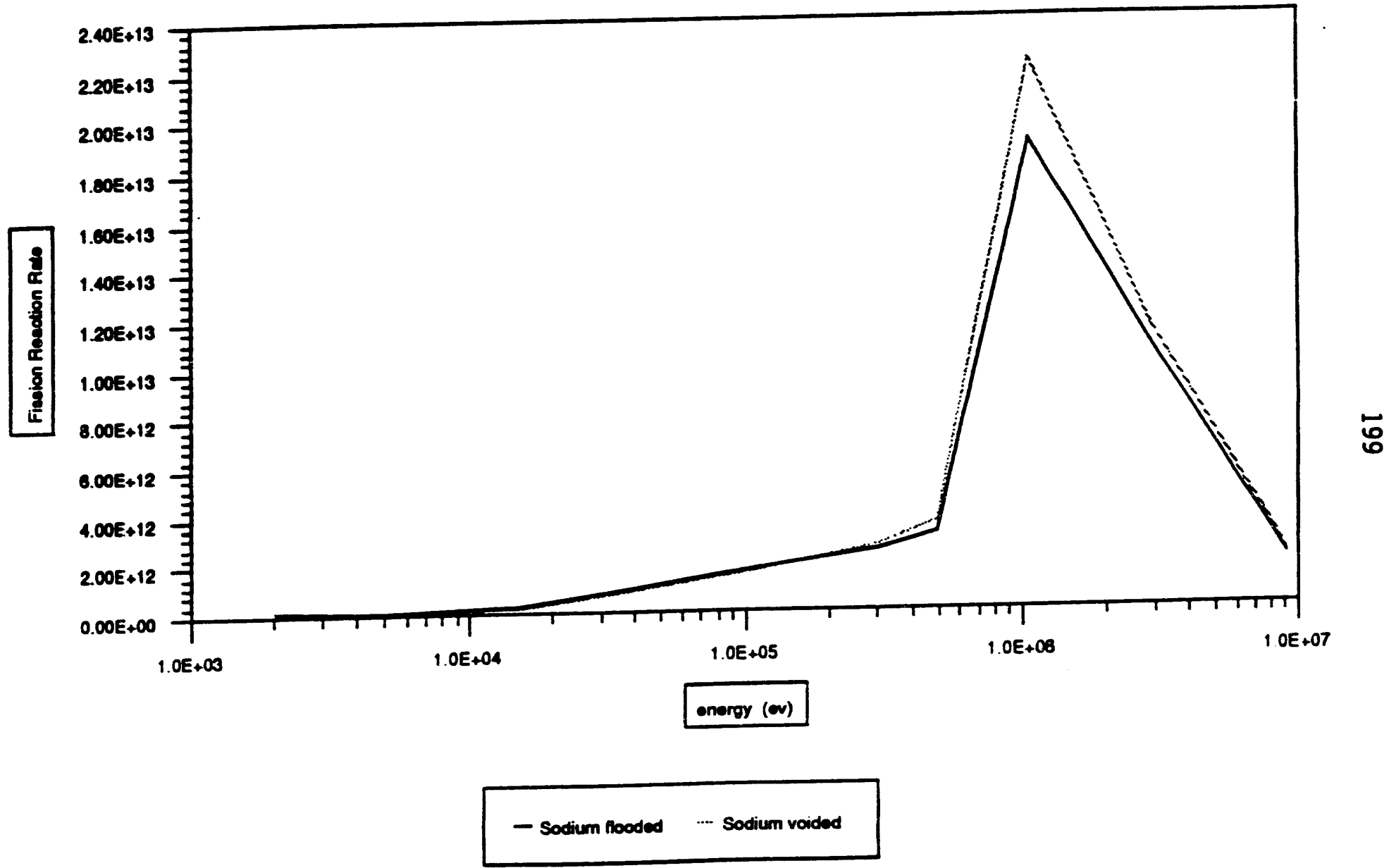

FIGURE C-78: Fission Reaction Rate for ${ }^{240} \mathrm{Pu}$ in a Metal 2 Cycle Radial Blanket. 


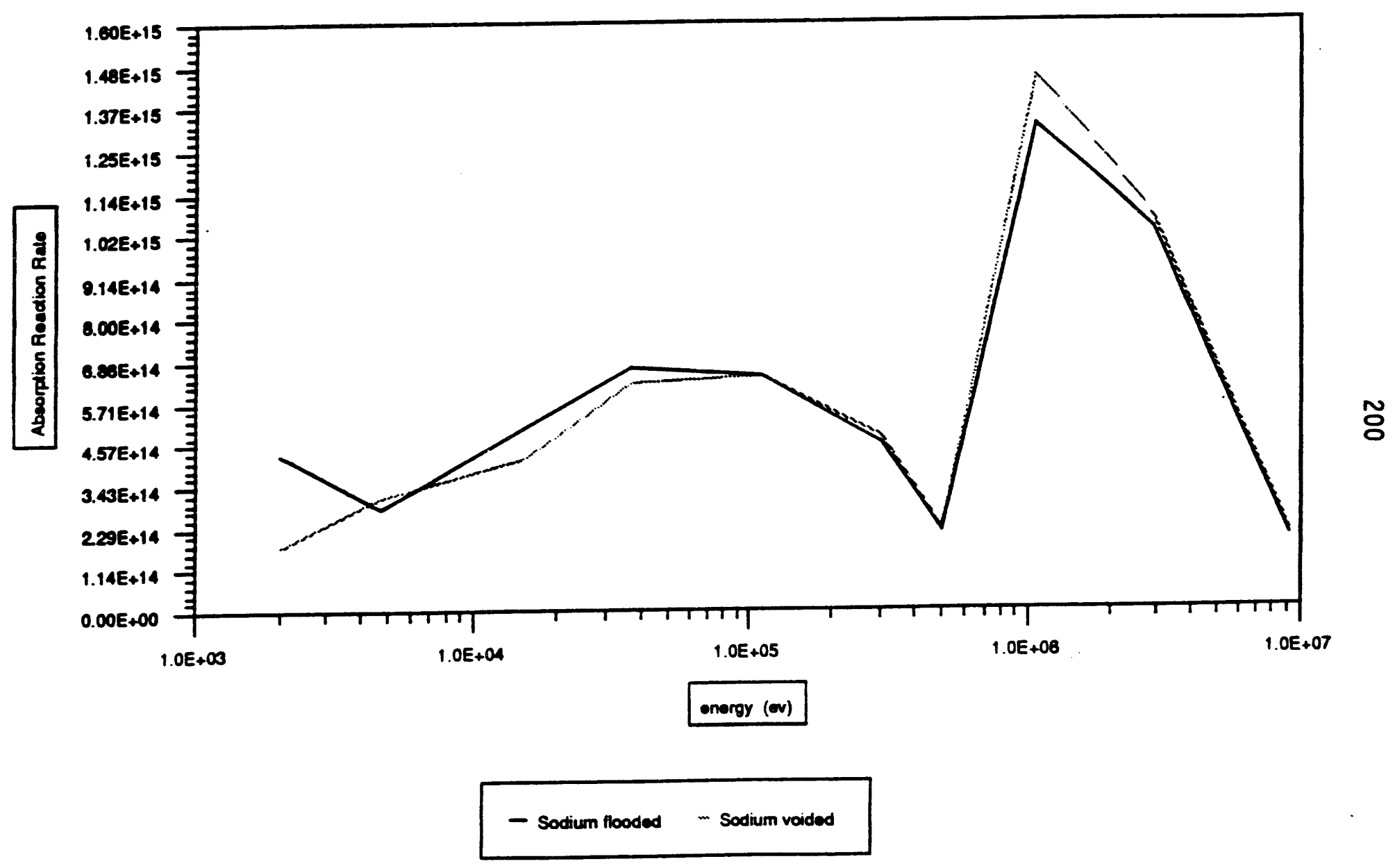

FIGURE C-79: Absorption Reaction Rate for ${ }^{240} \mathrm{Pu}$ in an 0xide Inner Fuel Assembly. 


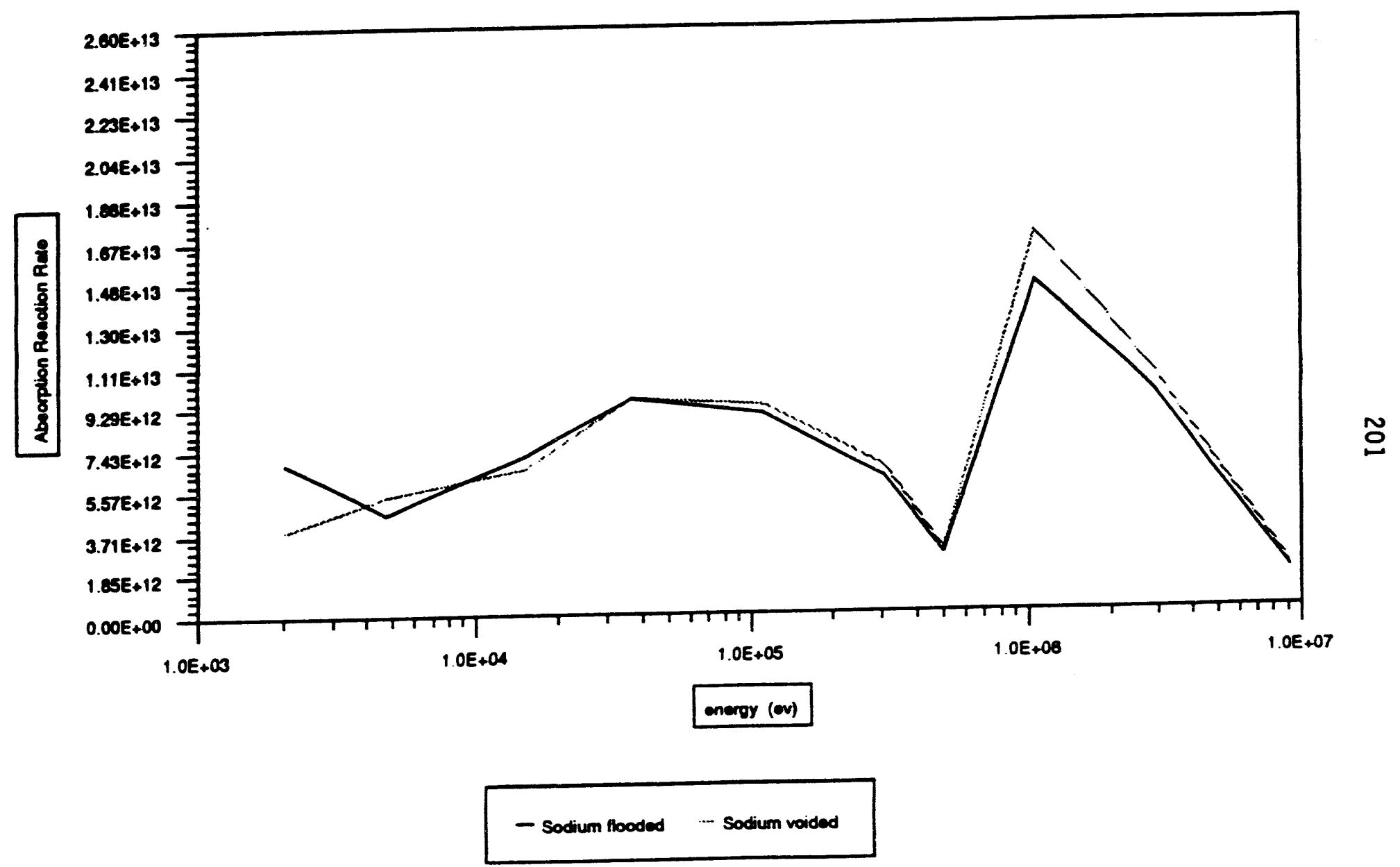

FIGURE C-80: Absorption Reaction Rate for ${ }^{240} \mathrm{Pu}$ in an 0xide 2 Cycle Radial Blanket. 


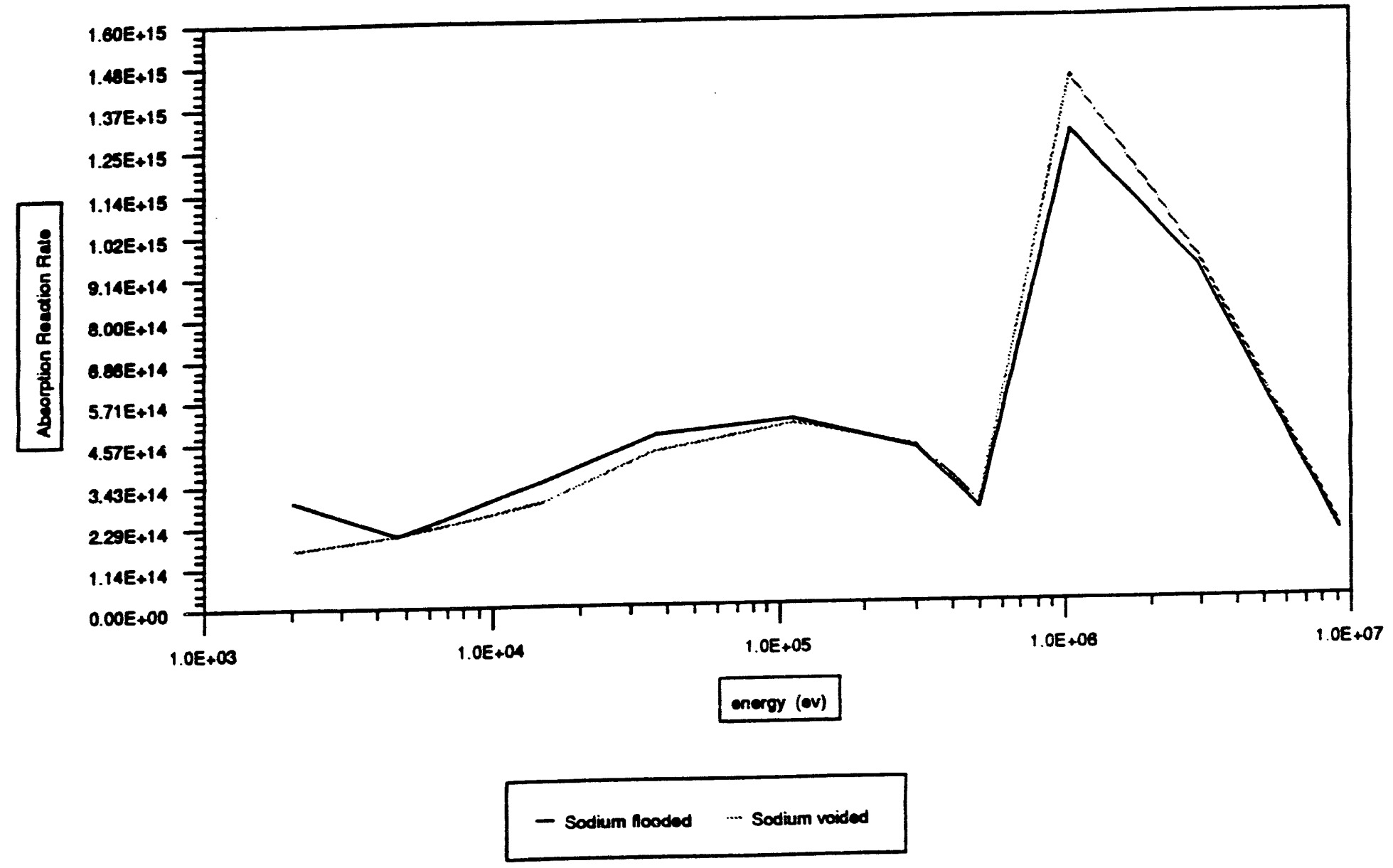

FIGURE C-81: Absorption Reaction Rate for ${ }^{240} \mathrm{Pu}$ in a Nitride Inner Fuel Assembly. 



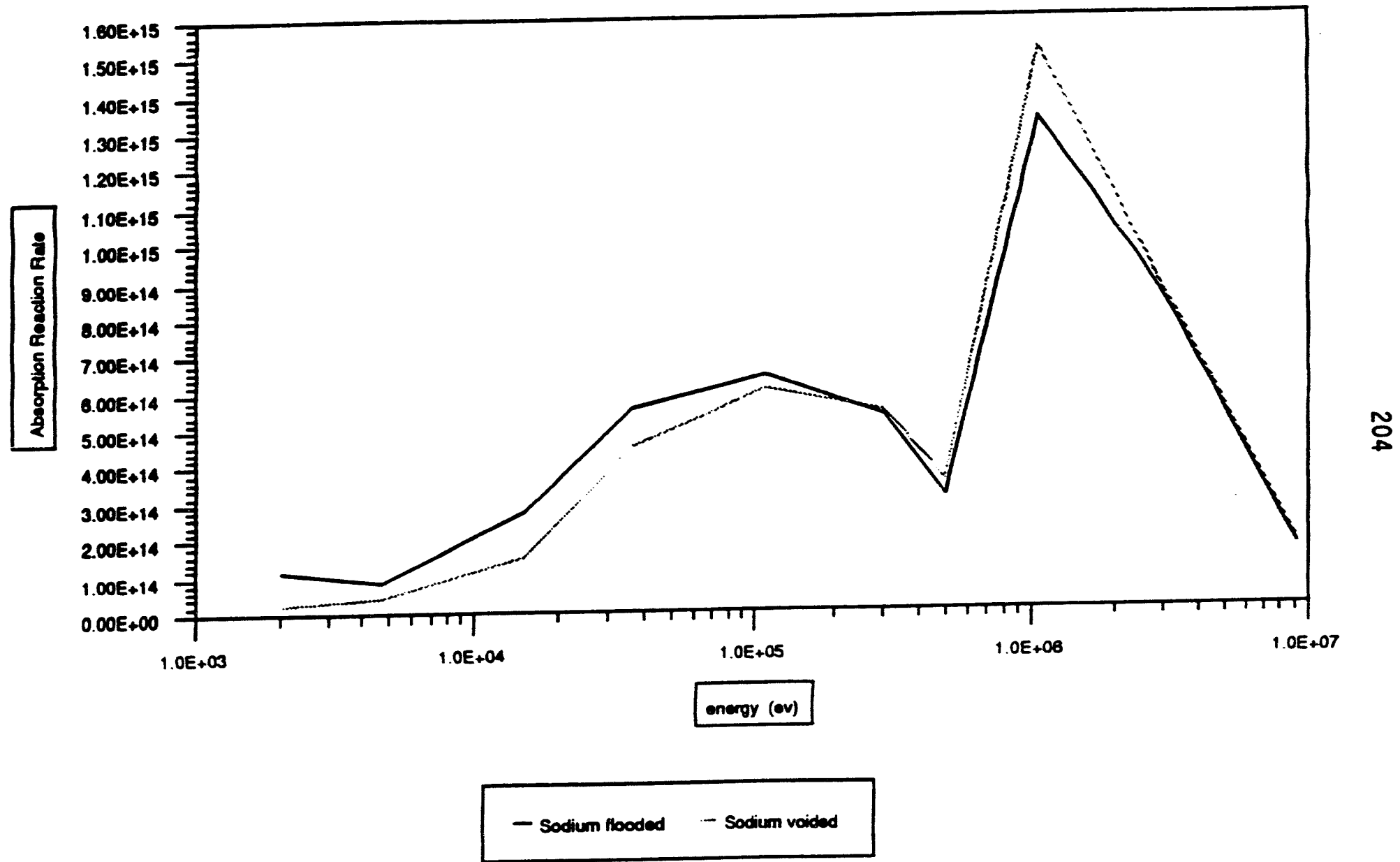

FIGURE C-83: Absorption Reaction Rate for ${ }^{240} \mathrm{Pu}$ in a Metal Inner Fuel Assembly. 



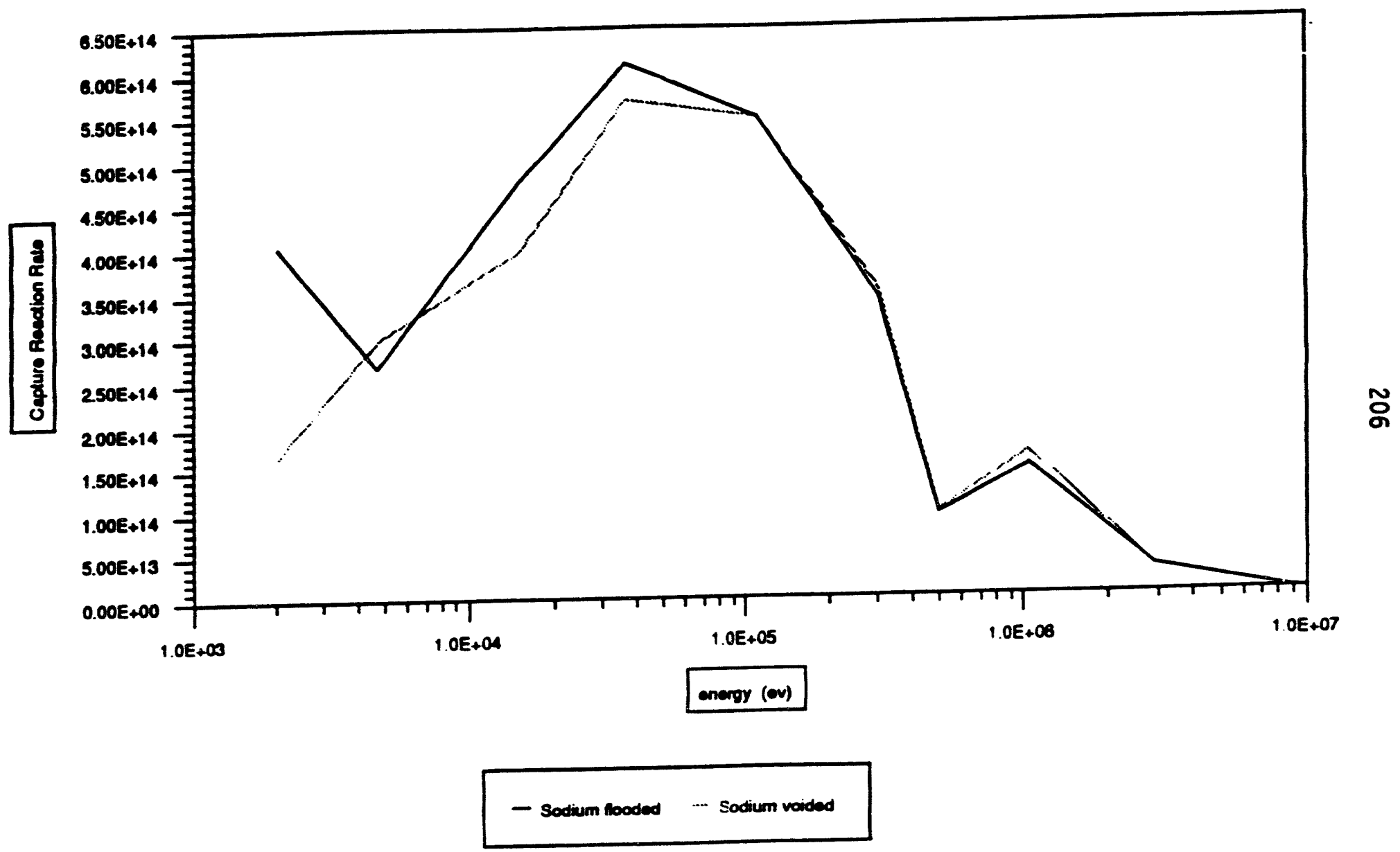

FIGURE C-85: Capture Reaction Rate for ${ }^{240} \mathrm{Pu}$ in an 0xide Inner Fuel Assembly. 



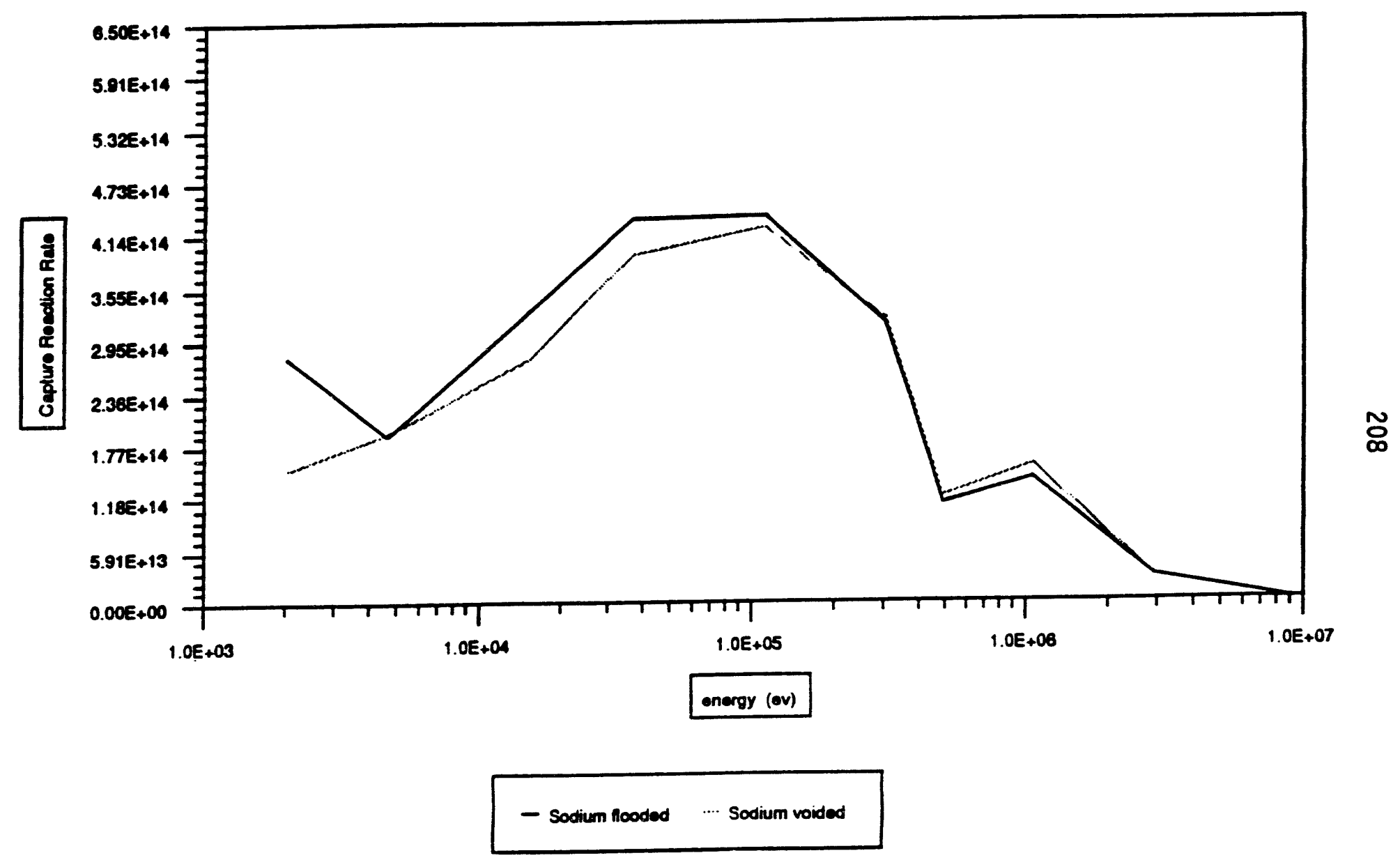

FIGURE C-87: Capture Reaction Rate for ${ }^{240} \mathrm{Pu}$ in a Nitride Inner Fuel Assembly. 


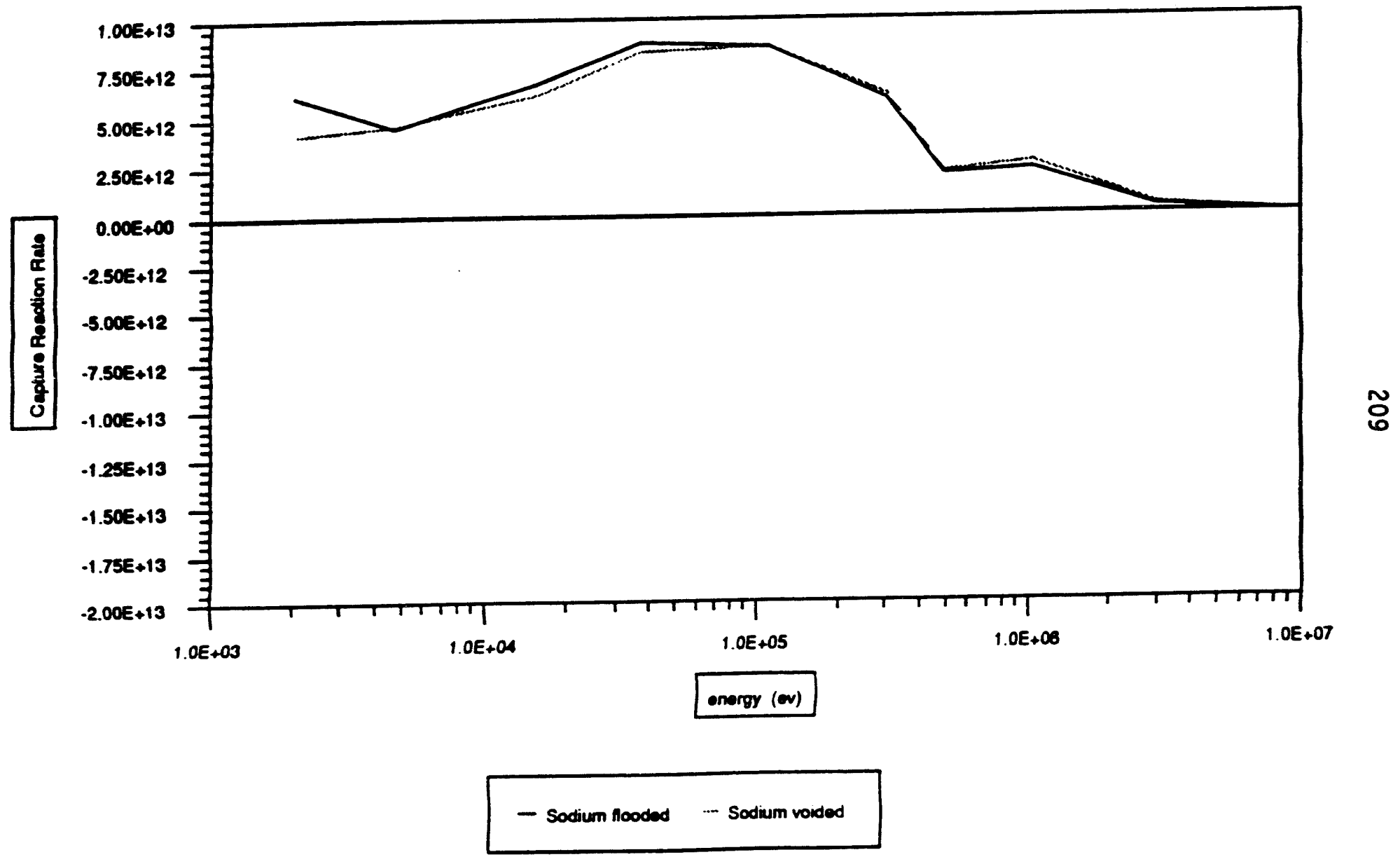

FIGURE C-88: Capture Reaction Rate for ${ }^{240} \mathrm{Pu}$ in a Nitride 2 Cycle Radial Blanket. 


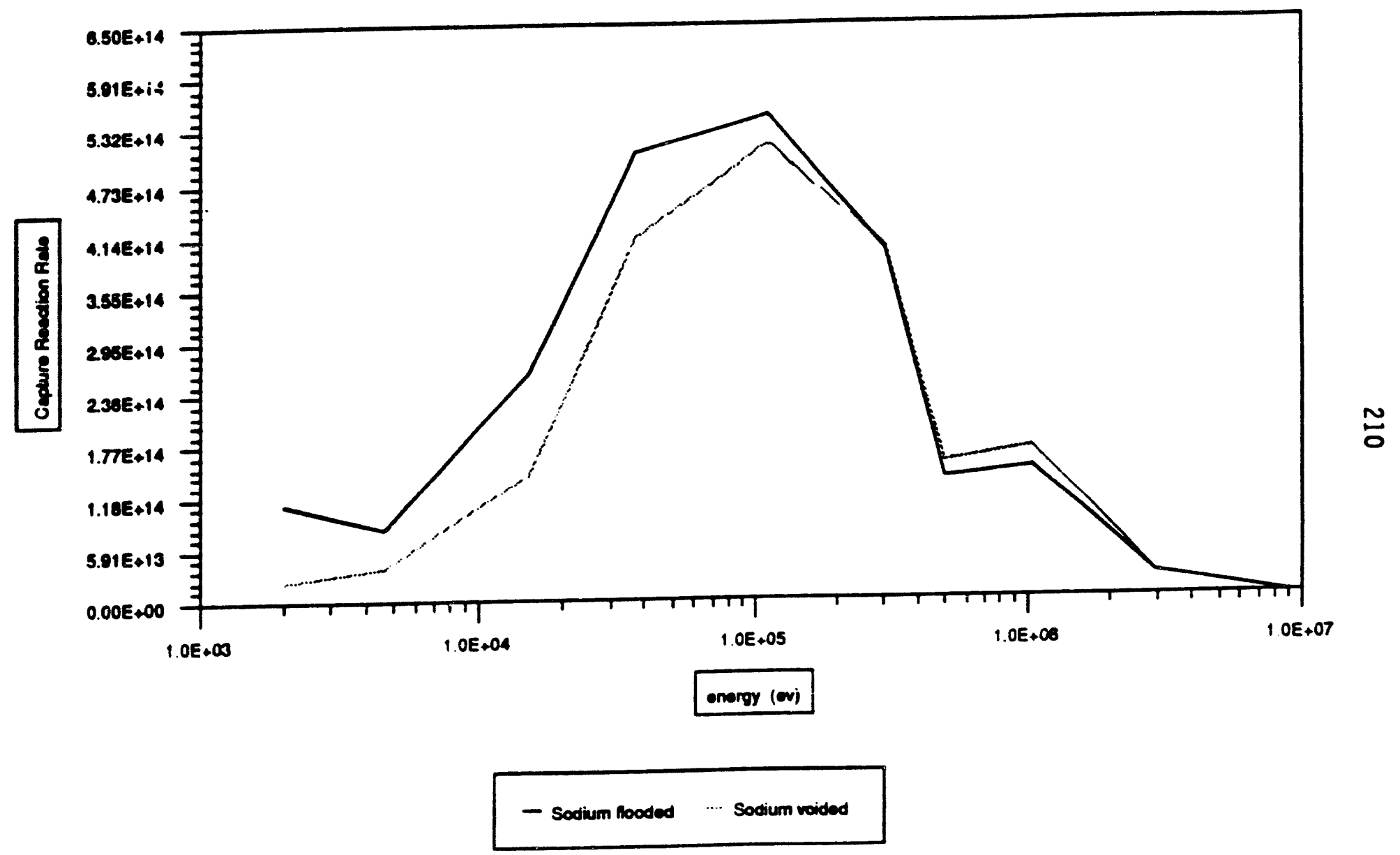

FIGURE C-89: Capture Reaction Rate for ${ }^{240} \mathrm{Pu}$ in a Metal Inner Fuel Assembly. 


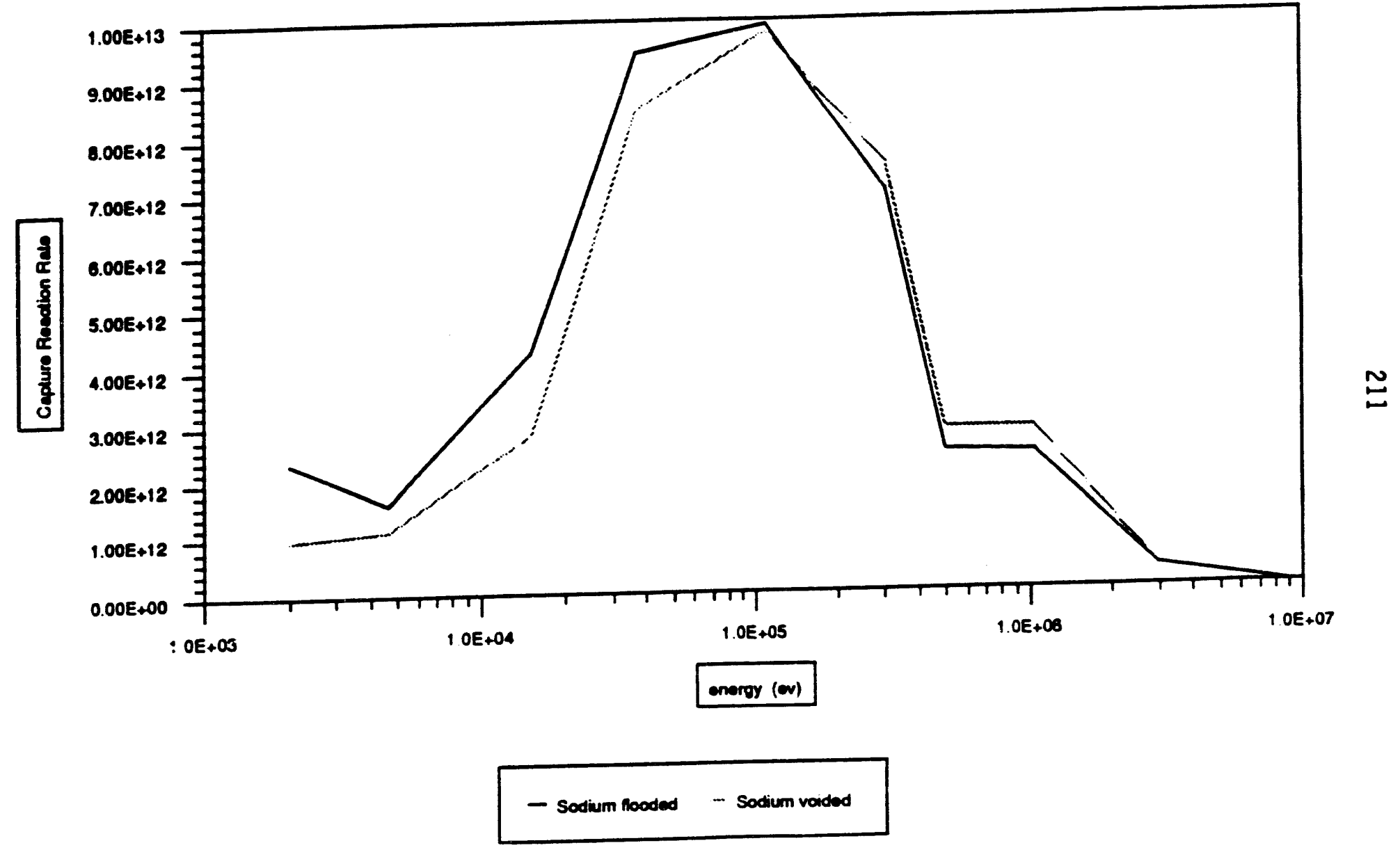

FIGURE C-90: Capture Reaction Rate for ${ }^{240} \mathrm{Pu}$ in a Metal 2 Cycle Radial Blanket. 


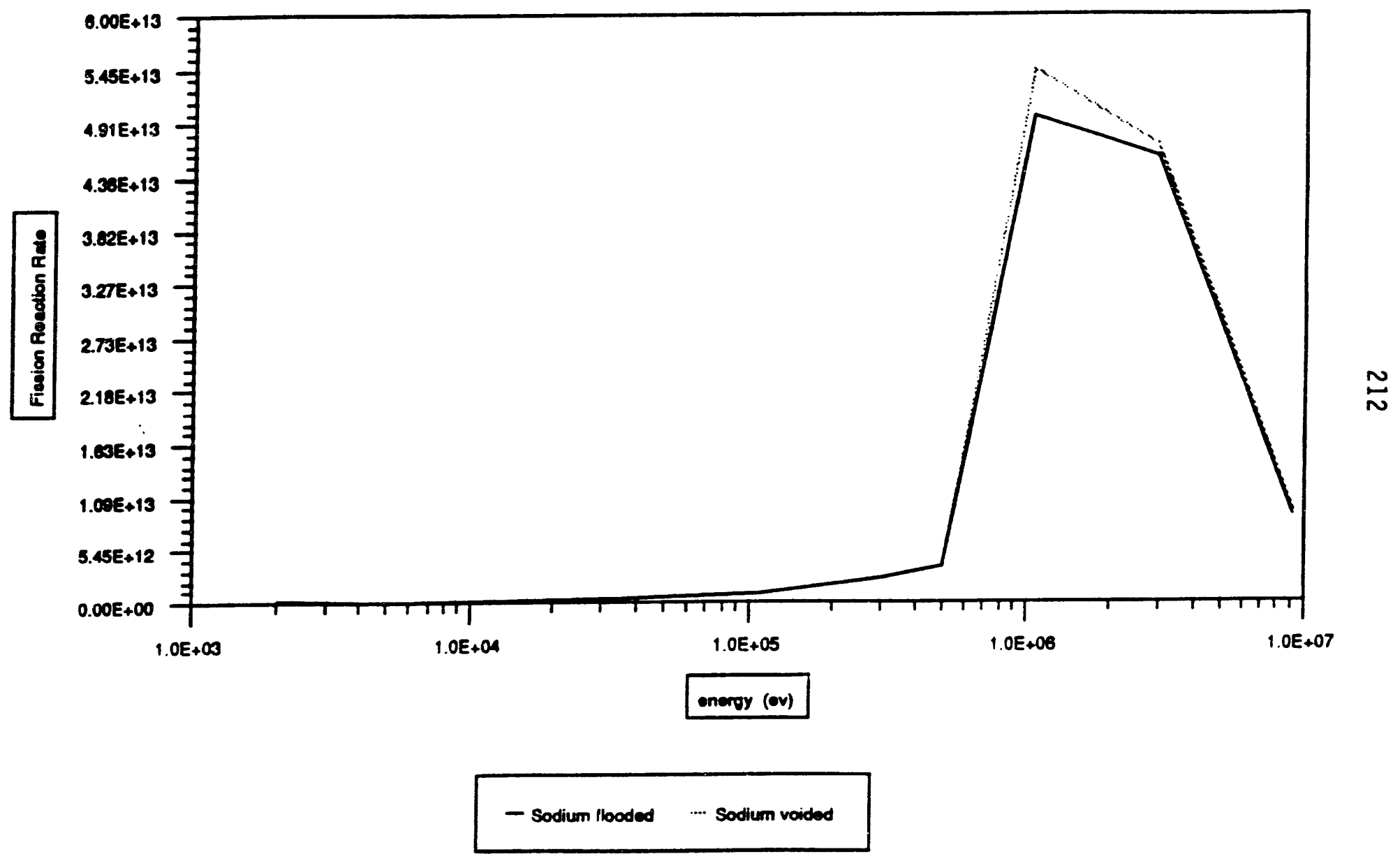

FIGURE C-91: Fission Reaction Rate for ${ }^{242} \mathrm{Pu}$ in an 0xide Inner Fuel Assembly. 


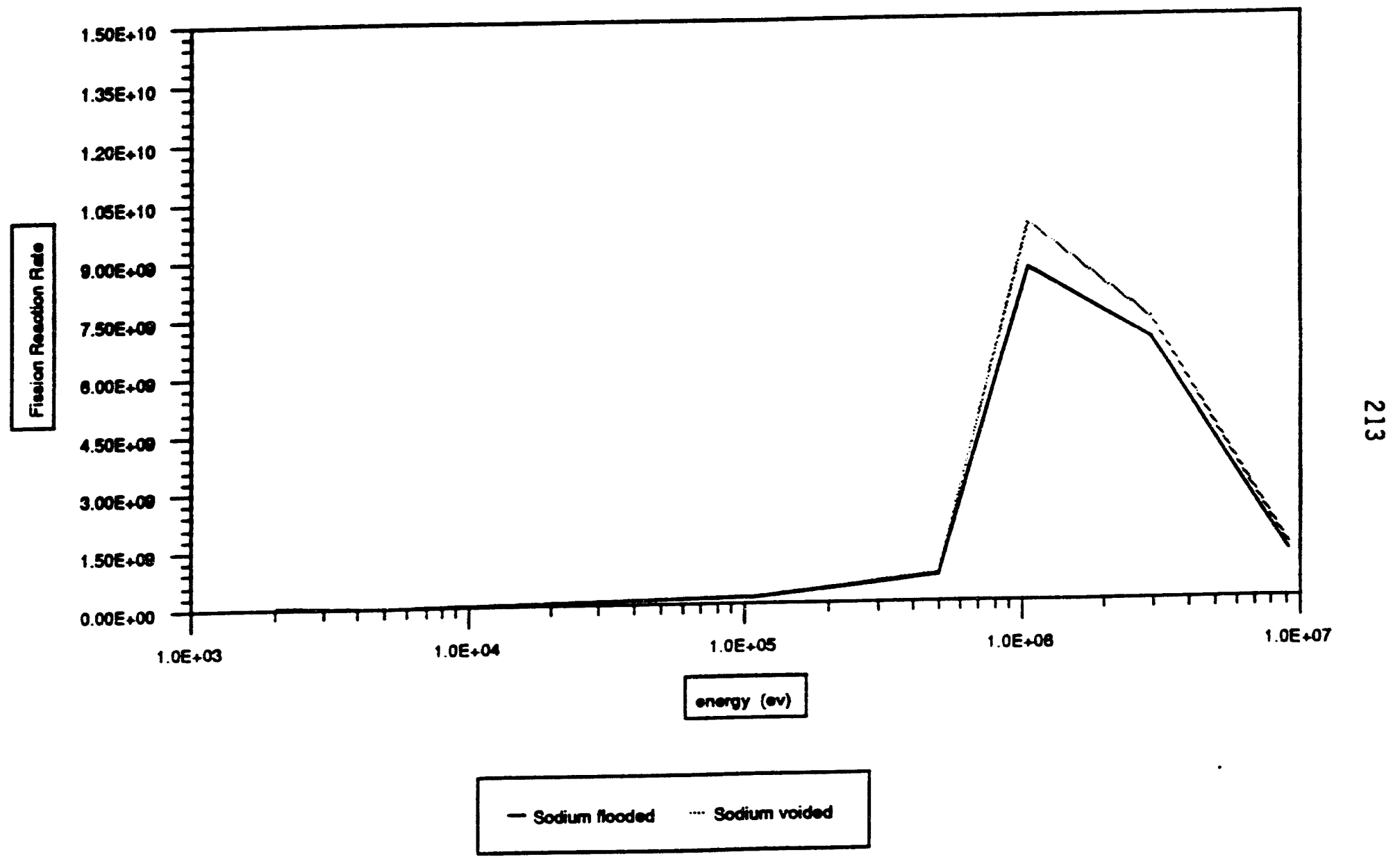

FIGURE C-92: Fission Reaction Rate for ${ }^{242} \mathrm{Pu}$ in an 0xide 2 Cycle Radial Blanket. 
214

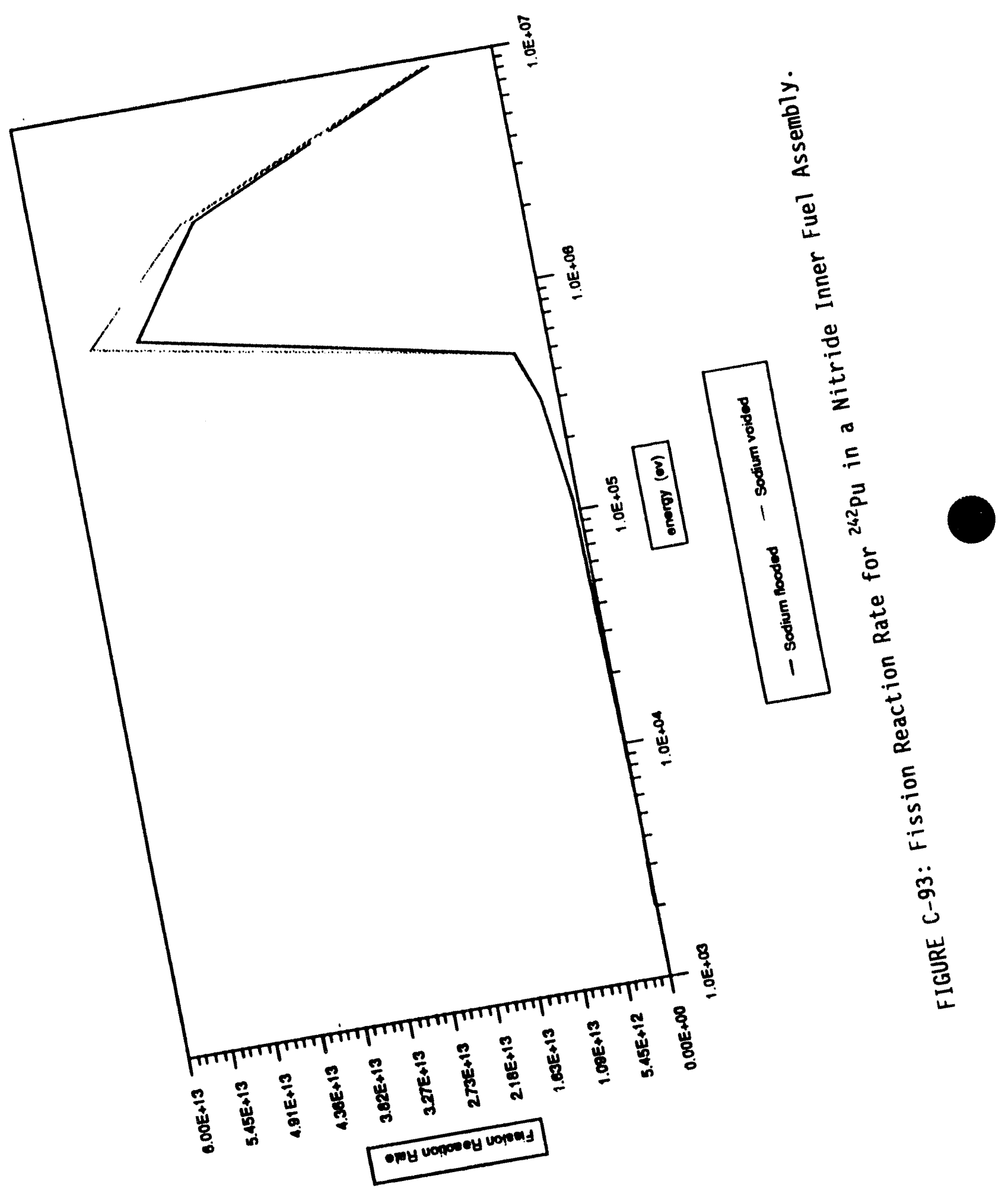




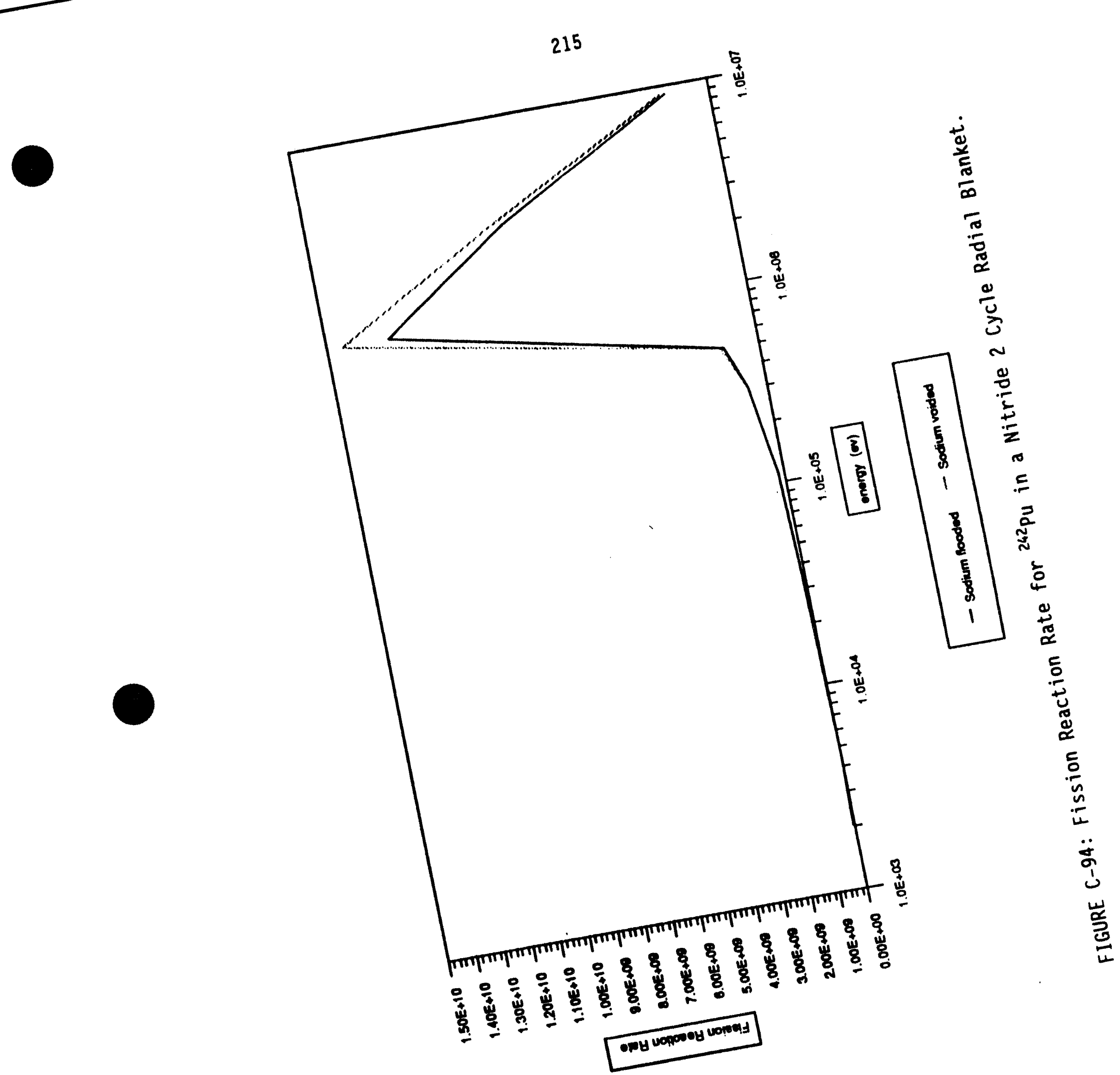






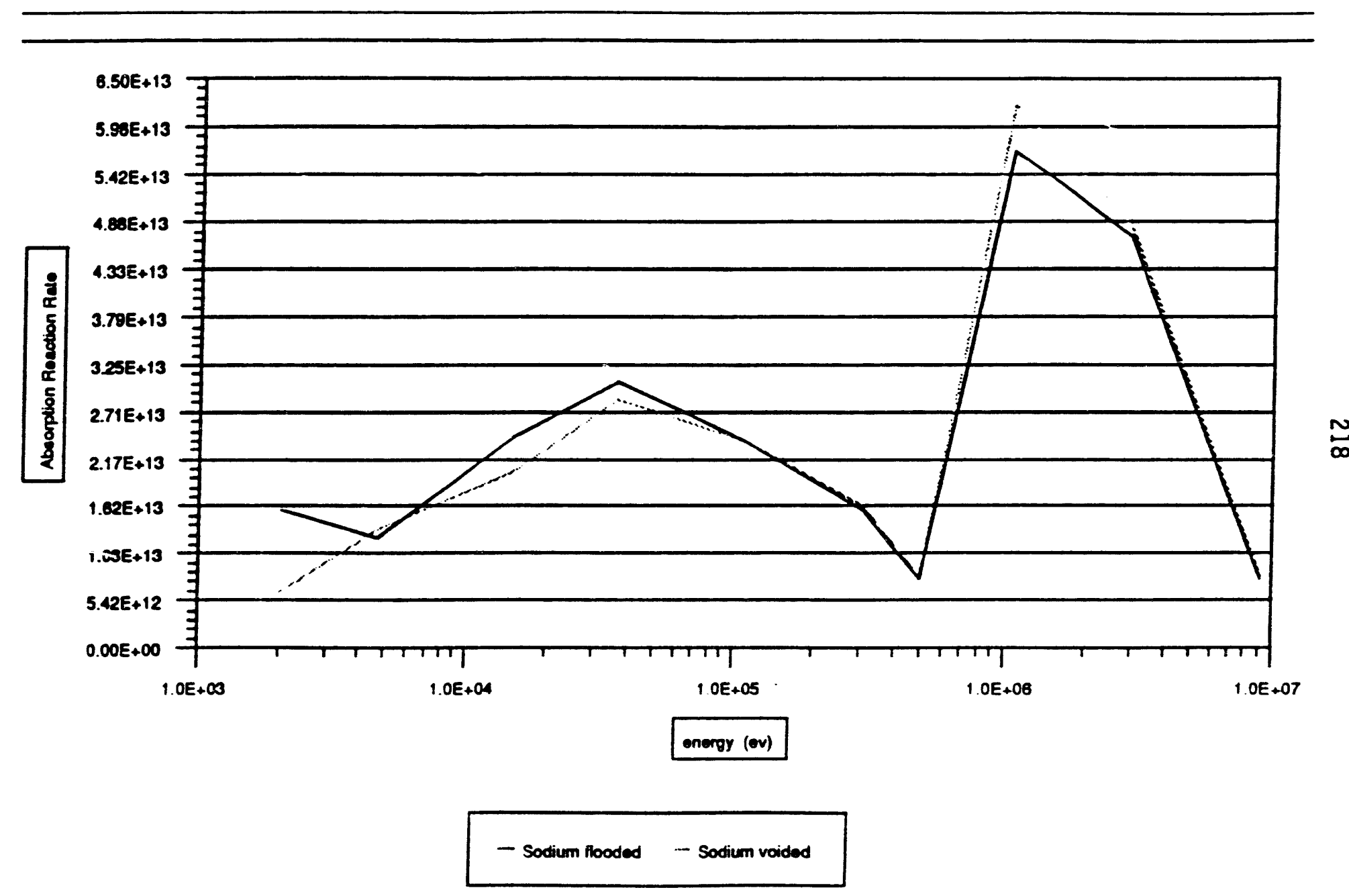

FIGURE C-97: Absorption Reaction Rate for ${ }^{242} \mathrm{Pu}$ in an 0xide Inner Fuel Assembly. 


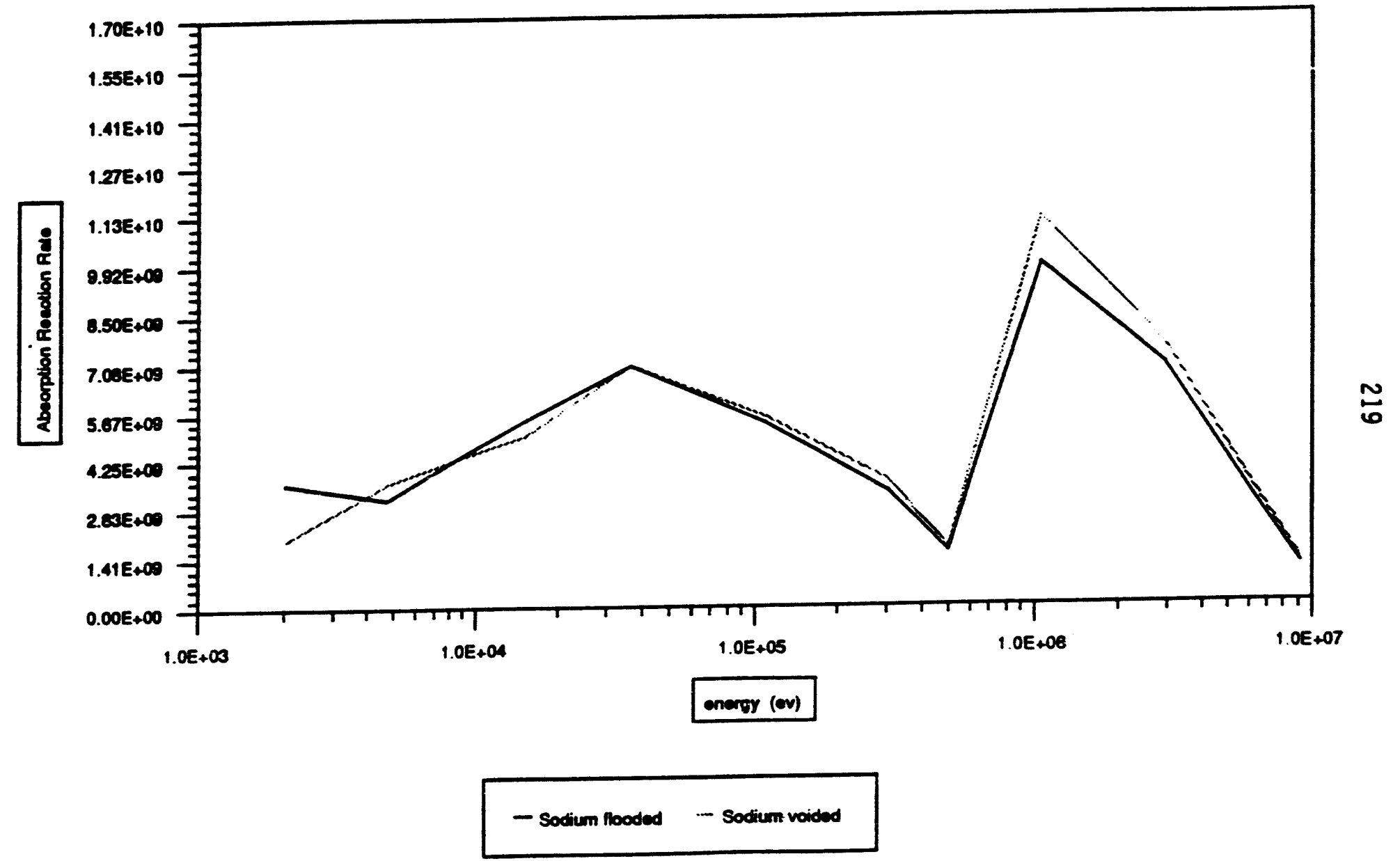

FIGURE C-98: Absorption Reaction Rate for ${ }^{242} \mathrm{Pu}$ in an 0xide 2 Cycle Radial Blanket. 


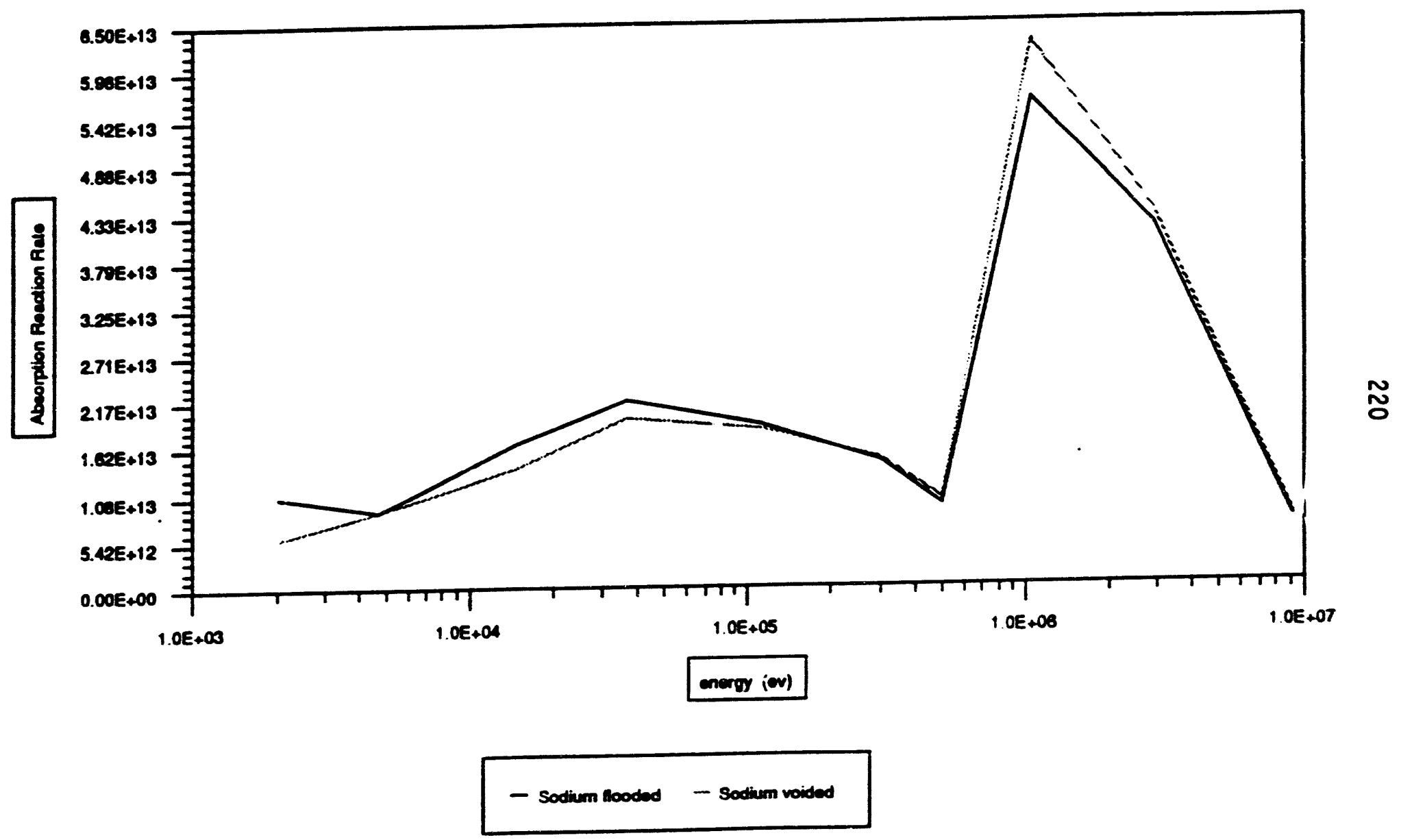

FIGURE C-99: Absorption Reaction Rate for ${ }^{242} \mathrm{Pu}$ in a Nitride Inner Fuel Assembly. 


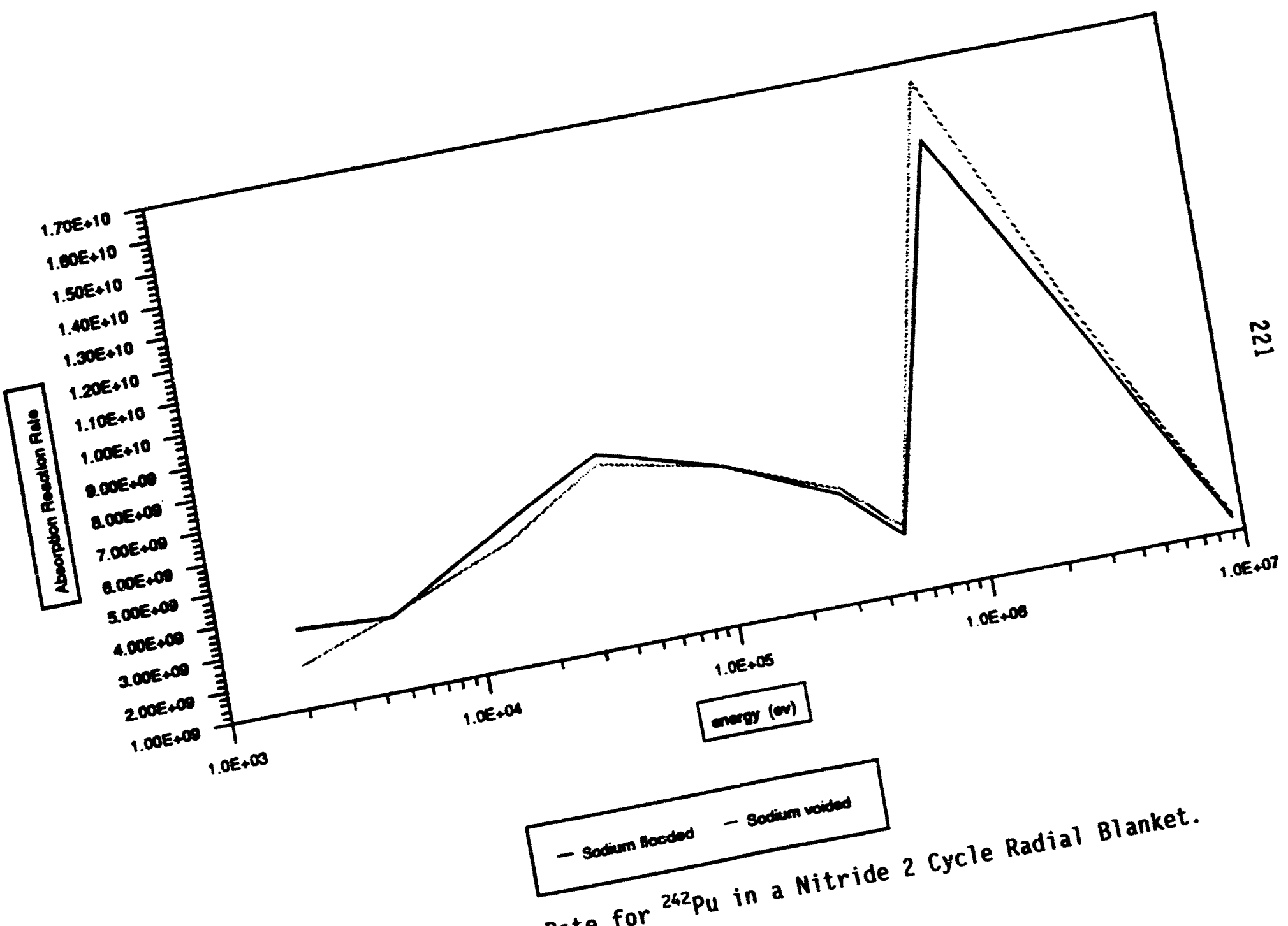

FIGURE C-100: Absorption Reaction Rate for 
-

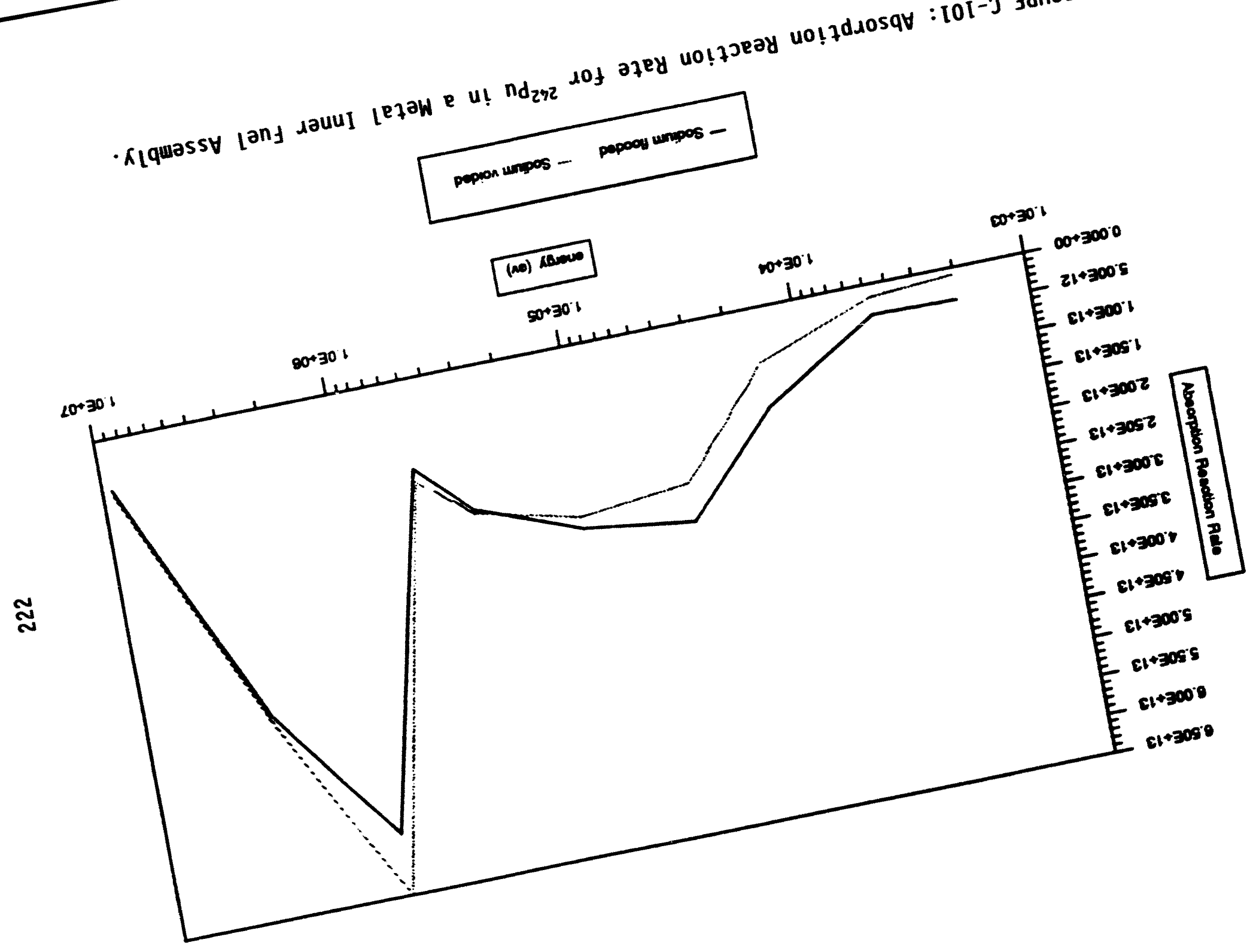




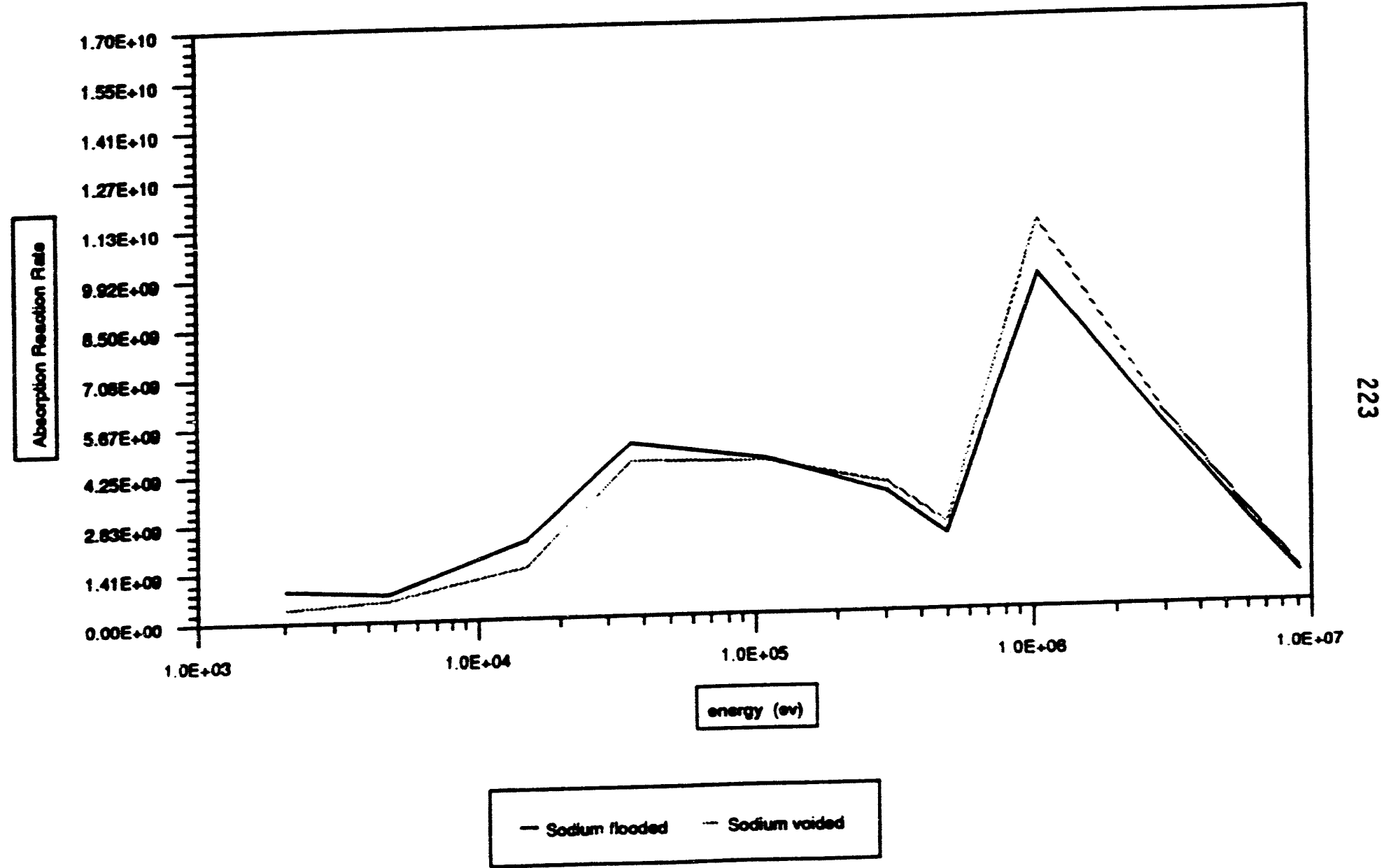

FIGURE C-102: Absorption Reaction Rate for ${ }^{242} \mathrm{Pu}$ in a Metal 2 Cycle Radial Blanket. 


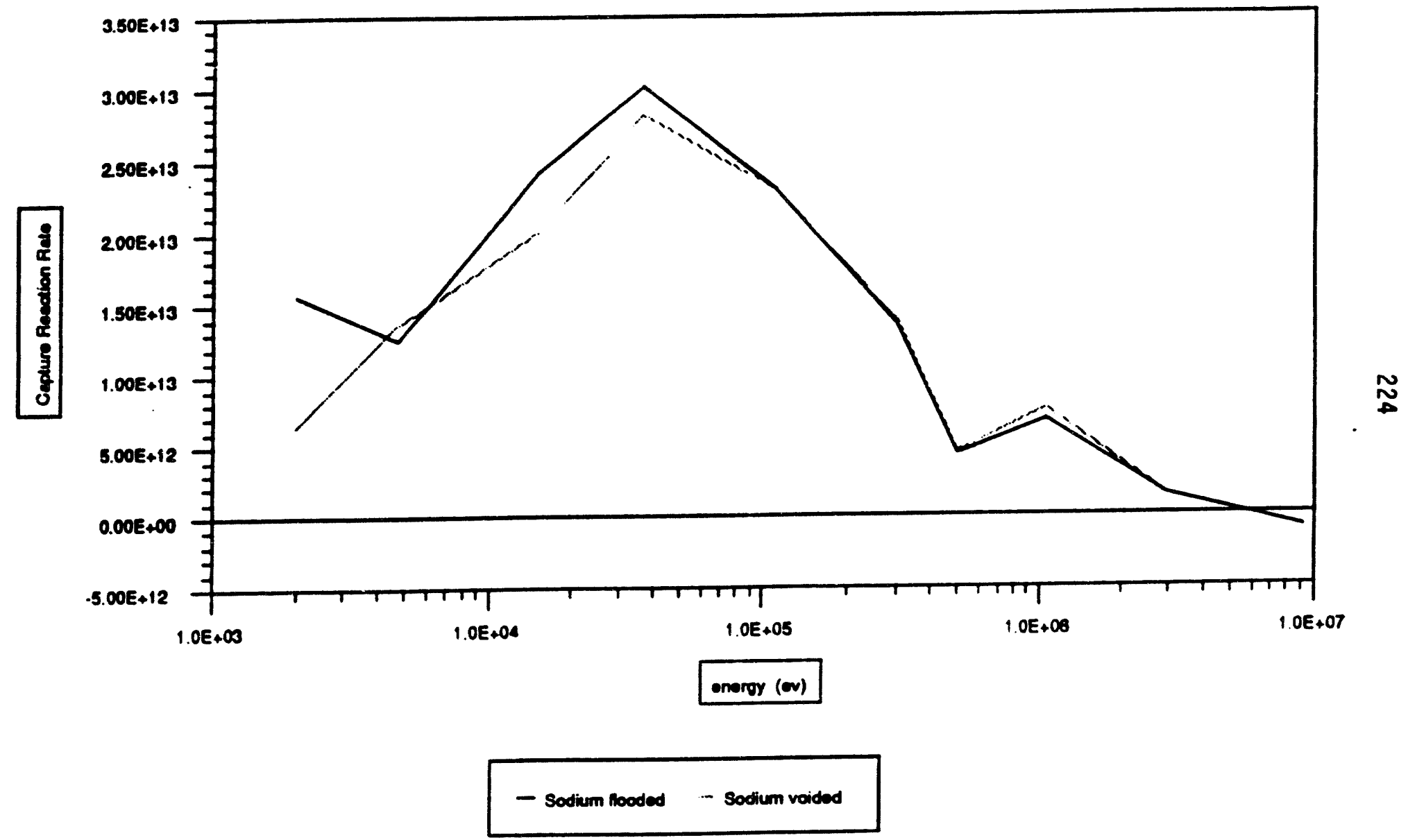

FIGURE C-103: Capture Reaction Rate for ${ }^{242} \mathrm{Pu}$ in an Oxide Inner Fuel Assembly. 



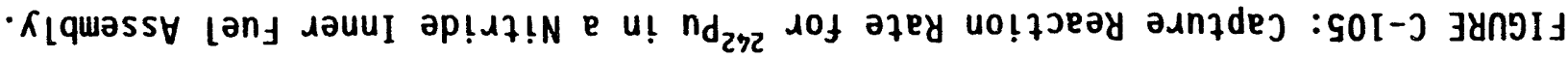

pepuon unppos - pepooy unipos -

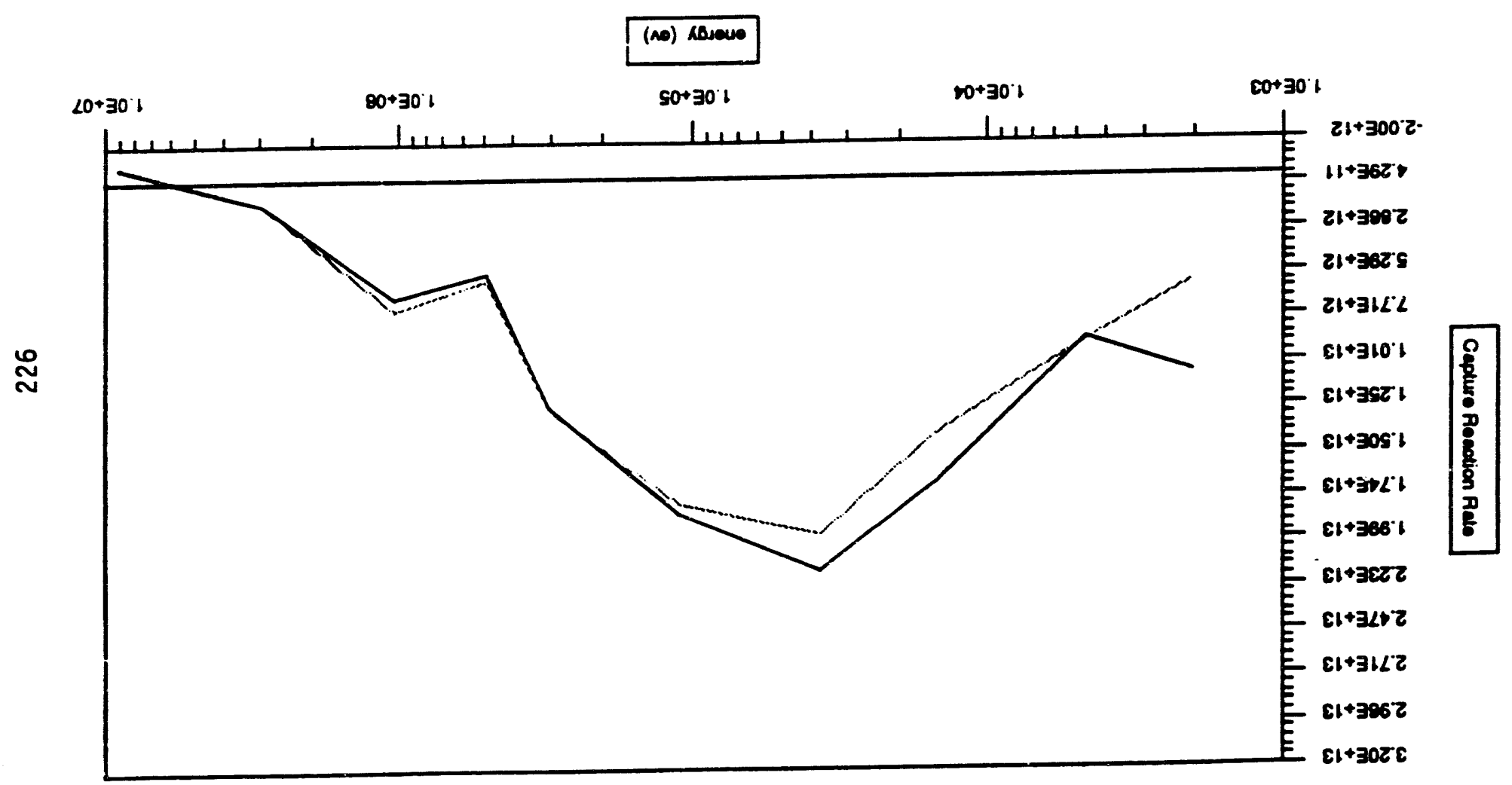





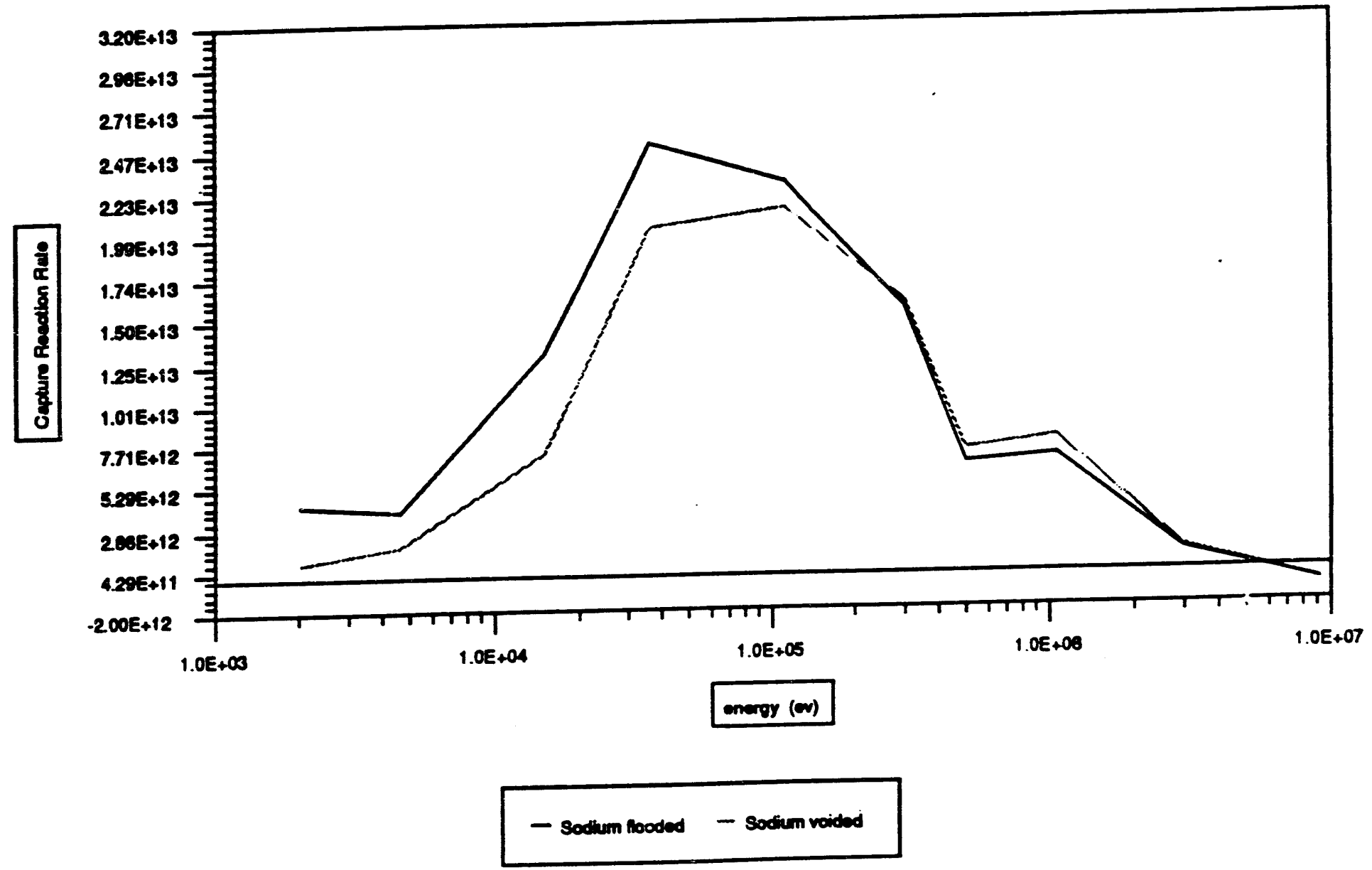

FIGURE C-107: Capture Reaction Rate for ${ }^{242} \mathrm{Pu}$ in a Metal Inner Fuel Assembly. 


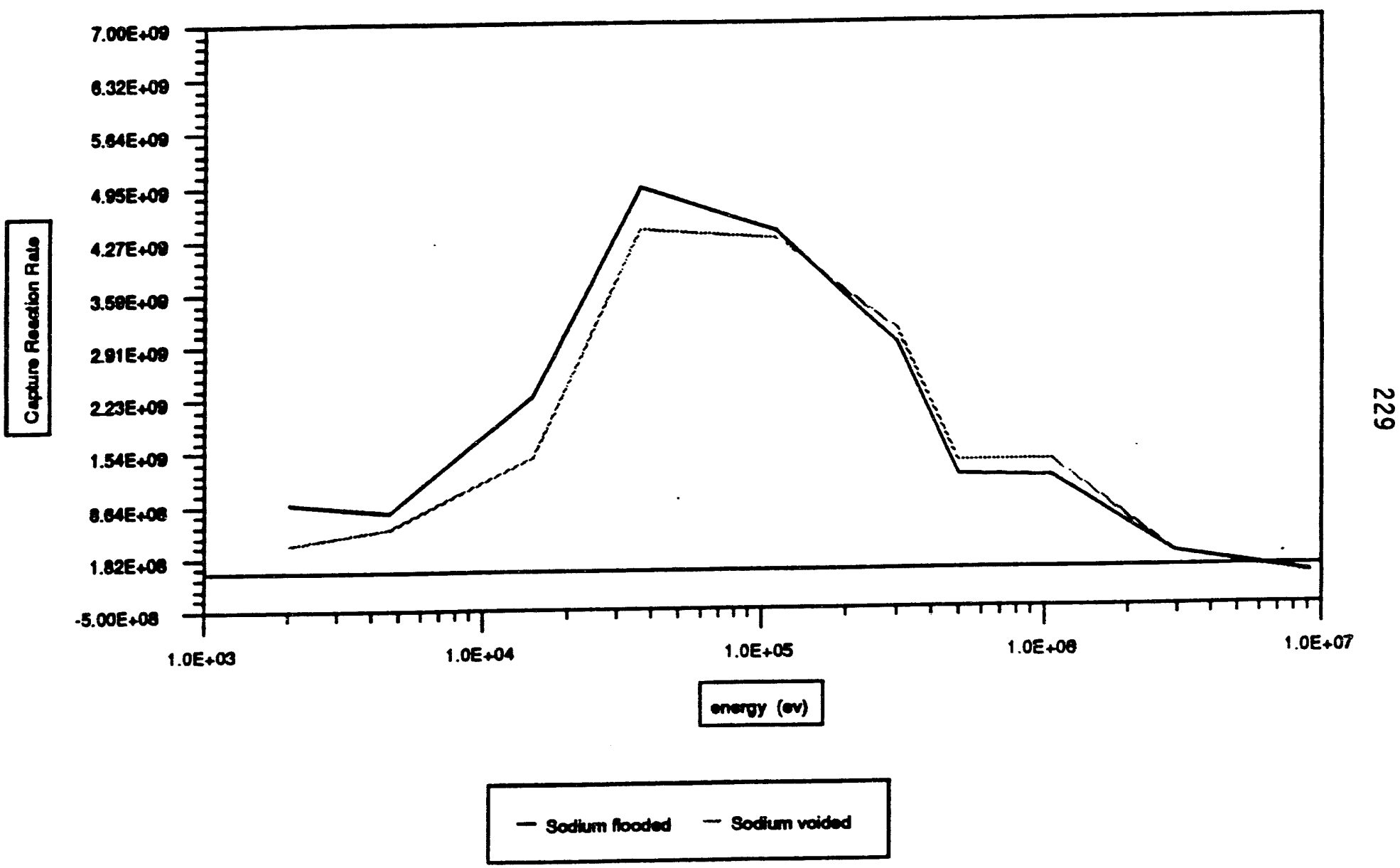

FIGURE C-108: Capture Reaction Rate for ${ }^{242} \mathrm{Pu}$ in a Metal 2 Cycle Radial Blanket. 
WHC-MR-0451 Rev. 0

\section{DISTRIBUTION}

\section{Number of copies}

ONSITE

1

U.S. Department of Energy,

Richland Operations office

Public Reading Room

H2-53

14 Westinghouse Hanford Company

J. W. Daughtry

N2-32

K. D. Dobbin

R. A. Harris

S. F. Kessler (5)

R. P. Omberg

A. E. Waltar

Document Processing and Distribution (2)

Central Files

Information Release

Administration

N2-32

$\mathrm{HO}-39$

N2-32

$\mathrm{HO}-40$

$\mathrm{HO}-32$

L8-15

L8-04

L8-04 

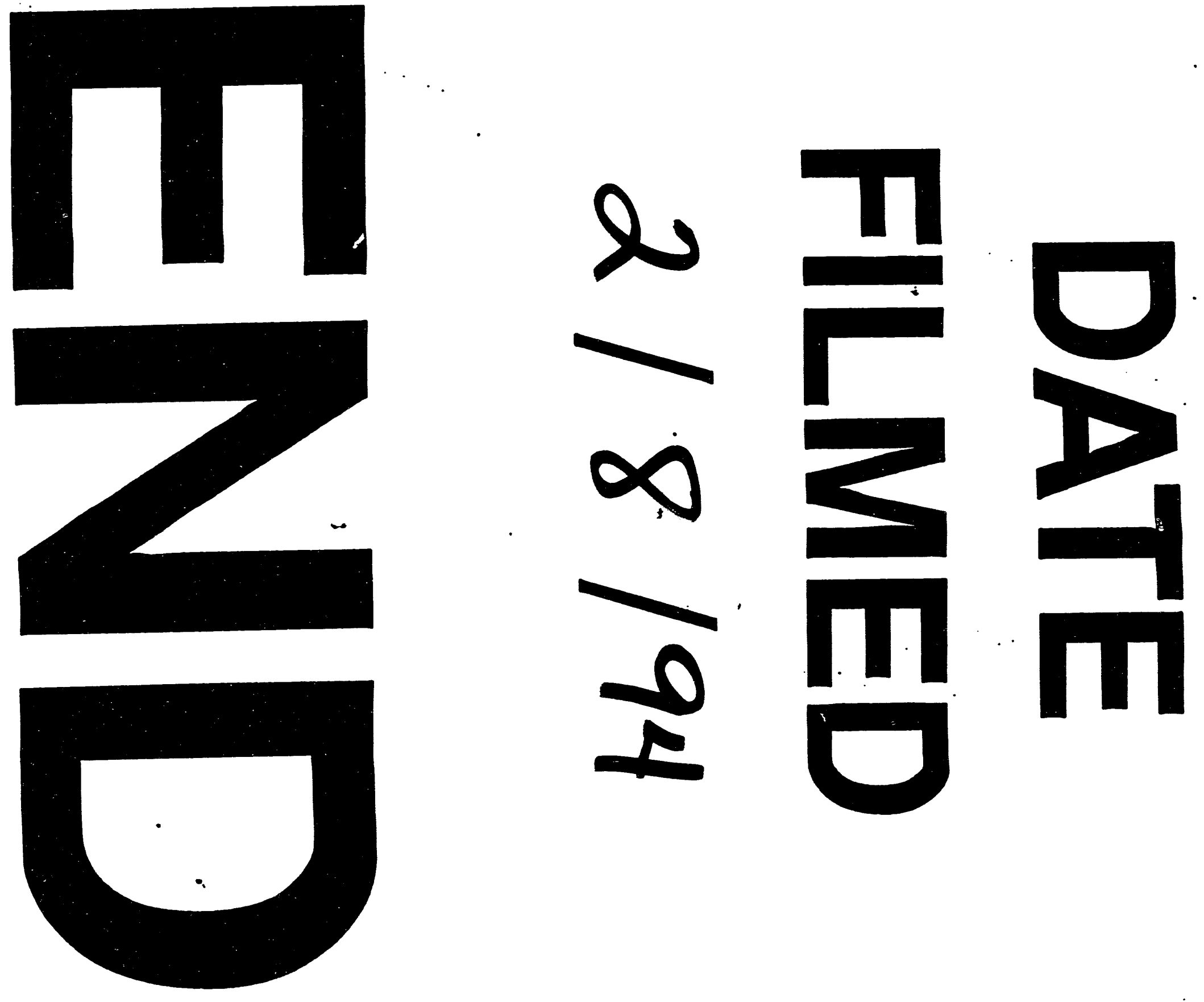
$\mid$ 